\title{
REMOTE SENSING BASED STUDY ON VEGETATION DYNAMICS IN DRYLANDS OF KAZAKHSTAN
}

\author{
Dissertation \\ zur Erlangung des Doktorgrades \\ der Mathematisch-Naturwissenschaftlichen Fakultäten \\ der Georg-August-Universität zu Göttingen
}

vorgelegt von

Pavel Propastin

aus Ust-Kamenogorsk/Kazakhstan

Göttingen, 2006 
D 7

Referentin/Referent: $\quad$ Prof. Dr. M. Kappas

Korreferentin/Korreferent: Prof. Dr. G. Gerold

Tag der mündlichen Prüfung: 18.01.2007 


\section{Contents}

$\begin{array}{ll}\text { Introduction } & 1\end{array}$

Problem description 1

Objectives and aims of the study 3

$\begin{array}{ll}\text { 1. Theoretical background to dry ecosystems } & 6\end{array}$

1.1. Dynamics of dry ecosystems: ephemeral versus permanent changes 6

1.1.1. Brief characterization of ecosystems in dry regions 6

$\begin{array}{ll}\text { 1.1.2. Dynamics of ecosystems in drylands } & 7\end{array}$

1.2. Remote sensing based investigations of vegetation changes and their $\begin{array}{ll}\text { explanatory factors } & 9\end{array}$

2. Study area 12

2.1. Geographical location and mean characteristics 12

2.2. Climate conditions 12

2.3. Soils 15

$\begin{array}{ll}\text { 2.4. Vegetation } & 16\end{array}$

2.5. Land use 20

2.6. Change in land use practices $\quad 21$

2.7. Problem of land degradation in Central Asia 24

3. Data used in the study and their preprocessing 25

3.1. Climate data and their preparation 25

3.1.1. Climate records 25

3.1.2. Preparation of gridded climate maps 25

3.2. Satellite data 26

3.2.1. Data of coarse spatial resolution 26

3.2.2. Data of fine spatial resolution 28

3.3. Digital terrain model 29

3.4. Maps 30

3.5. Agrarian and population statistics $\quad 30$

$\begin{array}{ll}\text { 3.6. Field data } & 30\end{array}$

4. Methodology of data analysis 32

4.1. Analysis of vegetation distribution, variability and change in space and time $\quad 32$

4.1.1. Simple methods of descriptive statistic 32

4.1.2. Calculation of time-trends 32 
4.2.1. Autocorrelation 32

4.2.2. Spatial autocorrelation 33

4.2.3. Kriging with an external drift 34

4.3. Analysis of the relationship between vegetation change and its explanatory factors $\quad 35$

4.3.1. Correlation coefficient 35

4.3.2. Multiple correlation coefficient 35

4.3.3. Partial correlation coefficient 36

4.4. Modelling relationship between vegetation patterns and explanatory factors $\quad 36$

4.4.1. Simple linear regression model 36

4.4.2. Multiple linear regression model 37

4.4.3. Problem of non-stationarity by analysing spatial relationship 37

4.4.4. Moving window regression 38

4.4.5. Geographically weighted regression 39

4.5. Assessment of modelling accuracy 41

4.5.1. Root Mean Square Error (RMSE) 42

4.5.2. Standard error $\quad 42$

4.5.3. Spatial autocorrelation for accuracy assessment 43

4.6. Evaluation of land cover change and its driving forces 43

4.6.1. Background for discrimination between climate-induced and humaninduced vegetation change 43

4.6.2. Identification of climate and anthropogenic signals in the vegetation time-series $\quad 45$

4.6.3. Analysis of regression residuals for identification of areas experiencing $\begin{array}{ll}\text { anthropogenic impact } & 46\end{array}$

5. Analysis of climatic conditions $\quad 47$

5.1. Network of climate stations in the study region 47

5.2. Modelling spatial patterns in climate parameters 48

5.3. Statistical analysis of climate data. $\quad 50$

5.3.1. The inter-annual variability of precipitation and temperature. $\quad 50$

5.3.2. Trends in climatic parameters $\quad 52$

5.4. Discussion and conclusion $\quad 54$ 
6. Within-season dynamics of vegetation activity and their relationship to climate factors

6.1. Spatial distribution of Normalized Difference Vegetation Index (NDVI) and climatic factors in the study area

6.2. Average characteristics of NDVI

6.3. Temporal behaviour of climatic factors and vegetation within the growing season

6.4. Within-season relationship between NDVI and precipitation

6.4.1. Stratification of NDVI-precipitation relationship by land cover type 63

6.4.2. Stratification of NDVI-precipitation relationship by vegetation communities

6.5. Within-season relationship between NDVI and temperature 65

6.6. Spatial patterns in NDVI-climate relationship 66

6.7. Inter-annual variations in within-season NDVI-climate relationship 68

6.8. Discussion and conclusion

7. Inter-annual change in vegetation activity and its relation to climate

7.1. Patterns in monthly time-series $1982-2001$

7.2. Inter-annual relationship between NDVI and climatic parameters

7.2.1. Analysis of spatially averaged NDVI versus precipitation 73

7.2.2. Relationship between spatially averaged NDVI and temperature. 76

7.2.3. Spatial patterns in inter-annual NDVI-climate relationship 77

7.3. Quantifying temporal variability in vegetation conditions 79

7.3.1. Standard deviation of NDVI 79

7.3.2. Variance of NDVI values over the study period 80

7.3.3. Dependence of $N D V I_{c v}$ on the relief 82

7.4. Discussion and conclusion 86

8. Spatial response of vegetation cover to climatic factors 88

8.1. Growing season relationship between NDVI and precipitation 88

$\begin{array}{ll}\text { 8.1.1. NDVI-rainfall correlation coefficients } & 88\end{array}$

8.1.2. NDVI-rainfall relationships by vegetation type 89

8.1.3. Influence of growing season rainfall on NDVI-rainfall correlation 91

8.1.4. Spatial patterns in NDVI anomalies and their relationship to rainfall 92

8.2. Within-season relations between NDVI and rainfall 
8.2.1. Spatial patterns in intra-annual dynamic of NDVI and climate parameters

8.2.2. Within-season NDVI-rainfall correlation coefficients

8.2.3. Influence of vegetation type on within-season relations between NDVI and rainfall

8.2.4. Influence of precipitation amount on NDVI-rainfall relations

8.3. Growing season relationship between temperature and NDVI

8.3.1. NDVI-temperature correlation coefficients

8.3.2. NDVI-temperature correlation coefficients by vegetation type

8.3.3. Influence of annual rainfall on NDVI-temperature correlation

8.4. Within-season relationship between NDVI and temperature

8.4.1. General patterns in the NDVI-temperature correlation

8.4.2. Influence of cover types on within-season relationship between NDVI and temperature

8.5 Discussion and conclusion

9. Application of the geographically weighted regression to modelling relationship between vegetation patterns and climate factors

9.1. Problem of non-stationarity in modelling spatial relationship and approaches to overcome it

9.2. Reducing uncertainty in modelling NDVI-precipitation relationship: a comparison between OLS and GWR regression techniques

9.2.1. Global OLS regression model and its deficiencies

9.2.2. Stratification of NDVI-precipitation relationship by land cover type 117

9.2.3. Local variability in relationship between vegetation and precipitation 119

9.2.4. Analysis of regression residuals

9.3. Analysis of temporal variations in NDVI-precipitation relationship using

9.3.1. Variations in the relationship strength

9.3.2. Trends in NDVI-rainfall relationship and their linkages to land use/land cover change

9.4. Discussion and conclusion

10. Detection of climate-induced and human-induced vegetation change 
10.1.2. Trends in seasonal NDVI

10.2. Spatial patterns of NDVI trends

10.3. Effects of precipitation and temperature on NDVI trends

10.3.1. Effects of climate on changes in spatially averaged NDVI

10.3.2. Spatial patterns in climate effects on NDVI trends

10.4. Vegetation changes which are not explained by climate

10.4.1. Spatial patterns in NDVI trends not explained by rainfall and temperature

10.4.2. Verification of results and explanation of trends induced by nonclimatic factors

10.5. Human-induced change in vegetation cover in areas without significant NDVI trends

10.5.1. General approach

10.5.2. Implementation of the suitable regression models for identification of the climatic signal

10.5.3. Modelling the climatic signal in the inter-annual NDVI time series 150

10.5.4. Identification of areas experiencing human-induced vegetation change

10.6. Discussion and conclusion

11. Summary

12. References 


\section{List of Figures}

Figure 1.1. Distribution of drylands throughout the world

Figure 2.1. (a) The location of the study area (white square) on the map of Kazakhstan (b) The study area: its relief (altitude, m), climate stations, and borders of the districts

Figure 2.2. Total rainfall amount (mm) during the growing season (April-October) for the region of the Balkhash lake catchment

Figure 2.3. Mean air temperature $\left({ }^{\circ} \mathrm{C}\right)$ over the growing season (April-October) for the region of the Balkhash Lake drainage basin

Figure 2.4. Map of the land cover in the study area

Figure 2.5. Typical landscape impressions from the study area

Figure 2.6. Change in stock heads, arable area and crop production in Kazakhstan during the period 1981-2000

Figure 2.7. Traces of the economical crisis $1992-1998$ in the study area

Figure 4.1. Framework explaining how the GWR works in the practice with an example of a $7 * 7$ kernel size

Figure 4.2. Scenarios illustrating the combine use of NDVI and precipitation timeseries for discrimination between climate- and human-induced vegetation changes

Figure 4.3. Difficult cases of trends interpretation

Figure 5.1. Map showing the distribution of the climate stations used in the study

Figure 5.2. Maps showing the spatial distribution of mean temperature

Figure 5.3. Kriging average growing season temperature (a) and total precipitation (b) without external drift

Figure 5.4. The time series of mean temperature and total precipitation for growing season during 1985-2002

Figure 5.5. Coefficient of variation in precipitation versus elevation $(\mathrm{m})$ as computed for the weather stations in the study area

Figure 6.1. (a) Mean growing season NDVI calculated from the average of 8-km NOAA AVHRR for the period 1982-2003. (b) Regionalized total precipitation amount throughout the growing season

Figure 6.2. NDVI, precipitation and temperature for each 10-day period of the growing season (spatially averaged over the entire region)

Figure 6.3. Within-season dynamic of climatic parameters and NDVI

Figure 6.4. Relationship between 10-day NDVI and 10-day precipitation

Figure 6.5. Dependence of correlation coefficient between 10-day NDVI and precipitation on time lag imposed to the NDVI data. Stratification by land cover type

Figure 6.6. Dependence of correlation coefficient between 10-day NDVI and precipitation on time lag imposed to the NDVI data. Stratification by vegetation community

Figure 6.7. Comparison between the values of correlation coefficient obtained for NDVI-precipitation and NDVI-temperature relationship

Figure 6.8. Complete amount of pixels, amount of pixels that exhibited significant NDVI-precipitation, and amount of pixels with significant NDVI-temperature correlation for every vegetation type 
Figure 6.9. Spatial distribution of correlation coefficient for NDVI-precipitation and NDVI-temperature

Figure 6.10. Spatial distribution of time lag (10-day units) imposed for calculation of correlation coefficient between NDVI and precipitation

Figure 6.11. Time-latitude section of within-season correlation coefficient between 10- 68 day NDVI and 10-day precipitation from 1982 to 1998

Figure 7.1. Hovmoller diagram of maximum monthly NDVI, corresponding NDVI anomalies and monthly precipitation amounts throughout 1982-2001

Figure 7.2. Spatially averaged time series of growing season NDVI and growing season precipitation over the period 1985-2001

Figure 7.3. Average growing season NDVI as a function of precipitation.

Figure 7.4. Correlation coefficients between NDVI and precipitation as a function of time duration over which precipitation was totalled, with separate curves for desert, semi-desert, short grassland, steppe and the area average

Figure 7.5. Spatially averaged time series of spring NDVI and spring temperature over the period 1985-2001

Figure 7.6. Spring NDVI as a function of spring temperature over 1985-2003

Figure 7.7. Spatial patterns in inter-annual NDVI-climate relationship

Figure 7.8. Spatial patterns of standard deviation of growing season NDVI throughout the study period $1985-2000$

Figure 7.9. Coefficient of variation in seasonal NDVI during the period 1982-2001 calculated for spring, summer, autumn and for the growing season

Figure 7.10. Influence of altitude on coefficient of variation of NDVI in the study area

Figure 7.11. Relationships between $N D V I_{c v}$ and $P_{c v}, N D V I_{c v}$ and $T_{c v}$ for the whole $83-$ growing season, spring, and summer

Figure 7.12. Regression between coefficients of variation of growing season NDVI and that of growing season rainfall

Figure 8.1. Dynamics of correlation coefficient between NDVI and precipitation versus NDVI value

Figure 8.2. Correlation coefficients as a function of number of years over which precipitation is summed

Figure 8.3 Linear regression between long-time averages of growing season rainfall and growing season NDVI for the main vegetation types

Figure 8.4 Scatter plot of NDVI-rainfall correlation coefficients and growing season rainfall amounts averaged over the whole study area

Figure 8.5. Evolution of vegetation conditions in the study region during the period 1982-2003

Figure 8.6. Standardised anomalies in precipitation amount for the Shetsky district during the period 1982-1999

Figure 8.7. Maps of mean monthly composite NDVI for the territory of the Shetsky district

Figure 8.8. Maps of averaged monthly precipitation amount $(\mathrm{mm})$ for the territory of the Shetsky district

Figure 8.9. NDVI values, correlation coefficients between spatial distribution of 10day NDVI and precipitation and 10-day rainfall 
Figure 8.10. The same as in Figure 8.7 but for the wet year 1988

Figure 8.11. The same as in Figure 8.7 but for the dry year 1995

Figure 8.12. Correlation coefficient, 10-day NDVI values and 10-day rainfall for desert

Figure 8.13. Correlation coefficient, 10-day NDVI values and 10-day rainfall for semi-desert

Figure 8.14. Correlation coefficients, 10-day NDVI values and 10-day rainfall for steppe grassland

Figure 8.15. Regression graph between 10-day NDVI-rainfall correlation coefficients and 10-day precipitation averaged over the study period

Figure 8.16. Regression graph between 10-day NDVI-rainfall correlation coefficients and 10-day precipitation for the wet year 1988

Figure 8.17. Regression graph between 10-day NDVI-rainfall correlation coefficients and 10-day precipitation for a dry year 1995

Figure 8.18. Correlation coefficients between spatial pattern of NDVI and temperature obtained for the data averaged over the period 1985-2001

Figure 8.19. Total growing season rainfall versus NDVI-temperature correlation coefficient

Figure 8.20. Time-profile of 10-day NDVI-temperature correlation coefficient and 10-day temperature averaged over the study period 1985-2000

Figure 8.21. Time-profiles of 10-day correlation coefficient between spatial patterns of NDVI and temperature for desert, semi-desert and steppe vegetation cover. Relationship between 10-day NDVI-temperature correlation and mean 10-day temperature for different vegetation types

Figure 9.1. Accumulated growing season NDVI calculated from a combination of 1-km NOAA AVHRR and SPOT-VEGETATION for the period 199295/1998-2004. Regionalized total precipitation amount throughout the growing season

Figure 9.2. Scatter diagram between measured and predicted $N D V I_{\text {accum }}$

Figure 9.3. Spatial autocorrelogramms for $N D V I_{\text {accum }}$ and precipitation

Figure 9.4. Scatter diagram between measured $N D V I_{\text {accum }}$ and $N D V I_{\text {accum }}$ predicted by the stratified OLS regression model

Figure 9.5. Spatial variations in regression outputs from the GWR analysis of growing season accumulated NDVI against precipitation

Figure 9.6. Scatter plot between measured $N D V I_{\text {accum }}$ and computed from the GWR model

Figure 9.7. Spatial patterns of regression residuals and corresponding residuals histograms for the global OLS model, the stratified OLS model, and the GWR model

Figure 9.8. Spatial autocorrelograms for OLS residuals and residuals from the GWR model 
Figure 9.9. Maps demonstrating variability in NDVI-precipitation relationship during 1985-2001

Figure 9.10. Inter-annual variations in $\mathrm{R}^{2}$ averaged for vegetation types

Figure 9.11. Time-series of $\mathrm{R}^{2}$ for four individual sites demonstrating typical linkages between the NDVI-rainfall relationship and LULC change

Figure 10.1. Areas of statistically significant linear trends of NDVI in the study region from 1982 to 2003

Figure 10.2. Distribution of trends in NDVI which are driven by trends in climate parameters

Figure 10.3. Distribution of trends in NDVI which are not explained by climate factors

Figure 10.4. Landsat TM image of the test site 1

Figure 10.5. Test site 2 on the Landsat TM image 141

Figure 10.6. Test site 3 on the Landsat images 142

Figure 10.7. Time-series of growing season NDVI during 1982-2003 averaged over the third test site

Figure 10.8. Landsat TM and Landsat ETM+ images of test site 4

Figure 10.9. Linear regression between growing season precipitation and NDVI, and the temporal trend of associated residuals

Figure 10.10. Parameters of the GWR between NDVI and precipitation related to year 1988

Figure 10.11. Results of the temporal regression between growing season NDVI and precipitation for the period 1985-2003

Figure 10.12. Goodness-of-fit statistic, $\mathrm{R}^{2}$, for the multiple regression incorporating NDVI and the both climatic parameters

Figure 10.13. Maps of growing season NDVI predicted by the temporal multiple regression modelling

Figure 10.14. Spatial autocorrelograms for residuals from the spatial OLS model, the multiple temporal model and the GWR model

Figure 10.15. Significant trend in residuals from the GWR model 1985-2003

Figure 10.16. Comparison of two subsets from Landsat TM and Landsat ETM+ showing the expansion of wheat cultivation into the steppe grassland between the years 1992 and 2001 


\section{List of Tables}

Table 3.1. Geographical characteristics and principal vegetation classes for the meteorological stations used in the study

Table 3.2. Satellite data used in the study and their characteristics

Table 5.1. Coefficient of variations of precipitation and temperature during the period 1985-2004 as computed for the individual climate stations from the study area

Table 5.2. Mean spring, summer, autumn and growing season amount of precipitation $(\mathrm{mm})$ and their change $(\mathrm{mm})$ over the period 1985-2004 for 6 climate stations from the 53 study area

Table 5.3. Mean spring, summer, autumn and growing season temperature $\left({ }^{\circ} \mathrm{C}\right)$ and their change $\left({ }^{\circ} \mathrm{C}\right)$ over the period 1985-2004 for 6 climate stations from the study area

Table 6.1. Averaged characteristics of NDVI values for various vegetation types 54

Table 6.2. Within-season correlation coefficients between climatic parameters and NDVI for vegetation communities in desert, semi-desert and steppe as computed for dry and wet years

Table 7.1. Inter-annual correlation coefficient between NDVI and precipitation for every land-cover type

Table 7.2. Number of pixels and percentage (\%) of vegetated pixels exhibiting positive correlation with inter-annual climate change over 1985-2003

Table 7.3. Standard deviation of spatially averaged NDVI values for different vegetation types through 1985-2001

Table 7.4 Variation coefficient of spatially averaged NDVI values over the period 1985-2001

Table 8.1. Strength of relationship between 10-day NDVI-rainfall correlation and 10day rainfall amounts, and the "limit of saturation" (turning-point) for the three land cover categories

Table 8.2. Correlation between spatial patterns of growing season NDVI, growing season rainfall and growing season temperature for different vegetation types

Table 10.1. Trends of spatially averaged time-series of growing season, spring, summer and autumn NDVI over 1982-2003

Table 10.2. Number of pixels with significant upward trends in growing season, spring, summer, and autumn NDVI for individual vegetation types and for the area average

Table 10.3. Number of pixels with significant downward trends in growing season, spring, and summer NDVI for individual vegetation types and for the area average

Table 10.4. Total number of pixels with significant upward or downward trend and number of pixels which trends are explained by climate change for growing season, spring and summer

Table 10.5. Simple, partial and multiple correlation coefficients between NDVI and explanatory variables for period 1985-2001 


\section{Introduction}

\section{Problem description}

From currently published studies it is known that the vegetation on the surface of the Earth is rapidly changing. Change is occurring to the phenology, the distribution of vegetation on the earth surface and to the annual dynamics of photosynthetic activity (Kowabata et al., 2001; Reed et al., 1994). The change of vegetation cover is both naturally and anthropogenically influenced. This change has direct implications for human society as well as for the earth system, since the processes occurring in the vegetation cover are tightly coupled to the processes occurring in other components of this system such as meteorological, hydrological and biogeochemical. Thus, understanding the causes of vegetation variability and measurement of vegetation responses to natural and anthropogenic influences are of great scientific importance.

Great magnitude changes in vegetation activity result from the contemporary global warming of the earth climate leading to redistribution of precipitation and temperatures on the earth surface (IPCC, 2001). Most of these changes are observed in the high latitudes of North America and Eurasia and associated with an increase in vegetation activity due to prolongation of the growing season caused by temperature rise, particularly throughout the spring months. Rapid increase of $\mathrm{CO}_{2}$ content in the atmosphere is reported to be a driving force of this phenomenon. Changes in vegetation activity can also result from a variety of other environmental factors, such as desiccation and droughts, El Nino-Southern Oscillation (ENSO) (Anyamba et al, 2001; Gutmann et al, 2000) or human activities (e. g. land-use). Inter-annual changes associated with a decrease of vegetation activity are observed in wide areas of Australia, South and Central Africa, South America and in some regions of Asia. Causes of diminishing vegetation activity are the increasing dryness of the climate in these regions and inadequate human influence.

The consequences of the contemporary climate change have been observed in all regions of the Earth but the most devastated consequences are to be expected in the ecosystems of low stability to internal forces. Such ecosystems are presented in drylands and cover more than $30 \%$ of the terrestial surface. On the one hand, the natural environment of the drylands is highly vulnerable and fragile, variations of climate conditions here are the highest among all terrestrial ecosystems and that is why any unwise action of people in resources development can lead to a disturbance of equilibrium in nature, and accelerates 
processes of land degradation and desertification. On the other hand, drylands are densely populated and extensive used for agricultural production.

There is a great demand for a better understanding of nature of climate impacts on the drylands as a whole system and on the vegetation cover as an important component of this ecosystem at all scales from global to regional and local. This understanding requires detailed investigations on the vegetation response to climate factors. On the one hand, knowledge of this response holds the potential for discrimination of threatened areas and forecasting of damage grade by drought events. On the other hand, this knowledge subsequently improves planning of protection arrangements. Another benefit is associated with forecasting of regional agricultural yields for drought years which improves planning for food supply for times of food scarcity.

The hot debate about the concept of dryland dynamic has its roots in the specific features of dry lands, namely high variability of climatic conditions and high dependence of ecosystem dynamics in dry lands on this variability. According to this, it is not surprising, that this debate is accompanied by the debate about equilibrium or non-equilibrium of the dry land ecosystems. Detection of vegetation cover change in drylands and understanding of its causes and consequences depend on the point of view in the equilibrium concept (Sillivan \& Rohde, 2002; Herrmann \& Hutchinson, 2005; Vetter, 2005; Robinson et al., 2002).

According to the equilibrium concept, the dry lands are believed to have only a weak mechanism of internal regulation which, consequently, enables a weak resistance to external factors such as climatic perturbations including drought and desiccation hazards, fire and human activities. Therefore, it seems likely that any trend in ecosystem conditions may be highly dependent on the trends in various climatic factors, mainly, precipitation and temperature. In order to identify changes that are attributed alone to human influence, this climatic component must be identified and removed from the evident ecosystem changes (Evans \& Geerken, 2004; Li et al., 2004). Thus, an evaluation and monitoring of land performance may begin with an investigation of climatic factors dynamics and their changes over monitoring time and resilience and resistance of the ecosystem to these changes. After that, when this task is solved, one can look at ecosystem changes that are caused by anthropogenic impact.

In the last two decades, capabilities for monitoring global and regional environmental phenomena were significantly improved. The dryland theory shifted to characterizing and understanding external forcing as possible explanations for ecosystem variability. Studies of relationships between satellite derived vegetation index, NDVI, and climatic data have shown 
that most ecosystem variability in dry regions is directly dependent on rainfall variability (Tucker \& Nicholson, 1999; Anyamba \& Tucker, 2005; Olsson et al., 2005; Xiao \& Moody, 2004). It is primarily caused by changes in rainfall patterns, which leads to change in biomass production, that climate change will affect land degradation and desertification. Changes in rainfall can be controlled by regional or global processes such as global circulation changes related to patterns of sea-surface temperature or El Nino Southern Oscillation (Young \& Harris, 2005; Gurgel \& Ferreira, 2003; Verdin et al., 1999; Anyamba \& Tucker, 2001). The dynamics of ecosystem in dry lands are essentially driven by climatic variability. Deficits in rainfall, especially during drought and desiccation events, seriously reduce biomass and vegetation cover. This can give a start to process of land degradation, if the ecosystem resources are used with the same intensity degree as during wet years. The developing degradation disrupts ecological and social patterns and can hinder an ecosystem recovery after the climatic hazards. However, it does not always follow that climatic hazards will give rise to desertification in every case. Much depends on the resource management (Herrmann \& Hutchinson, 2005).

\section{Objectives and aims of the study}

This thesis was not only focused on a monitoring vegetation conditions and climate in a dry region of Kazakhstan but also on discrimination between climatic and anthropogenic forces in the complex of dryland dynamics. The work tried to find out what the proportion between them is and how they influence the dynamic and changes of ecosystems in the study region over the last two decades of the $20^{\text {th }}$ century. On the one hand, the large size of the study region (approximately $3^{\circ *} 3^{\circ}$ latitude/longitude) reveals problems caused by a significant heterogeneity of its surface features through a large quantity of landscape types. On the other hand, it achieved advantages for a discussion of the final results: a variety of ecosystems exhibited a broad spectrum of influence proportions between climatic factors and human impact of various types; some ecosystems demonstrated a full dependence of their changes on climatic change, while many others display a full prediction of their dynamics by human impact.

The investigation deals with several research questions:

1. How strong are vegetation patterns affected by the patterns of climatic factors both from year to year and within growing season? 
2. What dependency exists between the within-season/inter-annual vegetation dynamics and the dynamics of their explanatory factors?

3. To what extent is a change in vegetation activity over the last two decades predicted by a climate change?

4. Is there a presence of any non-stationarity in the relationship between vegetation activity and climatic factors? How can the non-stationarity be overcome and used for a reduction of uncertainties in the analysis?

5. To what extent is the change in vegetation activity predicted by a change in land use practices (change in anthropogenic impact)?

6. To what extend has the constitutional change in 1991 influenced vegetation cover?

The research questions 1-4 deal with investigation of response, resilience and resistance of vegetation cover to the first main external factor, climate, while the questions 5 and 6 deal with the second main factor, human impact, and its discrimination from the climatic impact. The discrimination between climate-induced and human-induced change was made through a detection of the climatic signal in the inter-annual ecosystem dynamics and exclusion of it. It was proposed that after eliminating the climatic component, the remaining changes in ecosystem conditions are attributed to human influence. The areas displaying a negative trend of the remained changes in ecosystem conditions over time were considered as degrading.

An introduction to drylands, their dynamics and problems of their investigation follows in section 1 . This section also deals with remote sensing approaches for investigation vegetation-climate relationship. Section 2 includes an introduction to the study region. In section 3 and 4 a description of data used and methods of data analysis follows. In section 4 also an introduction to a local statistical technique known as geographically weighted regression (GWR) is given. This technique enables us to reduce uncertainties in statistical analysis of spatial data very significantly. Chapter 4 also introduces to the concept of discrimination between two main driving forces of vegetation change, climate and human impact. Theoretical sections 1-4 form the basis for the analysis of the data which follows in chapters 5-10. Chapter 5 deals with statistical characteristics of climate factors in the study region. Spatial and temporal inter-annual dynamics of climate parameters will be highlighted and analysed. Chapter 6 reports the results of analysis of within-season dynamics of vegetation activity and investigated their relationship to climate parameters. Chapter 7 deals 
with inter-annual variability in vegetation activity, while chapter 8 investigates spatial response of vegetation cover to climatic factors. An effort to improve the results of chapter 8 is undertaken in chapter 9 by use of the geographically weighted regression (GWR), a new technique for modelling spatial relationship. In chapter 9, the GWR has been applied for a spatio-temporal analysis of relationship between vegetation activity and rainfall. Supervises of GWR over other regression models have been analysed and discussed. Sections 6-9 form a basis for discrimination between human-induced and climate-induced changes in vegetation. The results of this discrimination are presented in chapter 10. The last sections include a discussion of the derived results with an outlook on the further development of drylands monitoring as well as the potentialities of the investigated approaches and the new sensors. 


\section{Chapter 1}

\section{Theoretical background to dry ecosystems}

\subsection{Dynamics of dry ecosystems: ephemeral versus permanent changes}

\subsubsection{Brief characterization of ecosystems in dry regions}

Dry lands include areas where rainfall does not meet the evaporative demand. They occupy around 45 percent of the land surface, contain about 30 per cent of the world's total carbon in above- and below-ground biomass (Mainguet, 1999), and include grasslands, shrublands, savannas, xerophytic woodlands, and hot and cold deserts (Figure 1.1). Their rangelands support approximately 50 per cent of the world's livestock and provide forage for both domestic animals and wildlife. In dry lands, the evolution developed specific ecosystems, whose characteristics distinguish from that of other earth regions.

Climate of dry land shows a severe aridity, it means that potential evapo-transpiration is higher than precipitation. By the value of an aridity index, which is calculated as ratio of annual precipitation to annual potential evapo-transpiration, dry lands are classified into hyper-arid $(<0.05)$, arid $(0.05-0.20)$, semi-arid $(0.20-0.50)$, and dry sub-humid $(0.50-$ 0.65). In dry lands, rainfall patterns within the year are characterized by a dry period whose length varies from region to region (2-10 months). One typical feature of climate is seasonal precipitation. Mostly time the vegetation societies are stressed by water shortages and have developed adaptations to cope with the phenomena. An amount of precipitation which is smaller than potential evapo-transpiration combined with contructed seasonal distribution contribute to great air dryness. High temperatures and high air dryness are responsible for high evaporation from soils and the surrounding atmosphere. This results in soil dryness and in an increase of plant transpiration.

Drylands are generally characterized by severe deficit of surface water. Rivers in this geographical zone often have only irregular runoff that occurs during two to six months per year. The rest time of the year, their beds fall dry or lead only a few amount of water. 


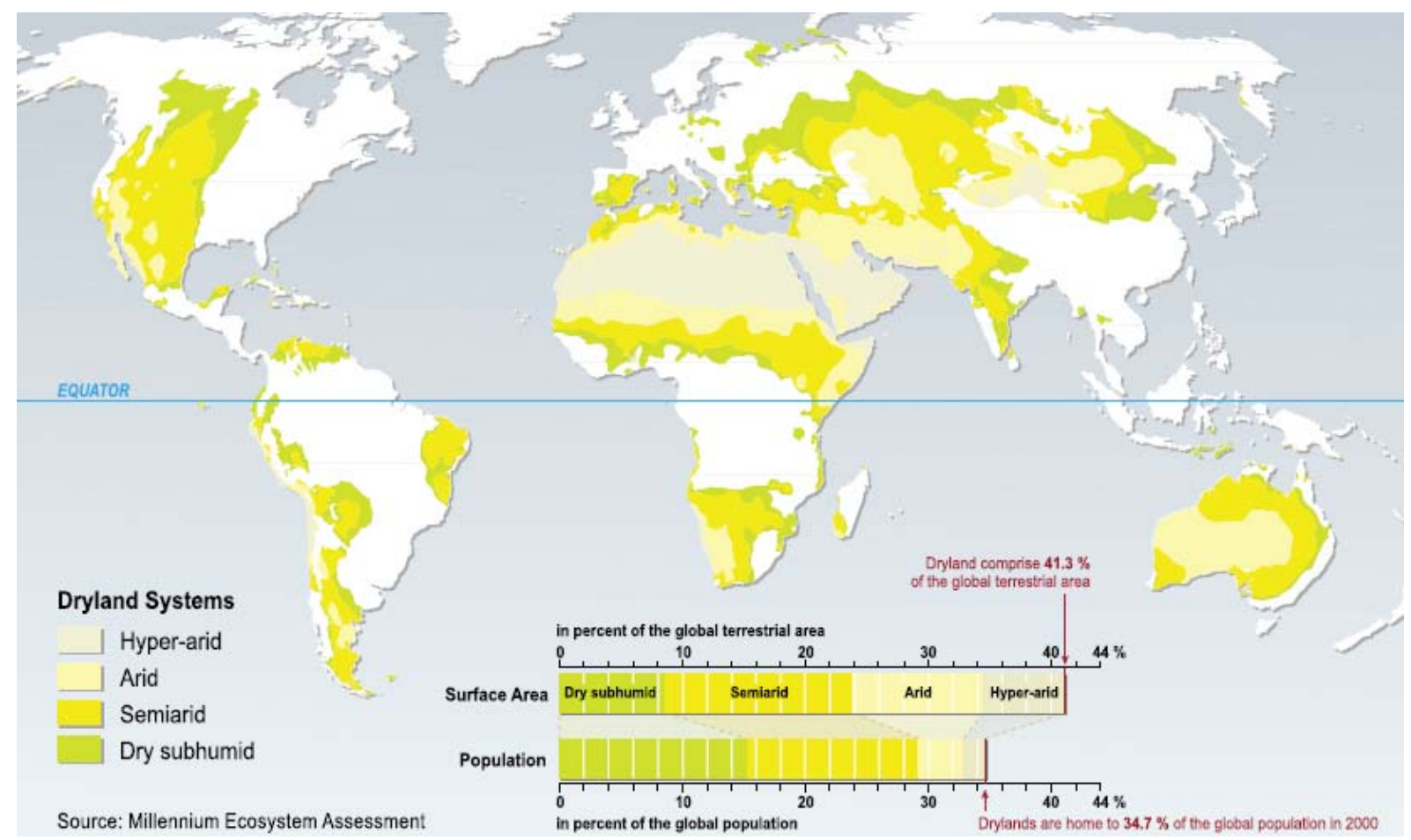

Figure 3.1. Distribution of drylands throughout the world (UNEP, 2000).

\subsubsection{Dynamics of ecosystems in drylands}

Physical-geographical processes that change the earth's surface, its water household and soil conditions also greatly affected the composition and distribution of plants, caused a change of varieties. Because of moisture deficit throughout the vegetation period, all plant species living in dry lands show a high degree of adaptation to aridity factor. A large variety of xeromorphic, sclero-xeromorphic and ephemeric grasses, shrubs and dwarf half-shrubs are to be found in the vegetation cover. Ephemerals are especially abundant during the rainfall period or in the short period after plenty rainfall events.

Ecosystem dynamics of dry regions are influenced by hazards such as drought and desiccation. Drought refers to the naturally occurring short-term (1-3 years) phenomenon when precipitation is significantly below the long-time mean value. A recovery of the ecosystem after the rain return occurs rapidly during the next 1-2 years, if the system is not overexploited beyond its resilience thresholds. Desiccation refers to longer-term (decadal order) deficits in rainfall which seriously disrupts ecological balance in the system. Recovery after desiccation is much slower, for vegetation cover it can take years to recover.

Even if the current understanding of the ecological functioning of arid, semi-arid and sub-humid rangelands emphasizes a high dependence of the ecosystem dynamics on climatic perturbations, the debate about the validity of the two paradigms of vegetation dynamics in 
rangelands is not at an end. The question debated is the so-called equilibrium or nonequilibrium system of rangelands ecology. Implications for current interpretation of land degradation and desertification depend on the answer on this question (Vetter, 2005; Robinson et al., 2002).

The equilibrium paradigm is based on the assumption that every environment has climax vegetation determined by biophysical characteristics, such as the mean annual precipitation, soil type and biophysical characteristics, which determine its potential primary productivity. The equilibrium model proclaims that internal ecosystem regulation is achieved by negative feedback mechanisms that move the system toward stability. When the climax is perturbed, vegetation is pushed back in the successional sequence to a sub-climax. Within this model, at a particular time vegetation development represents a stage in plant succession on the range line between two end states of vegetation development - poor (or very disturbed) and excellent (or climax). Rainfall is thought to affect the vegetation via similar mechanism where drought reduces range condition by pushing the vegetation community towards a pioneer stage. High rainfall improves range conditions. This model is believed to be applicable for dry ecosystems with low climate variability, but it is reported to have no adequacy to describe vegetation dynamics in arid and semi-arid ecosystems with high variability of climatic factors (Sillivan \& Rode, 2002; Vetter, 2005).

The non-equilibrium paradigm describes vegetation dynamics driven by periodic and stochastic climatic events, which result in discontinuous and non-reversible changes. The nonequilibrium model is based on the suggestion that every ecosystem has a threshold of its conditions, crossing this threshold due any disturbance leads to irreversible changes. The ecosystem may not enter into its stage which it had before a disturbance. The ecosystem can enter into a number of other possible states. This means irreversibility of the ecosystem change even after removal of the disturbance causing the change. The recovered ecosystem would reach a new functional state via changes in physical properties and biogeochemical cycles. It proclaims that every ecosystem has a number of alternative equilibria (states), which may be entered after a disturbance (Shepherd \& Caughley, 1987; Illis \& Connor, 1999).

In most cases, dry lands are believed to be far-from-equilibrium systems, because their dynamics of productivity and species composition are generally controlled by external factors such as climatic variables, depletion of above-ground biomass by herbivores or fire and human activities. The internal regulatory mechanism of the ecosystem in dry regions is weaker than the external mechanism. The ecosystem dynamics are essentially event-triggered, climate of arid regions is unsteady because of its high variability (Sillivan \& Rohde, 2002; 
Herrmann \& Hutchinson, 2005). High variability of climate in dry regions manifests particularly in high precipitation variations; the coefficient of variation of rainfall is between $25-40 \%$. Study results from dry regions show that long-term ecosystem behaviour is better explained by rainfall variability than by the mean values. For a rangeland in Australia, the threshold between equilibrium-type dynamics and non-equilibrium (event-triggered) dynamics were reported to be localized at the coefficient of variation of annual rainfall $30 \%$; for African rangelands, the threshold is formed by $400 \mathrm{~mm}$ annual rainfall isohyete (Shepherd \& Caughley, 1987; Ellis et al., 1993).

Equilibrium and non-equilibrium dynamics are not exclusive, but present two end sides of a wide continuum spectrum of possible types of ecosystem dynamics. Depending on spatial and temporal scales, most systems can exhibit both types of dynamics. There are examples for time shifts between equilibrium and non-equilibrium dynamics (Illius \& O’Connor, 1999).

The advances of environmental monitoring strategies in the last to decades, particularly with the use of remote sensing, facilitate to understanding the ecosystem variations and ecosystem changes as well as their causal relationships. Data from satellite sensors reveal patterns of inter-annual and seasonal variations in land surface attributes that are driven by climatic variability. The results of studies from dry regions around the world prove a highly variable, event-triggered non-equilibrium process, and highlighted a new research view of the commonly accepted wisdom of land degradation and desertification. The variations of ecosystems are controlled by the impact of El Nino Southern Oscillation (ENSO) phenomena (Gutman et al., 2000), drought and desiccation (Lambin \& Ehrlich, 1996; Kogan, 1997), desiccation and rainfall fluctuations (Tucker et al., 1999; Anymba \& Tucker, 2006; Olsson et al, 2006), and temperature growth (Xiao \& Moody, 2004). The modern knowledge about equilibrium and non-equilibrium dynamics of ecosystem in dry regions leads to the perception that assessment of land degradation and desertification need to be long-term and take climatic variability into account. Many of the former diagnoses and forecasts of desertification phenomena have been revised (Thomas, 1997; Robinson et al., 2002).

\subsection{Remote sensing based investigations of vegetation changes and their explanatory factors}

Spatial distribution of vegetation cover is strongly related to the distribution of the mean climatic conditions, such as rainfall and temperature. On the other hand, the climatic factors vary in the space depending on the relief characteristics. Particularly in the arid 
regions, where a lack of moisture is the permanent property of the geographical surrounding during the most time of the year, the relief characteristics can be the most predicting factor for the distribution and condition of vegetation. But the influence of the relief to vegetation is not direct; it acts through the climatic factors.

Satellite derived Normalized Difference Vegetation Index (NDVI) is a convenient tool for monitoring of vegetation cover at all scales from global to local. It enables regular detection of seasonal and inter-annual changes in vegetation activity. The NDVI has successfully served as vegetative indicator in many studies on desert encroachment and desertification (Tucker et al., 1999; Wessels et al., 2004; Symeonakis and Drake, 2004), drought monitoring (Kogan, 1997; Song et al., 2004), El-Nino impacts on ecosystems (Anyamba \& Tucker, 2001), global phenology and bioclimatology (Tateishi \& Ebata, 2004; Chen et al., 2004). These and other similar studies are motivated by the appropriation of NDVI for the analysis of vegetation cover at a wide range of spatial scales.

The correlation between NDVI and above-ground biomass is well established. The satellite derived NDVI can serve as a general surrogate for vegetation conditions (Justice et al., 1985; Tucker \& Sellers, 1986). Temporal and spatial correlations between NDVI and climatic factors are investigated in many research works. Particularly well correlation in the arid regions, both spatial and temporal, show NDVI and rainfall (Richard \& Poccard, 1998; Chen et al, 2004; Weiss et al, 2004; Tateishi \& Ebata, 2004), the relationship between NDVI and temperature are reported to be weaker but also significant (Kowabata et al., 2001; Schultz $\&$ Halpert, 1995). According to recent studies, precipitation has a strong effect on the interannual variability of vegetation activity especially in dry regions (Yang et al, 1998; Richard \& Poccard, 1998; Wang et al, 2003; Li et al., 2002).

Numerous studies have suggested a linear relationship between NDVI and climate predictors. Theoretically, NDVI can be considered as climatic recorder, mainly as a rainfall recorder. This assumption was used in various drought watching and drought early warning systems (Kogan, 1997; Song et al, 2004). However, the relationship is linear only in a limited range of rainfall conditions. The upper thresholds for the linear relationship between NDVI and rainfall were reported to be approximately $500 \mathrm{~mm} / \mathrm{yr}$ for semi-arid Botswana (Nicholson \& Farrar, 1994), 700-800 mm/yr for Senegal (Li et al, 2004), and 500-700 mm/yr for China (Li et al, 2002). Above these limits, NDVI increases with rainfall only at a slower rate.

The response of NDVI to rainfall and temperature is dependent on vegetation types and varies by geographical region. Woodland and forest vegetation shows a lesser correlation between NDVI and climate factors. Shrubs and desert vegetation patterns are reported to 
correlate stronger with temporal and spatial variations of climate factors. Vegetation patterns in steppe grassland and savanna show evidence of the highest correlation with that of rainfall and temperature (Li et al, 2002; Wang et al, 2001, Li et al, 2004). Nicholson \& Farrar (1994) reported for Botswana the response of NDVI to rainfall to be more dependent on soil types than on vegetation types.

Many studies proved a high sensitivity of NDVI to inter-annual rainfall anomalies. Thus NDVI can be used as a good proxy for the study of inter-annual climate variability on regional and global scales or for identification of climatic signal by evaluation of land degradation (Kuwabata et al, 2001; Evans \& Geerken, 2004). However, there are limits of rainfall amounts beyond which only a weak NDVI sensitivity to inter-annual rainfall anomalies can be found. This rainfall limit varies by geographical region, but generally, a minimum of $200-300 \mathrm{~mm} / \mathrm{yr}$ seems sufficient to induce a NDVI sensitivity to rainfall anomalies (Nicholson et al, 1990; Richard \& Poccard, 1998). Temperature deviation from average reported to not correlate with NDVI deviation from average (Wang et al, 2001).

Vegetative cover is the best measurable indicator of ecosystem change and can be easy detected by remote sensing methods. Vegetation cover performance is strongly predicated on macro- and micro-climatic factors, such as global temperature and rainfall distribution change, local topography characteristics etc. Therefore, discrimination between different causes of change in vegetation cover, climate and human activity, is very difficult. The neglecting of this aspect can lead to mistakes by evaluation of land conditions (Binns, 1990; Hellden, 1991). A few recent studies have developed methods for application of discrimination by use of satellite data time-series and time-series of climatic variables (Evans \& Geerken, 2004; Li et al., 2004). These methods have been based on identification of climate signal in inter-annual dynamic of vegetation activity. Once the climate signal is identified, it can be removed from the trends in vegetation activity. The remaining vegetation changes are attributed to human influence and these areas considered to experience a human-induced degradation/rehabilitation of vegetation cover. 


\section{Chapter 2}

\section{Study area}

\subsection{Geographical location and mean characteristics}

The study area is located in the middle part of Kazakhstan between 46 and $50^{\circ}$ northern latitude and $72^{\circ}$ and $76^{\circ}$ eastern longitude in the northern sector of the watershed of the Balkhash Lake and covers the south-western part of the Kazakh Hills as well as its southern margin. It consists of the whole area of the Shetsky raion (district) of Karaganda oblast' (province) and the bordered areas of the neighbouring raions. In the northern section of the study area Karaganda is situated, the most populated (ca. 400000 inhabitants) and the main industrial city of the Middle Kazakhstan (Figure 2.1). The largest part of the study area is only sparsely populated (population density is about 3-5 people per $\mathrm{km}^{2}$ ) and used as pasture land and for crops production.

In terms of surface structure the study area is divided into two large regions: a plateau of rolling upland in the southern, western, and northern parts with average elevations between 300-700 meter and hills and low mountains in the central and north-eastern parts with elevations 700-1100 meter.

The study region is only pure drained. In the eastern part of it, the valley of river Sarysu extends. The Sarysu is the largest river in the region. Most time of the year the bed of the Sarysu falls dry and is filled by water only during 3-4 spring and summer months. In the south-east there are mid-large perennial rivers that mouth to the Balkhash-lake. Some of them dry up completely to form dry gulches and deltas in the desert and semi-desert.

\subsection{Climate conditions}

The climate of the region is dry, cold and highly continental. According to the climate classification of Köppen, the climate of the study area belongs to the Cs-climate category. The mean annual temperature is $2.1^{\circ} \mathrm{C}$ (Figure 2.2). The temperature amplitude is relatively high: average January temperature is below $-12^{\circ} \mathrm{C}$ and average July temperature is about $25-28^{\circ} \mathrm{C}$, what gives an annual temperature amplitude of over $40^{\circ} \mathrm{C}$. The growing season starts in April and continues till October. The length of vegetative season is equal to 170-190 days, whereas the period of active growth, during which the mean daily temperature rises above $10^{\circ} \mathrm{C}$, is only 150-170 days (mid to late April until to late October). 


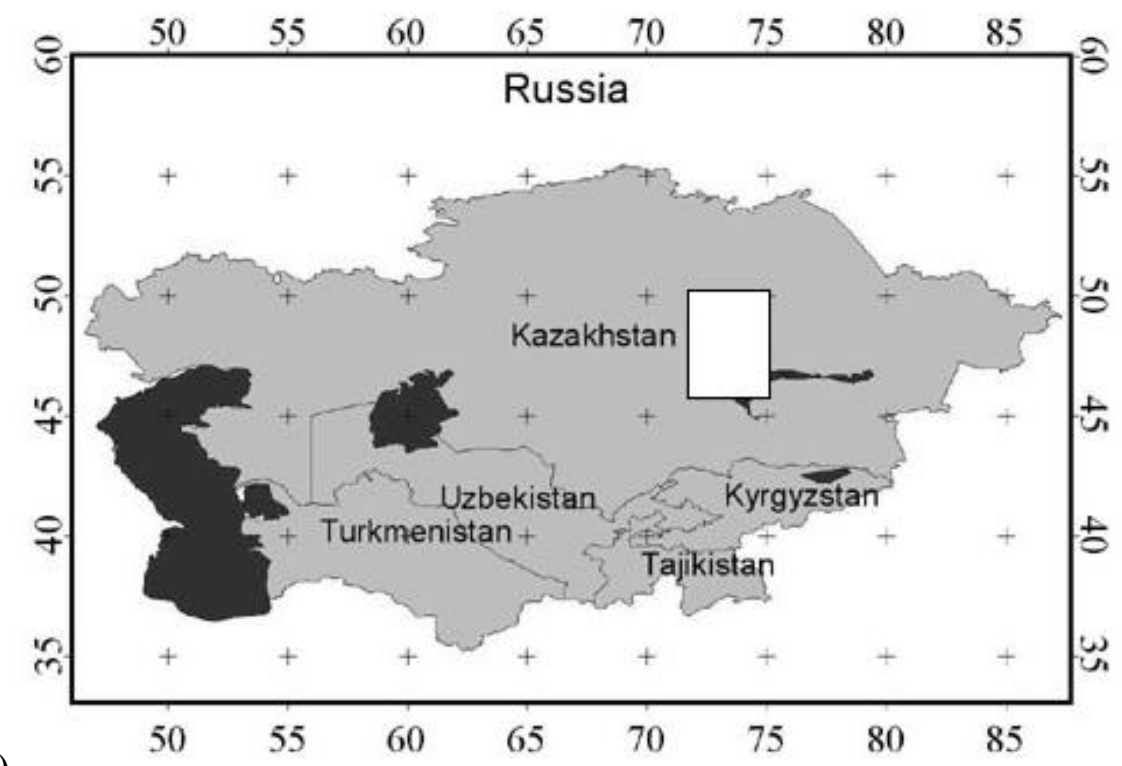

(a)

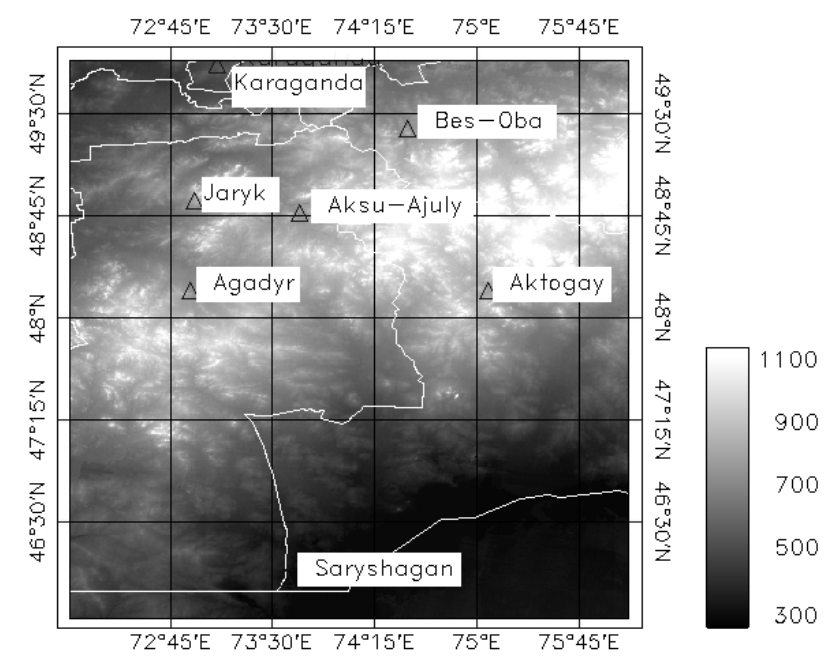

(b)

Figure 4.1. (a) The location of the study area (white square) on the map of Kazakhstan (b) The study area: its relief (altitude, m), climate stations, and borders of the districts.

Average annual precipitation is above $250-300 \mathrm{~mm}$ per year in the north of the study area, and below $150 \mathrm{~mm}$ in the south (Figure 2.3). The evaporative power of the air is very high. The relative humidity at the northern part of the study site averages $60 \%$ during daylight from June to August, and $30-35 \%$ in the southern part. The most part of precipitation falls during warm period from March to October, whereas the proportion in summer is $60-70 \%$. The potential evapo-transpiration amounts to 1100-1200 mm. This stands for a water deficit throughout the year. The deficit develops slowly in the spring, reaching a peak in mid to late summer when the potential evapo-transpiration is highest and precipitation is low. During the last century, the annual rainfall shows a coefficient of variation of $20-35 \%$. The region is 
often affected by drought hazard, during the last century there were many periods of two or more years with rainfall substantially below the average. The amount of years with negative annual rainfall anomaly surpasses that of years with positive anomaly. This means that during most time the vegetation societies are stressed by water shortages. They have developed adaptation mechanisms to cope with the phenomena.

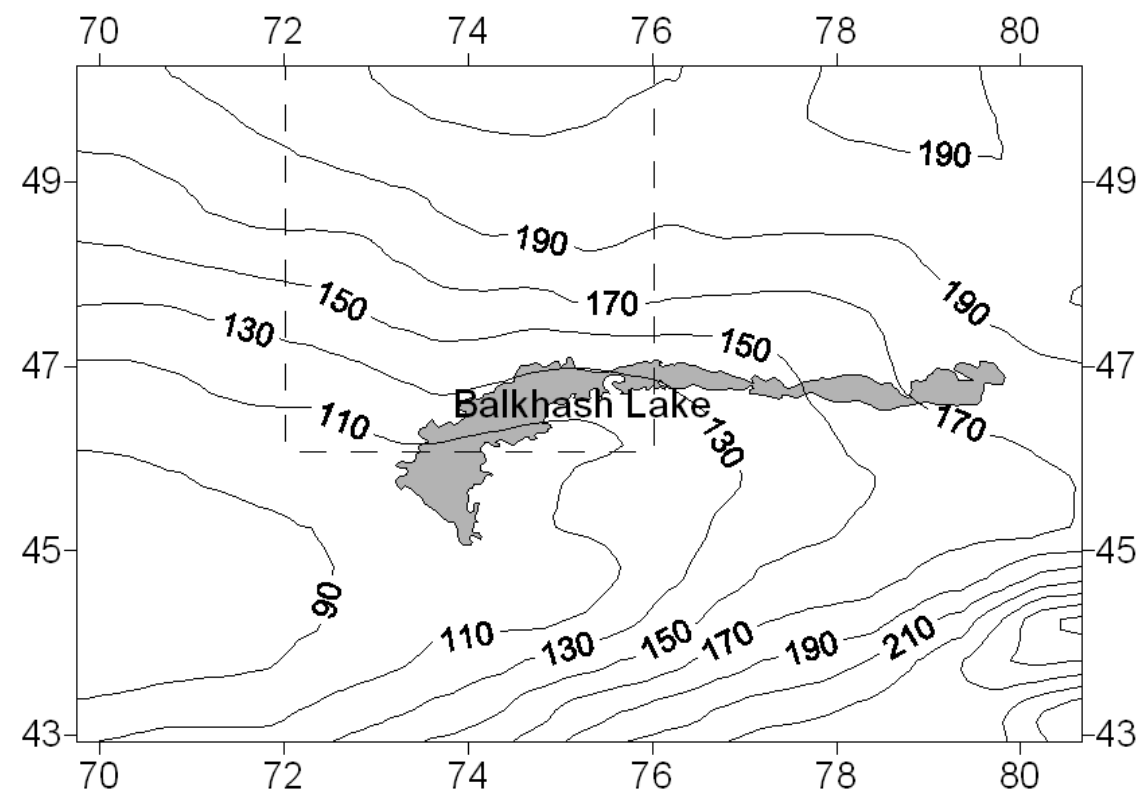

Figure 2.2. Total rainfall amount (mm) during the growing season (April-October) for the region of the Balkhash lake catchment. The study area is determined with a dashed line.

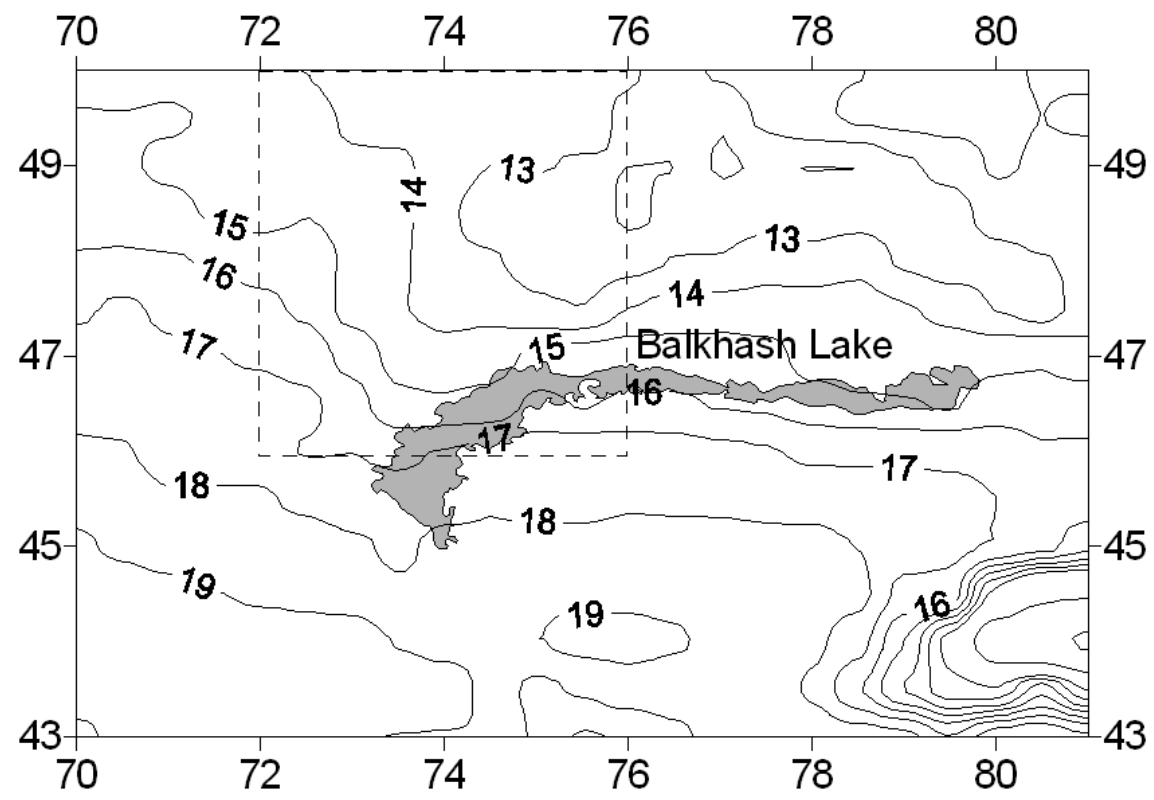

Figure 2.3. Mean air temperature $\left({ }^{\circ} \mathrm{C}\right)$ over the growing season (April-October) for the region of the Balkhash Lake drainage basin. A dashed line presents the borders of the study area. 


\subsection{Soils}

Several external factors (soil-forming factors) - parent material, climate, plants and other organisms, topography or relief - are responsible for the formation of soils. The soilforming factors control the characteristics of the soil system. An abundance variance of the external factors of the study area predicts a diversity of soil types here. In spite of this diversity, there are a great variety in humidity percent of soil surface horizon. One can find here both soils with well-humified surface horizons and soils with only weakly humified surface horizons there.

In the northern part of the study area, in the steppe zone kastanozem soils are prevalent. These are soils with brown to dark-brown, relatively thin surface horizons often underlained by a brown, prismatic, lime-free layer and then a calcareous layer at the depth of $40-60 \mathrm{~cm}$. The horizons are usually sharply differentiated. Reaction is neutral to slightly alkaline at the surface, increasing to moderately and strongly alkaline in the $\mathrm{C}$ horizon. Organic-matter content is between 1.5 and $5.0 \%$ at the surface, decreasing with the depth. There are two types of kastanozem soils in the study area, - calcic and haplic kastanozems. Calcic kastanozems are mostly common in local areas associated with more steeply sloping topography or finer-textured parent materials where leaching is minimal. These areas are located on the border of the desert where evapo-transpiration greatly exceeds precipitation and therefore leaching potential is minimal. Leached kastanozems are commonest in areas where sodium salts are available to encourage some dispersion of clays. This must be coupled with enough precipitation for leaching of salt and translocation of clay. Soda salinization is widespread in the dry steppe zone.

The arid climate causes a special type of soil formation in the desert zone of the study area. This zone is characterized by different types of grey and grey-brown desert soils (serozems). The soil formation process here is still in its initial stage. Water-soluble salts as carbonates, sulfates and sodium chloride are typically abundant in the soils. The horizons of these soils are slightly differentiated. Grey-brown desert soils typically have a clayrich $A_{k}$ crust horizon with crack net. This crust is $2-7 \mathrm{~cm}$ thick. $A_{k}$ horizon is underlined by a friable light-grey thin $A$ horizon, less than 10-15 cm thick. Hard brown calcareous and saline horizons are located under the $A_{k}$ and $A$ horizons. As the vegetation is very sparse and only small amounts of plants residue accumulate in the desert soils, they contain very little organic material (0.5-1.5\% of humus). Grey desert soils typically have more organic carbon in their humus horizons, $1-3.5 \%$, than the grey-brown desert soils. The organic matter content rash 
decreases with depth and carbonates appear in the soil profile. A powerful hard calcareous horizon is located at the depth of 1.5-2 m.

Spatial variances of groundwater table predict the genesis of azonal soil types. These are solonetzs and solonchaks, which are widely distributed in the study area. Solonetzic soils are soils whose genesis is controlled by the presence of sodium ions. A groundwater source of sodium is indispensable for origin of this type of soils. Solonetzic soils often have a relatively thin $A$ horizon $(<15 \mathrm{~cm}$ ), overlying a clay-rich columnar or prismatic $B$ horizon which is very hard. Sodium and other salts are usually present in this horizon, and become more concentrated with depth. The $C$ horizons are usually calcareous and saline. Solonetz soils occur in saline clays, relief depressions and alluvial deposits of valleys and are mostly associated with kastanozem soils in the study area. Solonchaks occur in the desert zone and are associated with grey and grey-brown desert soils. This soils contain usually large amounts of soluble salts (more than 1\%) in the upper horizon. They typically have minimum profile development, reflecting a combination of low organic-matter production and minimal leaching of salts. A high water table and a high evaporation of groundwater are two necessary factors for genesis of solonshaks. Solonchaks are located in relief depressions and in drying up valleys of the southern part of the study area.

\subsection{Vegetation}

Spatial distribution of vegetation is strongly influenced by spatial patterns of predicting factors, i.e. climate, soil types, stage of underground water table etc. The main factor, which predicts the zonal types of vegetation in the study area, is rainfall amount. The rainfall amount in the study area decreases from $260-280 \mathrm{~mm}$ in the north to $100-150 \mathrm{~mm}$ in the south. It causes the change of vegetation formations from steppe in the north to semidesert, and to desert in the south (Figure 2.4). All vegetation features change with decreasing aridity. Species diversity is reduced from 40-50 species in a hectare in steppe to $12-15$ species in semi-desert and desert. The canopy hight decreases from $60-80 \mathrm{~cm}$ in the north to $15-20 \mathrm{~cm}$ in the south; and foliage cover decreases from $70-90 \%$ to $10-20 \%$, and less. Much of the variations within the zonal types of vegetation are related to edaphic characteristics. Some landscape impressions from the study area are presented in Figure 2.5. 


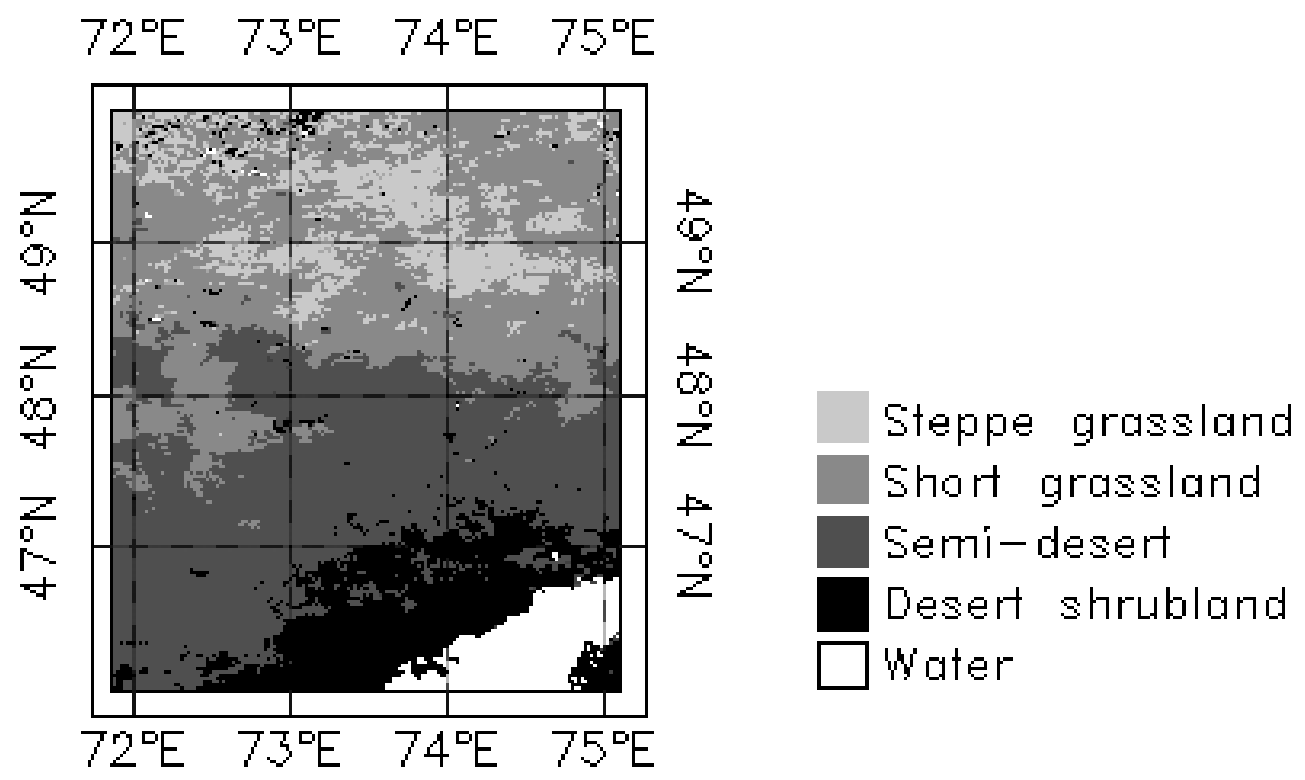

Figure 2.4. Map of the land cover in the study area based on analysis of satellite imagery and a vegetation map from 1995.

The typical vegetation classes of northern desert and steppe are represented in the study area. Because of moisture deficit throughout the vegetation period, all vegetation species living here show a high degree of adaptation to aridity factor. A large variety of xeromorphic, sclero-xeromorphic and ephemeric grasses, shrubs and dwarf half-shrubs are to be found in the vegetation cover. Ephemerals are especially abundant in the mid and in the south, a few mesomorphic species are only rarely represented in the north of the study area.

The vegetation of the desert is sparse, low-growing, and of a monotonous light grey colour. The desert zone is dominated by sagebrush and perennial saltwort associations. The most spreading vegetation species here are Artemisia terrae-albae, Artemisia pauciflora and various halophilous species. Ephemeroids and ephemerals are also typical: Crocus reticulates, Geranium tuberosum and Poa steposa. Saltwort in complex with sagebrush occupies the plains in the most southern part of desert zone. Salsola arbusculiformis, Anabasis salsa and Artemisia turanica predominate in their communities. In basins and depressions with high groundwater table, were solonchaks and solonetzs develop, the halophytic species such as Anabasis salsa, Artiplex cana, Salsola orientalis and Salsola arbusciliformis are prevalent. Here they build communities in mixing with Artemisia terrae-albae. Sagebrush with grasses in complex with sagebrush and saltwort occupy the northern part of the desert zone. The prevalent species here are Artemisia semiarida, Artemisia sublessingiana, Stipa kirgisorum and Salsola arbusculiformis. 
(a)

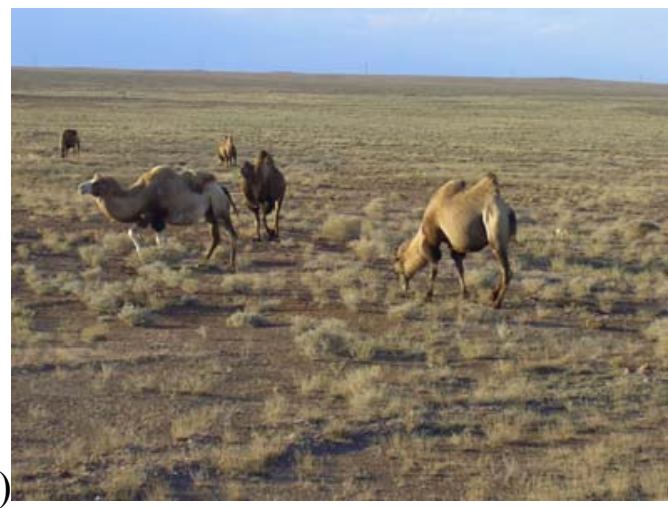

(c)

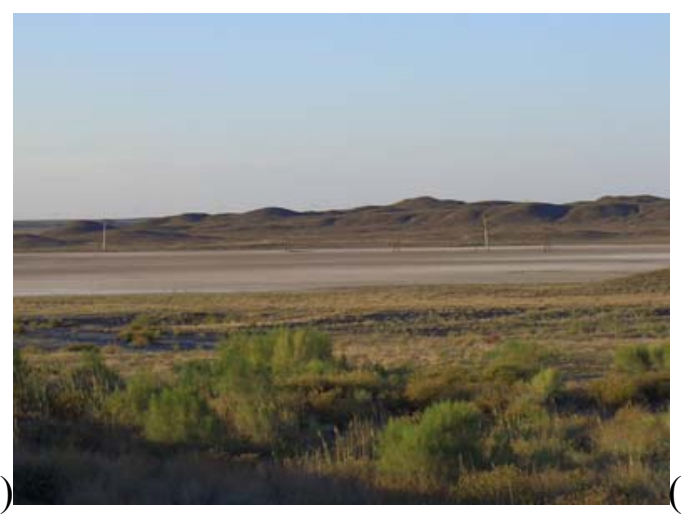

(e)
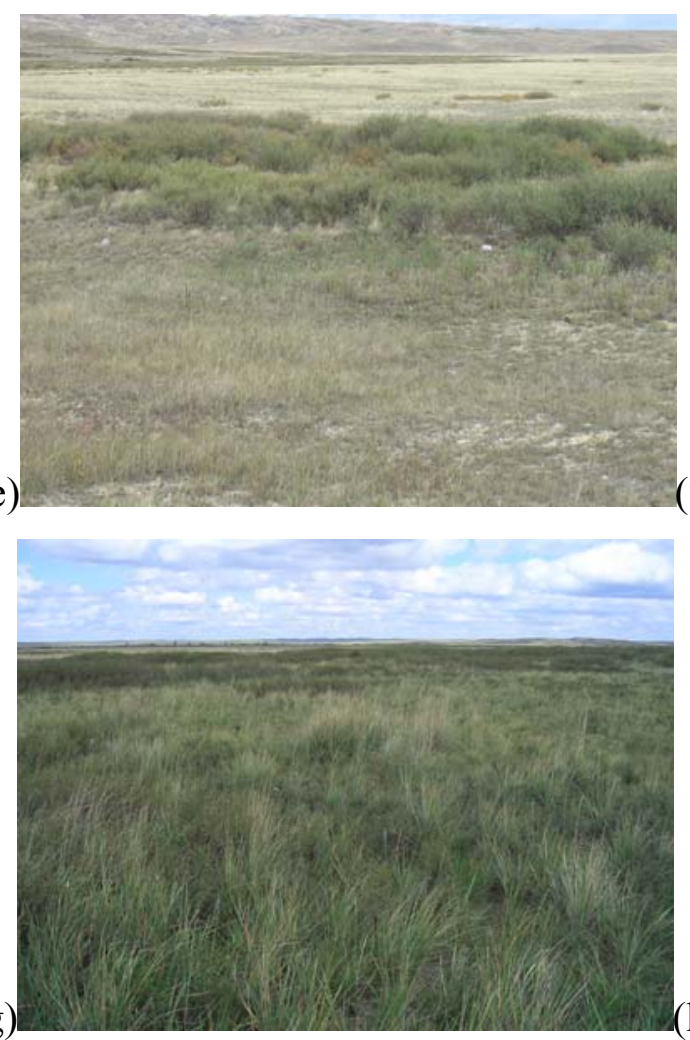

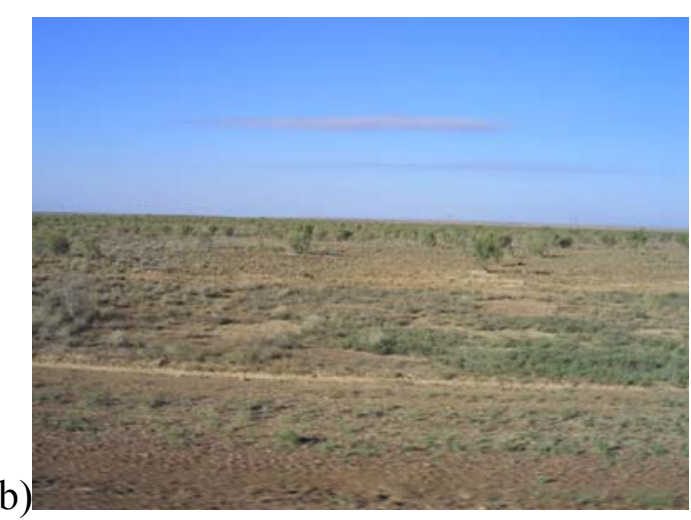

d)
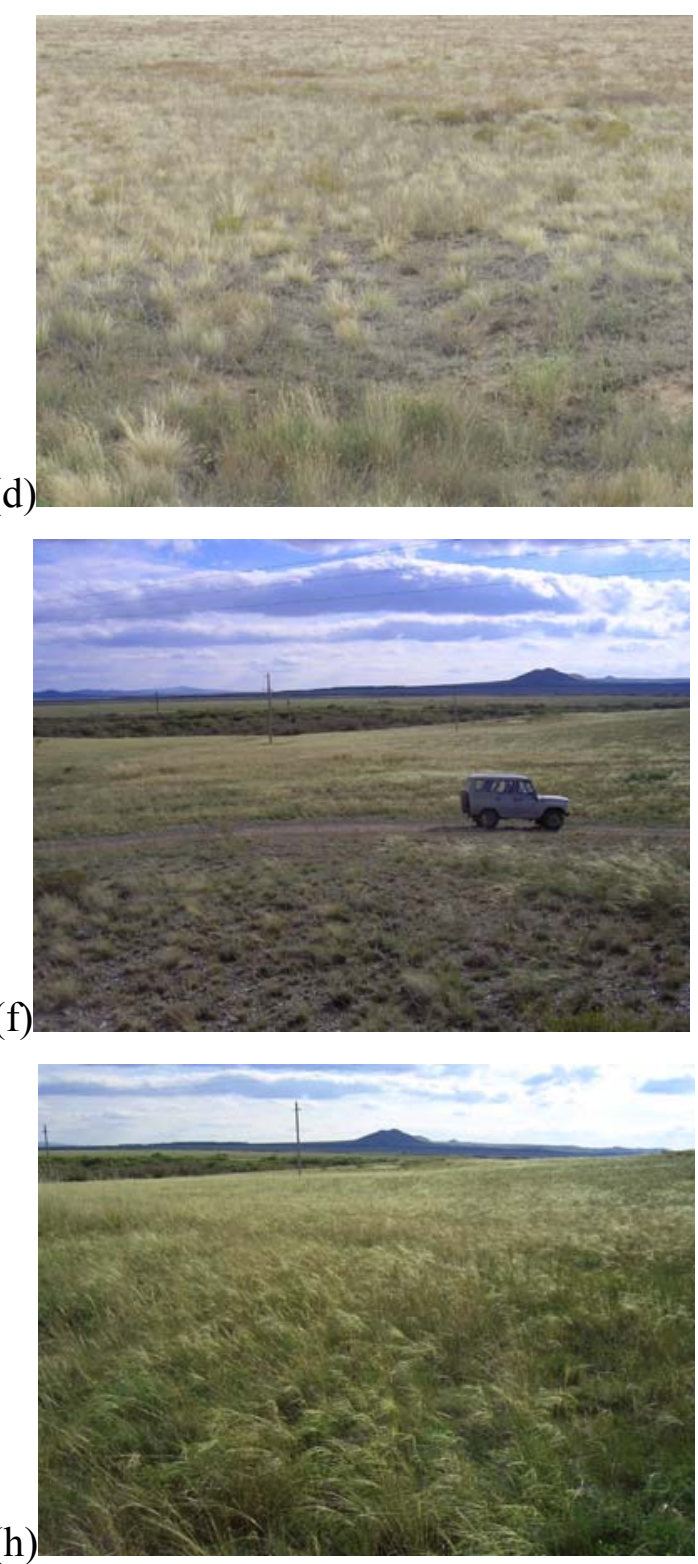

Figure 2.5. Typical landscape impressions from the study area: (a) gravely desert covered by dwarf shrubs of Artemisia turanica and Anabasis salsa; (b) sandy desert with Haloxylon aphulum in the first vegetation layer, Artemisia turanica in the second, and Carex physodes in the third layer; (c) solonchak in the desert zone deprived of vegetation cover; (d) semi-desert with vegetation community formed by Stipa lessingiana and Artemisia grasilences; (e) semi-desert with thickets of Caragana leucophloea; (f) dry steppe on gravely soil in low hills; (g) dry steppe in a placor dominated by grasses of Stipa-species and forbs Erysimum leucanthemum; (h) typical steppe dominated by Stipa-species. 
The dry steppes in the north of the study area are distinguished by domination of xerophilous species of bunch grasses and by a presence of forbs. Perennial mesophilous, xerophilous and sclerophilous bunch grasses predominate in steppe communities. The plant community here is formed by dry bunch grasses, herb-bunch grasses which provide most of the phytomass. It is usually composed of a combination of relatively tall bunch grasses mostly species of Stipa, of shorter bunch grasses of the genera Festuca, and dwarf bunch species of Carex or dwarf species of Stipa. Xerophytic or mesophytic diverse forbs and sometimes dry caespitose grasses are mixed with the bunch grasses in the community.

The zonal characteristics of steppe vegetation are exemplified by the plakor, - a flat, well-drained plain with loamy soils and a deeply location of the groundwater. The typical dry steppe here are characterized by the grasses Stipa lessingiana, Stipa zalesski, Festuca valesiaca, Festuca sulcata and forbs species such as Erysimum leucanthemum and Alyssum turkestanicum. Variations from the plakor petrophytic or halophytic characteristics markedly affect the nature of vegetation. They are found in stony and gravely soils, and in soils with high salt content. Areas of gravely soils in melkosopochniks (low hills) are characterized by communities with a dominance of dwarf half-shrubs, such as Artemisia hololeuca and Androsace kozopoljanskii with a dispersal bunch grasses. In some places within the steppe zone, shrubs of specie Caragana leucophloea occupy large areas. Thickets of Caragana leucophloea occur on the slopes of ravines and in gullies formed by water erosion.

The semi-desert type of vegetation is a gradual transition from desert to steppe type. This transition zone is about $80-150 \mathrm{~km}$ wide and is located lengthways at $48^{\circ}$ northern latitude. The semi-desert vegetation has a complex combination of real steppe grasses, shrubs and dwarf half-shrubs with a large abundance of epheroids. The typical community of the zonal semi-desert vegetation is dominated by bunch grasses (Stipa lessingiana - Festuca valesiaca) and a dwarf half-shrub (Artemisia gracilescens or Artemisia lessingiana) in kastanozem soils. Both the number of species of shrubs, dwarf half-shrubs and their proportional contribution to biomass increases from north to south within the semi-desert region, because of increased climate aridity. A large variance of soil characteristics (soil type, structure, groundwater table, depth of carbonate horizon) within the semi-desert zone predicts a spatial mosaic of vegetation. Thus, the places with solonetz or solonchak soils are dominated by halophilous dwarf half-shrubs such as Anabasis salsa, Kochia prostrata and Halocnemum strobilaceum. 


\subsection{Land use}

The land resources in the desert, semi-desert and steppe zones of Kazakhstan were always used by the Kazakh people as pasture. This type of land use also remained here during the time of Russia Empire until Kazakhstan in early 1920 was absorbed into the Soviet Union. Since this time, Kazakhstan became a major source of livestock products and an important producer of crops. During the soviet period, animal numbers in the steppe and desert regions grew strongly from the 1940s onwards until the 1991, the time-point of the Soviet Union break up. The virgin lands campaign in the 1950s lead to ploughing up the productive steppe zone, with rainfall above $300 \mathrm{~mm}$. Since then, the major pastoral zones have moved in the semi-desert and desert regions. On the peak of agricultural development in the mid of 1980s, Kazakhstan produced over 26 million ton crops and had over 46 million stock heads. After the disintegration of the Soviet Union, during the period 1991-2000 Kazakhstan experienced a strong economical crisis, which massively reduced all agricultural and industrial productions. Thus, the arable land decreased from 35.2 million ha to 21.3 million ha, the crop production fell to 9.5 million ton. The livestock reduced to 12.7 million heads (Figure 2.6).

The study area experienced all processes of land use dynamics described above for the whole Kazakhstan. Before the Soviet period, the wide grassland of the Karaganda oblast was used for extensive pasture by the nomadic people. There were only rare little settlements (especially in valleys) in the region with peasant agriculture. The increase in animal numbers was forced in the years of the disastrous collectivisation (1927-1933). The collectivisation made the nomads, which had been wandering with their herds in the study area, settle down. Many new rural settlements throughout the Karaganda oblast were created in form of kolkhozes (collective farms) and sovkhozes (state farms).

During the virgin lands campaign in the 1950s, the most steppe regions in the north of the study area were ploughed up, even though the rainfall amount here are less than $300 \mathrm{~mm}$. On these arable lands winter wheat and silage grasses were grown. Frequent drought hazards often killed the biggest part of the year yield. To preserve the crop yields, large areas of arable lands were watered by moving irrigate systems.

After 1991, the land use system of the study area experienced a change similar to collapse: a large part of the arable land was abandoned, crops production massively decreased, and livestock rash reduced (Figure 2.7, a). The collective and state farms, kolkhozes and sovkhozes, were abolished. The people, having been discharged by the kolkhozes and sovkhozes, left their settlements and moved into the nearest cities hopping to 
find a job. Numerous settlements were fully abandoned and nowadays stay uninhabited (Figure 2.7, b).

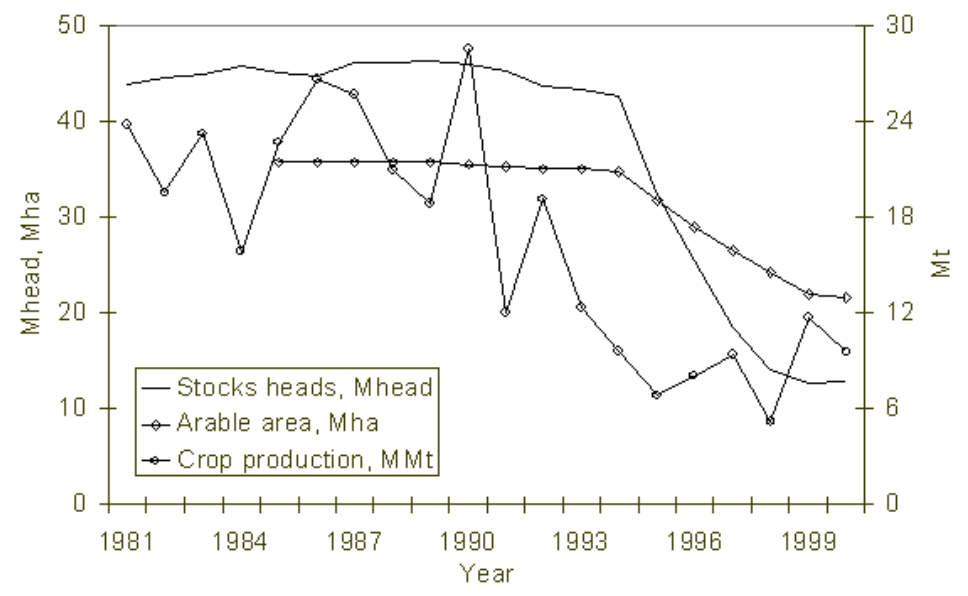

Figure 2.6. Change in stock heads, arable area and crop production in Kazakhstan during the period 1981-2000. After the constitutional change in 1991, a rapid drop of all agricultural indices has been observed.

(a)
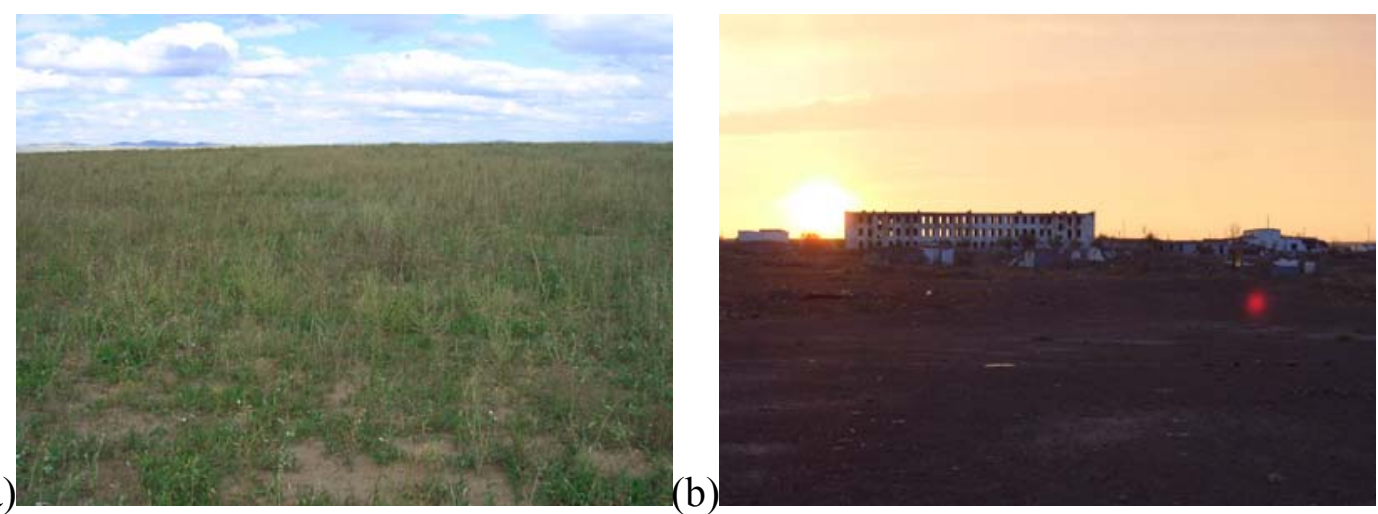

Figure 2.7. Traces of the economical crisis 1992-1998 and radical changes in land use in the study area. (a) Abandoned crop field. After the abandonment, the land has been rapidly conquered by vegetation communities dominated by Artemisia-species. (b) Abandoned settlement: a block of a large kolkhoz settlement in 2004. The large building in the mid part of the photo is the former school. This settlement had been fully abandoned during 1994-2000.

\subsection{Change in land use practices}

Until the last century, the nomads in Kazakhstan have used the broad areas of grass land especially for extensive pastoralism. Practices of pasture use were determined by nature conditions such as biomass amount to feed by animals and water availability in the steppe. The amount of fodder in the natural pasture is strongly predicted by climate, especially by 
precipitation. As annual precipitation in the Kazakh grassland shows a high variability, the livestock also varies following the precipitation variations. Frequent drought years rash reduced the amount of animals. A kazakh term which refers to massive animal death is " $d z h u t$ ", and this is the word that stands for the mean misfortune of the nomadic peoples. During a "dzhut" various nomadic tribes fought for better pasture land. Because of hunger, dhzut years also reduced the population.

In years with normal or abundant precipitation, the use of grassland pastures was strongly determined by rules which predict migratory routes of herds and the time of migration. Thus, stock wintered in sandy desert pastures (such as Moyinkum or Sary-EsikOtyrau in the south of Kazakhstan) due to their low snowfall and shrubby vegetation. These areas have dunes, the south slopes of which have a fast snow melt, and provide shelter from storms. The summer stock spent in the steppe and in the semi-desert of mid Kazakhstan (Karaganda oblast). Autumn and spring were spent in Djaylau,- mountain pastures,- along the rivers (Chu river just south of the study area) or in clay deserts (Betpak-dala). This way of pastoralism used the whole complex of the pasture resources and avoided a possible overgrazing and was the best method for a sustainable existence of the population in accordance with the nature conditions. These rules of land use practices were in force during the last thousand years (with the exception of $d z h u t$ years).

In Soviet times, the migration of herds was shorter and animals only went as far as mid of Karaganda oblast in the semi-desert zone. This was due to the establishment of new state farms in the region of the former summer pastures and ploughing up wide areas in the steppe zone. On these new farms shorter migration took place, animals moving within the farm boundaries or to designed seasonal pastures nearby. The grazing organization was harshly altered after the 1930s, as the collectivisation had been finished and numerous state farm with a stock of 2,000-60,000 sheep each were created. Many of these farms blocked migratory routes. Pastures which formerly would have been used shortly during migration periods started to be used for a long time. The frequency of pastures change was reduced.

The new form of organisation caused a massive increase of livestock and its production in Kazakhstan and in the study area. The goal of livestock production was to produce maximum meat (or wool) yields per hectare of pasture. Due to winter and summer (in drought years) provision the former major cause of animal death was essentially eliminated. Animal movements and herd sizes were determined by administrators of state farms. The individual herder had no free choice as to where and how grazing was organized. 
After abolishment of the centrally planned system in 1991, state farms collapsed or were sold to private farmers. The process of privatisation has been accompanied by a considerable reduce of livestock. The livestock amount in mid of 1990s became equal to that in 1900-1910s, the period preceding the collectivisation. In accordance with that change, the grazing practices again sharply altered. Large state farms with a livestock of many thousand sheep each were replaced by a numerous private stock owners, the largest amount of them have no more than 500 sheep. Most of the new private stock owners neglect the old rules of pastures change and do not migratory routes that have been existed before the Soviet period. The shepherds today tend to graze their animals all year round in the same place nearby the permanent stands for herds. These places are located in the winter or autumn pastures. Only few shepherds who have many animals do still conduct limited migrations.

Socio-economic factors were the major causes for the rapid change of grazing practices after the end of the centrally planned system. The former customs of nomadic pastoralism were destroyed during the Soviet period when the Kazakh nomads were forced to settle down and to inhabit new settlements organized in form of state farms. The former nomads became "settled nomads". This means that the most of Kazakh peoples lived in permanent rural settlements and did not have a possibility to rove through the land with their herds. Only few Kazakh people worked as shepherds at state farms and lead a nomad way of life, but their migratory routes and time were determined by administrators of kolkhozes and sovkhozes. All other former Kazakh nomads worked as drivers, combine operator, milkmaid etc. Many of them have moved to cities and became engineers or workers in industry. After 1991, the Kazakh people could theoretically have been returned to the former nomadic way of life, but this was not possible. The customs and practices of nomadic life were lost and only insignificant part of the Kazakh people wish they were nomads again.

Therefore, there is a tendency for shepherds to graze their animals all year round in the same place, namely around the permanent settlements where the shepherds with their families live. This tendency was promoted by the fact that the pastures now are either ungrazed, or grazed by a tiny fraction of the animals which would previously have used them (Robinson et al., 2002). Sheep numbers in Karaganda oblast dropped by more than two-thirds between 1991 and 2000, the herd sizes are also greatly reduced. The area of grass pastures increased, because numerous crop fields are abandoned since 1991 and may be now used for grazing. Today, the stock number in the grassland is very low, considerably under the carrying capacity of the grass ecosystem. This furthers a recovery huge parts of grassland pastures had been degrading in 1950-1990. 


\subsection{Problem of land degradation in Central Asia}

The soviet researchers of land degradation and desertification in the Central Asia and Kazakhstan, which published their studies in the 1970-1980s, meant that Kazakhstan rangelands were in a situation of permanent crisis. This crisis was caused by a too high amount of livestock and an incorrect grazing system that was common in the sovkhozes and kolkhozes. During the Soviet period, there was almost nothing to be found in the Western literature on Kazakhstan rangeland and its degradation status. A few research works on Kazakhstan dry land pastures and crop lands, published in English, appeared after the independence of Kazakhstan. They deals with re-evaluation of pastures degradation in the central Kazakhstan (Robinson et al, 2002), degradation of dry lands in Kazakhstan and Central Asia (Kharin et al, 2002), desert problems and desertification in Central Asia (Babaev \& Kharin, 1999), influence of institutional change on land surface phenology in Kazakhstan (de Beurs \& Henebry, 2004), and a feedback between inter-annual vegetation conditions and precipitation in the Aral See region (Nezlin et al, 2005). The first three studies published by Robinson et al (2002), Kharin et al. (1999) and Babaev (1999) also assessed the degradation status of dry lands in Kazakhstan. Both authors, who are living and working in Central Asia (Kharin and Babaev) suggested in their research works that the whole of Southern and a most part of Central Kazakhstan are currently degraded. They determined many types of degradation. In pastoral areas vegetation degradation and wind erosion are the most important; while in croplands water erosion and deflation of soils by wind are called to be the most prevalent.

On the contrary, investigations carried out by scientists from the western countries found no catastrophic extend of desertification processes throughout the region, and even reported about very good conditions of pastoral lands. Robinson et al. (2002) described the pastures in Kazakhstan as "either ungrazed .... than overgrazed". DeBeurs \& Henebry (2004) found improvement of vegetation cover during the 1990s also in irrigated lands. Their results agree with the results from some studies of the Kazakh scientists published in Russian literature. These research works suggested that the rangelands in the Central Kazakhstan were largely in good condition, apart from areas, localized around villages. 


\section{Chapter 3}

\section{Data used in the study and their preprocessing}

\subsection{Climate data and their preparation}

\subsubsection{Climate records}

Climate data were retrieved from the annual statistics by the National Hydrometeorological Centre of Kazakhstan (NHMCK). These data contain 10-day records of 9 climate stations placed in the study area for growing seasons (April-October) during the period 1985-2004. We used two variables for our analysis: mean 10-day temperature $\left({ }^{\circ} \mathrm{C}\right)$ and 10-day rainfall total amount $(\mathrm{mm})$. The climate stations are regularly distributed over the study area and represent all land cover types found there. The mean characteristics of the climate stations are shown in Table 3.1. There were a few gaps in the decade data during the period 1993-1998 for some stations. These gaps may be explained by a bad function of climate stations what characterised the period of the catastrophic economical crises of 19931998. The gaps were removed by averaging data from the nearest neighbour stations or decades from neighbour years.

Table 3.2. Geographical characteristics and principal vegetation classes for the meteorological stations used in the study.

\begin{tabular}{|l|l|l|l|}
\hline Climate station & Altitude, m & $\begin{array}{l}\text { Geographic } \\
\text { coordinates }\end{array}$ & Principal vegetation classes \\
\hline Saryshagan & 360 & $46.10^{\circ} \mathrm{N}, 73.60^{\circ} \mathrm{E}$ & Saltwort-Artemisia-shrubland \\
\hline Kzyltau & 587 & $47.90^{\circ} \mathrm{N}, 71.47^{\circ} \mathrm{E}$ & Artemisia-Stippa-shrubland \\
\hline Aktogay & 692 & $48.30^{\circ} \mathrm{N}, 72.90^{\circ} \mathrm{E}$ & Artemisia-Fescue-shrubland \\
\hline Agadyr & 732 & $48.20^{\circ} \mathrm{N}, 75.10^{\circ} \mathrm{E}$ & Fescue-Artemisia-grassland \\
\hline Jana-Arka & 485 & $48.70^{\circ} \mathrm{N}, 71.70^{\circ} \mathrm{E}$ & Feather-Fescue-grassland \\
\hline Aksu-Ajuly & 714 & $48.80^{\circ} \mathrm{N}, 73.70^{\circ} \mathrm{E}$ & Stipa-Fescue-grassland \\
\hline Jaryk & 777 & $48.90^{\circ} \mathrm{N}, 72.90^{\circ} \mathrm{E}$ & Fescue-Feather-grassland \\
\hline Bes-Oba & 736 & $49.40^{\circ} \mathrm{N}, 74.50^{\circ} \mathrm{E}$ & Mixed grassland \\
\hline Karaganda & 520 & $49.87^{\circ} \mathrm{N}, 73.10^{\circ} \mathrm{E}$ & Mixed grassland \\
\hline
\end{tabular}

\subsubsection{Preparation of gridded climate maps}

Preparation of gridded climate maps was made by interpolation of these records based on the longitude, latitude and elevation of the weather stations. Use of a secondary variable, elevation, for modelling gridded maps was important because there is a strong influence of 
relief on the spatial patterns of climate parameters in the study area. The magnitude of elevation ranges from $340 \mathrm{~m}$ to $1100 \mathrm{~m}$. The general increase in precipitation with elevation is well known, it is due to fact that hills are barriers to moist airstreams, forcing the airstreams to rise and they act as high-level heat sources on sunny day. Several studies have compared different algorithms for deriving predictions of precipitation from point data in conjunction with secondary data (Hevesi et al., 1992a, 1992b; Gomez-Hernandez et al., 2001; Lloyd, 2002). These algorithms included such techniques as inverse distance weighting (IDW), simple kriging with locally varying means (SKlm), ordinary co-located cokriging (OCK) and kriging with an external drift (KED). All these techniques exploit relationship between primary and secondary variables by regionalizing climate data from point data and enable to increase the prediction accuracy essentially.

In this study, all raster maps of precipitation and temperature for the study region were constructed using the interpolation method known as kriging with an external drift (KED). A brief description of the KED technique will be given in Chapter 4 .

\subsection{Satellite data}

\subsubsection{Data of coarse spatial resolution}

The most recent studies of changes in vegetation activity at global or regional scales have been based on the use of data time-series from Advanced Very High Resolution Radiometer (AVHRR) launched by the National Oceanic and Atmospheric Administration (NOAA) in 1981. The sensor has given a continuous spatial cover of the entire earth area on a regular frequency. The coarse spatial resolution $(1-16 \mathrm{~km})$ and fine temporal frequency have made products from NOAA AVHRR indispensable for use in environmental studies on regional to global scale. AVHRR derived data have been successfully used for monitoring vegetation activity and environmental changes [1, 2, 3], detection of droughts [4], desertification and land degradation studies [5], estimation of El-Nino Southern Oscillation (ENSO) impact on vegetation cover [6]. In this study, we used different NOAA AVHRR datasets with spatial resolution of $1 \mathrm{~km}$ and $8 \mathrm{~km}$.

\section{8-km NOAA AVHRR NDVI}

A general surrogate of all vegetation characteristics (green biomass, ground covering percent, photosynthetic activity, leaves area, etc.) is Normalized Differenced Vegetation Index (NDVI). The vegetation absorbs a great part of incoming radiation in the visible portion 
of the spectrum (VIS=220-680 $\mathrm{nm}$ ) and reaches maximum reflectance in the near-infrared channel (NIR=730-1100 nm) (Tucker and Sellers, 1986). The NDVI, defined as ratio (NIRVIS)/(NIR+VIS), represents the absorption of photosynthetic active radiation and hence is a measurement of the photosynthetic capacity of the canopy (Tucker, 1985; Tucker \& Sellers, 1986). Negative NDVI values indicate non-vegetated areas such as snow, ice, and water. Positive NDVI values indicate green, vegetated surfaces, and higher values indicate increase in green vegetation.

To monitor temporal variations and long-time trends of vegetation activities we used the Global Inventory Monitoring and Modelling System (GIMMS) NDVI dataset derived from the NOAA AVHRR sensor. The data, at 8- $\mathrm{km}$ spatial resolution, are originally processed as 15-day composites using the maximum value procedure to minimize effects of cloud contamination (Holben, 1986). For this research, we created monthly composites from the 15-day composites. These monthly NDVI data for consecutively three and twelve months were averaged to generate seasonal and annual NDVIs for each year. The data cover the period from 1982 to 2003. Even if the GIMMS dataset is pre-processed for radiometric and atmospheric corrections, calibration for sensor differences and orbital drift, slight variability in the NDVI records has remained in the data time-series. In order to improve the dataset, we have made an additional calibration of the GIMMS NDVI data against three time invariant desert targets located in the Big Arabian Desert, Nubia Desert and Taklamakan Desert using a method described by Los (1993).

Table 3.2. Satellite data used in the study and their characteristics.

\begin{tabular}{|l|l|l|l|l|}
\hline $\begin{array}{l}\text { Satellite } \\
\text { system }\end{array}$ & Sensor & $\begin{array}{l}\text { Spatial } \\
\text { resolution }\end{array}$ & $\begin{array}{l}\text { Temporal } \\
\text { resolution }\end{array}$ & $\begin{array}{l}\text { Time-period/ } \\
\text { Acquisition date }\end{array}$ \\
\hline NOAA & AVHRR & $\begin{array}{l}8 \mathrm{~km} \\
1 \mathrm{~km}\end{array}$ & $\begin{array}{l}10 \text {-day } \\
\text { 10-day }\end{array}$ & $\begin{array}{l}1982-2003 \\
1992-93,1995\end{array}$ \\
\hline SPOT & VEGETATION & $1 \mathrm{~km}$ & 10 -day & $1999-2004$ \\
\hline Landsat & MSS & $57 \mathrm{~m}$ & & 1978 \\
& TM & $28.5 \mathrm{~m}$ & & 1992 \\
& ETM+ & $28.5 \mathrm{~m}$ & & 2001 \\
\hline
\end{tabular}

\section{1-km NOAA AVHRR NDVI and SPOT VEGETATION NDVI}

We used two NDVI data sets of 1-km spatial resolution in this study. First, 10-day 1$\mathrm{km}$ NDVI data set from the global AVHRR archive for every growing season (April-October) during the years 1992, 1993, and 1995 were assembled. Second, we acquired 10-day SPOT Vegetation index data at 1-km resolution for growing season during 1999-2004. Both data 
sets are generated using a maximum value composite (MVC) procedure, which selects the maximum NDVI value within a 10-day period for every pixel (Holben, 1986). This procedure is used to reduce noise signal in NDVI data due to clouds or other atmospheric factors. In addition to that, we removed noisy pixels which remained in the NDVI maps characterized by exceptionally high or low NDVI values relatively to their pixel neighbourhood. The method of the identification of noisy pixels used a window with a size of $3 * 3$ pixels which was moving over NDVI scenes and calculated a mean value of the surrounding pixels for every point. After subtracting the original pixel value from the mean value of surrounding pixels, differences of NDVI more than 0.12 were considered as noise. Then, pixels identified as noisy were replaced by the surrounding mean.

From the AVHRR NDVI and SPOT Vegetation NDVI data sets, we computed a 9year mean NDVI for every 10-day period beginning with April through October. At last, a NDVI data set accumulated over growing season, $N D V I_{\text {accum }}$, was produced by summing the 10-day mean values derived. Several studies used the $N D V I_{\text {accum }}$ as a measure of the magnitude of greenness available through the growing season time which reflects the capacity of the land to support photosynthesis and net primary production for a growing season. A close relationship between $N D V I_{\text {accum }}$ and precipitation, especially in arid and semi-arid regions has been well established in the literature (Tucker \& Sellers, 1986; Reed et al., 1994; Yang et al., 1998; Li et al., 2004; Budde et al., 2004). Therefore, we decided to use the $N D V I_{\text {accum }}$ in modelling spatial relationship between vegetation activity and precipitation for our study.

\subsubsection{Data of fine spatial resolution}

The Landsat sensor was specifically designed for studies such as land cover mapping. Essentially, detection of changes in land cover involves the ability to quantify temporal differences using multi-temporal data sets. One of the major applications of remotely sensed data obtained from Earth Orbiting Satellites is change detection because of repetitive coverage, fine spatial resolution, and consistent image quality.

The Landsat satellite image data employed in this study were acquired in 1979, 1991, and 2000. In spite of large time gap between the image acquisitions, application of the Landsat dataset to change detection in the Ili delta is believed to be justifiable for two main reasons. Firstly, the years of image acquisition corresponded well to the main phases of 
environmental change in the study region: 1980-1991 is the phase of high human impact and degradation due to overgrazing and crop production under bad climate conditions; 1992-95 is the initial stage of situation improvement caused by a rapid diminishing the human impact; since 1995 is the stage of a strict land use change and rehabilitation of the most grass landscapes. Secondly, the intra-annual discrepancies between the images reflecting different phenological phases of vegetation due to months of their acquisition (July-August) were expected to be fewer than the long-time differences caused by the general change in the environment of the study region.

The Landsat imagery was used to check out changes in surface features over the last three decades. Concerning the information extraction from the Landsat data, we were mainly interested in identification of changes in spatial patterns of land use and land cover in the study area.

Pre-processing of the Landsat dataset included common procedures of satellite data treatment such as radiometric and geometric correction, rectification and co-registration of all images. The Landsat TM and Landsat ETM images from 1991 and 2000 were resized to the spatial resolution of $57 \mathrm{~m}$ in order to mach the Landsat MSS images. In addition, a set of topographic maps dated 1982 and covering the whole study area was used to compare the analysed satellite images.

\subsection{Digital terrain model}

A tile plot for the study area of the GTOPO30 digital terrain model with a pixel size of 30 arc second (approximately $1000 \mathrm{~m}$ ) was used for our work. GTOPO30 is freely available at http://edcwww.cr.usgs.gov/landdaac/gtopo30/gtopo30.html. The terrain model was indispensable for pre-processing of satellite data and the supplementary statistical analysis in the main part of the study. First, high relief amplitude $(340-1180 \mathrm{~m})$ in the study area can induce illumination effects causing variations in reflectance of similar ground features. Therefore, a topographic normalization of NDVI scenes was carried out to remove these effects. Second, by analysing spatial relationships between vegetation patterns, climatic factors and relief, the terrain model played an important role appearing in regression equations as an independent constant. 


\subsection{Maps}

Two types of topographic and thematic maps were used in our research work. We used analogue maps of topography (scale 1:100,000) from 1982, an analogue vegetation map (scale 1:500,000) from 1995 covered the whole study region as well as a digital map of landcover derived from Moderate Resolution Imaging Spectroradiometer (MODIS) by Friedl et al. (2001) that have been accessible in the United States Geological Survey (USGS) archive centre. Originally, this map has $1 \mathrm{~km}$ spatial resolution. The topographic maps were useful for geometrical correction and rectification of the satellite data, especially that of fine resolution. The vegetation maps were used for identification of areas covered by various vegetation types and validation of the results of modelling land cover change.

\subsection{Agrarian and population statistics}

Statistics of agrarian production and population were obtained from the annual state statistical reports of the USSR and Kazakhstan. These statistics characterize not only the study region but also the whole area of Kazakhstan. As the agrarian statistics clearly reflected the significant change in production structure and production rate which happened during the period 1982-2004, we considered to use these statistics to detect a general trend in human impact that is associated with the years before and after the constitutional change in 1991 . Population amounts may reinforce the agrarian statistics. We used the following statistics:

1. Livestock: cattle, sheep.

2. Crop production: wheat, maize, potatoes.

3. Area of agricultural used land: irrigated land, arable land, pasture.

4. Population: rural, urban, structure, distribution over the land.

\subsection{Field data}

Together with a group of scientists from the Remote Sensing Institute of Kazakh Science Academy the author undertook two field trips (each one month) to the study region during the summers of 2004 and 2005. During these field trips across the entire region, a large amount of different field data has been collected in order to be used for further analysis, validation and modelling of satellite data. The author has also used some data 
derived by the research group during other field travels. The main data set contains surveys of vegetation distribution (dominant species) and soil types. Contemporary land use (land use type, crops composition/change etc.) has been checked directly in the field. Data for historical dynamics of land use have been derived by interviews with farmers or from statistic reports of local authorities. In order to estimate density of vegetation cover, nadir photos of vegetation cover have been made at every test site. Common indicators for degradation processes have been noted and evaluated where any degradation of vegetation cover was actual. 


\section{Chapter 4}

\section{Methodology of data analysis}

\subsection{Analysis of vegetation distribution, variability and change in space and time}

\subsubsection{Simple methods of descriptive statistic}

An analysis of spatial and temporal variability in vegetation cover was based on the use of elementary methods and variables of descriptive statistic. This methods and variables have been widely used and are described in every statistic book. So, we do not need to make any explanations to their use. We still have to make a listing of them:

- $\quad$ NDVI average over the study period as well as average values for every season (with the exception of winter),

- $\quad$ standard deviation of NDVI, $\left(N D V I_{\text {stdev }}\right)$,

- coefficient of variation in NDVI over the space or the study period, $\left(N D V I_{c v}\right)$.

The variables $N D V I_{\text {stdev }}$ and $N D V I_{c v}$ were derived for spatial averages of each vegetation type. In order to understand spatial patterns of variations, we also made these calculations for each pixel.

\subsubsection{Calculation of time-trends}

Linear time-trends were calculated by regressing a variable (for example, NDVI or precipitation) as a function of time over the study period, using least-squares estimation. The time-trend calculations included determination of both the regression slope coefficient and increase/decrease of the variable during the study period. Values under zero were considered to display a decrease in the variable, while values over zero show an increase. The time-trends were determined for area-averaged classes of every variable and, in order to exhibit spatial patterns in trends, for every grid cell.

\subsection{Methods of geostatistical analysis}

\subsubsection{Autocorrelation}

One of the central tools in geostatistical analysis is autocorrelation. Autocorrelation, as the name implies, involves correlating a sequence of data with itself. The process only 
becomes interesting when the correlation is calculated between duplicates of the sample data which are displaced relative to each other. In other words, the two sets of numbers to be correlated are achieved by pairing each value $y_{i}$ with $y_{i+\tau}$, where $i$ gives the time or position in the space and $\tau$ is an integer value of displacement known as the lag. The correlation coefficient between the samples and a displaced copy of itself is known as the autocorrelation coefficient, $r_{\tau}$. It can be calculated at successive lags and the resulting series of $r_{\tau}$ values revealing useful information on the structure of the data. These are plotted on an $r_{\tau}$ versus $\tau$ graph called an autocorrelogram (Swan \& Sandilands, 1995, pp. 246-248). Where $\tau$ is zero, pairs of $y$ values are identical and the coefficient of autocorrelation clearly equals 1 . As $\tau$ increases, the similarity between the pairs of $y$ values is likely to decrease and the $r_{\tau}$ decreases. At a certain value of $\tau$, we reach a point at which the $r_{\tau}$ ceases to decrease: this is the range value. Points whose distance exceeds the range value are independent.

\subsubsection{Spatial autocorrelation}

Spatial autocorrelation measures the similarity between samples for a given variable as a function of spatial distance. The spatial autocorrelogram describes the degree and form of spatial dependence, which is similarity between values separated by a given distance. Positive autocorrelation means that geographically nearby values of a variable tend to be similar on a map: high values tend to be located near high values, and low values near low values. In contrast, with negative spatial autocorrelation geographically nearby values of a variable tend to be dissimilar on a map: high values tend to be located near low values, and low values near high values. Totally random data will show an arbitrary small $r_{\tau}$ at lag $\tau$, and this will fluctuate randomly at higher lag. Most ecological data tend to be moderately positive spatially autocorrelated because of the way phenomena are geographically organized (Griffith, 2003, pp. 4-5).

The coefficient of autocorrelation can be calculated on different ways. The Moran's I coefficient is the most commonly used coefficient in univariate autocorrelation analysis and is given as:

$$
I=\left(\frac{n}{s}\right)\left[\frac{\sum_{i} \sum_{j}\left(y_{i}-\bar{y}\right)\left(y_{j}-\bar{y}\right) w_{i j}}{\sum_{i}\left(y_{i}-\bar{y}\right)}\right]
$$

where $n$ is the number of samples, $y_{i}$ and $y_{j}$ are the data values in quadrats $i$ and $j$,

$\bar{y}$ is the average of $y$ and $w_{i j}$ is an element of the spatial weights matrix $\mathrm{W}$. under the null 
hypothesis of no spatial autocorrelation, $I$ has an expected value near zero, with positive and negative values indicating positive and negative autocorrelation, respectively.

\subsubsection{Kriging with an external drift}

Kriging with an external drift (KED) is a geostatistical method used for regionalization of point data in space which takes into account one or more external influences on data distribution. Generally, KED is used for deriving prediction of point data in conjunction with secondary data. It is essential that secondary data are available at the locations of the primary data as well as at all locations for which predictions are required. The second condition of KED using is that the secondary data have to be related to the primary variable. A benefit of using KED for regionalization of climate data is the possibility of incorporation of relief variable into a kriging system as external drift function. In this chapter, only a brief description of the KED technique will be given. For further details see Wackernagel (1998).

The KED predictions are a function of (i) the form of the variogram model, (ii) the neighbouring primary data (climate data), and (iii) the modelled relationship between the primary variable and the secondary variable (elevation) locally. The local mean of the primary variable is derived using the secondary information and ordinary kriging (OK). The KED prediction is given by the following equation:

$$
\hat{z}_{K E D}\left(x_{0}\right)=\sum_{a=1}^{n} \lambda_{a}^{K E D} z\left(x_{a}\right)
$$

The weights are determined through the KED system of linear equations:

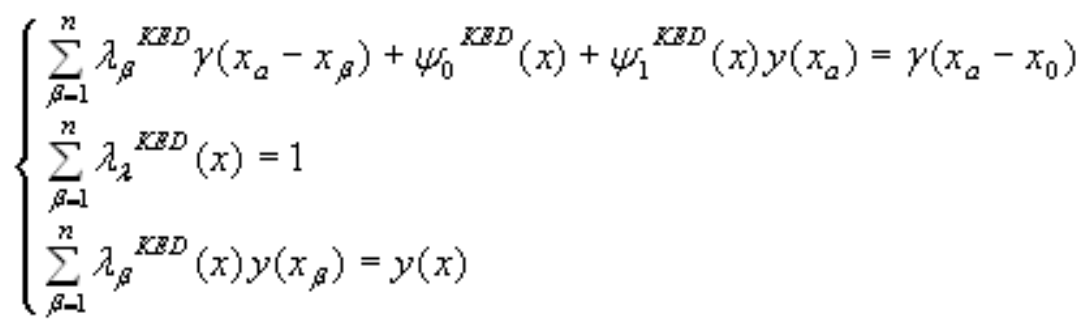

where $y(x)$ are the secondary (elevation) data.

In the practice, kriging with an external drift was preformed as follows: (i) deriving the underlying (trend-free) predictions for primary data by ordinary kriging; (ii) estimating external drift coefficients at all locations as well as at the nodes of the estimation grid 
through modelling the relationship between primary and secondary variable; (iii) pertaining the obtained coefficients for external drift to the trend-free predictions.

\section{factors \\ 4.3. Analysis of the relationship between vegetation change and its explanatory}

\subsubsection{Correlation coefficient}

In a bivariative distribution where two variables are involved, we were interested to find out if any relationship exists between the variables under study. The existence of any relationship can be proved by calculation of correlation for the couple of variables. If the change of these variables is in the same direction, the correlation is said to be positive. If the variables deviate in the opposite direction, the correlation is negative. A measure of correlation strength reflects correlation the coefficient which may be given as:

$$
r(x, y)=\frac{\operatorname{Cov}(x, y)}{\sigma_{x} \sigma_{y}}=\frac{\frac{1}{n} \sum\left(x_{i}-\bar{x}\right)\left(y_{i}-\bar{y}\right)}{\sqrt{\frac{1}{n}} \sum\left(x_{i}-\bar{x}\right)^{2} \frac{1}{n}\left(y_{i}-\bar{y}\right)^{2}}
$$

\subsubsection{Multiple correlation coefficient}

Multiple correlation is believed to represent the combined effect of several explanatory variables on a response variable. In this study, the multiple correlation enables to estimate the collective influence of climatic factors on NDVI. The used equation for calculation of multiple correlation coefficient from the derived simple correlation coefficients is given as:

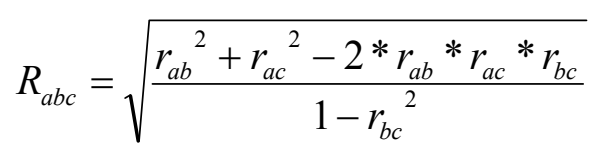

Where $R_{a b c}$ is multiple correlation coefficient; $r_{a b}, r_{a c}$ and $r_{b c}$ are simple correlation coefficients between variables NDVI, rainfall and temperature. 


\subsubsection{Partial correlation coefficient}

Sometimes it happens that explanatory variables are strongly correlated among themselves. That means that the effect of a single variable is supported by the effect of other single variable and the calculated simple correlation coefficient does not show a real picture of relationship. This phenomenon is called multicollinearity. In order to overcome multicollinearity and highlight real relationship, we calculated the coefficient of partial correlation. This coefficient enables to exclude a role of other variables by estimation of strength in the relationship between two variables. The partial correlation coefficient was calculated by using the equation:

$$
r_{a b . c}=\frac{r_{a b}-r_{a c} * r_{b c}}{\sqrt{\left(1-r_{a c}{ }^{2}\right) *\left(1-r_{b c}{ }^{2}\right)}}
$$

where $r$ is correlation coefficient; $a, b$ and $c$ represent NDVI, rainfall and temperature.

\subsection{Modelling relationship between vegetation patterns and explanatory factors}

\subsubsection{Simple linear regression model}

The simple linear model, usually fitted by ordinary least squares methods (OLS), is:

$$
y=\alpha+\beta^{*} x+\varepsilon
$$

where $a$ is the intercept, $\beta$ represents the slope coefficient for independent variable $x$, and $\varepsilon$ is a random error.

In this model, the two variables to be related are $y$, the dependent variable (typically $N D V I$ ), and $x$, the independent variable (one of the environmental predictors, such as rainfall, temperature, evapo-transpiration etc.). The regression model parameters $a$ and $\beta$ derived by the above approach are assumed to be stationary globally over the analysis space. In other words, applying the conventional global regression model to studying relationships between vegetation distribution and its conditions and environmental parameters, one bases on the calculation on the assumption, that at each point of the study area this model is absolutely representative and the quantified relationship is constant. 


\subsubsection{Multiple linear regression model}

A multiple linear regression analysis was performed using the response variable, NDVI, and both of the climatic variables. For every year we fitted a multiple linear regression model described the NDVI value for each pixel in its dependence from the climatic predictors. The full linear model equation is expressed as:

$$
y=\alpha+\beta_{1}^{*} x+\beta_{2} * x+\varepsilon
$$

where $\alpha$ is the intercept, $\beta_{1}$ and $\beta_{2}$ are regression coefficients of the climatic predictors and $\varepsilon$ is random error.

The coefficients were estimated with the ordinary least squares procedure. The model parameters were tested sequentially: first, the term for precipitation $\beta_{1}$, next, the term $\beta_{2}$ for temperature and then the intercept $\alpha$. Where the two terms were evaluated as not significantly different, then these parameters were averaged and the model was refitted, using the averaged parameters.

\subsubsection{Problem of non-stationarity by analysing spatial relationship}

Statistical regressions and correlations have been the most common techniques used to quantify the relationship between a response variable (mostly NDVI) and explanatory variables in studies on monitoring vegetation change. The authors tended to use conventional ordinary least squared $(O L S)$ simple and multiple regression analysis as the basic methods for definition of relationships between NDVI and biophysical variables. However, these conventional statistical methods, especially by quantifying spatial relationships at regional or global scales, are usually not adequate for spatially different data. The $O L S$ regression implies a spatial stationarity in the relationship between the variables under study. This approach assumes the constancy of this relationship at every point of the analysis space, uniformity over space. Unfortunately, in many cases this relationship is not stable in space and appears to vary over space (Foody, 2003; Ji \& Peters, 2004; Brundson et al., 2001). The differences between regression models established at different locations can be large with both the magnitude and the sign of the model parameters varying.

In such circumstances, the parameters of the global regression model derived by applying conventional $O L S$ regression, may not represent local conditions within the study 
area. One can suppose, that especially in the areas with high variance of relief conditions, the local model parameters should vary more significantly.

Local regression techniques, such as moving window regression (MWR) and geographically weighted regression (GWR) overcome this problem and calculate the model parameters varying in space. These techniques are believed to provide a more appropriate and accurate basis for descriptive and predictive proposals and are quite common in geography (Fotheringham et al., 1996; Pavlov, 2000; Paez et al., 2002a, b; Brunsdon et al., 1996; Brunsdon et al., 2001). On the field of remote sensing there are only rare studies applying the local regression techniques for analysis of spatial relationships between NDVI and biophysical variables (Foody, 2003; Ji \& Peters, 2004).

\subsubsection{Moving window regression}

Moving window regression $(M W R)$ overcomes the problem of non-stationarity through local disaggregation of global statistics and calculates the relationship between NDVI and its predicting variables for every point. In this technique, a regression and its parameters in each point (pixel) of the study region is quantified separately and independently from other points. This has been achieved by moving a window of definite size over the study region. The size of the moving window is less than the region size and can be varied from one point to another. The regression model is calibrated on all data that lie within the region described around a regression point and the process is repeated for all regression points. The resulting local parameter estimates can then be mapped at the locations of the regression points to view possible non-stationarity in the relationship being examined. The regression model is then calculated on all data that lie within the moving window. With the moving window regression the relationship between the variables can be expressed as

$$
y=\alpha(\Theta)+\beta(\Theta) * x+\varepsilon
$$

where $\Theta$ indicates that the parameters are to be estimated at a location for which the spatial coordinates are provided by the vector $\Theta$.

The resulting local parameter estimates can then be mapped at the locations of the regression points (usually in the middle of moving window) to view possible non-stationarity in the relationship being examined. 


\subsubsection{Geographically weighted regression}

Geographically weighted regression $(G W R)$ being a local technique works in the same way as the moving window regression except that each data point is weighted by its distance from the regression point. This means, that a data point closer to the regression point is weighted more heavily in the local regression than are data points further away. For a given regression point, the weight of a data point is at maximum when it has the same location as the regression point, and is more lightly when it has a location at a range of the moving window. In GWR an observation is weighted in accordance with its proximity to location $i$ so that the weighting of an observation is no longer constant but varies with $i$. The matrix form of parameter estimation for $i$ is expressed as:

$$
\hat{\alpha}(\theta), \hat{\beta}(\theta)=\left(X^{T} W(\theta) X\right)^{-1} X^{T} W(\theta) y
$$

where $\hat{\alpha}$ and $\hat{\beta}$ are intercept and slope parameter in location $i$; and $W(\theta)$ is weighting matrix whose diagonal elements represent the geographical weighting associated with each site at which measurements were made for location of $i$.

Spatial weighting function can be calculated by several various methods. For fixed kernel size, the weight of each point can be calculated by applying Gaussian function

$$
w_{i j}=\exp \left[-1 / 2\left(d_{i j} / b\right)\right]^{2}
$$

where $d_{i j}$ is the distance between regression point $i$ and data point $j$, and $b$ is referred to as a bandwidth.

An alternative way is the bi-square function

$$
w_{i j}=\left[1-\left(d_{i j} / b\right)^{2}\right]^{2}
$$

when $d_{i j}<\mathrm{b}$ and $w_{i j}=0$ otherwise.

The weighting of an observation in the analysis is not constant, but a function of location. Data from observations close to point $i$ are weighted more than data from observations father away. 
Rainfall

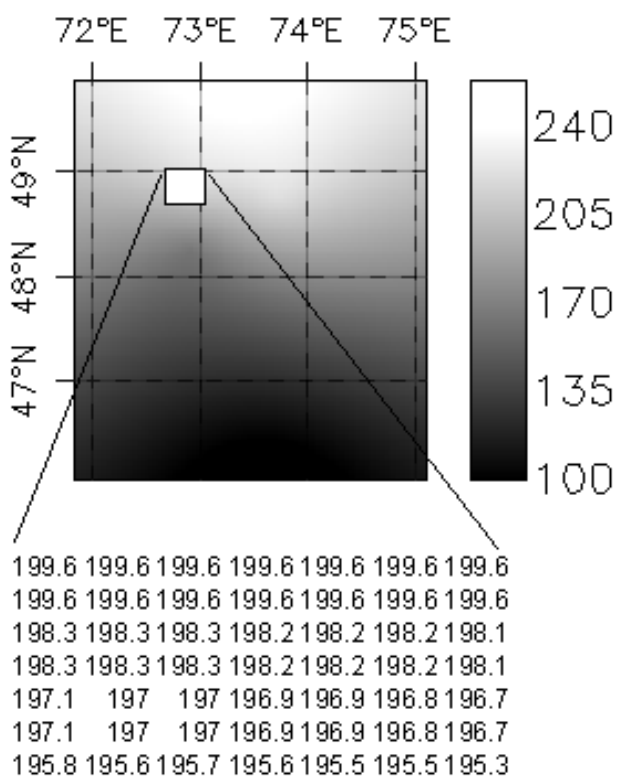

NDVI

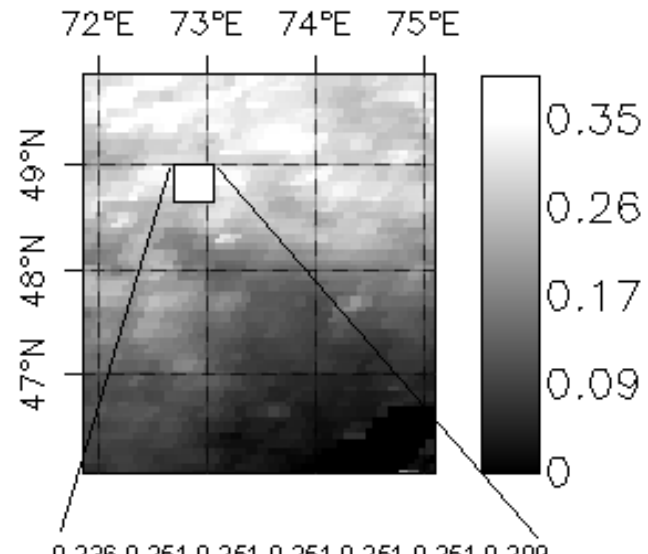

$\begin{array}{llllllll}0.236 & 0.251 & 0.251 & 0.251 & 0.251 & 0.251 & 0.209\end{array}$ $\begin{array}{llllllllll}0.236 & 0.251 & 0.251 & 0.251 & 0.251 & 0.251 & 0.209\end{array}$ $\begin{array}{lllllllll}0.236 & 0.251 & 0.251 & 0.251 & 0.251 & 0.251 & 0.209\end{array}$ $\begin{array}{lllllllll}0.236 & 0.251 & 0.251 & 0.251 & 0.251 & 0.251 & 0.209\end{array}$ 0.2350 .2350 .2350 .1920 .1920 .1920 .192 0.2350 .2350 .2350 .1920 .1920 .1920 .192 0.2350 .2350 .2350 .1920 .1920 .1920 .192

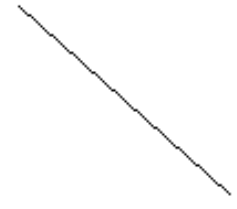

\section{Multiplication}

Weight matrix

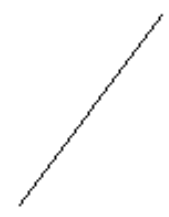

\begin{tabular}{l|l|l|l|l|l|l}
0.25 & 0.40 & 0.52 & 0.56 & 0.52 & 0.40 & 0.25 \\
\hline
\end{tabular}

\begin{tabular}{l|l|l|l|l|l|l|l}
0.25 & 0.40 & 0.52 & 0.56 & 0.52 & 0.40 & 0.25 \\
\hline 0.40 & 0.60 & 0.74 & 0.79 & 0.74 & 0.60 & 0.40 \\
\hline
\end{tabular}

\begin{tabular}{l|l|l|l|l|l|l|}
\hline 0.52 & 0.74 & 0.89 & 0.94 & 0.89 & 0.74 & 0.52 \\
\hline 0.56 & 0.79 & 0.94 & & 0.94 & 0.79 & 0.56 \\
\hline
\end{tabular}

\begin{tabular}{l|l|l|l|l|l|l}
0.56 & 0.79 & 0.94 & 1 & 0.94 & 0.79 & 0.56 \\
\hline
\end{tabular}

\begin{tabular}{l|l|l|l|l|l|l}
\hline 0.52 & 0.74 & 0.89 & 0.94 & 0.89 & 0.74 & 0.52 \\
\hline 0.40 & 0.60 & 0.74 & 0.7 & 0.74 & 0.60 & 0.40 \\
\hline
\end{tabular}

\begin{tabular}{l|l|l|l|l|l|l}
\hline 0.40 & 0.60 & 0.74 & 0.79 & 0.74 & 0.60 & 0.40 \\
\hline
\end{tabular}

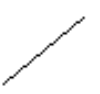

\begin{tabular}{l|l|l|l|l|l|l}
\hline 0.25 & 0.40 & 0.52 & 0.56 & 0.52 & 0.40 & 0.25 \\
\hline
\end{tabular}

\section{Weighted Rainfall}

$49.981 .4104 .2112 .2104 .181 .4 \quad 49.9$ 81.4120.7148.0157.7148.0120.7 81.4 103.4147 .0176 .8187 .4176 .8146 .9103 .3 111.5156 .6187 .4198 .2187 .4156 .6111 .4 102.7146 .0175 .7186 .1175 .6145 .9102 .6 $80.4119 .1146 .0155 .5146 .0119 .0 \quad 80.3$ $\begin{array}{llll}48.9 & 79.8102 .0 & 110.0102 .0 \quad 79.7 \quad 48.8\end{array}$
Weighted NDVI

0.0590 .1020 .1300 .1410 .1300 .1020 .052 0.0960 .1510 .1860 .1980 .1860 .1510 .085 0.1230 .1860 .2230 .2370 .2230 .1860 .109 0.1320 .1980 .2370 .2510 .2370 .1980 .117 0.1220 .1740 .2080 .1810 .1710 .1420 .101 0.0950 .1420 .1740 .1510 .1420 .1160 .078 0.0580 .0950 .1220 .1080 .1000 .0780 .048

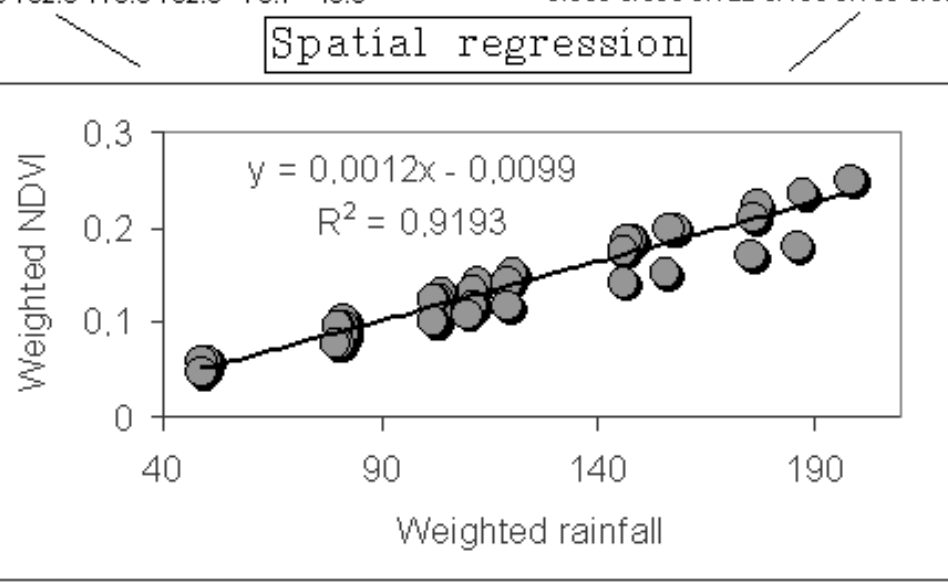

Figure 4.1. Framework explaining how the GWR works in the practice with an example of a $7 * 7$ kernel size. In this example, the GWR is derived for the pixel located in the centre of the kernel. 
In the practice, for each variable from equation (2) its weighting value can be calculated by applying a weighting matrix $\mathrm{W}(\Theta)$. The weighting matrix is an $n$ by $n$ matrix whose off-diagonal elements are zero and whose diagonal elements denote the geographical weighting of each of the $\mathrm{n}$ observed data for regression point $i$. After that, a local regression at each point in the analysis area can be derived by moving a kernel over the space.

Estimated parameters in geographically weighted regression depend on the weighting function of the kernel selected. As the bandwidth, $b$, becomes larger, the closer the model solution to that of global OLS will be. Conversely, as the bandwidth decreases, the parameter estimates will increasingly depend on observations in close proximity to regression point $i$ and will have increased variance. The problem is therefore how to select an appropriate bandwidth in GWR. The selection of the weighting function can be determined using different methods such as a cross-validation (CV) approach described by Brundson et al. (2001) and Fotheringham et al. (2002), the generalized cross-validation criterion (GCV) proposed by Loader (1999), or the Akaike Information Criterion (AIC) from Hurvich et al. (1998).

To establish an appropriate bandwidth, $b$, we used the cross-validation approach (CV) which determines $b$ by minimisation of the sum of squared errors between predicted variables and those observed. According Fotheringham et al. (2002), the equation for the crossvalidation sum of squared errors CVSS is statistically expressed as:

$$
C V S S=\sum_{i=1}^{n}\left[y_{i}-\hat{y}_{i}(b)\right]^{2}
$$

where $y_{i}$ is the observed value and $\hat{y}_{i}(b)$ is the fitted value of $y_{i}$ for bandwidth $b$.

As general rule, the lower the CVSS, the closer the approximation of the model to reality. The best model is the one with the smallest CVSS. For our regression model, the bandwidth of 5 pixel was decided to be the most appropriate.

An extended description of geographic weighted regression and its treatments is provided by Fotheringham et al. (2002), Foody (2003) and Paez et al. (2002a, b).

\subsection{Assessment of modelling accuracy}

It is important to distinguish between error and accuracy. Essentially, error relates to a single value and is associated with a local accuracy while accuracy relates to the average of an ensemble of values. Accuracy analysis involves the computation of prediction uncertainty in 
the model outputs. As a guides to the accuracy and error assessment of the model-based predictions we used the following variables:

- The root mean squared error (RMSE),

- The standard error (SE).

- The correlation coefficient between measured NDVI and regression model predicted NDVI,

- The Moran's $I$ of the residuals from the models.

\subsubsection{Root Mean Square Error (RMSE)}

Accuracy depends on a statistical model. It is an expectation of the overall error. Where an independent data set is used to assess uncertainty (in this study - measured NDVI), accuracy may be predicted directly. In particular, the root mean square error which is sensitive to both systematic and random errors, can be used to predict accuracy.

$$
R M S E=\sqrt{\frac{\sum_{i=1}^{n}\left(z_{i}-\hat{z}_{i}\right)^{2}}{n}}
$$

\subsubsection{Standard error}

Using the standard error to estimate the prediction error (and, therefore, imprecision) is based on central limit theorem. This theorem says that for large sample size $n$ the conditional distribution of the error should be approximately Gaussian (or normal). For a given sample the standard error can be calculated by the equation:

$S E=\frac{\sigma_{z}}{\sqrt{n}}$

where,

$$
\sigma_{z}=\sqrt{\frac{\sum_{i=1}^{n}\left(\bar{z}_{i}-\hat{z}_{i}\right)^{2}}{n-1}}
$$


where, $\sigma_{z}$ is the standard deviation of the variable $\sigma_{z}$ and $\mathrm{n}$ is the number of data used. In this case, $\bar{z}_{i}$ exposes the mean value of a given kernel and the number of data is depend on the kernel size.

\subsubsection{Spatial autocorrelation for accuracy assessment}

An accuracy assessment based on an independent data set may provide a spatially distributed set of errors. These errors can be analysed statistically without the local information. For example, one might be interested in the local pattern of over- or underprediction: the map of errors might show areas of over-prediction (positive errors) and underprediction (negative errors). It has been found that in many cases such spatially distributed errors are spatially autocorrelated (Wang et al., 2005;). A diagnostic statistics indicating problems in regression modelling with spatial data is the degree of spatial autocorrelation exhibited by the residuals from the model. The standard errors are usually underestimated when positive autocorrelation is present.

For each regression model, we calculated the Moran's $I$ of the residuals to examine the effect of calibrating the models locally. It is proved that the local calibration removes much of the problems of spatially autocorrelated error terms included in traditional global OLS model (Wang et al., 2005; Fotheringham et al., 2003, pp. 112-117). We were interested in the comparison of the results from the global and local models.

\subsection{Evaluation of land cover change and its driving forces}

4.6.1. Background for discrimination between climate-induced and human-induced vegetation change

Previous studies have shown a strong relationship between inter-annual changes in vegetation activity and precipitation or temperature. It is clear that climate signal in NDVI time series must be very strong. Climate should have a substantial control on NDVI through annual precipitation. This control, however, should be predictable in every point of the study area where the relationship between NDVI and climate change are statistically significant. Identification and quantification of climate signal should help to discriminate between two major factors of vegetation change, climatic and anthropogenic. Some examples of dealing with climatic signal and discrimination between human-induced and climate-induced 
degradation have been presented in the recent literature (Li et al., 2004; Evans \& Geerken, 2004).

A system of discrimination between climate and human driving forces in vegetation change has been developed in this work. This simple system is based on the concept of synchrony and asynchrony of time-trends in vegetation and climate factors. This concept is explained on an example framework (Figure 4.2). In panel (a), the upward trends in NDVI and precipitation are synchronous. Obviously, here we observe improving vegetation cover due to increasing precipitation amounts. In panel (b), the downward trends in NDVI and precipitation are synchronous. In this case, decreasing NDVI is driven by a decrease of precipitation, and one cannot speak about "human-induced" worsening of vegetation cover, because human impact is not evident in the trends. In (c), the trends are asynchronous. NDVI increases even as precipitation decreases. This would be the case when vegetation cover is recovering due to diminishing human impact. In (d), the trends are once more asynchronous, but an increase of precipitation did not cause an improving of vegetation cover. On the contrary, the NDVI trend is negative. Here, we can suppose human-induced degradation of the vegetation cover.
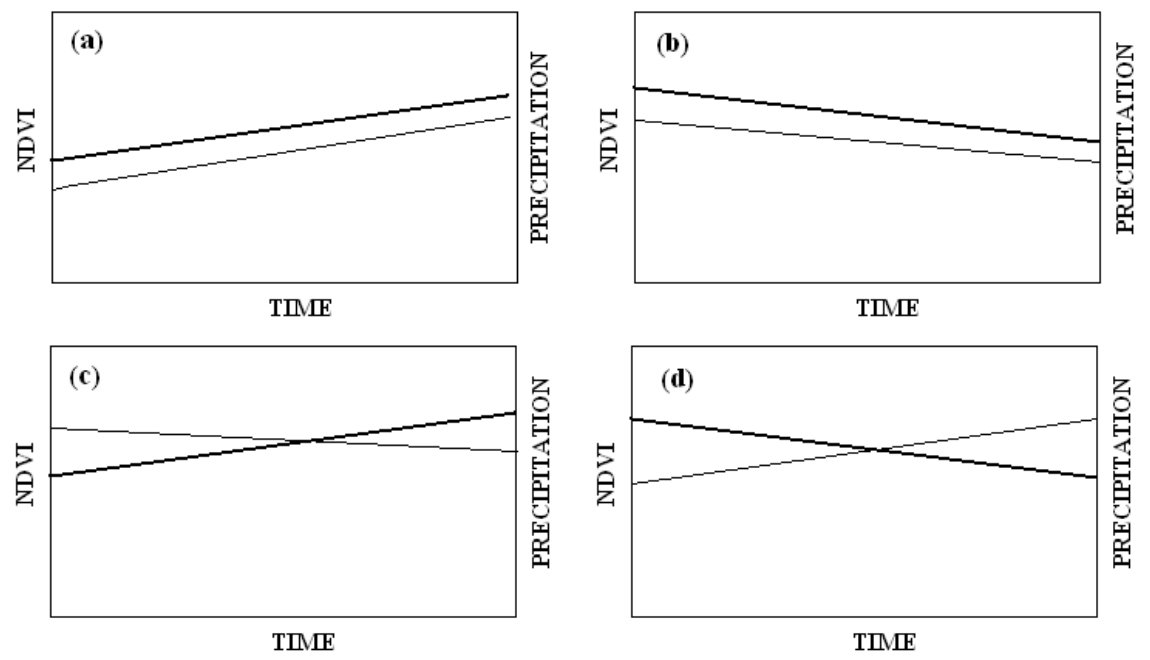

Figure 4.2. Scenarios described to illustrate how the combine use of NDVI and precipitation timeseries may help to detect a vegetation cover being improved or degraded. A thick and a thin line depict NDVI and precipitation trends, respectively. Panel (a) displays improving vegetation cover caused by increase in precipitation; (b) vegetation degradation due to climate change; (c) recovering vegetation cover; (d) degradation of vegetation cover caused by human impact. See closer explanation in the text. 


\subsubsection{Identification of climate and anthropogenic signals in the vegetation time-series}

It is clear that this system would work only in areas where relationship between trends in vegetation and trends in climate factors are statistically significant and strong enough. In order to detect these areas, trends in vegetation cover were computed and compared with trends in climatic predictors. This task was solved in three steps. First, areas with statistically significant trends in vegetation activity over the study period were identified and extracted. Second, correlation and regression analysis with inter-annual time series of precipitation and temperature have been carried out for every pixel in the extracted areas. Third, synchrony or asynchrony between trends in vegetation conditions and trends in climate factors was analysed and determined by comparing the trend direction of vegetation activity and correlation coefficient with climate factor.

For example, if a trend in vegetation cover is positive and this area reveals statistically significant positive correlation with precipitation, it considers to indicate a climate (precipitation) driven change in vegetation cover (Figure 4.2, a). If a trend in vegetation cover is positive but the area reveals negative correlation with precipitation, it considers indicating improvement of vegetation cover due to a decrease of human impact (Figure 4.2, c). The same approach was applied to identify climate-induced and human-induced degradation of vegetation cover (Figure 4.2, b and d).
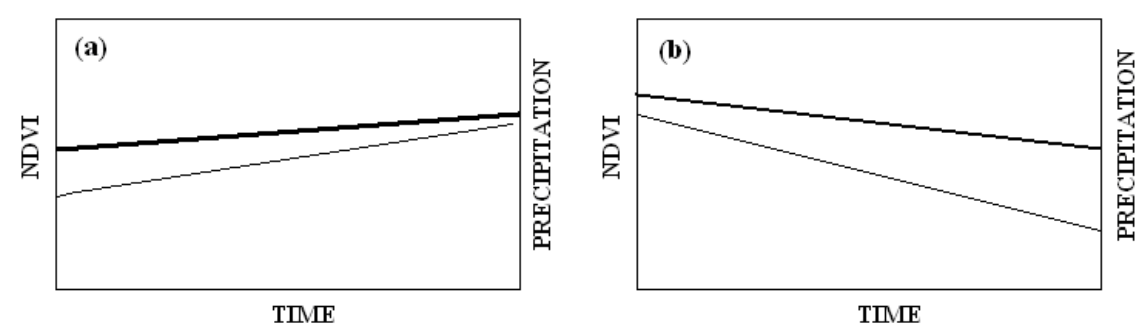

Figure 4.3. Difficult cases of trends interpretation: (a) both trends are positive but the trend in vegetation reveals a much lower magnitude, which should indicate a slight process of degradation in spite of good climate conditions; (b) opposite case presenting a slight rehabilitation of vegetation cover in spite of rainfall decrease. 
4.6.3. Analysis of regression residuals for identification of areas experiencing anthropogenic impact

The scenarios in Figure 4.2. describe idealistic conditions which are not always to be found in the reality. It is expected that not all trends will exhibit asynchrony or synchrony with values of equal magnitude. Special cases of this problem are shown in Figure 4.3. The trends in these panels are synchronous but exhibit different magnitudes. It means that in 4.3. (a) vegetation response to precipitation is getting worse. An opposite case is shown in panel 4.3. (b). Here, vegetation cover demonstrates increasing response to precipitation.

In order to detect these areas, an analysis of residuals from regressions between NDVI and climate factors was undertaken. For a given value of rainfall, a value of NDVI predicted by the regression, abbreviated as $N D V I_{\text {pred }}$, was obtained for every pixel and for each year, this value was considered to reveal the time trend in climatic component. The observed NDVI, abbreviated as $N D V I_{\text {obs }}$, may show deviations from the regression line. We suggested that positive deviations indicate better response of vegetation to climate while negative deviations indicate worse response. Deviations in $N D V I_{\text {obs }}$ from $N D V I_{\text {pred }}$ expressed in the regression residuals were computed at pixel-by-pixel basis for every year. Then we calculated temporal trend of regression residuals for each pixel over the study period. We suggested that any trend through time presented in the residuals would indicate changes in NDVI response not due to climatic variables. A negative trend would mean diminishing response of vegetation cover to climate. This reduce can be caused either by a decrease of vegetation cover or by a change in plant species composition. According to this suggestion, this negative trend, if it is statistically significant, would indicate an area experiencing human induced degradation. An opposite case would indicate a positive trend in residuals. This positive trend would indicate an area with improving vegetation cover.

Concerning the panels shown in Figure 4.3, positive trend in residuals would represent the case in panel (b), and, on the contrary, panel (a) displays a negative trend in residuals. 


\section{Chapter 5}

\section{Analysis of climatic conditions}

\subsection{Network of climate stations in the study region}

The network of meteorological observation stations in the Republic of Kazakhstan is administrated by the National Hydrometeorological Centre of Kazakhstan (NHMCK). The number of stations in the network has varied over the years with a maximum value of 257 . The first meteorological stations in the republic were established at the end of 19. century by the Russian Geographical Society and with this time are associated first climate records from the region. During the period of Russian Empire until 1917, the network remained very thinly. A very rapid growth of the stations network in Kazakhstan is associated with the period of economical development of the region in 1930-50s, particularly with the virgin land campaign at the end of 1950s when wide areas of tselina (virgin land) were ploughed up and taken into agricultural use. During the time between 1950-1970, the network reached its maximum density and remained at that level untill the collapse of the Soviet Union in 1991.

The constitutional change has had a negative influence on climate observations in the region of Kazakhstan and other republics of the formerly Soviet Union in Central Asia. Many climate stations were abolished and abandoned because of diminishing financial support by the country government. In the remaining stations, climate observations have revealed many deficiencies in measurements and reporting. At some meteorological stations, climate observations have been carried out not by skilled specialists but by occasional people without any special education and experience which are employed for a low salary. There has been some improvement of the implementation of the climate network within the last years but the entire situation remains insufficient.

For this study, climate stations in the study area and the nearest to that were used. Fortunately, all the climate stations were operational both before and after the constitutional change in 1991. The general characteristics of the stations are listed in Table 3.1 (Chapter 3). Here, the spatial distribution of the climate stations is shown (Figure 5.1). The network seems to exhibit insufficient density of the climate stations, particularly in the southern part of the study area. Mean distance between the climate stations equals to approximately $85 \mathrm{~km}$ while distance from the station Saryshagan in the south to the nearest station in the north is about $240 \mathrm{~km}$. This density might appear insufficient. But we must take it into account that the southern portion of the study area is occupied by a straight plain with an elevation magnitude 
of 340-380 m over $200 \mathrm{~km}$. Here, we do not have to expect any significant local variances in climate conditions like in the northern part of the study area.

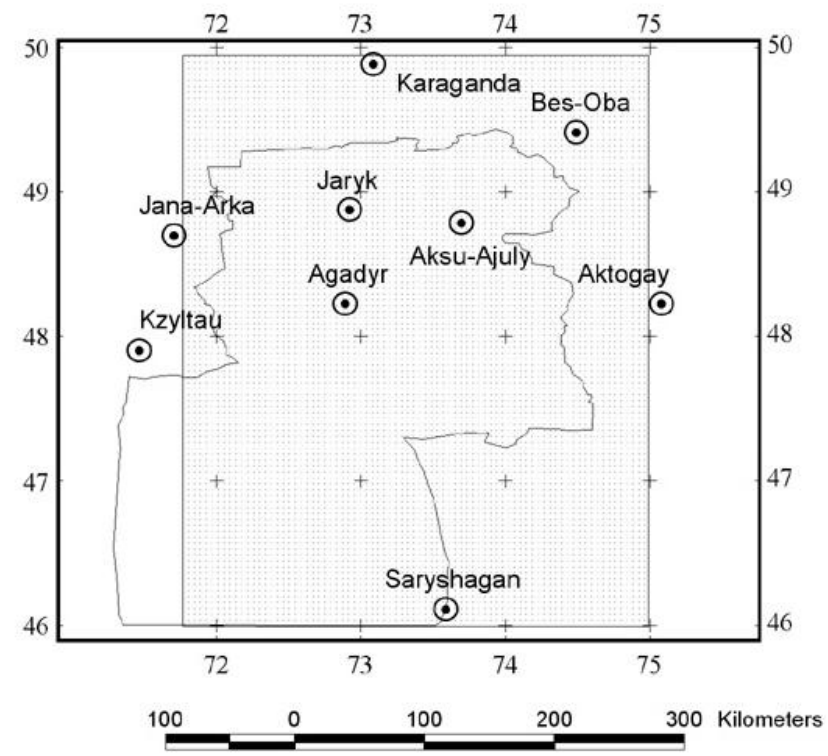

Figure 5.1. Map showing the distribution of the climate stations used in the study. Line displays the borders of the Shetskiy district. The study area is presented by the light grey square.

\subsection{Modelling spatial patterns in climate parameters}

The spatial patterns in average temperature and precipitation are shown in Figure 5.2. Average precipitation increased markedly from south to north: from below $100 \mathrm{~mm}$ in the desert to over $260 \mathrm{~mm}$ in the steppe zone. Average growing season temperature generally decreased from south to north. In the south of the study region the temperature achieves 16-17 ${ }^{\circ} \mathrm{C}$ and the northern area is about $3-5^{\circ} \mathrm{C}$ cooler.

These results were obtained using kriging with external drift (KED). There are prominent anomalies in the patterns caused by influence of relief on the climate. The magnitude of elevation in the study region is about $700 \mathrm{~m}$, the altitude ranges from $350 \mathrm{~m}$ to over $1000 \mathrm{~m}$. Therefore, this external explanatory factor for spatial distribution of climate variables had to be incorporated in the kriging model by preparing gridded maps. 

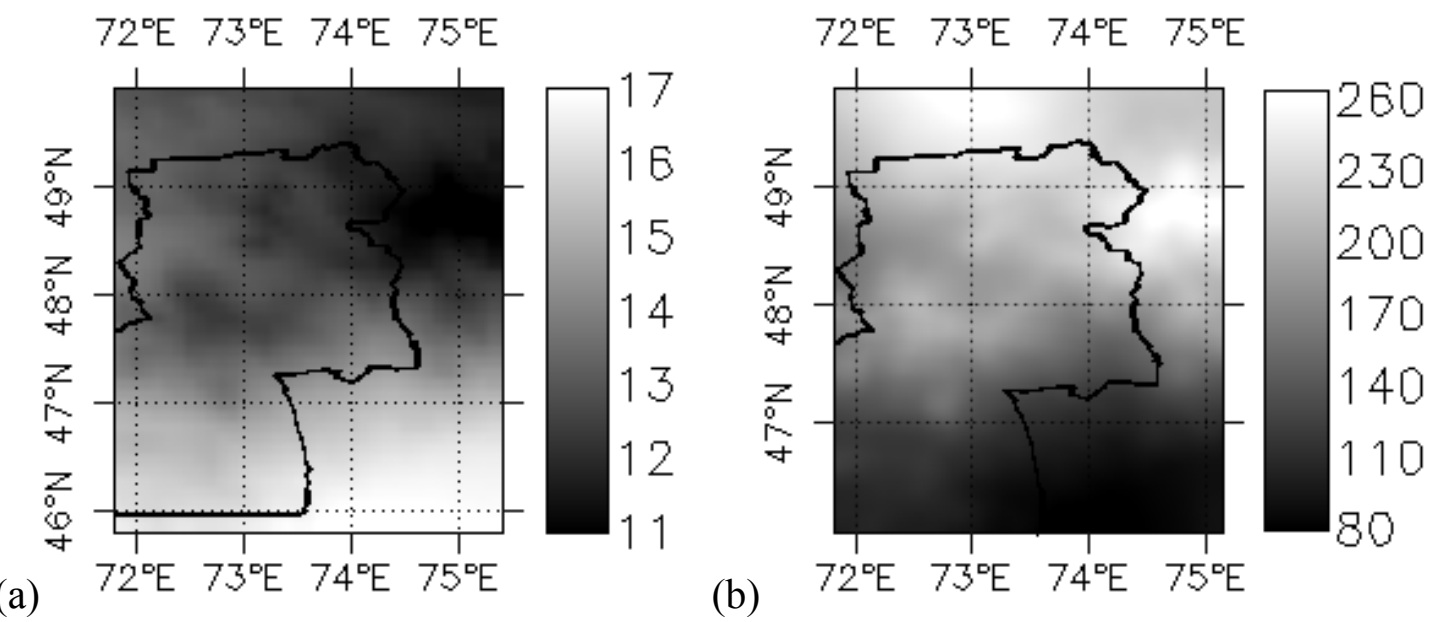

Figure 5.2. Maps showing the spatial distribution of mean temperature (a) and total amount of rainfall (b) over the growing season derived using elevation data as external drift in KED.
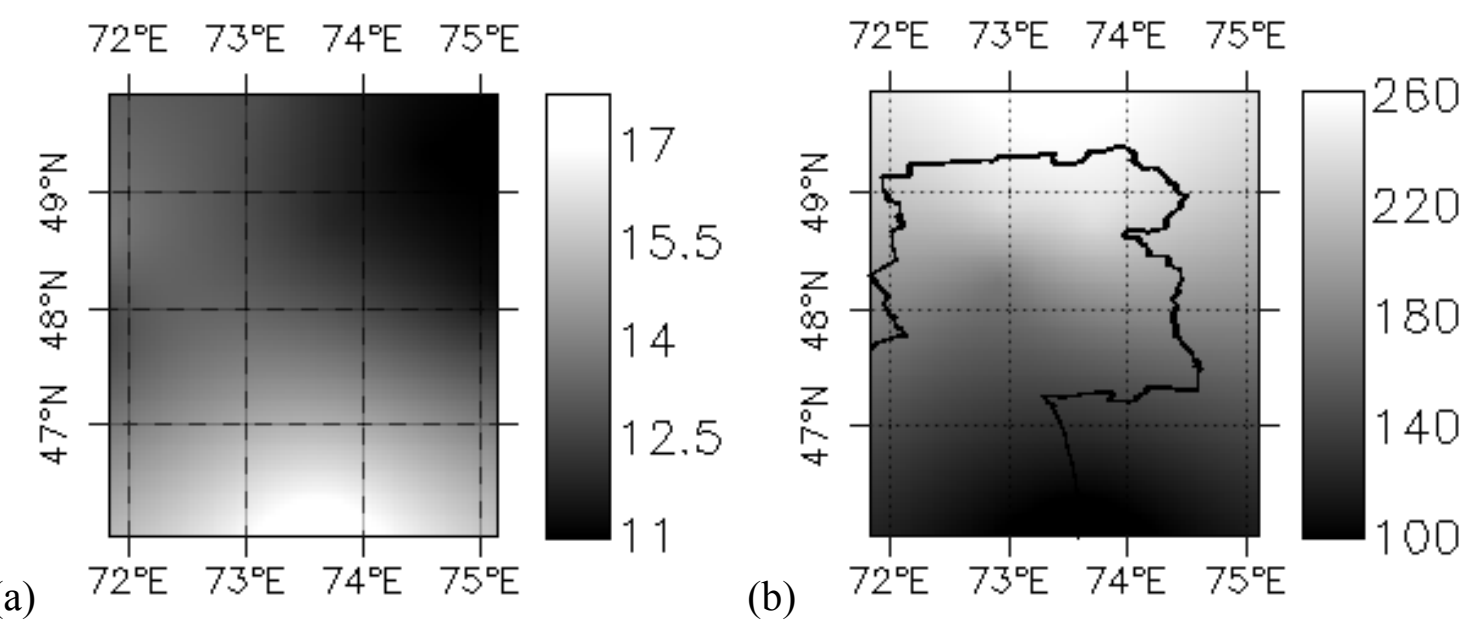

Figure 5.3. Kriging average growing season temperature (a) and total precipitation (b) without external drift.

The results obtained using ordinary kriging without external drift $(\mathrm{OK})$ are presented in Figure 5.3. They can be characterized as a near gradual upstep in rainfall and downstep in temperature when going northwards. This maps do not take into account any external influence on climate patterns. They are more smooth than that for KED (Figure 5.2) which show clearly the form of the terrain, particularly in the mid and northern parts of the study region. In order to assess the accuracy of the data preparation, we randomly reserved 3 weather stations from the interpolation for one of the 10-day from every year and recorded values. Average error was less than $6 \%$ for KED and about $9 \%$ for OK. It means that the approach of kriging with external drift worked more effectively. The root mean squared error (RMSE) was also used as a guide to the accuracy of the prediction. For KED, the RMSE was 
$8.3 \mathrm{~mm}$ for 9 climate stations, while for OK it was $10.5 \mathrm{~mm}$. For these data, there appear to be benefits in using kriging with external drift.

\subsection{Statistical analysis of climate data.}

\subsubsection{The inter-annual variability of precipitation and temperature.}

The arid and semi-arid climates are characterized by high variability of climate parameters from one year to another, particularly extremely high rainfall variability. On the map of the inter-annual variability of rains around the globe, the areas of greatest irregularities correspond to the desert areas (Mainguet, 1999, pp. 84). The pronounced deserts exhibit a variability of above $40 \%$. In the northern hemisphere, these areas are associated with the deserts and semi-deserts of Central Asia and Kazakhstan. The high variability in precipitation causes high variability of ecosystem conditions and is the main cause for the difficulties of vegetation and animals survival in the dryland.

The variability of climate factors may be illustrated with the aid of standard deviation and coefficient of variation (CV). In this study, coefficient of variation was computed for precipitation and temperature data for each climate station. The results are presented in Table 5.1 .

Throughout the study region, the variability in precipitation increases from the north towards the south and shows a mean value of $27 \%$ growing season precipitation. On the contrary, the variability in temperature increases from the south to the north with a mean value of $6.2 \%$. The variability in temperature is very low in comparison with that in rainfall, thus we may support that temperature plays a minor role in ecosystem dynamic in the study region.

The highest CV for growing season precipitation is in Saryshagan and the lowest in Jaryk, with values of 32.2 and 21.5, respectively. Shepherd \& Caughley (1987) determined a threshold value for variation of rainfall $(30 \%)$ which defines the border between equilibrium and non-equilibrium dynamics of drylands. Based on the results of $\mathrm{CV}$ analysis, the border between these two types of inter-annual dynamic may be proposed to be located approximately along the $48^{\circ} \mathrm{N}$ where the stations Kzyltau, Agadyr and Aktogay are situated. This area is associated with semi-desert zone which combines the features of desert and steppe. Obviously, the ecosystem of semi-desert should exhibit both types of inter-annual dynamics. 
Table 5.1. Coefficient of variations of precipitation and temperature during the period 1985-2004 as computed for the individual climate stations from the study area.

\begin{tabular}{|l|l|l|l|l|l|l|l|l|}
\hline Season & \multicolumn{2}{l}{ Spring } & \multicolumn{2}{l|}{ Summer } & \multicolumn{2}{l|}{ Autumn } & \multicolumn{2}{l|}{ Growing season } \\
\hline Parameter & Rain & Tem. & Rain & Tem. & Rain & Tem. & Rain & Tem. \\
\hline Karaganda & 36.8 & 18.3 & 48.3 & 5.4 & 45.9 & 21.0 & 28.5 & 7.7 \\
\hline Kzyltau & 39.2 & 18.8 & 49 & 4.8 & 50.4 & 24.1 & 29.8 & 8.0 \\
\hline Aksu-Ajuly & 34 & 19.2 & 45.5 & 5.3 & 37.3 & 22.1 & 22.8 & 8.0 \\
\hline Agadyr & 49.2 & 14.1 & 42 & 3.5 & 44.5 & 19.5 & 30.2 & 6.5 \\
\hline Jaryk & 41.6 & 12.4 & 37 & 4.6 & 41.8 & 16.1 & 21.5 & 6.4 \\
\hline Bes-Oba & 25.4 & 18.9 & 32 & 5.0 & 35.1 & 21.3 & 25.1 & 7.8 \\
\hline Aktogay & 31.8 & 18.2 & 40 & 4.9 & 37.6 & 18.8 & 29.1 & 7.6 \\
\hline Jana-Arka & 28.2 & 17.1 & 38 & 4.7 & 36.3 & 21.9 & 28.4 & 7.6 \\
\hline Saryshagan & 37.2 & 10.8 & 51.8 & 3.2 & 33.2 & 11.9 & 32.2 & 4.4 \\
\hline Average & $\mathbf{2 9 . 6}$ & $\mathbf{1 4 . 7}$ & $\mathbf{3 0 . 5}$ & $\mathbf{4 . 1}$ & $\mathbf{3 6 . 2}$ & $\mathbf{1 7 . 9}$ & $\mathbf{2 7 . 0}$ & $\mathbf{6 . 2}$ \\
\hline
\end{tabular}

The variability of precipitation and temperature for separate seasons is higher than that for the entire growing season. Such, CV of precipitation for summer ranges from 37 to 52 with a mean value of 30.5 . The highest variation is associated with the climate station in Saryshagan whereas the lowest another time with Jaryk. Surprisingly high values of CV were observed in Karaganda and Aksu-Ajuly, the two stations situated on the northern edge of the study region. They exhibited dynamic with variability of $48.3 \%$ and $45.5 \%$, correspondingly. Autumn was the season with the highest variations of precipitation and temperatures. The autumn CV for the area average amounts to 36.2 for precipitation. In comparison to other seasons and to the growing season, Saryshagan being the most southern station exhibited the lowest CV of precipitation.

Summer temperature varied only a little over the period of 1985-2004, the CV equals to 4.1. High variations were observed for spring and autumn temperatures with mean $\mathrm{CV}$ values of 14.7 and 17.9 averaged for the entire region. Particularly autumn temperatures showed high variability for individual climate stations with values above $20 \%$ for Karaganda, Kzyltau, Aksu-Ajuly, Bes-Oba and Jana-Arka. The high variability of spring and autumn temperatures may be explained by a current increase in year temperature throughout the 20 . century caused by climate change. This increase is mostly associated with rising temperatures in cold year season. One of the consequences for this temperature rise is persistence of the growing season due to earlier start up and later finish of greening conditions in the northern latitudes (Tucker et al., 2001; Xiao \& Moody, 2004). 


\subsubsection{Trends in climatic parameters}

Although time series of precipitation averaged over the study region for the period 1985-2002 include drought years and to some extend also present extremely dry conditions, there is clear evidence of positive trend in the amount of rainfall (Figure 5.2). Altogether, the precipitation amount increased by $11 \mathrm{~mm}$ during the 18 -year period. That is about $5 \%$ from the precipitation mean value. There was also a slight increase in growing season temperature between 1985 and 2002. Even though the $\mathrm{R}^{2}$ value of the trends in precipitation and temperature was low, only 0.10 and 0.08 , correspondingly, these trends may serve as indicators for positive dynamic of climate conditions in the study region. During the study period, two severe drought episodes with duration 2 years occurred in 1985-86 and 1994-95. Besides, two years (1991 and 1997) exhibited dry conditions with rainfall deviation of 30-40 $\%$ below the long-time mean. In 2000, the amount of rainfall was $20 \%$ below the average value. Wet conditions were observed in 1987-88, 1994, 2001 and 2002.

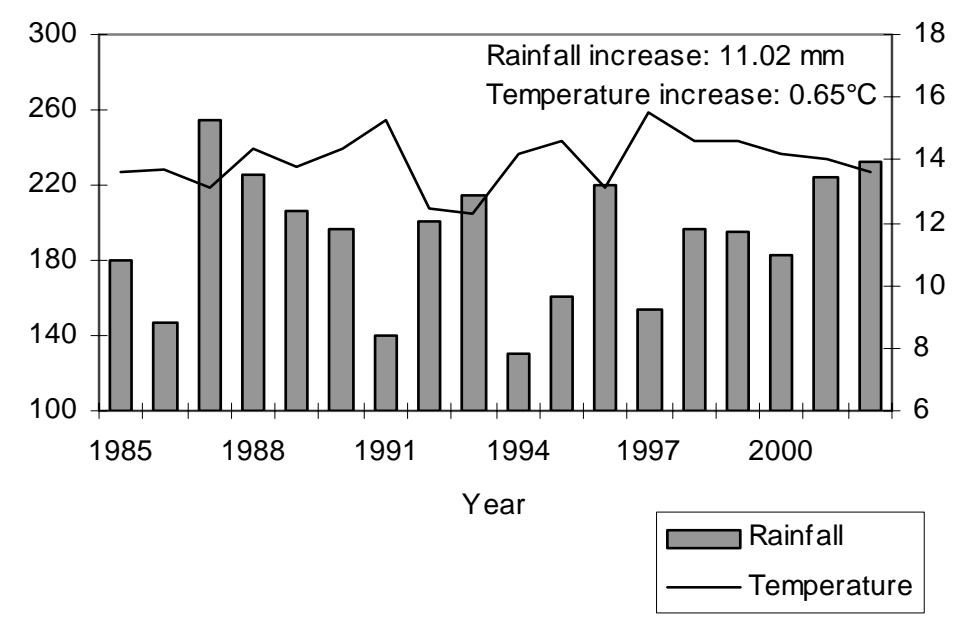

Figure 5.4. The time series of mean temperature and total precipitation for growing season during 1985-2002. The values are averaged over the whole study area.

The trends in precipitation and temperature over the period 1985-2004 for individual climate stations are shown in Table 5.2 and 5.3. Magnitudes of trends varied by climate station and season to be analyzed. Unfortunately, the most trend values for most stations exhibited only low coefficient of determination, $\mathrm{R}^{2}$, and can not be believed to be statistically significant. The reason is a relatively short period comprised for the time series analysis. Thus, three climate stations exhibited significant trends in growing season precipitation. Kzyltau showed a decrease with value of $-26.70 \mathrm{~mm}$, on the contrary, Jaryk and Sarishagan 
exhibited increases in precipitation with values of 41.75 and $9.46 \mathrm{~mm}$, respectively. As for seasonal trends of precipitation, four stations demonstrated significant changes of seasonal precipitation. Karaganda, Kzyltau and Aksu-Ajuly exhibited trends in spring precipitation with values of $26.55 \mathrm{~mm},-8.01 \mathrm{~mm}$ and $13.50 \mathrm{~mm}$, correspondingly. Significant downward trends occurred in Kzyltau also in summer and autumn while Jaryk exhibited significant upward trends in these season with values of $50.64 \mathrm{~mm}$ and $8.06 \mathrm{~mm}$.

In comparison with precipitation, temperature showed more statistically significant changes over the study period. Thus, all examined stations with an exception of Aktogay exhibited strongly significant upward trend in spring temperature. The trend magnitudes varied only a little by climate stations. All spring trends showed an overall increase value between 1.58 to $1.93^{\circ} \mathrm{C}$. The results indicate a strong general tendency for spring temperature.

On the contrary, the trends observed for other season and for the whole growing season have demonstrated statistical significance only in a small number of cases. Karaganda, Aksu-Ajuly and Saryshagan exhibited significant trends in autumn temperature. Aksu-Ajuly showed significant increase in growing season temperature.

Table 5.2. Mean spring, summer, autumn and growing season amount of precipitation $(\mathrm{mm})$ and their change $(\mathrm{mm})$ over the period 1985-2004 for 6 climate stations from the study area. Fat records indicate statistically significant increases in precipitation.

\begin{tabular}{|l|l|l|l|l|l|}
\hline Climate station & & Spring & Summer & Autumn & $\begin{array}{l}\text { Growing } \\
\text { season }\end{array}$ \\
\hline \multirow{2}{*}{ Karaganda } & Mean & 71.85 & 122.3 & 53.42 & 240.30 \\
\cline { 2 - 6 } & Change & $\mathbf{2 6 . 5 5}$ & 23.30 & -22.36 & 11.85 \\
\hline \multirow{3}{*}{ Kzyltau } & Mean & 62.88 & 71.27 & 50.16 & 181.87 \\
\cline { 2 - 6 } & Change & $\mathbf{- 8 . 0 1}$ & -23.39 & $-\mathbf{3 6 . 0 0}$ & $-\mathbf{2 6 . 7 0}$ \\
\hline \multirow{2}{*}{ Aksu-Ajuly } & Mean & 56.87 & 108.38 & 61.28 & 222.68 \\
\cline { 2 - 6 } & Change & $\mathbf{1 3 . 5 0}$ & -7.41 & $\mathbf{1 9 . 6 3}$ & 12.24 \\
\hline \multirow{2}{*}{ Agadyr } & Mean & 59.50 & 83.54 & 37.79 & 169.45 \\
\cline { 2 - 6 } & Change & 14.65 & -3.31 & -2.92 & 4.92 \\
\hline \multirow{2}{*}{ Jaryk } & Mean & 69.15 & 97.40 & 56.80 & 214.38 \\
\cline { 2 - 6 } & Change & 8.15 & $\mathbf{5 0 . 6 4}$ & $\mathbf{8 . 0 6}$ & $\mathbf{4 1 . 7 5}$ \\
\hline \multirow{2}{*}{ Saryshagan } & Mean & 37.60 & 51.30 & 15.80 & 98.00 \\
\cline { 2 - 6 } & Change & 2.00 & 9.39 & -2.31 & $\mathbf{9 . 4 6}$ \\
\hline
\end{tabular}


Table 5.3. Mean spring, summer, autumn and growing season temperature $\left({ }^{\circ} \mathrm{C}\right)$ and their change $\left({ }^{\circ} \mathrm{C}\right)$ over the period 1985-2004 for 6 climate stations from the study area. Fat records indicate statistically significant increases in temperature.

\begin{tabular}{|l|l|l|l|l|l|}
\hline Climate station & & Spring & Summer & Autumn & $\begin{array}{l}\text { Growing } \\
\text { season }\end{array}$ \\
\hline \multirow{2}{*}{ Karaganda } & Mean & 9.17 & 19.23 & 8.15 & 13.20 \\
\cline { 2 - 6 } & Change & $\mathbf{1 . 7 2}$ & 0.14 & $\mathbf{1 . 3 1}$ & 0.92 \\
\hline \multirow{3}{*}{ Kzyltau } & Mean & 8.71 & 18.69 & 7.54 & 12.67 \\
\cline { 2 - 6 } & Change & $\mathbf{1 . 5 8}$ & 0.51 & 0.71 & 0.87 \\
\hline \multirow{2}{*}{ Aksu-Ajuly } & Mean & 8.58 & 18.77 & 7.15 & 12.54 \\
\cline { 2 - 6 } & Change & $\mathbf{1 . 9 3}$ & 0.72 & $\mathbf{1 . 1 7}$ & $\mathbf{1 . 2 0}$ \\
\hline \multirow{3}{*}{ Aktogadyr } & Mean & 9.44 & 19.67 & 8.11 & 13.44 \\
\cline { 2 - 6 } & Change & $\mathbf{1 . 7 2}$ & -0.28 & 0.21 & 0.43 \\
\hline \multirow{2}{*}{ Saryshagan } & Mean & 7.85 & 18.63 & 6.59 & 13.76 \\
\cline { 2 - 6 } & Change & -0.23 & -0.26 & -0.60 & -0.40 \\
\cline { 2 - 6 } & Mean & 12.53 & 23.59 & 11.57 & 16.50 \\
\cline { 2 - 6 } & Change & $\mathbf{1 . 6 5}$ & 0.51 & $\mathbf{1 . 2 4}$ & 1.04 \\
\hline
\end{tabular}

Due to the rather short time series of the climate records obtained for the stations and used in the study, only a shorter periods can be treated as being of significance. Certainly, the time series are too short to allow any reliable conclusions from the trend analysis. Only trends in spring temperature that were observed in most of the stations with a high probability have been occurred during the period 1985-2004.

\subsection{Discussion and conclusion}

The climate is the most important factor predicting dynamic of dryland ecosystem which are characterized by high inter-annual variability. High dependence of dryland ecosystem on climate has been already investigated in several research works and caused Toupet (1992) to talk about tyranny of the climate, especially, precipitation in these regions (cited in Mainguet, 1999). This chapter examined climate features in the study area and made every effort to create a basis for further analysis of vegetation dynamic and its interrelationship to climate factors. The parameters of precipitation and temperature, spatial distribution, inter-annual and inter-seasonal variability and change over the 19-year period, have been investigated for 9 weather stations in the study region.

The network of climate stations in the region of Central Asia and Kazakhstan existed since the second half of the 20 . century but its intensive constructing in the study area is 
associated with the years of a rapid agricultural development of Kazakhstan during 1950-60s with the begin of the government program of tselina colonization. The constitutional change has had a negative influence on network functioning and climate observations in Kazakhstan and other republics in Central Asia. Fortunately, these transformations concerned the network of climate stations in the study area only marginally. All 9 stations used in the study existed both before and after the constitutional change. The density of the climate stations is not equal throughout the study region, it is scarce in the southern part, but it enabled to make prediction for every point and build gridded maps of precipitation and temperature.

The spatial distribution of climate parameters in the study region is influenced by external force and elevation, which ranges from $340 \mathrm{~m}$ in the south to above 700-800 $\mathrm{m}$ in the mid part and about $600 \mathrm{~m}$ in the northern portion of the study region. Because of the relationship between elevation and climatic parameters, two methods of data interpolation were tested by preparation of gridded maps. The first was ordinary kriging without any external drift and the second was kriging with an external drift. The results of KED suggest that it provides more accurate predictions than OK. The degree to which KED shows higher accuracy is a function of the relationship between climate variables and elevation locally at a given time. The benefits of using KED compared with $\mathrm{OK}$ were demonstrated by computing RMSE and assessment of prediction accuracy through random selection of weather stations and reading their recorded values from constructed maps.

Both climatic parameters varied during the period 1985-2004. Particularly precipitation amount is characterized by high variability. For the spatial average of the entire study area, the variability in growing season precipitation amounts to $27 \%$, that in mean temperature amounts to $6.2 \%$. For individual stations, coefficient of variation in precipitation ranged from 22.8 to 32.2 . Based on the threshold value of coefficient of variation in rainfall reported by Shepherd \& Caughley (1987), we can set the border between equilibrium and non-equilibrium dynamics of ecosystem approximately along the $48^{\circ} \mathrm{N}$.

High variations were observed for spring and autumn temperatures with average values of $14.7 \%$ and $17.1 \%$, respectively. The changeability in precipitation and temperature strongly depends on geographical location and elevation of the station. Variability in growing season precipitation increases from the north to the south, whereas that in temperature increases in the opposite direction. Strong relationship exists between rainfall variability and relief. There is a decrease in precipitation amounts with increasing altitude above the sea level (Figure 5.5). 


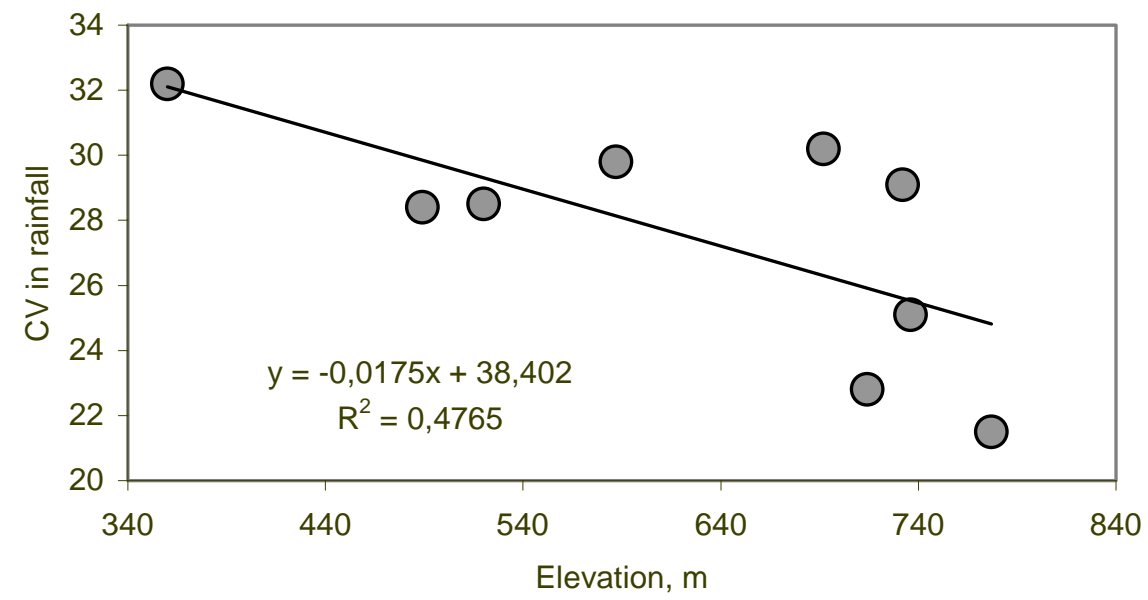

Figure 5.5. Coefficient of variation in precipitation versus elevation $(\mathrm{m})$ as computed for the weather stations in the study area.

The results of analysis of trend in climate parameters exhibited low statistic inference of trends for the most stations and seasons. Although all stations (with exception of Kzyltau) exhibited upward trends in growing season precipitation, only two of them, Jaryk and Saryshagan, showed trends which were significant with a probability of $95 \%$. Trends in growing season, summer and autumn temperature were also insignificant in the most weather stations. On the contrary, spring temperatures were characterized by strongly significant upward trend in all stations with exception of Aktogay. Change in spring temperature ranged from 1.55 to $1.93{ }^{\circ} \mathrm{C}$ between individual climate stations. These results are in agreement with the research results from global and regional studies on contemporary climate change. According to these studies, the mean long-time increase in temperature occurs in winter, spring and autumn (Xiao \& Moody, 2004; Tucker et al., 2001; Tateishi \& Ebata, 2004). 


\section{Chapter 6}

\section{Within-season dynamics of vegetation activity and their relationship to climate factors}

\subsection{Spatial distribution of Normalized Difference Vegetation Index (NDVI) and climatic factors in the study area}

There are two factors influencing the spatial patterns of vegetation and climatic variables in the study area: the south-north direction and altitude gradient. Generally, the spatial variance of NDVI and both climatic variables are strongly predicted by the south-north factor, but the relief conditions slightly deform this rule and make the spatial patterns more difficult. Vegetation and rainfall variable display similar spatial patterns. Average precipitation increased markedly from south to north: from about $100 \mathrm{~mm}$ in the desert to over $280 \mathrm{~mm}$ in the steppe zone (Figure 6.1). The 10-year average of NDVI ranges from less than 0.05 in the southern area of the study region to more than 0.30 in the steppe zone. These are typical values for dominant xerophytic formations. Values lower than 0.05 in the southern area indicate areas with no photosynthetic activity. These are non-vegetated desert surfaces or solonchaks. Rare little forested islands in the steppe show NDVI values over 0.35. They are placed at altitudes 1000-1200 meter and manifest a presence of vertical zonality in the study region. Average seasonal temperature generally decreased from south to north. In the south of the study region the temperature achieves $16-17{ }^{\circ} \mathrm{C}$ and the northern area is about $3-5^{\circ} \mathrm{C}$ cooler.
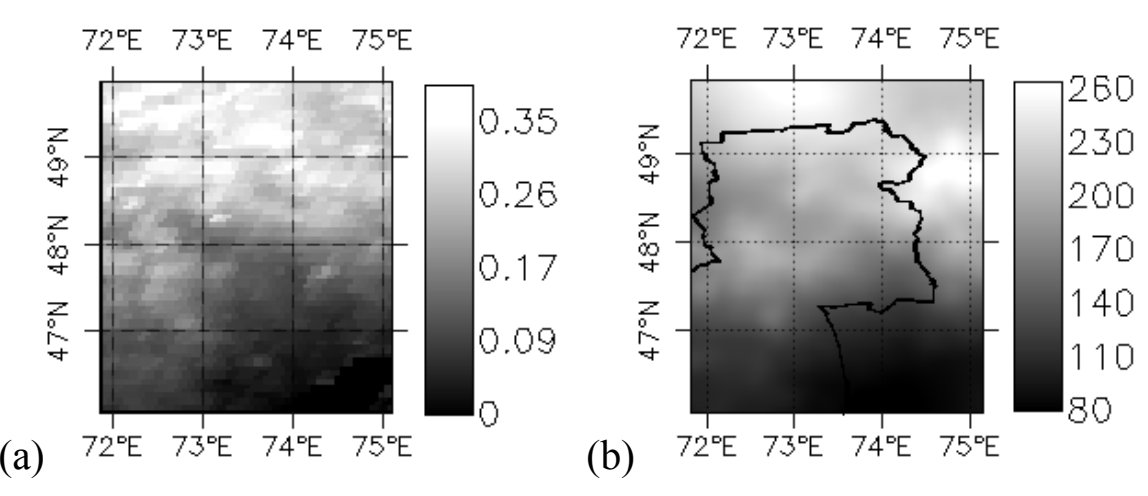

Figure 6.1. (a) Mean growing season NDVI calculated from the average of 8-km NOAA AVHRR for the period 1982-2003. (b) Regionalized total precipitation amount throughout the growing season, the graph presents an average over the period 1985-2004. 


\subsection{Average characteristics of NDVI}

The three major types of vegetation cover in the study area are strongly distinguished by different values of NDVI (Table 6.1). The steppe grassland records the highest average NDVI values for growing season (0.26), followed by the semi-desert vegetation $(0.15)$. The desert vegetation displays the lowest values (0.11). Observing the seasonal averages NDVI values displays other results. The highest values in spring are associated with the desert vegetation, NDVI $=0.13$. On the contrary, the short grassland of steppe regions shows the lowest value, NDVI $=0.07$. For summer and autumn averages, distribution of NDVI values between the vegetation types is similar to that described for the whole growing season, the NDVI value decreases from the short grassland, to semi-desert short grassland/shrub, and to desert shrubland. NDVI values computed for the different vegetation types are reasonable close to corresponding vegetation in other studies performed in the central Kazakhstan. These regions also showed ordinal consistency, with short grass regions highest NDVI, grass/shrub regions second highest, and shrubby desert regions lowest, in agreement with values in this study.

Table 6.1. Averaged characteristics of NDVI values for various vegetation types.

\begin{tabular}{|l|l|l|l|l|}
\hline \multirow{2}{*}{ Variable } & \multicolumn{4}{|l}{ Average NDVI over 1985-2001 } \\
\cline { 2 - 5 } & Spring & Summer & Autumn & Growing season \\
\hline Steppe & 0.07 & 0.30 & 0.16 & 0.26 \\
\hline Short grassland & 0.09 & 0.24 & 0.13 & 0.20 \\
\hline Semi-desert & 0.11 & 0.17 & 0.11 & 0.15 \\
\hline Desert & 0.13 & 0.07 & 0.07 & 0.11 \\
\hline Area-average & 0.09 & 0.19 & 0.12 & 0.16 \\
\hline
\end{tabular}

\subsection{Temporal behaviour of climatic factors and vegetation within the growing season}

Figure 6.2 illustrates the within-season cycles of NDVI and climate factors averaged over the entire study region. 16-year average of 10-day NDVI values (1985-2001) increased rapidly during spring (early April-mid-May), peaked during the summer months (mid-Mayearly July), and decreased during August-September-October. Precipitation showed two peaks, increasing from early April to early June and peaking in late May-early June. After that a slight decrease follows showing again an increase till the next peak in mid-July. Minimum 
of precipitation occurs in August-September. The duration of the growing season is approximately from April to October. The growth of vegetation begins between the second and the third decade of April; approximately 1 decade after temperature value has risen above zero. The curve of temperature displays a very symmetric form with a peak value in mid-Julyearly August. Generally, temperature rises during the months April-July, and then gradually decreases during August-October.

Figure 6.3 (a) and (b) show the mean growing season evolution of rainfall and temperature for every pixel in the study region. These illustrations presenting hovmoller diagrams (time-latitude) provide a general overview of the dynamic of the climate parameters. The temporal pattern in temperature seems to be similar throughout the study area. On the contrary, the pattern in rainfall varies in the space. Thus, in the southern part of the region, we have only two peaks in precipitation in the 7 and the 15 decade, and than a precipitation lack during the rest of summer and autumn, whereas in the north there are 3 high peaks and 1 low peak in rainfall. In the middle part of the study area between $48^{\circ}$ and $49^{\circ}$ latitude, one can distinguish at least 2 high peaks and 1 low peak, at the 7, the 12, and the 21 decade. The hovmoller diagrams exhibit that the NDVI within-season cycle corresponds stronger with patterns in temperature than with that of precipitation amounts. An additional correlation analysis has to prove this assumption statistically (see $\S 6.5$ and 6.6).

Considerable uniform time-series behaviour during the growing season exists in each year also among the vegetation types (Figure 6.3, d). All vegetation types have NDVI values under zero at the beginning of the growing season, in April. Generally, all vegetation types display increases in NDVI from April into June-July, followed by permanent decreases in August-October. Generally, the 16-year average NDVI time-series of the vegetation types show uniform behaviour through the growing season. The dry steppe grassland, semi-desert grassland and desert shrubland have approximately similar values during the spring months April-May. The separation in NDVI values begins in the first decade of June. Despite similar values of NDVI during the spring, the desert shrubland and the semi-desert grassland exhibit lower NDVI values than the dry steppe grassland during the summer and the first month of the autumn, September. In October, the NDVI values of all three vegetation types become again almost analogous.

Desert vegetation begins its development earlier in spring than semi-desert and steppe and culminates in a minimum in late July or at the beginning of August. Usually, the NDVI associated with the desert vegetation turns over the zero in the first decade of April. The semidesert vegetation begins its growing season in the second decade of April, and after that, this 
makes the short grassland associated with the steppe areas. During the spring months a rapid increase of NDVI values follows. The shrub vegetation of the desert zone reaches the maximum value between first and third decade of May, depending on the rainfall regime of the associated year. After that, the values graduately decrease during the summer and autumn months, reaching their minimum at the end of October. The grass/shrub regions show their maximum NDVI value, generally, in mid June. As well as the short grassland of the steppe regions, then its NDVI values remain high until mid July, afterwards decreasing slowly until the end of the growing season. The 16-year average seasonal cycle of NDVI provides a clear distinction between the major vegetation types. The best distinction between the time profiles can be made within the summer months, from June to August. During this time, the vegetation types display quite different and clear distinguishable attributes of their canopy such as leaf area, percent coverage, and biomass. These differences in the vegetation cover attributes reflect in clear differences in the 10-day NDVI time-series. The highest discrepancy between NDVI values of the separate vegetation types is observed in the mid June when the vegetation types exhibit their NDVI maximums: dry steppe 0.35 , semi-desert 0.25 , and desert 0.13 .

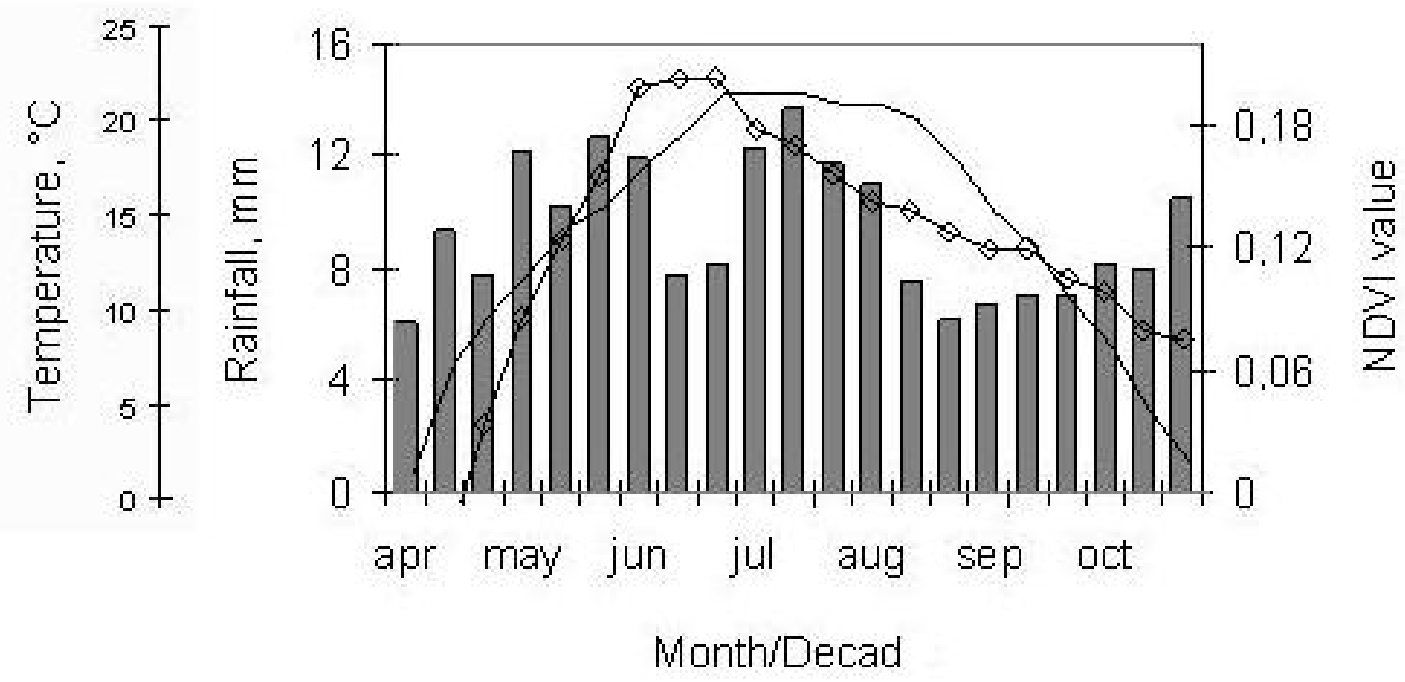

Figure 6.2. NDVI (line with squares), precipitation (pillars) and temperature (solid line) for each 10day period of the growing season (spatially averaged over the entire region). 


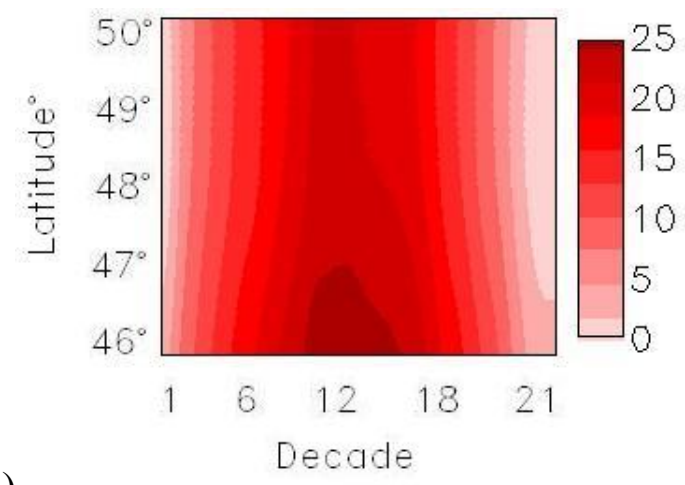

(a)

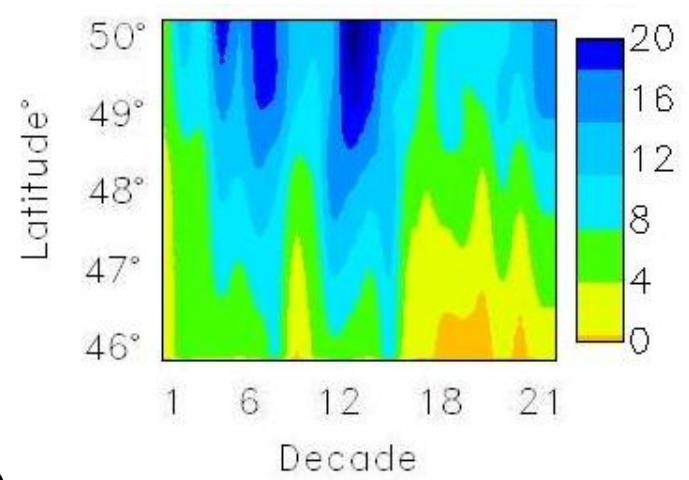

(b)
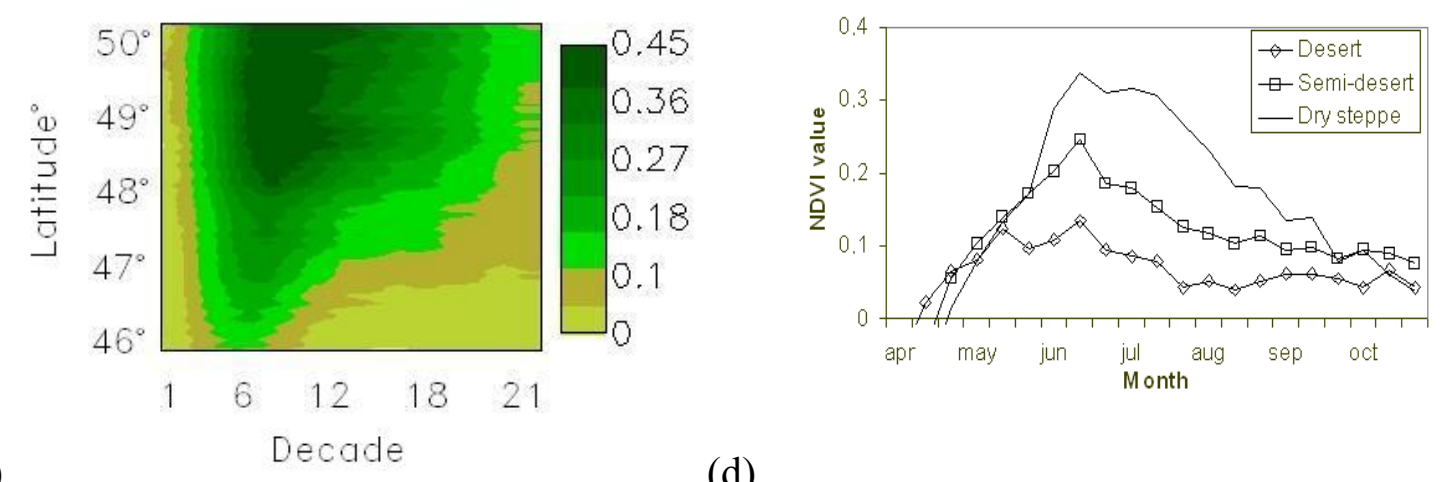

(d)

Figure 6.3. Within-season dynamic of climatic parameters and NDVI. (a) Hovmoller diagram of 10day mean temperature through April-October showing a uni-modal distribution pattern. The temperature steady increases from the first decade of April to the third decade of July overall in the study region. After that, the temperature slowly drops during the rest time of the growing season. Corresponding hovmoller diagram of 10-day precipitation for the same spatial domain is shown in (b) and that for 10-day NDVI in (c). Temporal behaviour of spatially averaged NDVI for desert, semidesert and dry steppe within the growing season is shown in (d). Note the drifting of the peaking time from May, to June, and to the beginning of August observed for desert, semi-desert and steppe vegetation, accordingly.

Reasons for a large discrepancy is a large difference in moisture and temperature conditions over the territory of the study area and differential responses of vegetation cover to summer climate conditions such as responsiveness to precipitation or limitations from high temperatures. In this section we abandoned a description of existing influence of climatic predictors on vegetation development during the phenological cycle. This influence is very versatile and complicated, it reveals differently during various time-periods of phenological cycle. We carried out a detailed investigation of relationships between NDVI and ecoclimatic parameters during the growing season and devoted two separate sections to the results description. Temporal responses of vegetation cover to climatic factors within the growing season will be examined in detail in the following chapters. 


\subsection{Within-season relationship between NDVI and precipitation}

For natural vegetation, precipitation is usually a major source for soil root zone moisture, which is critical to plant survival and productivity. It was reported that change in NDVI of native vegetation during the growing season can be affected by the amount and timing of rainfall (Schultz \& Halpert, 1995). The previous studies have also shown presence of a time-lag between a weather event, especially rainfall, and the vegetation response to it (Yang et al., 1998; Wang et al., 2003; Richard \& Poccard, 1998). Figure 6.2 illustrates that there is a time-lag of approximately 2-3 decades between precipitation and NDVI time-series averaged over the whole study area. On the contrary, the profiles of NDVI and temperature are synchronous. Therefore, while analysing NDVI-precipitation relationship for individual land-cover classes, we calculated correlation coefficients imposing different time-lags from 0 to 2 months. Significance level of 0.95 was set for all correlation calculations.

At the scale of the entire study area, correlations calculated with time-lags of 0-3 decade imposed to the NDVI data have been significant and strong. The highest correlation coefficient was achieved by imposing a time-lag of 2 decades. Figure 6.4 shows the corresponding scatter plot between 10-day NDVI and 10-day rainfall amount. About $38 \%$ of all variations in NDVI are explained by variations in rainfall. This devises a high dependence of vegetation growth on rainfall but a large amount of NDVI variance remains unexplained. It means that other explanatory factors may play an important role too. These predicting factors may be both of climatic and non-climatic nature such as air and soil temperature, evaporation, parent rocks, soil type or vegetation type (Farrar et al., 1994; Yang et al., 1997). Another problem is that a spatial average over the entire study region gives a good general impression of the relationship between vegetation activity and precipitation but it screens response of individual vegetation types and vegetation communities to the climatic factor to be investigated. To investigate this response, we performed correlation analysis disaggregating the territory into areas occupied by different vegetation types. 


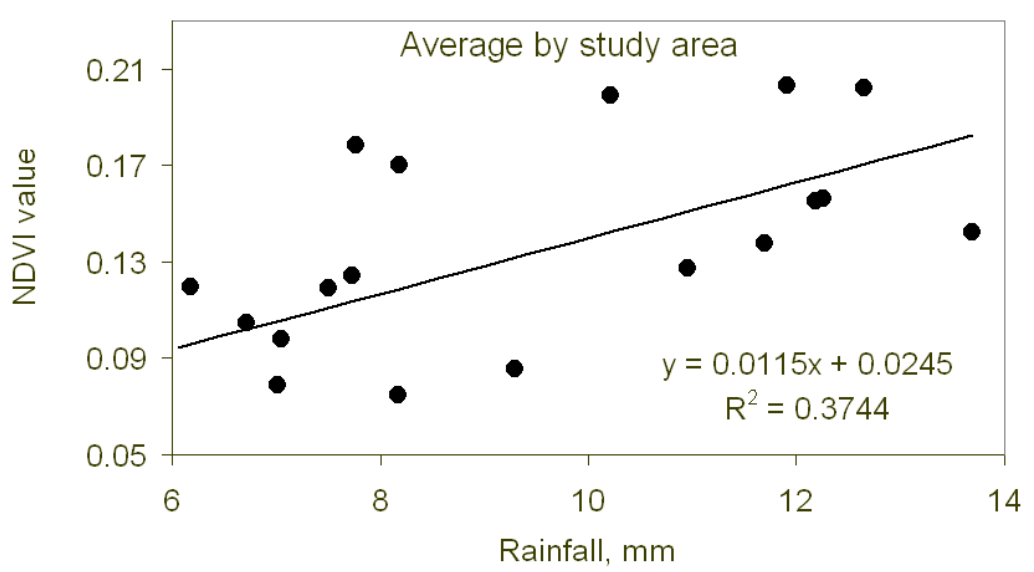

Figure 6.4. Relationship between 10-day NDVI and 10-day precipitation. The graph presents results derived with the area-averages of the both variables.

\subsubsection{Stratification of NDVI-precipitation relationship by land cover type}

For the land cover types, correlation coefficients between NDVI and precipitation are high in specific combinations of time duration and lag. The rainfall lag periods varied up to six 10-day periods. It indicates the time period for which an influence of rainfall on NDVI is the strongest. The results exhibited that the rainfall time lag increases with an enlargement of partial values in grass species in vegetation cover. The imposed time lag continually increases from desert shrubland, over semi-desert, to short grassland, and to steppe grassland (Figure 6.5). For desert shrubland, the best correlation between 10-day NDVI and precipitation is achieved by imposing no time lag, for semi-desert by imposing a time lag of 1-2, for short grassland and steppe grassland the best time lag is 3-4 weeks.

In terms of the strength of the NDVI-precipitation relationship, it gradually increases from desert shrubland, to semi-desert, to short grassland and to steppe vegetation, with a maximum value of correlation coefficient of $0.49,0.54,0.58$ and 0.67 , respectively. Vegetation cover of irrigated cropland and tundra exhibits only weak response to precipitation. This seems to be explained best by the diversity that exists between the different vegetation species associated with each vegetation type. The results of this analysis are in agreement with the research results obtained by others for dry regions (Yang et al., 1997; Wang et al., 2003; Richard \& Poccar, 1998). In accordance with the results, higher correlation coefficients between NDVI and precipitation are observed in landscapes with natural 
grassland vegetation cover. Correlations are getting weaker with a decrease of grasses in the vegetation cover.

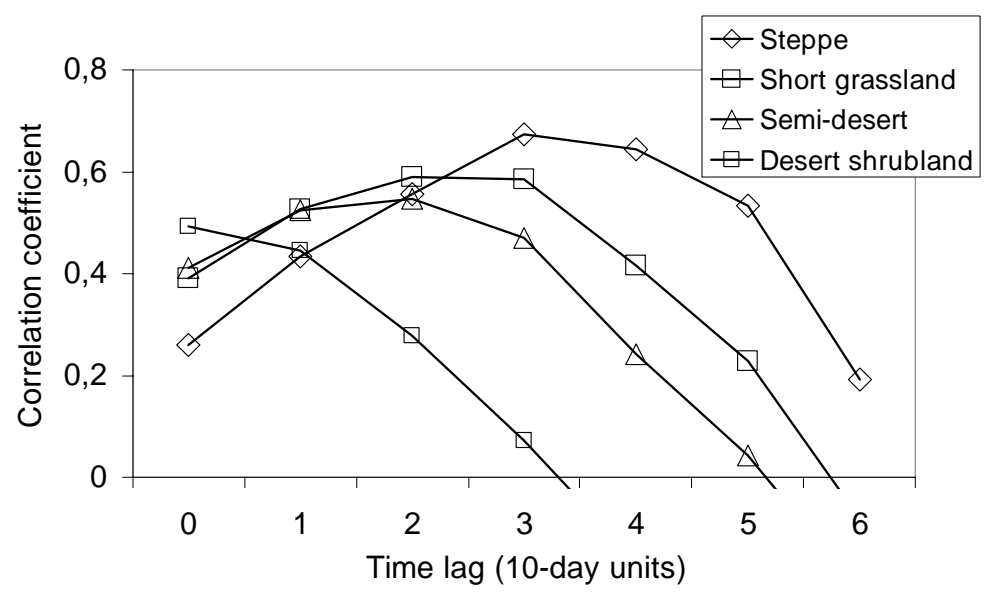

Figure 6.5. Dependence of correlation coefficient between 10-day NDVI and precipitation on time lag imposed.

\subsubsection{Stratification of NDVI-precipitation relationship by vegetation communities}

Supplementary, we computed correlation for vegetation communities prevailing in the land cover types. The land cover types do not exactly reflect distribution of different vegetation communities in the study area. Every land cover type is associated with 2 to 5 mean combinations of plant species which depend more on orographic and edaphic conditions and can vary within a small space. It was very difficult to identify all these variations in coarse resolution of data such as the 8-km AVHRR NDVI. We tried to discriminate only the most typical vegetation communities within every land cover type. The discrimination can be considered being successful because there are variations in response of vegetation to precipitation as the results demonstrate. The variation of the correlation coefficient and timelag between vegetation communities seems to be best explained by the combination of species that is associated with each ecosystem (Figure 6.6). Both the maximum correlation coefficient and the time-lag between precipitation and reaction of vegetation to it increase with decreasing amount of shrub and sagebrush species in vegetation communities.

Although water is the most important limiting factor in plant growth in desert zone, the weaker correlation between NDVI and rainfall obtained for desert vegetation should not surprise. In desert areas, supplement of rainfall water in the soils for plant growth is highly depended on the local infiltration ability of soils. Sparse vegetation cover and soil crust 
strongly influence distribution of fallen precipitation water and allow it flowing far away from the place of its fall. This results in lower NDVI-rainfall correlation coefficient. As the vegetation cover increases, plant growth and over ground biomass begins to depend more on rainfall. This is remarkable in dry steppe land cover category. In steppe areas, where vegetation cover is dense, there is no flash precipitation events and overland runoff. Rain water supplies at the place of precipitation fall. Only areas with degrading grass cover create conditions for sheet erosion and overland runoff. These areas show a weaker dependence of vegetation growth on rainfall.

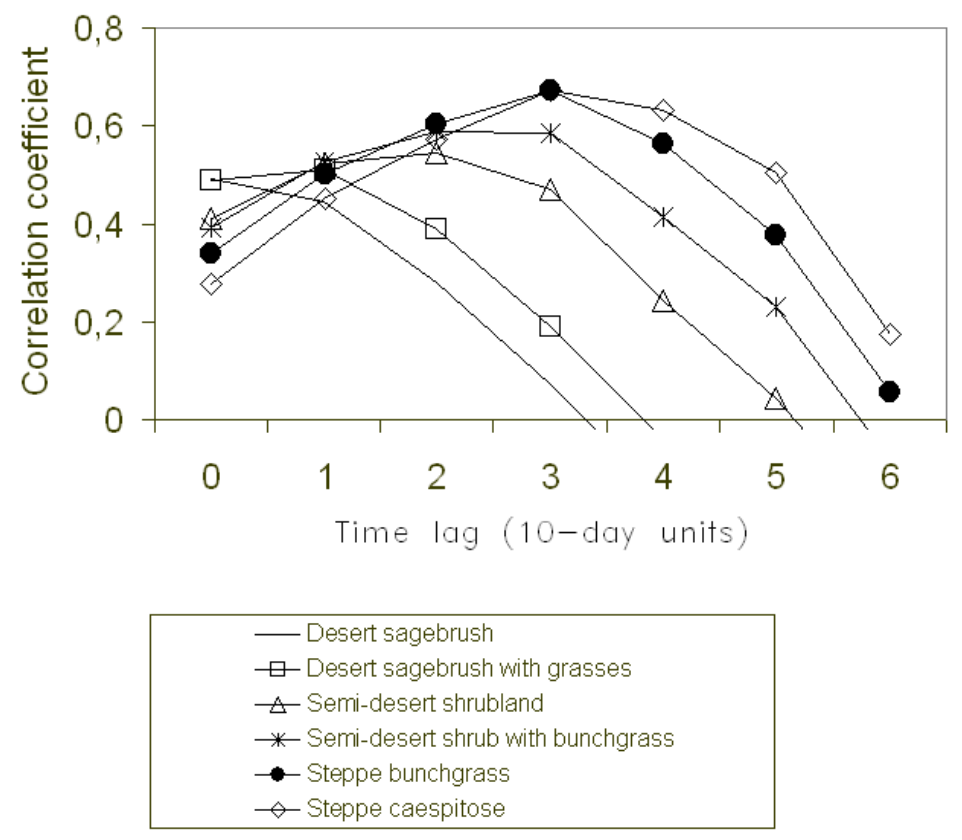

Figure 6.6. Dependence of correlation coefficient between 10-day NDVI and precipitation on time lag imposed to the NDVI data.

\subsection{Within-season relationship between NDVI and temperature}

The calculated NDVI-temperature correlation coefficients indicate that there is a significant relationship between NDVI and temperature for all vegetation types. 10-day NDVI was strongly correlated with temperature indices of the same period. We found no time lag in any vegetation type. The value of correlation coefficient between NDVI and temperature was $0.63,0.70,0.76$ and 0.84 , for desert shrubland, semi-desert, short grassland and steppe grassland, respectively. 
Temperature often serves as an indirect measure of available energy for plant growth. Above a certain base temperature, a plant's rate of growth is found to be proportional to temperature. Figure 6.7 displays that for all vegetation types, within-season NDVItemperature correlation coefficient was higher than that obtained for NDVI-precipitation. This agrees with the results reported by Li et al. (2002) for China and by Yang et al. (1998) for Nebraska, U.S.A.

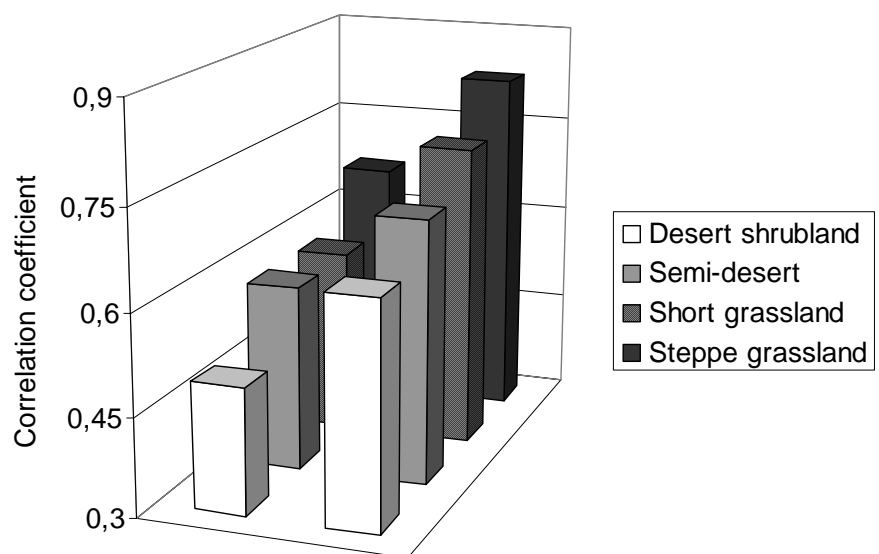

Figure 6.7. Comparison between the values of correlation coefficient obtained for NDVI-precipitation (left row of pillars) and NDVI-temperature (right row of pillars) relationship.

\subsection{Spatial patterns in NDVI-climate relationship}

The results of this study show that $70.52 \%$ and $94.90 \%$ of all pixels exhibited significant positive correlation $(r>0.48)$ between 10-day time-series of NDVI-rainfall and NDVI-temperature, respectively. The pixels with high correlation coefficients $(r>0.70)$ are mainly distributed in the north, south-west and east portion of the study area (Figure 6.9). The total area of pixels varied substantially by land-cover type and increased from desert shrubland, to semi-desert, to short grassland and to steppe.

Significant NDVI-rainfall correlations were observed for $24.72 \%, 65.56 \%, 84.65 \%$, and $98.41 \%$ of all pixels for every vegetation type, respectively (Figure 6.8). Compared with temperature, precipitation plays a minor role in explaining the greening patterns in these landcover types. Only for steppe grassland, precipitation makes a scarcely higher contribution to the greening patterns than temperature does. 
The results also exhibited a clear spatial pattern in time lag duration imposed by calculation of correlation coefficient between NDVI and precipitation. Figure 6.8 shows that the time lag duration generally increases in order from south to north. If we compare the map on Figure 6.10 with the map of vegetation types (Figure 2.2), we will consider a strong association between them. The vegetation type in the south, with a shorter time lag of 1 , is desert shrub according to the vegetation map, while the land cover type in the north, with a longer time lag of $3-4$, is steppe grassland. This agrees with our results derived for spatially averaged data (see $\S 6.1 .5$ and Figure 6.4). NDVI is affected by precipitation and this effect occurs with a time lag of 0-4 ten-day periods after the precipitation. The length of the time lag is dependent on land cover type and shows strong spatial patterns in the study area.

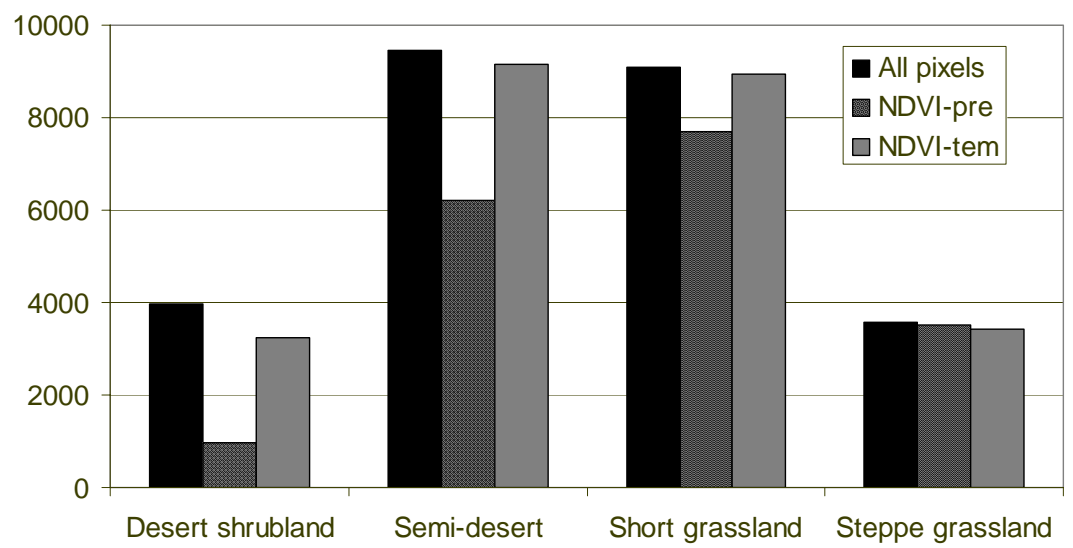

Figure 6.8. Complete amount of pixels, amount of pixels that exhibited significant NDVIprecipitation, and amount of pixels with significant NDVI-temperature correlation for every vegetation type.

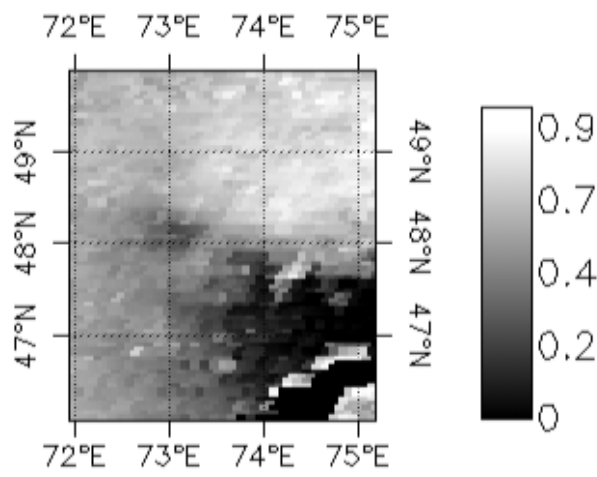

(a)

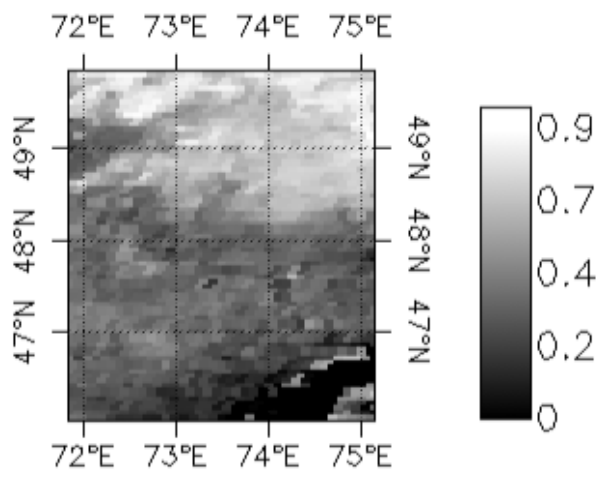

(b)

Figure 6.9. Spatial distribution of correlation coefficient for NDVI-precipitation (a) and NDVItemperature (b). 


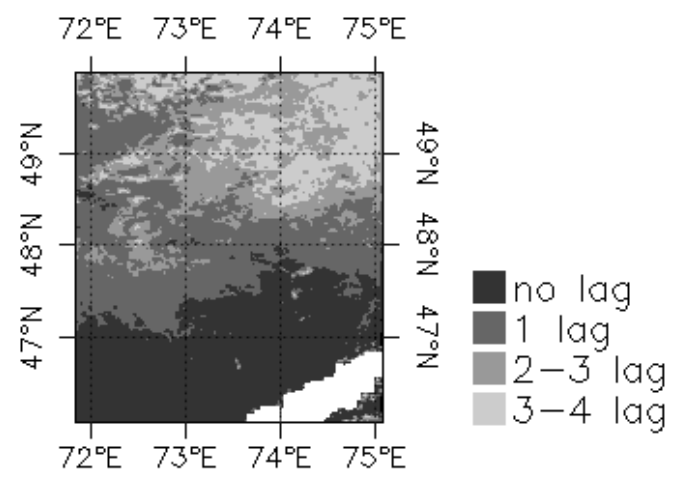

Figure 6.10. Spatial distribution of time lag (10-day units) imposed for calculation of correlation coefficient between NDVI and precipitation.

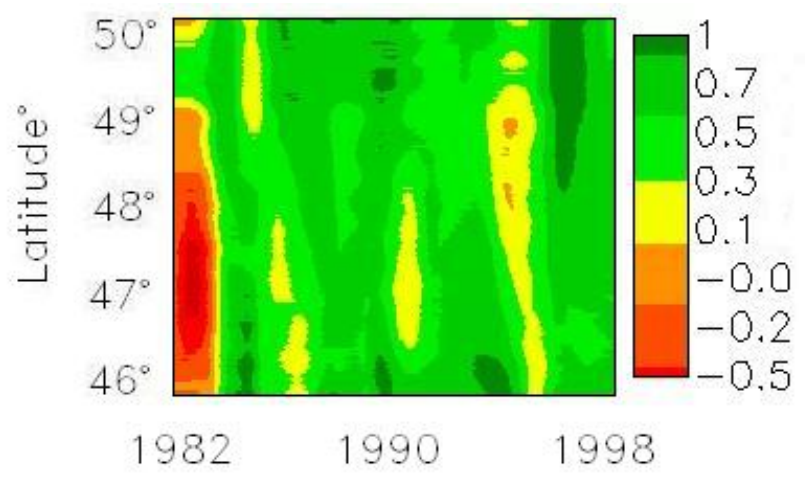

Figure 6.11. Time-latitude section of within-season correlation coefficient between 10-day NDVI and 10-day precipitation from 1982 to 1998.

\subsection{Inter-annual variations in within-season NDVI-climate relationship}

During the study period, there was considerable year-to-year variation in precipitation and NDVI. Variations in temperature were significantly lower. Also correlation coefficients between 10-day NDVI and 10-day precipitation/temperature in steppe, semi-desert and desert vary from year to year exposing variability in response of vegetation to rainfall. In spite of the great variability, a clear pattern in correlation variance was to be noted by explanation of the results. There was a notable association between the strength of NDVI-climate relationship and moisture conditions in according year. For desert and steppe vegetation communities, coefficients of correlation for NDVI-rainfall significantly increased in years with low rainfall and decreased in years with high rainfall. For semi-desert, we found only relatively slight decrease in NDVI-precipitation correlation during wet years. Correlation coefficient of 
NDVI-temperature showed an opposite pattern: it was very high in dry years and decreased in wet years (Table 6.2).

Analysis of the hovmoller diagram in Figure 6.11 supports these conclusions. The years with dry conditions exhibited higher values of the correlation coefficient. Particularly large increase in correlation coefficient during 1985, 1986, 1990 and 1995 one can note for the lower part of the diagram with which desert is to be associated.

Time-lag of NDVI response to precipitation also had shown variability. In our analysis (data not shown), vegetation responded more rapidly to precipitation during 1985, 1986, 1990, 1995 and 2001, which were dry years. By contrast, vegetation responded more slowly to precipitation during 1987, 1988, 1993 and 2000, which were wet years.

Table 6.2. Within-season correlation coefficients between climatic parameters and NDVI for vegetation communities in desert, semi-desert and steppe as computed for dry and wet years.

\begin{tabular}{|l|l|l|l|l|l|}
\hline \multicolumn{2}{|l|}{ Vegetation type/community } & \multicolumn{2}{l|}{ NDVI-rain correlation } & \multicolumn{2}{l|}{ NDVI-tem. correl. } \\
\cline { 3 - 6 } & Dry year & Wet year & Dry year & Wet year \\
\hline Desert & Sagebrush & 0.45 & 0.35 & 0.71 & 0.43 \\
& Sagebrush with grass & 0.51 & 0.33 & 0.73 & 0.45 \\
& Halophytic sagebrush & 0.49 & 0.35 & 0.75 & 0.48 \\
\hline Semi-desert & Shrubs & 0.60 & 0.55 & 0.67 & 0.33 \\
& Shrubs with bunchgrass & 0.64 & 0.58 & 0.75 & 0.32 \\
& & & & & \\
\hline Steppe & Bunchgrass & 0.75 & 0.63 & 0.82 & 0.51 \\
& Caespitose with bunchgrass & 0.76 & 0.71 & 0.81 & 0.53 \\
& Herb-bunchgrass & 0.76 & 0.67 & 0.83 & 0.58 \\
\hline
\end{tabular}

\subsection{Discussion and conclusion}

This chapter examined within-season interrelations between 10-day time-series of NOAA AVHRR NDVI and analogous series of precipitation and temperature variables over the 1982-2003 growing seasons in the Northern Balkhash. Strong correspondences between NDVI-precipitation, and NDVI-temperature were observed. The strength of NDVI-climate associations depends on land-cover type but there are variations in the response of NDVI to 
climate factors within each land-cover class on the per-pixel basis. The analysis exhibited that the correlations were stronger in areas dominated by grass vegetation and weaker in areas dominated by shrubs. This result is consistent with the observation of the relations between NDVI and climate parameters in other dry regions (Yang et al., 1997; Wang et al., 2001 and 2003; Li et al., 2002). Distinct time lags associated with NDVI's response to precipitation events were determined. Time lags increase in order from desert, to semi-desert and to steppe showing a different reaction speed of vegetation to precipitation events.

The correlation between NDVI and temperature was found to be higher than correlation between NDVI and rainfall. The result is indicative of the available energy and heat on plant growth during the growing season. Our analyses also showed that temperature plays a more important role for plant growth throughout the growing season. In comparison to precipitation, the correlation between NDVI and temperature was for all vegetation types higher. This was observed both for spatially averaged data and at per-pixel scale.

The results indicated high inter-annual variability of NDVI-climate relationship during the study period. Correlation coefficient between NDVI and precipitation increased significantly in dry years. In opposite to that, correlation between NDVI and temperature is low in dry years and high in wet years. This variability in vegetation response to precipitation is particularly remarkable for desert and steppe and insignificant for semi-desert. The variability in NDVI-precipitation is presented in all vegetation types equally. 


\section{Chapter 7}

\section{Inter-annual change in vegetation activity and its relation to}

\section{climate}

The region of Central Asia has experienced a warming trend in order of $1-2^{\circ} \mathrm{C}$ since the beginning of the $20^{\text {th }}$ century. This might have a strong impact on the regional temperature and precipitation regimes and also on vegetation cover (Lubimtseva et al., 2005). A better understanding of the inter-relationships between climate, vegetation cover and land-use changes will help to improve our understanding of Central Asia's dryland dynamic.

In this chapter, changes in vegetation activity seasonally and annually were examined using the 8-km NDVI dataset from 1982 to 2003. Spatially averaged time series of mean NDVI, mean temperature, and total precipitation over the growing season (April-October), spring (March-May), summer (June-August), and autumn (September-November) were generated for all pixels, and for each land-cover type. Correlations between seasonal and growing season NDVI and temperature or precipitation were computed to investigate climate effects on inter-annual change in vegetation activities. The correlation analysis comprises the years between 1985 and 2003. In order to highlight variability in NDVI-climate relationship within vegetation types, correlations were also computed at the pixel scale. All correlation calculations were made with significance at the 5\% confidence level. Areas with significant correlations were mapped and measured.

In order to quantify the inter-annual variability, average NDVI values for the spring, summer, autumn and whole growing season have been calculated for each vegetation type and every year in previous section were used to analyse the variability of vegetation activity. We calculated the following variables: standard deviation of NDVI, $\left(N D V I_{\text {stdev }}\right)$ and coefficient of variation, $\left(N D V I_{c v}\right)$. The variables $N D V I_{\text {stdev }}$ and $N D V I_{c v}$ were derived for spatial averages of each vegetation type. In order to understand spatial patterns of variations, we also made these calculations for each pixel. This section is devoted to investigations of inter-annual and inter-seasonal variability of NDVI values over time.

\subsection{Patterns in monthly time-series $1982-2001$}

The monthly time-series for the study region are presented as hovmoller diagrams from 1982 to 2001 as shown in Figure 7.1. The diagram in Figure 7.1 (a) shows spatial and 
temporal patterns in maximum monthly NDVI. Every individual growing season from the study period can be clearly separated from others because of its patterns in NDVI. Important information can be obtained from these diagrams. The diagrams enable us to distinguish both the length of every growing season and the time of vegetation peaking. The time of greening up can be read up from the diagram too. A hovmoller diagram of corresponding anomalies in NDVI is shown in Figure 7.1 (b) and contains information about inter-annual variability in vegetation conditions for every month of the growing season throughout the period 19822001. Interpretation of these two diagrams together with the diagram of monthly precipitation (Figure 7.1, c) gives an overview of climatic conditions and climate variability over the study period.

Vegetation seasonality is shown by the extent of the $0.08-0.5$ NDVI values over the region throughout the series. A pattern of these values across the study region is an indicator of rainfall conditions. Thus, during 1984-85, 1995-96 and 2001 the green pillars of NDVI values exhibit small length and are thinner than other pillars. These years should be associated with dry conditions. The diagram in Figure 7.1 (c) supports this assumption. Monthly values of precipitation in these years were not higher than 10-20 $\mathrm{mm}$ throughout the most area of the region. On the contrary, green areas in NDVI diagram exhibit the largest extend during 198788, 1990, 1994, and 1998, which were wet years.

Further examination of vegetation conditions and their variability is illustrated by the time-latitude section of NDVI anomalies in Figure 7.1 (b). The anomalies show departures from the long-term monthly means by every month in the growing season. This diagram provides a clear evidence of patterns in the time-series and their relationship to rainfall patterns. The years with favour and severe precipitation conditions are clearly distinguishable through analysis of anomaly distribution across the study region. In 1982, 1984, 1985, 1994, 1995 and 2001, most of the region shows below normal NDVI, with the most severe conditions in 1984-85, 1995 and 2001 covering the whole region with NDVI anomaly values ranging from -0.06 to -0.15 indicating widespread drought conditions. The 1984 drought episode exhibited the largest duration and intensity. The highest impact of this episode has been evident in the northern part, whereas the episodes of 1985, 1995, 1996 and 2001 affected the whole study region. The years 1988, 1997 and 2000 are dominated by normal vegetation conditions, while the years 1987, 1991, 1993 and 1998 are associated with above normal conditions with the highest values of NDVI anomaly during the growing seasons in the north of the region. 


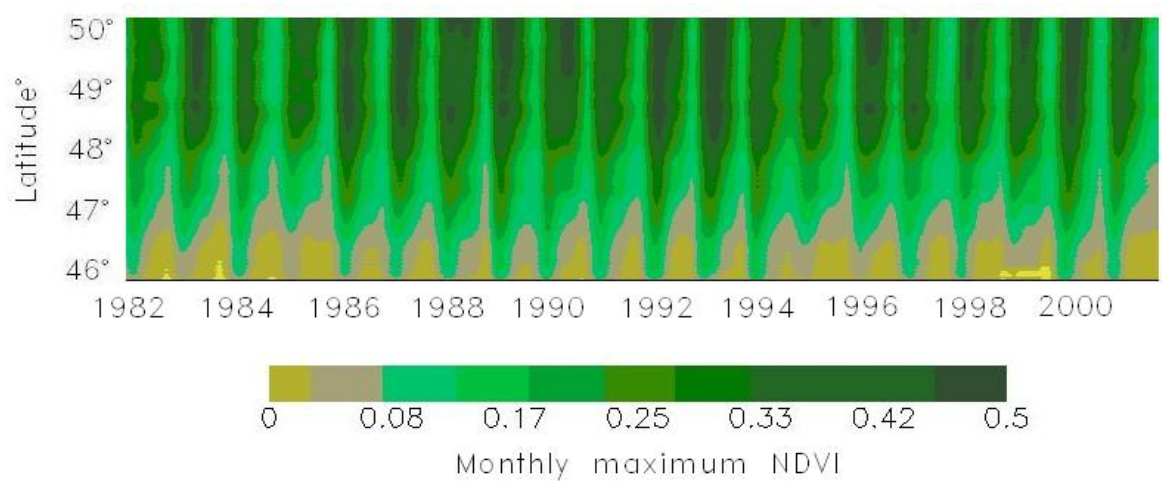

(a)

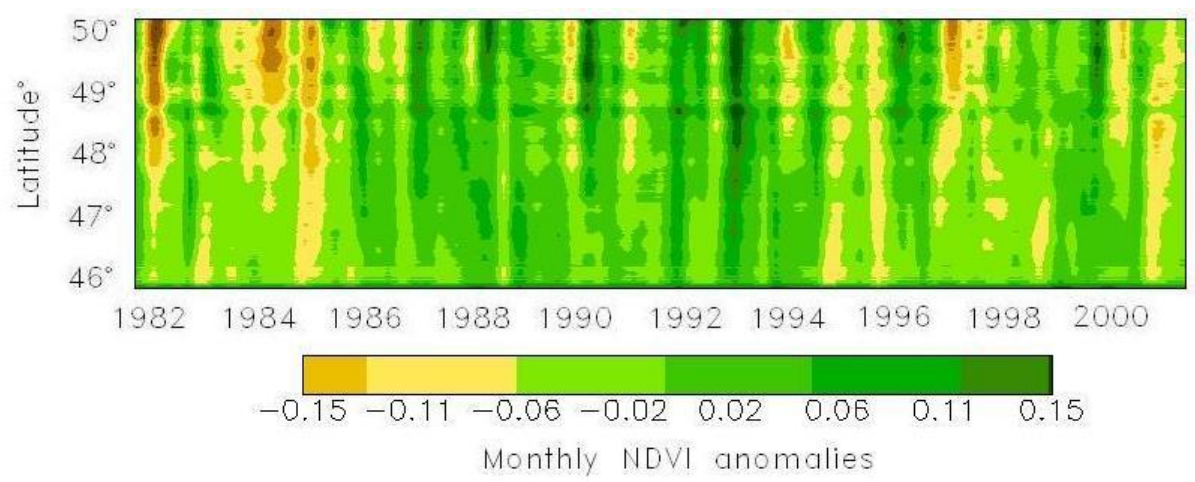

(b)

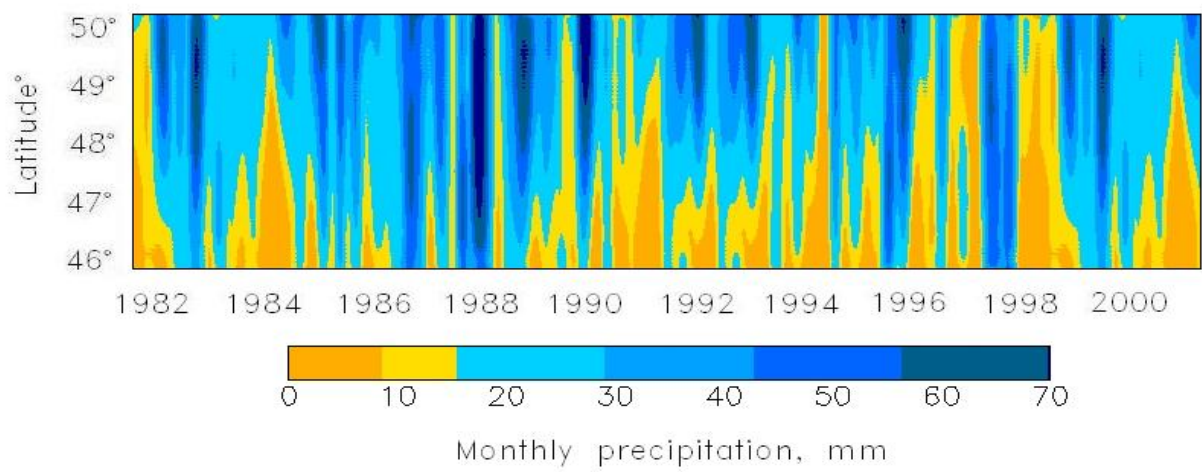

(c)

Figure 7.1. Hovmoller diagram of maximum monthly NDVI throughout 1982-2001 is shown in (a). Panel (b) presents the corresponding NDVI anomalies and panel (c) shows monthly precipitation amounts from 1982 to 2001 .

\subsection{Inter-annual relationship between NDVI and climatic parameters}

\subsubsection{Analysis of spatially averaged NDVI versus precipitation}

For the study region as a whole, correlation between synchronous data of growing season NDVI and precipitation was strong and statistically significant, $r=0.65$. At the level of individual vegetation types, correlations also were strong with value of $0.53,0.57,0.64$ and 0.74, for desert, semi-desert, short grassland and steppe, respectively (Table 7.1). 


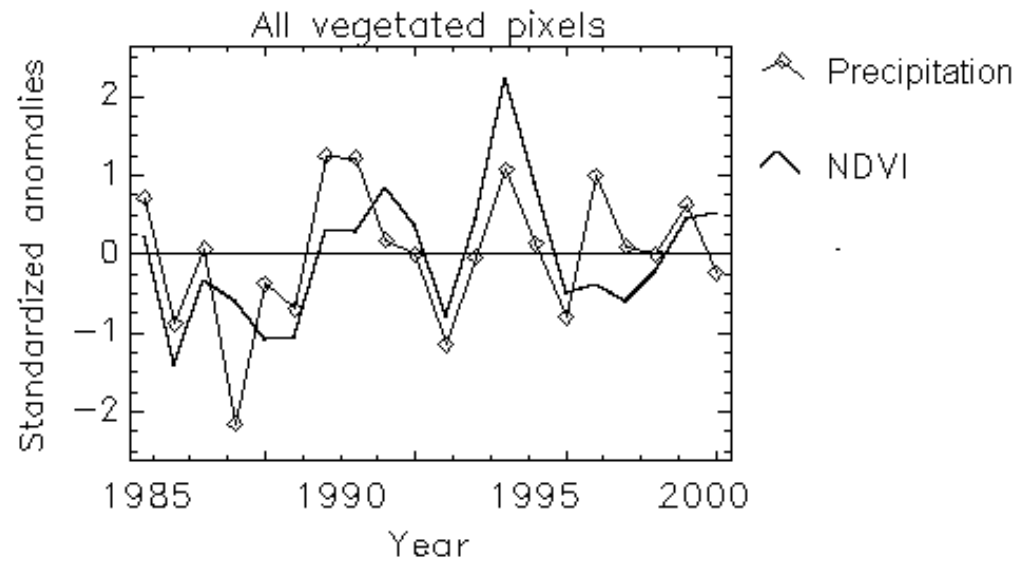

Figure 7.2. Spatially averaged time series of growing season NDVI and growing season precipitation over the period 1985-2001.

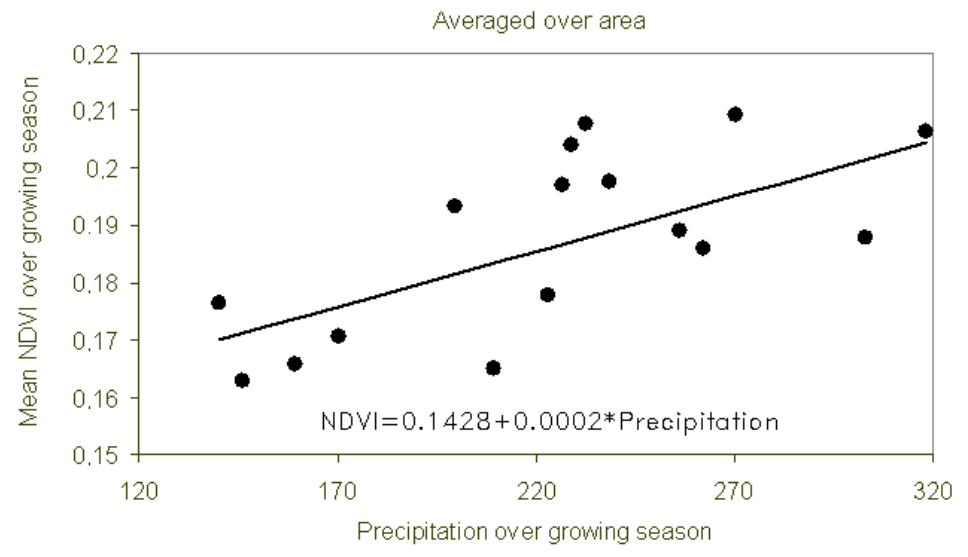

Figure 7.3. Average growing season NDVI as a function of precipitation. The linear regression was computed using values for all vegetated pixels and all years from 1985-2003.

It was reported that NDVI during an average growing season is influenced by precipitation of not only current growing season, but also precipitation in the months preceding the growing season, as well as the growing season of the preceding year (Wang et al., 2003). When correlation of the NDVI was computed with precipitation totalled over a longer time, correlation coefficients should increase. The results indicate that NDVIcorrelation peaked when the time interval reached 2 years for short grassland and for the entire region average. For semi-desert, totalling precipitation over two years brought no any significant change to the coefficient of correlation. Concerning the steppe spatial average, the correlation between NDVI and precipitation peaked by totalling precipitation over three years. 
In order to find decades of the growing season whose rainfall plays the most important role for vegetation growth, inter-annual correlations were also computed with rainfall data totalled throughout 1 to all decades for every analysing year. The results are shown in Figure 7.4. For the area average and steppe, correlation coefficient increased steadily and peaked when the time interval reached 16 decades. After that, the coefficient remained at the same level. For semi-desert, the correlation coefficient increased slowly since the first decade and peaked when the time interval reached 12 decades. Desert vegetation exhibited the shortest time interval of peaking the correlation coefficient, 2 decades. The second maximum of the correlation coefficient was reached when the time interval achieved 12 decades. Analysis of desert data shows that wet conditions at the beginning of the growing season determine the magnitude of the NDVI values. The desert vegetation starts its growth cycle very early in April and reaches the maximum NDVI values in May. Therefore, these spring decades play the most important role both in within-season and inter-annual dynamic. The second peak of correlation coefficient is exhibited when the time interval reaches 12 decades. This peak is associated with a maximum in precipitation in this decade. Interpretation of the desert results exposes that, generally, the first two-three spring decades and the last July decade determine the entire growth cycle of desert vegetation. On the contrary, the growth cycle of steppe vegetation is influenced not only by precipitation of the current growing season, but also by precipitation of the preceding years. Precipitation during the previous growing season influences vegetation conditions of perennial plants and overwintering crops which affect the growth cycle of the current year.

Table 7.1. Inter-annual correlation coefficient between NDVI and precipitation for every land-cover type. Correlation coefficients were computed not only between synchronous time-series but also when precipitation was totalled over the current year and one-two preceding years.

\begin{tabular}{|l|l|l|l|}
\hline \multirow{2}{*}{ Land-cover } & \multicolumn{3}{|l|}{ Totalled period } \\
\cline { 2 - 4 } & 1 year & 2 years & 3 years \\
\hline Steppe grassland & 0.74 & 0.75 & 0.78 \\
\hline Short grassland & 0.64 & 0.67 & 0.63 \\
\hline Semi-desert & 0.57 & 0.58 & 0.45 \\
\hline Desert & 0.53 & 0.50 & 0.48 \\
\hline All vegetated pixels & 0.65 & 0.73 & 0.47 \\
\hline
\end{tabular}




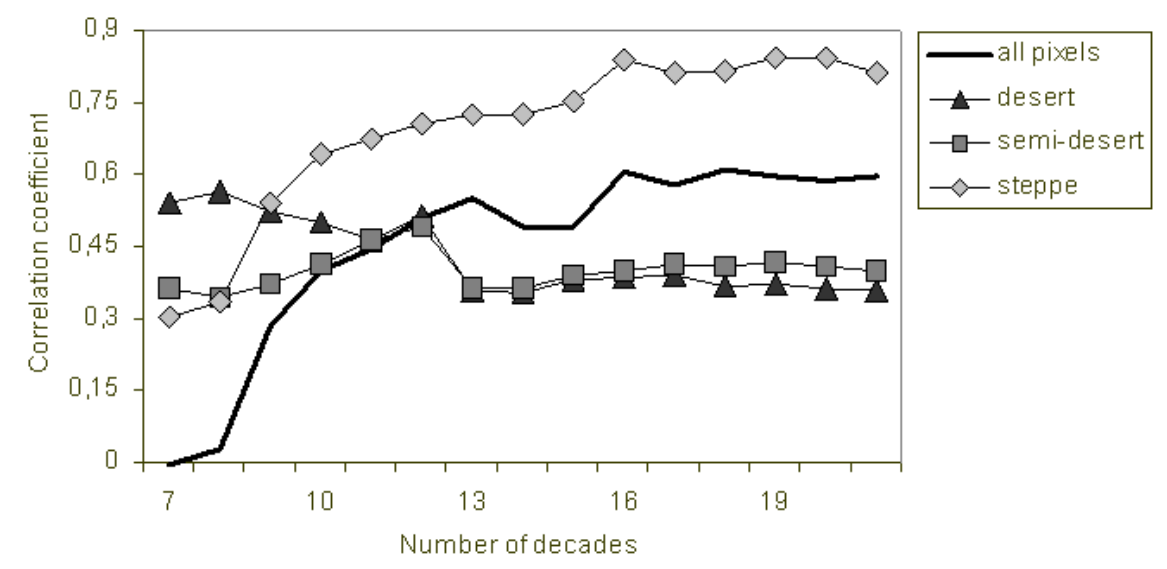

Figure 7.4. Correlation coefficients between NDVI and precipitation as a function of time duration over which precipitation was totalled, with separate curves for desert, semi-desert, short grassland, steppe and the area average. Correlation coefficients were calculated using data for all years, 19852003.

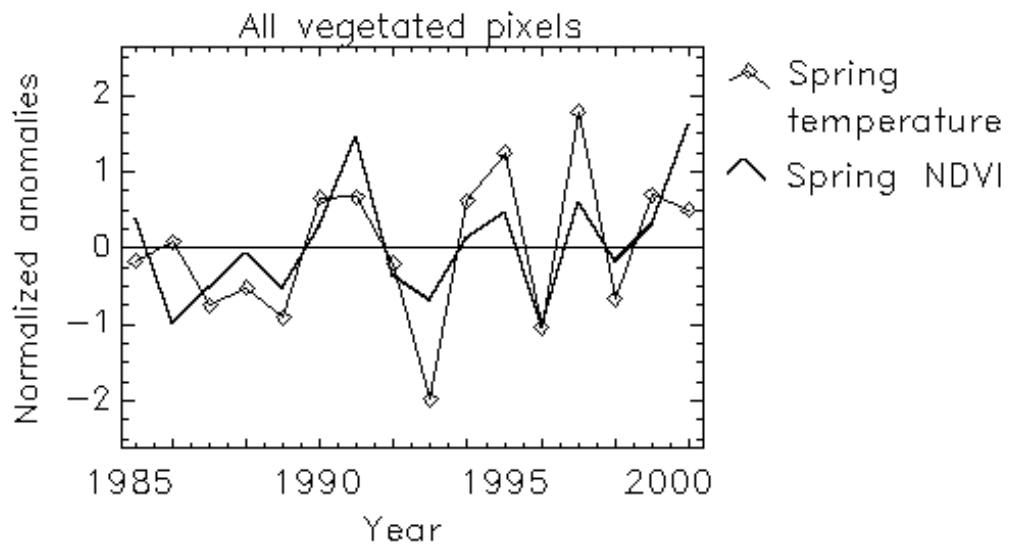

Figure 7.5. Spatially averaged time series of spring NDVI and spring temperature over the period 1985-2001.

\subsubsection{Relationship between spatially averaged NDVI and temperature.}

The NDVI versus temperature inter-annual correlations depicted the degree to which the two parameters are related over the entire study period. We calculated correlations both using annual average growing season values and annual average seasonal values. Inter-annual correlation between growing season NDVI and temperature were very weak and not significant. The same results were obtained for summer and autumn data.

We found very strong association between the time-series of spring NDVI and spring temperature over 16-year period (Figure 7.5). The spring NDVI-temperature correlation was 
significant in all vegetation types even though the magnitude of the correlation coefficient varied by land cover type. The value of the correlation coefficient was $0.67,0.77$, and 0.83 , for desert, semi-desert and steppe, respectively. For the spatial average of the entire area, the coefficient of correlation was higher with a value of 0.84 (Figure 7.6). These results support the results of the other studies suggesting that productivity in northern high latitudes is increasing in response to increased temperatures during spring (Tucker et al., 2001; Xiao et al., 2004). This increase of temperature during spring affects the spring NDVI values in two ways: first, by an earlier start of the growing season; and second, by a more rapid climb of NDVI values during the spring months.

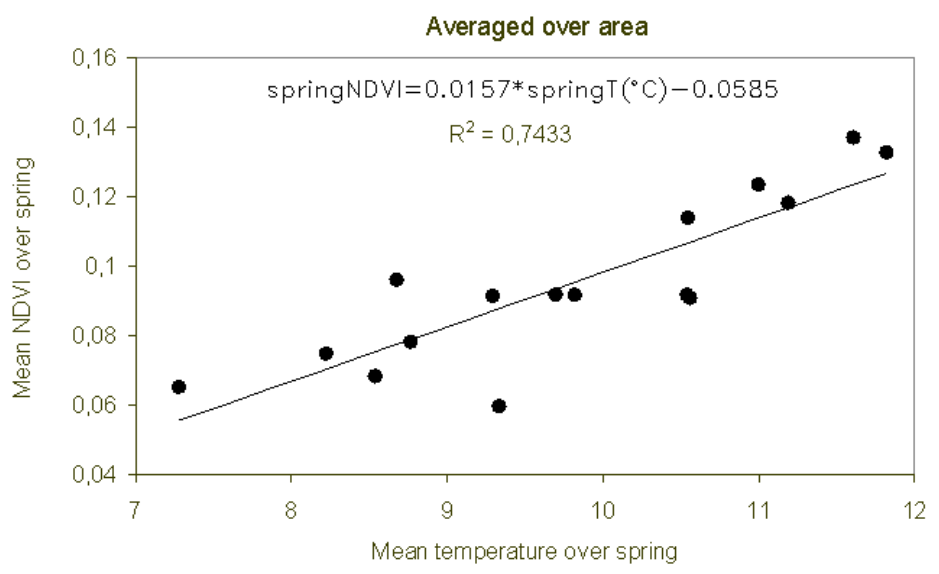

Figure 7.6. Spring NDVI as a function of spring temperature over 1985-2003.

\subsubsection{Spatial patterns in inter-annual NDVI-climate relationship}

Over the entire study region, $45.11 \%$ of the vegetated pixels exhibited significant correlation between the 19-year time-series of growing-season NDVI and that of precipitation (Table 7.2). Most of these pixels are situated in the central and northern part of the study region (Figure 7.7, a). The largest NDVI-precipitation correlation coefficients $(r>0.70)$ occur in northeast and north where steppe grassland dominates the landscapes. Steppe grassland also exhibited the highest percentage of pixels with significant correlation, above $75 \%$ of its area. The percentage of pixels with significant positive correlation decreased from short grassland to semi-desert and to desert, with $61.75 \%, 23.42 \%$ and $11.54 \%$, respectively.

Generally, the spatial patterns of the NDVI-precipitation correlation for summer relations correspond to that of growing season data, but the spatial extension of areas with significant positive correlation coefficients is smaller. Over the entire study region, only about 
$15 \%$ of the vegetated pixels exhibited correlation coefficients with significant values. Very low percentage of pixels with significant correlation is registered in the desert region, only about $1 \%$. This results from an early and very short greening phase of the desert vegetation which occurs at the beginning of the growing season.

For all vegetated pixels, $75.26 \%$ exhibited significant positive NDVI-temperature correlations using data from the spring season. These pixels are mainly distributed in the mid and northernmost portion of the study region (Figure 7.7, b). Regarding for semi-desert, short grassland and steppe grassland, $78 \%, 74.68 \%$, and $79.68 \%$ of all pixels exhibited positive NDVI response to spring temperatures, respectively. Desert vegetation showed a weaker response to spring temperatures. Only $29.06 \%$ of this area demonstrated significant correlation between spring NDVI and spring temperature.

Table 7.2. Number of pixels and percentage (\%) of vegetated pixels exhibiting positive correlation with inter-annual climate change over 1985-2003.

\begin{tabular}{|l|l|l|l|l|l|l|l|}
\hline \multirow{2}{*}{ Land cover } & \multirow{2}{*}{ Pixels } & \multicolumn{2}{|l|}{ NDVI-pre correlation } & \multicolumn{2}{l|}{$\begin{array}{l}\text { NDVI- } \\
\text { temperature }\end{array}$} \\
\cline { 3 - 9 } & & $\begin{array}{l}\text { Growing } \\
\text { season }\end{array}$ & $\%$ & Summer & $\%$ & Spring & $\%$ \\
\hline Desert & 3967 & 458 & 11.53 & 43 & 1.08 & 1153 & 29.06 \\
\hline Demi-desert & 9458 & 2216 & 23.46 & 495 & 5.23 & 7377 & 77.99 \\
\hline Short grassland & 9101 & 5619 & 61.74 & 2013 & 22.11 & 6797 & 74.68 \\
\hline Steppe grassland & 3586 & 2703 & 75.37 & 1304 & 36.36 & 2499 & 79.68 \\
\hline & & & & & & & \\
\hline All pixels & 26112 & 10996 & 42.11 & 3855 & 14.76 & 17826 & 75.26 \\
\hline
\end{tabular}

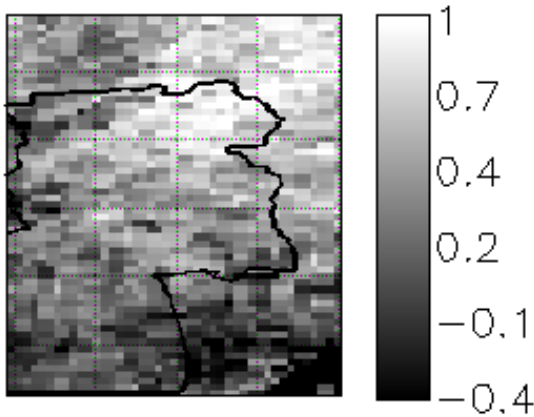

(a)

Figure 7.7. Spatial patterns in inter-annual NDVI-climate relationship: (a) correlation coefficient between growing season NDVI and growing season precipitation, and (b) correlation coefficient between spring NDVI and spring temperature. 


\subsection{Quantifying temporal variability in vegetation conditions}

\subsubsection{Standard deviation of NDVI}

One of the simplest methods to characterize a time-series of data and to estimate variability of these data through the time is to calculate the standard deviation. The standard deviation of NDVI values displays the scope of values calculated for individual years from the mean value having been calculated for the whole period. Low $N D V I_{\text {stdev }}$ indicates a good density of values of individual years around the mean value. On the contrary, high value of $N D V I_{\text {stdev }}$ is associated with a wide scattering of the year values from the mean value. This means a higher variability of NDVI over the time.

We calculated standard deviation of spatially averaged NDVI for each vegetation class and for every pixel in the study region. The results are presented in Table 7.3 and Figure 7.8. For spatially averaged $N D V I_{\text {stdev }}$, the desert vegetation displays the lowest values for the growing season, spring and autumn seasons. The highest values of $N D V I_{\text {stdev }}$ are associated with the steppe vegetation class, 0.029, 0.030, and 0.109, for spring, summer, and autumn seasons, accordingly.

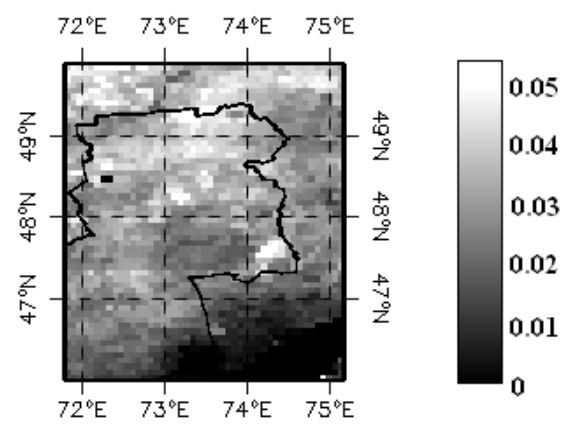

Figure 7.8. Spatial patterns of standard deviation of growing season NDVI throughout the study period 1985-2000.

For the whole growing season, the semi-desert vegetation displays the highest value, 0.026 , whereas this vegetation class shows the lowest values in summer.

Generally, the spatial patterns of $N D V I_{\text {stdev }}$ correspond to that of NDVI values. Lower values of $N D V I_{\text {stdev }}$ are associated with the southern, south-eastern and eastern sections of the study area. These areas are occupied by the desert shrubby and grass vegetation and demonstrate the lowest NDVI values. The central and northern part of the map display higher 
$N D V I_{\text {stdev }}$ values. In these regions, the steppe vegetation with dominance of grass and forbs species are presented. There are a number of places in the map with exceptionally high values of $N D V I_{\text {stdev }}$. These places are parts of flood plains of valleys of perennial rivers and beds of temporary water streams (known as wadies in arid zone of Africa and in the Near East). The exceptionally high $N D V I_{\text {stdev }}$ values of these places may be explained through a high variability of hydrological regime in the study region. The runoff varies very significantly from year to year, especially in the temporary water streams, and often changes its flow borders. Therefore, the conditions for flood plain vegetation are widely heterogeneous from one year to another. This is remarkable for very high values of $N D V I_{\text {stdev }}$.

Although $N D V I_{\text {stdev }}$ is a good quantity to estimate the variability of the temporal data over the time period, it is very inconvenient for comparing NDVI variability between the vegetation classes. The value of $N D V I_{\text {stdev }}$ is strongly dependent on NDVI value, which is individual by each vegetation class or every pixel. This makes it impossible to compare $N D V I_{\text {stdev }}$. Therefore, coefficient of variation, $N D V I_{c v}$, was used for comparing variability of NDVI between the vegetation classes and individual pixels. The $N D V I_{c v}$ will be discussed in the following section.

Table 7.3. Standard deviation of spatially averaged NDVI values for different vegetation types through 1985-2001.

\begin{tabular}{|l|l|l|l|l|}
\hline \multirow{2}{*}{ Variable/season } & \multicolumn{4}{|c|}{ Standard deviation of NDVI } \\
\cline { 2 - 5 } & Spring & Summer & Autumn & Growing season \\
\hline Steppe & 0.029 & 0.030 & 0.109 & 0.024 \\
\hline Semi-desert & 0.028 & 0.017 & 0.078 & 0.026 \\
\hline Desert & 0.023 & 0.021 & 0.031 & 0.011 \\
\hline Area-average & 0.026 & 0.022 & 0.071 & 0.021 \\
\hline
\end{tabular}

\subsubsection{Variance of NDVI values over the study period}

In order to investigate a variability of vegetation activity through the entire study period, we calculated the coefficient of variation for the spatially averaged seasonal and growing season NDVI values over the period 1985-2000, as well as these values for every pixel in the study area. Coefficient of variation is commonly calculated to compare the 
amounts of variation (in \% from the mean value) in different sets of data and enables to evaluate a robustness of vegetation to variability in climatic predictors. Thus, the coefficient of variation have been calculated for inter-annual time-series of growing season values may indicate the response of vegetation cover to inter-annual climate variability. The lower the variation coefficient of NDVI is, the lesser is the sensitivity of vegetation cover to climatic variations.

The results indicate a pattern in temporal variability of NDVI across the study region (Figure 7.9). The NDVI variation coefficients have the highest values in the southern, western and central parts. Desert and semi-desert vegetation communities dominate these sections of the region. They reveal a dominance of the shrubby vegetation with a lower presence of grass species. The northern region of the study area is characterized by the lowest values of the variation coefficient. The vegetation cover of this region is dominated by forbs and grass species.

The spatially averaged NDVI values derived for various vegetation types show similar results (Table 7.4). Desert vegetation zone is characterized by the highest values of variation coefficient in all separate seasons as well as in the whole growing season, 30.5, 45.0, 21.3 and 28.5 , accordingly. The lowest values are associated with the steppe zone. Here, the variation coefficients amount to 14.7 for spring, 14.9 for summer, 18.4 for autumn, and 13.3 for the growing season. Vegetation cover of steppe and semi-desert displays a higher variability during the autumn months. On the contrary, the highest values of variation coefficient for desert zone are calculated for the summer season.

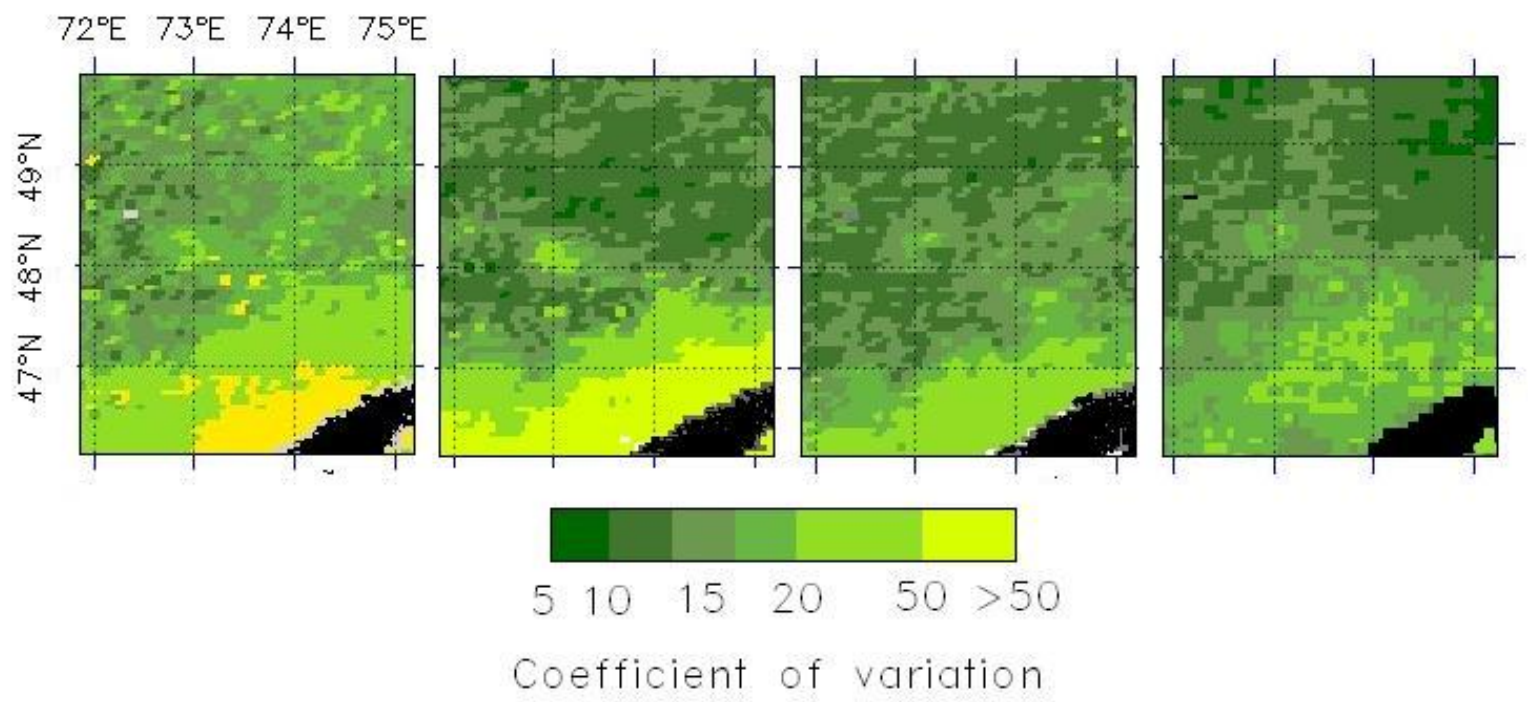

Figure 7.9. Coefficient of variation in seasonal NDVI during the period 1982-2001 calculated for spring, summer, autumn and for the growing season (from left to right). 
Table 7.4 Variation coefficient of spatially averaged NDVI values over the period 1985-2001.

\begin{tabular}{|l|l|l|l|l|}
\hline \multirow{2}{*}{ Variable/Season } & \multicolumn{4}{|c|}{ Variation coefficient of NDVI } \\
\cline { 2 - 5 } & Spring & Summer & Autumn & Growing season \\
\hline Steppe & 14.7 & 14.9 & 18.4 & 13.3 \\
\hline Semi-desert & 19.1 & 18.5 & 21.6 & 16.8 \\
\hline Desert & 30.5 & 45.0 & 21.3 & 28.5 \\
\hline Area average & 23.4 & 31.5 & 20.1 & 18.5 \\
\hline
\end{tabular}

\subsubsection{Dependence of $N D V I_{c v}$ on the relief}

Figure 7.10 visualizes the relationship between the variation coefficient of $N D V I$ during the period 1982-2001 and the altitude of relief. Note that the variation coefficient decreases with increasing the altitude. The variation coefficient in the desert and semi-desert zone, where the altitude varies between 340 and 500 meter, shows higher values than in the zone of low hills and mountains, where the altitudes are 700-1200 meter.

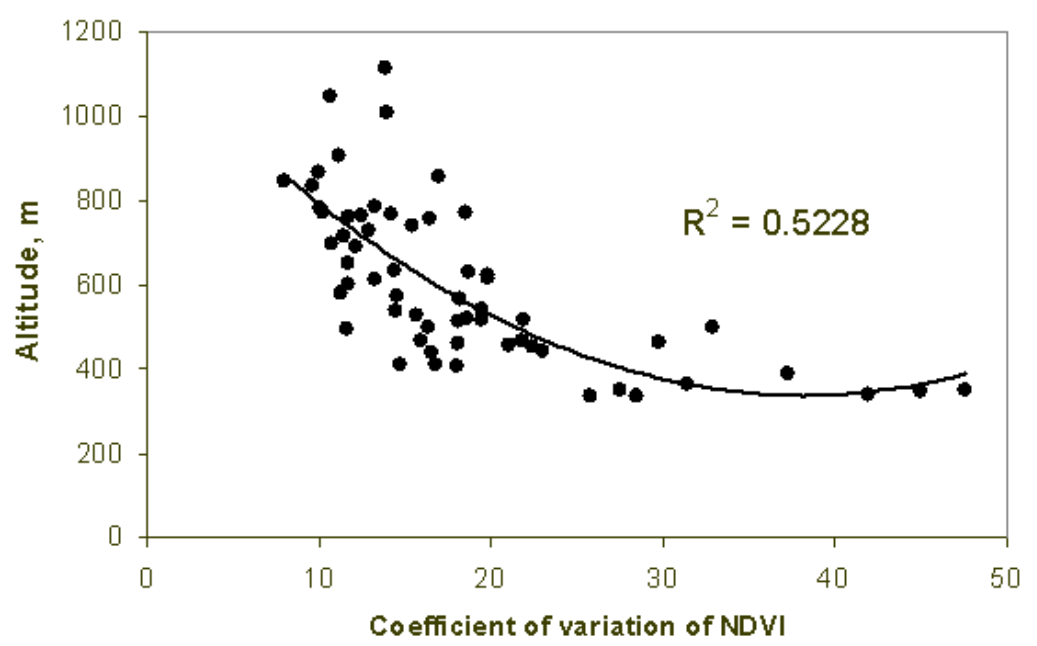

Figure 7.10. Influence of altitude on coefficient of variation of NDVI in the study area. It is to note that variability of NDVI increases with a decrease of altitude.

\subsubsection{Relationship between NDVI variability and climatic factors}

In order to evaluate how much the variability of climatic factors determines the variability of vegetation activity, we modelled relationships between coefficients of variation in NDVI, precipitation and temperature. The relationship was modelled separately for each 
season and for the whole growing season. Firstly, the coefficient of variation for rainfall and temperature, $P_{c v}$ and $T_{c v}$, for every climate station from the study area was computed. Secondly, coefficient of variation in NDVI associated with every climate station was computed. For that, a $3 * 3$ pixel rectangle surrounding a station, including an area of $72 \mathrm{~km}^{2}$, was extracted from AVHRR NDVI time-series and used for calculations. These rectangles delineate the analysis areas for each climate station. Next, we plotted $N D V I_{c v}$ against $P_{c v}$ or $T_{c v}$ and calculated corresponding regression equations. For better visualisation, we wrote the names of the individual meteorological stations on the plots. These scatter plots are presented in Figure 7.11.

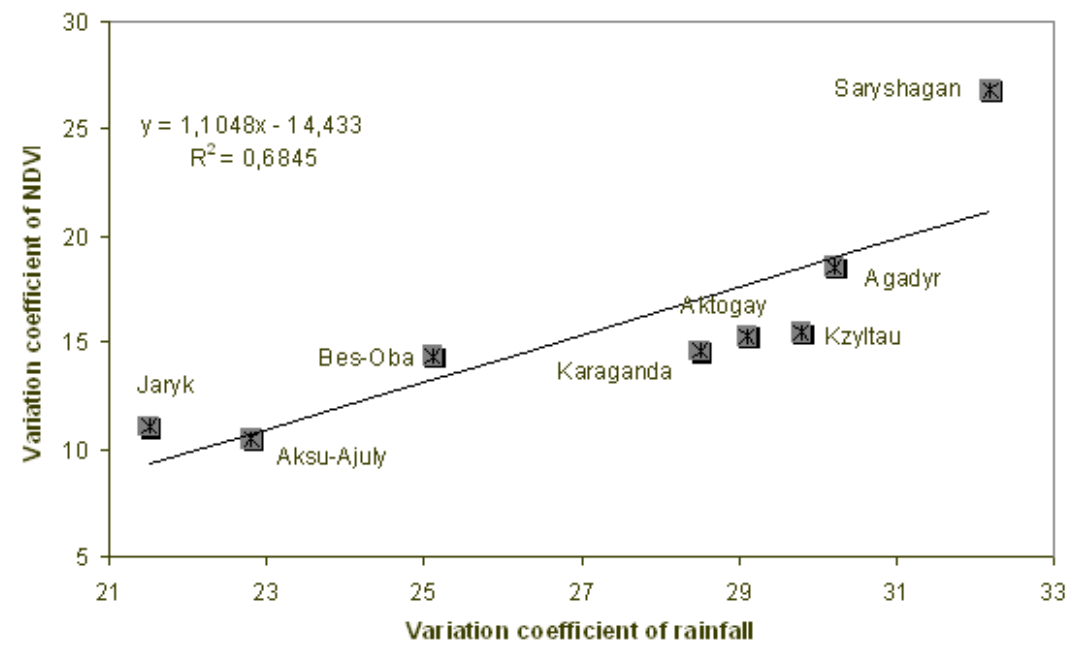

(a)

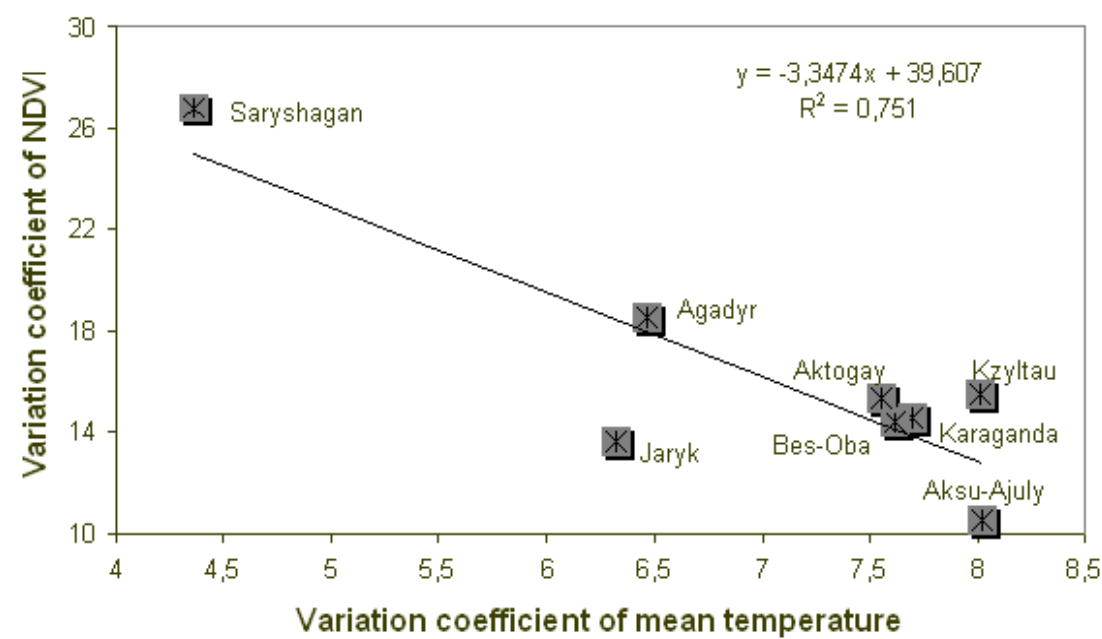

(b) 


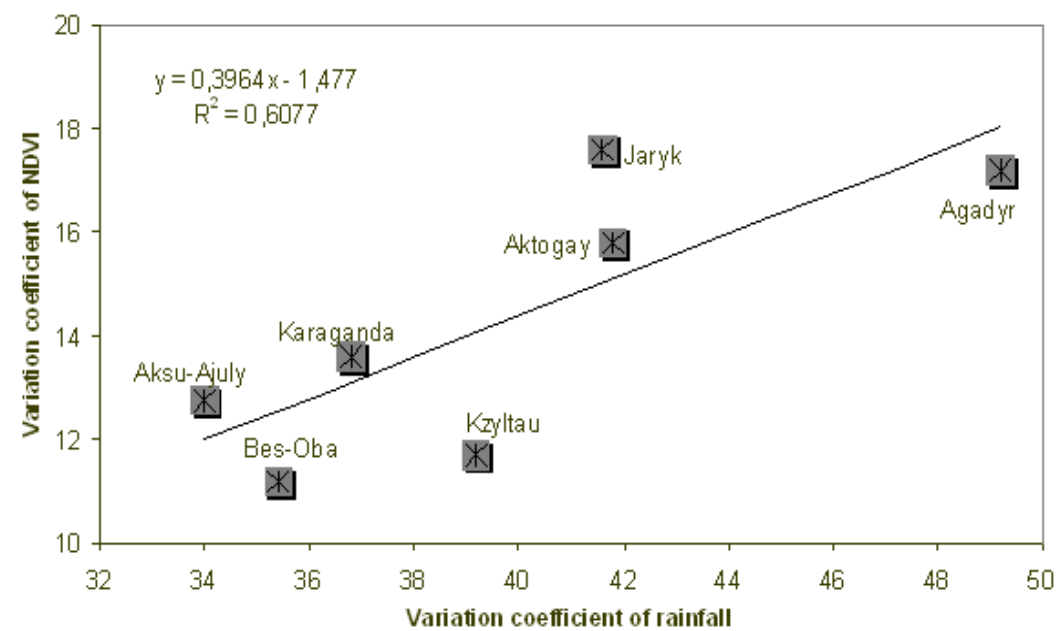

(c)

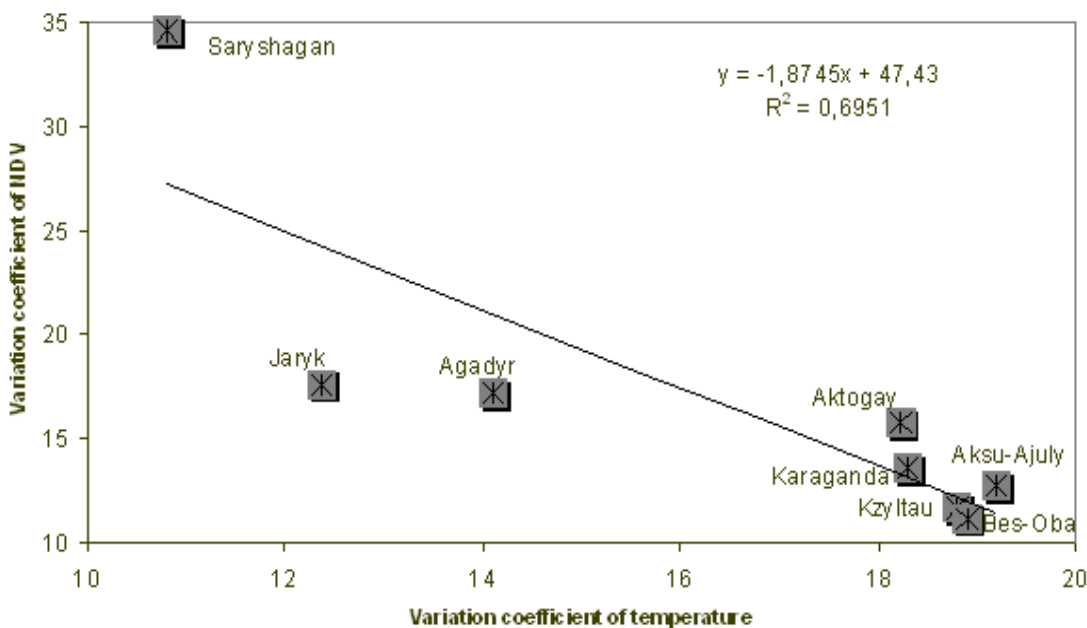

(d)

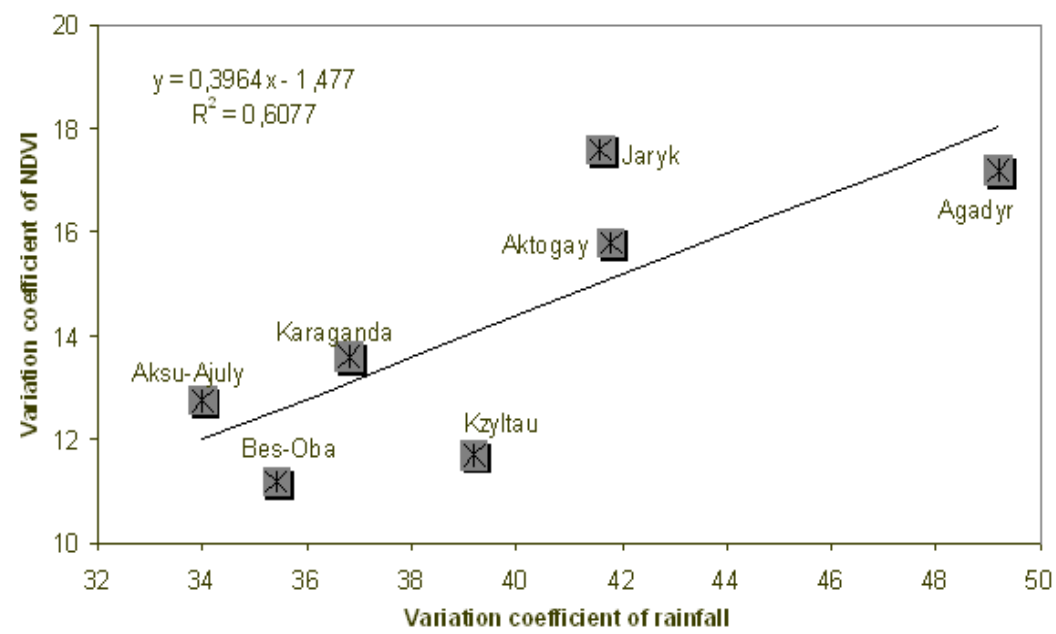

(e) 


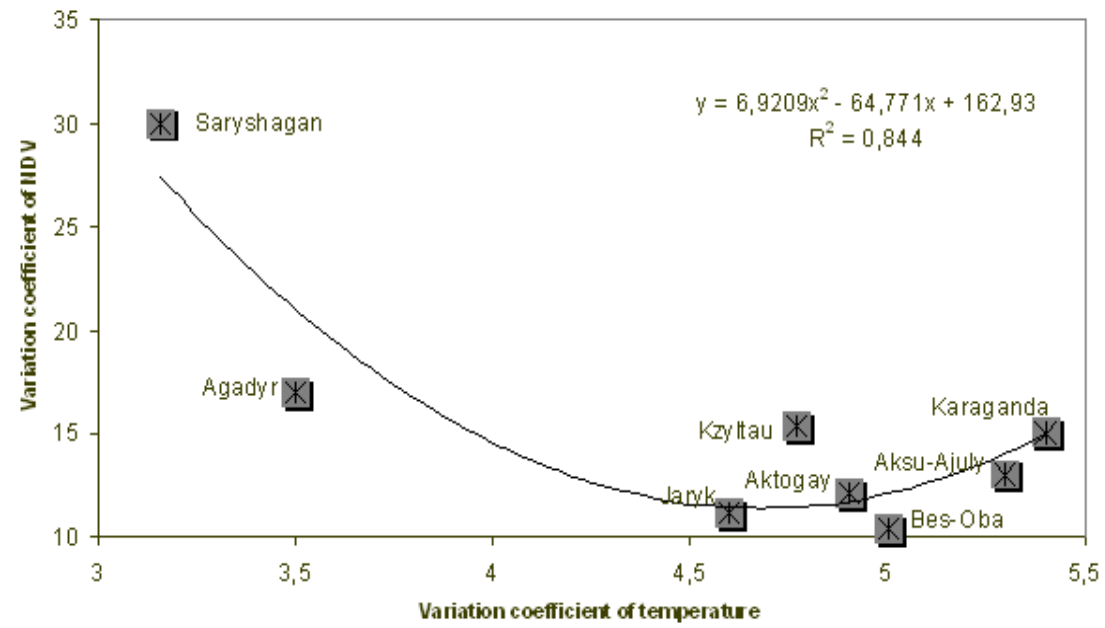

(f)

Figure 7.11. Relationships between $N D V I_{c v}$ and $P_{c v}, N D V I_{c v}$ and $T_{c v}$ for the whole growing season (panels a and b), for spring (panels $\mathrm{c}$ and $\mathrm{d}$ ), and for summer (panel e and f).

The results display significant positive correlative relationships between $N D V I_{c v}$ and $P_{c v}$ for every season and for the period April-October as a whole. The coefficient of determination, $R^{2}$, shows statistically reliable high values, $0.60,0.79$, and 0.68 , for spring, summer, and for the whole growing season, respectively. There was no significant relationship between $N D V I_{c v}$ and $P_{c v}$ for autumn season. It is remarkable, that the summer relationship is stronger than the relationship during other seasons. The higher inter-seasonal variations of precipitation amounts in summer may predict the higher $R^{2}$ for regression equation.

The results derived for relationships between $N D V I_{c v}$ and variation coefficients of temperature are more complicated. Thus, the $N D V I_{c v}$ for spring and for the growing season display a strong negative linear relationship to the variation coefficient of temperature, while there is no linear relationship for summer. In summer, some meteorological stations correlate negative (Saryshagan and Agadyr), whereas the others correlate positive with $N D V I_{c v}$. There was no significant relationship between $N D V I_{c v}$ and $T_{c v}$ for autumn season $\left(R^{2}=0.04\right)$. The strength of the relationship increases from spring, to growing season, and to summer, with values of $R^{2}$ amount to $0.69,0.75$, and 0.84 , accordingly.

If the $R^{2}$ values from the derived regression equations are analysed, one may draw remarkable conclusion. Firstly, the influence of temperature changeability on that of vegetation cover conditions is higher than the influence of rainfall changeability. This 
phenomenon was observed both for inter-seasonal and inter-annual relationships. Secondly, the highest prediction of $N D V I_{c v}$ by variability of climatic determinants was associated with the summer months. This seems to be logically for the relationship between rainfall and NDVI, because of the higher variability of rainfall in summer and the higher dependence of vegetation patterns on moisture patterns. Regarding for temperature, we can not explain why the relatively low variability of temperature in summer (comparing it with spring, autumn or growing season) displays the highest prediction of $N D V I_{c v}$.

In order to examine, whether the analysed relationships are to be observed across the region with other points which are not associated with the climate stations, we sampled 20 pixels randomly distributed over the region and computed a corresponding regression equation. Figure 7.12 presents the obtained result. In term of the strength on relationship, the derived equation is very close to that computed for the data of the climate stations. The result indicates a high co-variation of NDVI and precipitation over the space during the study period, $r=0.84$ (over $66 \%$ of common variance).

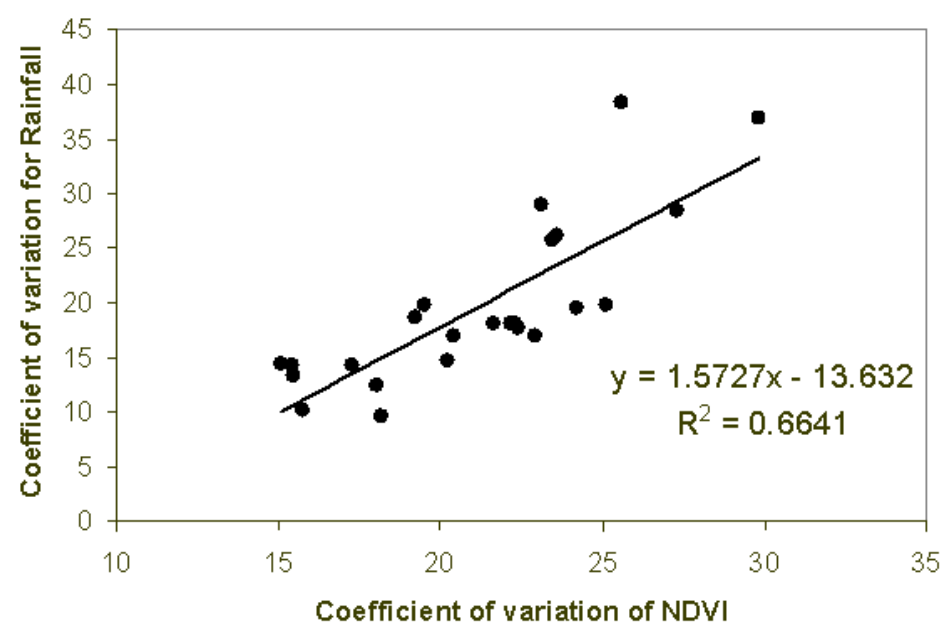

Figure 7.12. Regression between coefficients of variation of growing season NDVI and that of growing season rainfall.

\subsection{Discussion and conclusion}

This chapter examines inter-annual characteristics of NOAA AVHRR NDVI and their relationship with analogous series of climate variables for the years 1985-2003 in the study region. Strong temporal correspondence between NDVI-precipitation, and NDVI-temperature were observed. The strength of NDVI-climate associations depends on land-cover type but there are variations within each land cover class at the pixel scale. The correlation between 
NDVI and temperature was found to be higher than the correlation between NDVI and rainfall both for spatial averages of land cover types and at the pixel scale. The result is indicative of the available energy and heat on plant growth during the growing season.

The results indicated that the correlations between precipitation and NDVI are positive and exhibits a clear spatial pattern. The response of vegetation to the precipitation variability increases in order from desert to semi-desert, to short grassland and to grassland. Inter-annual analyses with growing season data demonstrated that NDVI of grasslands showed a stronger correlation with precipitation when the precipitation was totalled over the current year and 2-3 preceding years. These results are consistent with the observation of the relations between NDVI and precipitation in other dry regions (Wang et al., 2003; Yang et al., 1997; Li et al., 2002; Li et al., 2004).

Temperature exposed itself as the main predictor factor for inter-seasonal vegetation dynamics. For $75 \%$ of the entire study area, spring NDVI were correlated with spring temperatures. The results from spring support the suggestion about a high increase in earlyseason vegetation activity and its strong prediction by temperature established in the recent literature (Tucker et al, 2001; Zhou et al, 2001; Xiao \& Moody, 2004). There were no correlations between NDVI and temperature for any others seasons or for the entire growing season.

Temporal variability in NDVI values over the period 1985-2003 has been studied using simple techniques of descriptive statistic. The results show high variability of climatic predictors and NDVI in the study region. Coefficient of variations (CV) for growing season NDVI varied between 10-40\%. So did also variation coefficient for precipitation. The magnitude of inter-annual variations depends on vegetation type and relief. The highest CV was observed in desert and semi-desert vegetation zones, whereas the lowest is associated with steppe grassland. The terrain plays an important role in the inter-annual variability; the variability decreased with increasing altitude. In the plain areas, the coefficient of variation of NDVI and that of summed rainfall amounts for growing season is about $25-40 \%$. In the low hills and mountainous areas the coefficient of variation reached only 10-15\%. This study considered high variability of dryland ecosystem to be explained by variability of climate. The results presented high association between CV for NDVI and CV for precipitation. 


\section{Chapter 8}

\section{Spatial response of vegetation cover to climatic factors}

\subsection{Growing season relationship between NDVI and precipitation}

\subsubsection{NDVI-rainfall correlation coefficients}

Figures 5.1. provides a visual comparison of rainfall and NDVI averaged over the growing season and the entire study period. Even by the visual comparison one can support a significant association between spatial patterns of NDVI and precipitation. Calculations of correlation coefficient proved this assumption. We calculated the global spatial correlation between these both variables for every year within the period 1985-2000. Our calculations resulted in rainfall-NDVI correlations ranging from 0.45 to 0.91 with a mean value for all years of 0.77 . The consistently high correlations indicate a strong association between rainfall and NDVI averaged over growing season, although there is some significant inter-annual variation in the magnitude of the correlation coefficients (Figure 8.1).
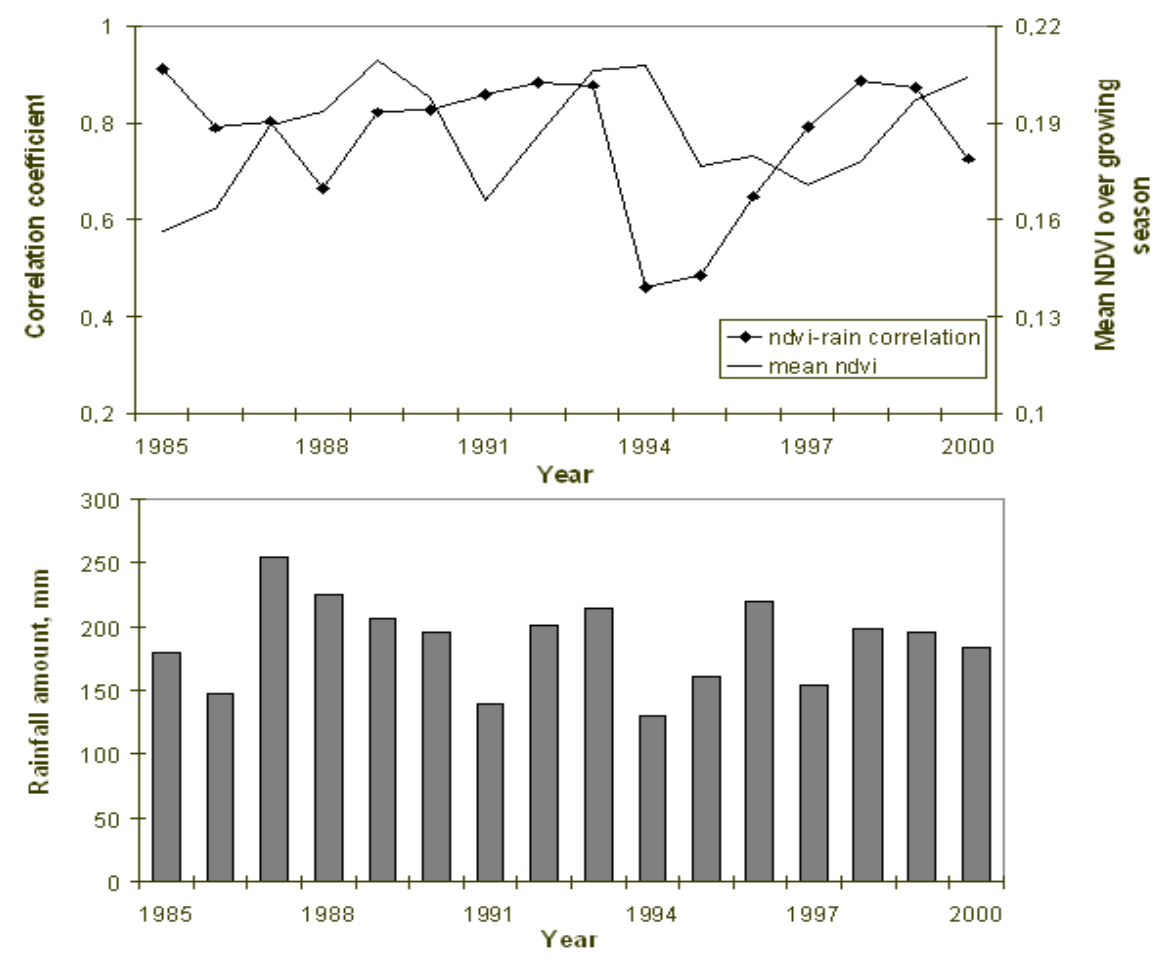

Figure 8.1. Dynamic of correlation coefficient between NDVI and precipitation versus NDVI value (upper panel). Evolution of total precipitation amount during 1985-2000 (lower panel). 
In order to estimate strength of influence of summer rainfall on spatial patterns of NDVI, we calculated correlation coefficients between rainfall amounts totalled throughout the summer months and mean NDVI averaged for summer. The strength of association between these two variables is marginally lower then that calculated for the entire growing season. Correlation coefficients varied from 0.30 to 0.79 , with a mean value of 0.76 .

Higher correlation coefficients were associated with precipitation totalled over the current year and a number of previous years. Precipitation summed over 2-4 years overall enlarges the correlation coefficients (Figure 8.2). Only for the years 1988 and 1989 a little decrease of correlation coefficient in comparison to that calculated for the corresponding single year precipitation is to note. It is remarkable that both these years had precipitation values over the long time average of the study period: 1987 with $40 \%$ and 1988 with $32 \%$ over the mean value.

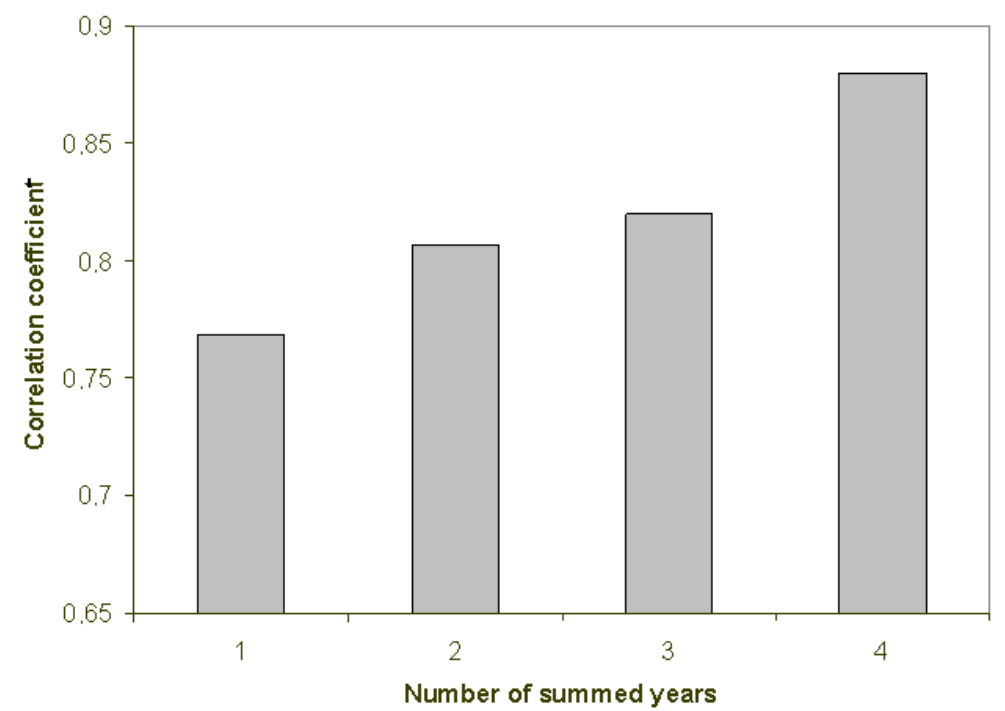

Figure 8.2. Correlation coefficients as a function of number of years over which precipitation is summed.

\subsubsection{NDVI-rainfall relationships by vegetation type}

In order to investigate the influence of vegetation type on the NDVI-rainfall relationship, a statistical analysis was performed on the three vegetation types presented in the study region. Figure 8.3 shows the linear regressions averaged over all years between rainfall and NDVI for the land cover classes. With regard to vegetation type, the results indicate that correlation coefficient values increase from desert to semi-desert and to steppe, with mean 
values of $0.60,0.78$, and 0.84 , respectively. The components of linear regression equation presented in Figure 8.3 vary in a wide range: there are notable differences in regression slope and intercept between the vegetation types. All these facts support a different response of vegetation to precipitation observed by various land cover categories. This result agrees with results of other research works from dry regions reporting about influence of NDVI-rainfall relationships by land cover type (Nicholson \& Farrar, 1994; Li et al., 2002; Wang et al., 2001; Li et al., 2004, Foody, 2004).

One can note that the NDVI-rainfall correlation is strongly influenced by the value of vegetation fraction of land cover. The bigger this value, the higher the correlation coefficient. Desert zone with a vegetation fraction between $0.05-0.25$ demonstrates a correlation coefficient of 0.60 , while dry steppe vegetation (vegetation fraction between 0.4-0.65) shows the highest correlation coefficient of 0.84 .

Although water is the most important limiting factor in plant growth for desert zone, the weaker correlation between NDVI and rainfall obtained for desert vegetation can not surprise. In desert areas, supplement of rainfall water in the soils for plant growth is highly depended on the local infiltration ability of soils. Sparse vegetation cover and soil crust strongly influence distribution of fallen precipitation water and allow to flow it far away from the place of its fall. This results in a lower NDVI-rainfall correlation coefficient. As the vegetation cover increases, plant growth and over ground biomass begins to depend more on rainfall. This is remarkable in the dry steppe land cover category. In steppe areas, where vegetation cover is dense, there is no flash precipitation events and overland runoff. Rain water keeps supplying at the place of precipitation. Only areas with degrading grass cover create conditions for sheet erosion and overland runoff. These areas show a weaker dependence of vegetation growth on rainfall. The variation of the correlation coefficient seems to be best explained by the diversity that exists between the different vegetation types associated with each ecosystem. 


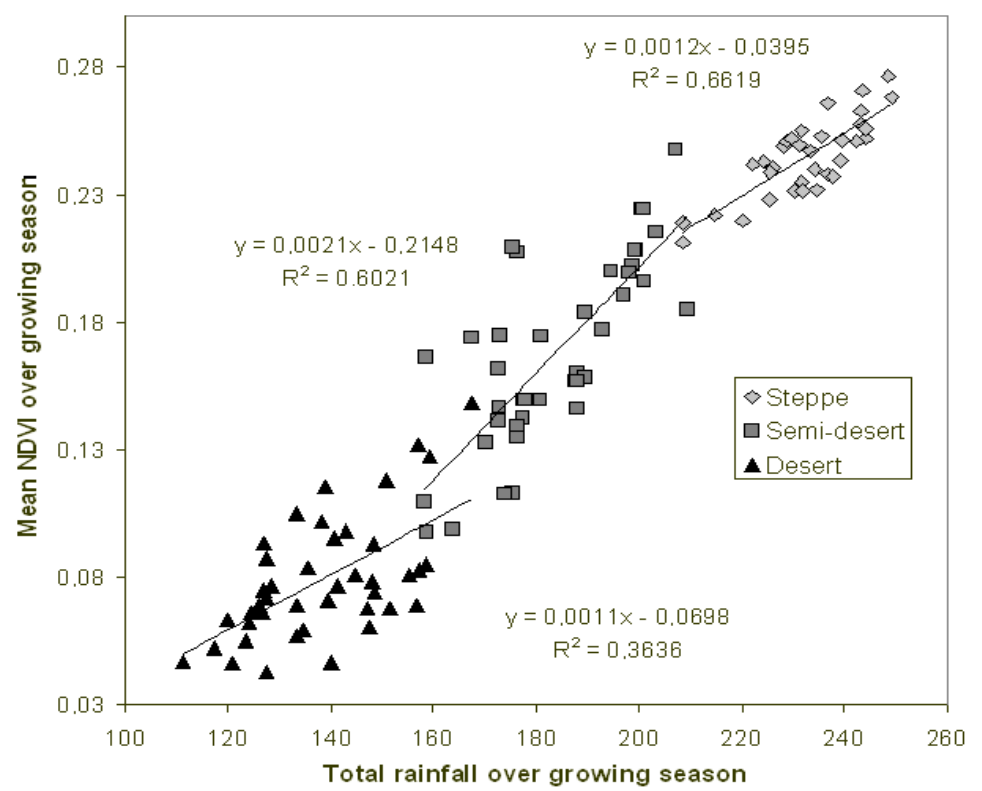

Figure 8.3 Linear regression between long-time averages of growing season rainfall and growing season NDVI for the main vegetation types.

\subsubsection{Influence of growing season rainfall on NDVI-rainfall correlation}

We found a significant relationship between correlation coefficients and growing season rainfall for both the entire study area and vegetation types level. In order to present this fact we plotted the NDVI-rainfall correlation coefficients (Figure 8.4) against the rainfall amounts for each of the study years. There is a notable association between the spatial correlation coefficient and the rainfall amount for the same year. The coefficients of correlation significantly increased in years with high rainfall and decreased in years with low rainfall. At the scale of vegetation types, we also found a strong positive relation between these both variables in desert and steppe, in semi-desert there was no statistically significant relation (data not shown).

The scatter plot demonstrates that the dependence between correlation coefficient and rainfall is not linear. Correlation coefficient for 1987 and 1988 were lower than they have been expected. That means an existence of a "saturation limit" above that the response of vegetation to rainfall drops. Obviously, in the study region, this limit is associated with 240$250 \mathrm{~mm}$ rainfall. The results agree with the research results obtained by Nicholson \& Farrar (1994). They reported to have found the "saturation" limit at 700-800 mm annual precipitation for the Botswana region in Africa. Li et al. (2002) investigated a relationship between NDVI-rainfall correlation and annual rainfall for China and localized the "saturation" limit at 450-500 $\mathrm{mm}$. 


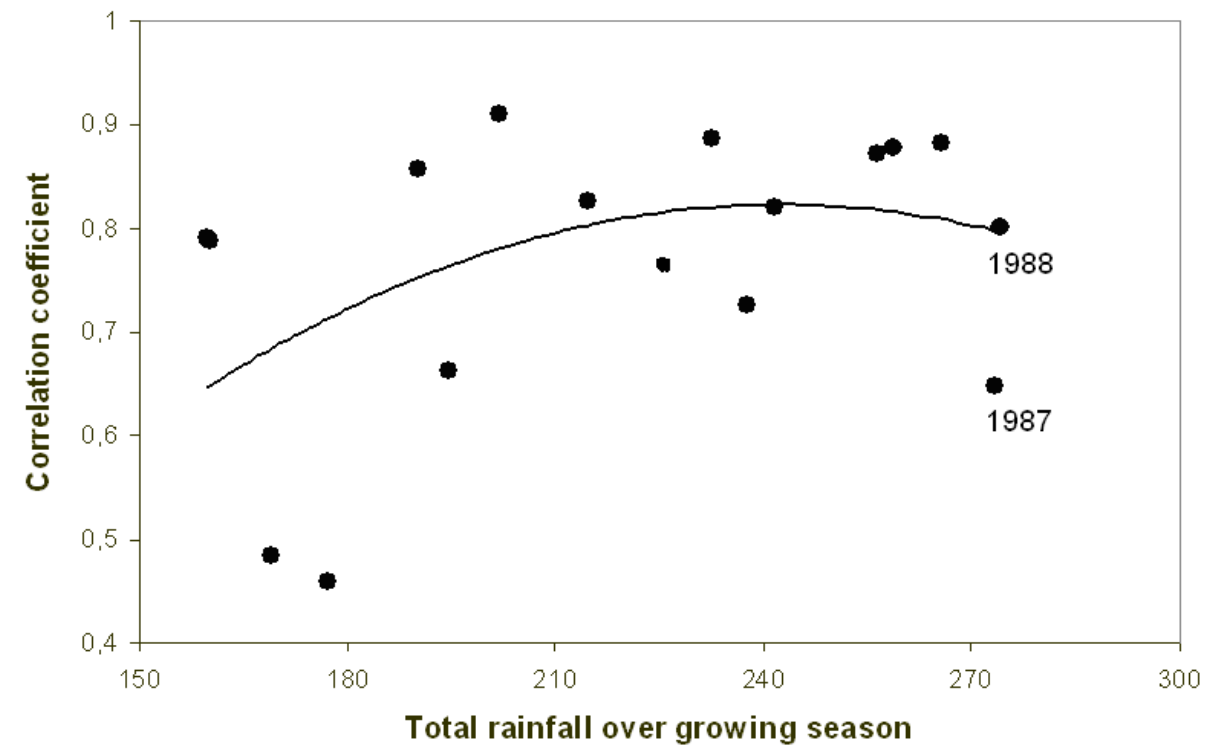

Figure 8.4 Scatter plot of NDVI-rainfall correlation coefficients and growing season rainfall amounts averaged over the whole study area.

\subsubsection{Spatial patterns in NDVI anomalies and their relationship to rainfall}

The spatial NDVI anomaly patterns for the study region are shown in Figure 8.5. These series of images show the patterns in standardised anomaly of growing season NDVI for every year from the period 1982-2003. During 1982-1985, most of the region shows below normal vegetation conditions with anomalies ranging between -1 and -3 roughly extending across the entire region showing the prevalence of drought conditions across the region. In 1982 and 1984, most of the pronounced negative anomalies were concentrated in the northern part of the region. Opposite to these years, in 1983, negative anomalies were mostly concentrated in the southern part. In 1985, the year with the worst vegetation conditions from the entire study period, negative anomalies occupied the whole region with exception of a few pixels. This year is associated with the lowest precipitation value during 1982-2003. In contrast to the drought years, 1986-1993 exhibited a pattern of above normal NDVI showing the prevalence of wet conditions. The maps of 1988, 1992 and 1993 demonstrate particularly high positive anomalies of NDVI with maximum values of standardised deviation over 2-3. In the term of precipitation amount, 1988 was the wettest year during 1982-2003. The pattern was a little poorer in 1990-1991 because of slightly drought conditions in the southern part of the region. The period after 1993 was also characterized by prevailing dry conditions which occupied in 1995-1996, 1999 mostly in the south, in 1997 in the north and during 1998 in the middle part of the study region. 
Accordingly to rainfall amount, the year 1997 should be associated with conditions close to normal across the most part of the region with exception of the eastern border of the Shetsky district, still the deviations in NDVI show that an above normal precipitation fell only in the south, whereas the north-east of the region was dry. 2000 and 2002 were nearly normal years while 2001 and 2003 can be associated with below normal precipitation conditions.

These series of NDVI anomalies show the spatial coherence and temporal persistence with rainfall conditions (Figure 8.6). The magnitudes of negative/positive NDVI departures during the years with severe or favourite conditions agree with rainfall departures patterns. Thus, in term of precipitation conditions the period 1982-1985 was associated with pervasive drought for most part of the region and the year 1985 was the driest year during the period 1982-2003. The patterns in NDVI anomalies showed evidence of the severe conditions. Pronounced high anomalies in NDVI were observed across the region during 1987, 1988 and 1993 and they agree with above normal patterns in the precipitation amount in these years. High positive anomalies of precipitation with values above 2 were observed for the largest part of the region. 

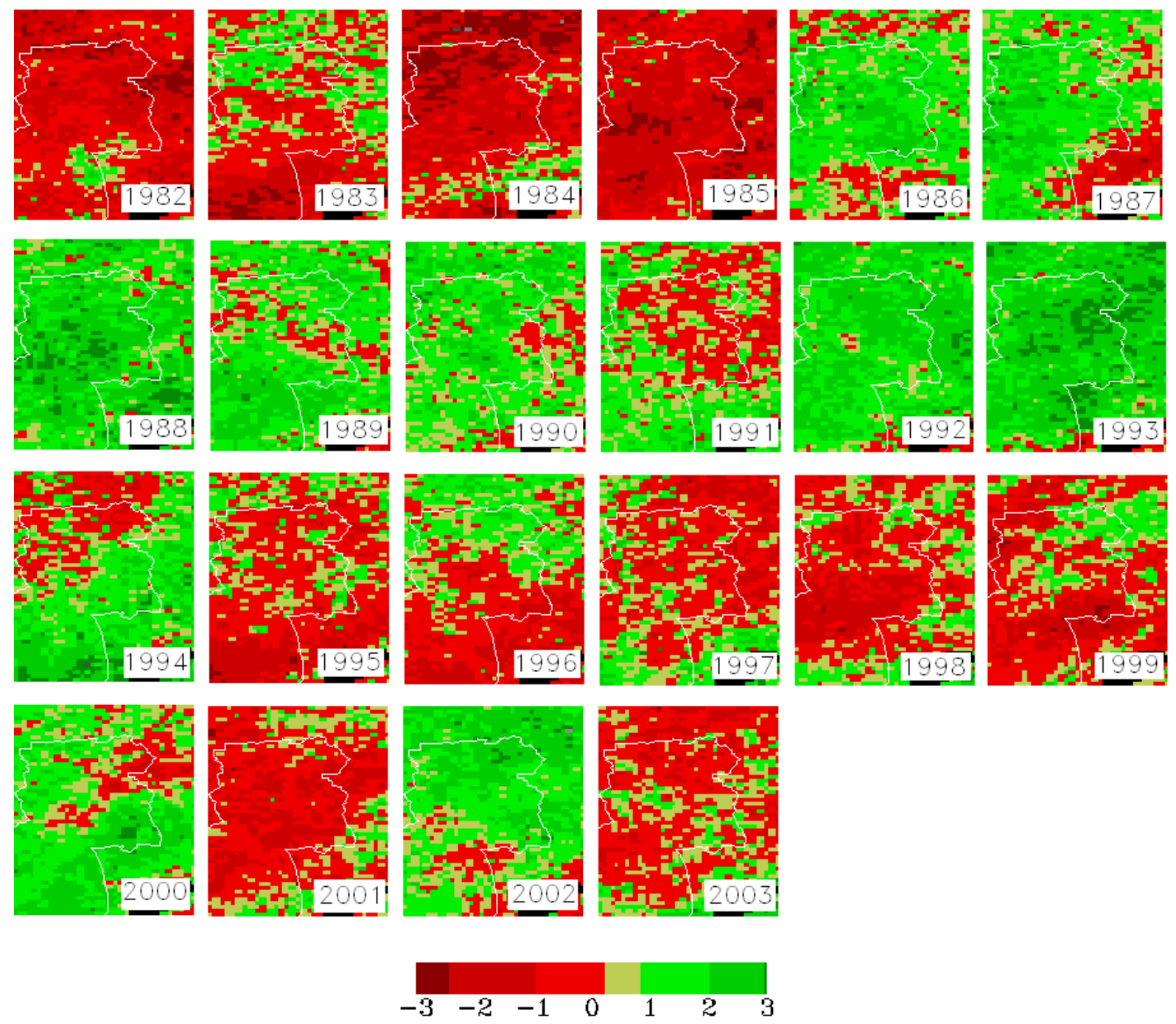

Standardised anomalies

Figure 8.5. Evolution of vegetation conditions in the study region during the period 1982-2003:

growing season NDVI anomaly patterns. The spatial patterns show two strong drought episodes during 1982-85 and 1995-1996 as well drought conditions in 19982001. 


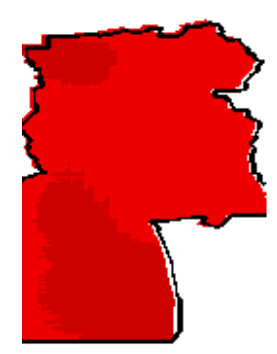

1982

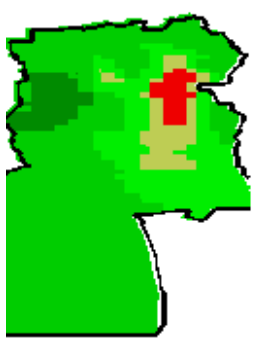

1988

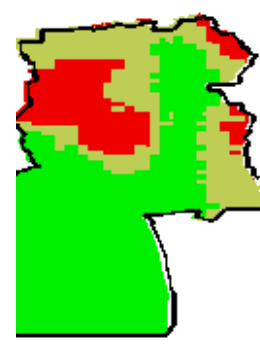

1994

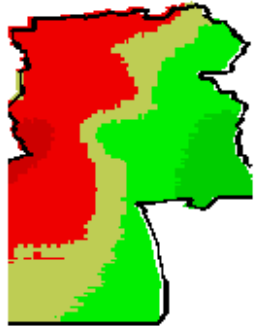

1983

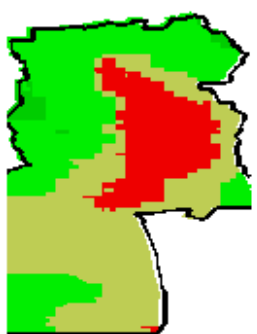

1989

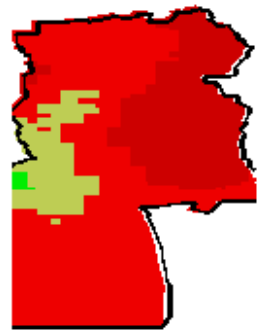

1995

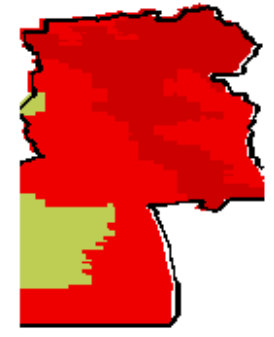

1984

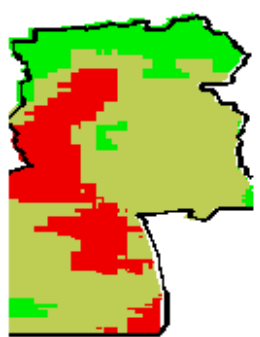

1990

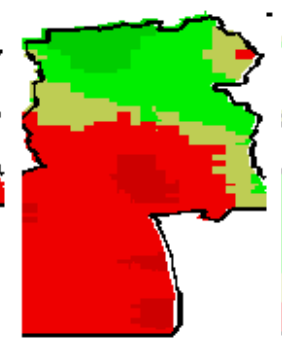

1996

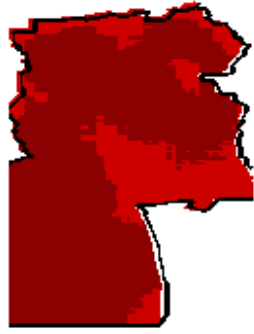

1985

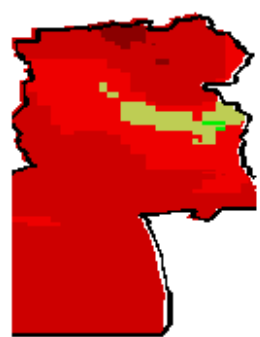

1991

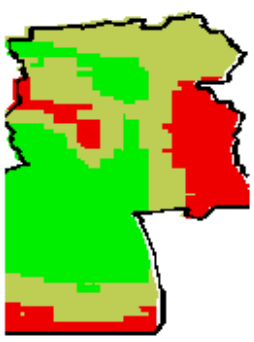

1997

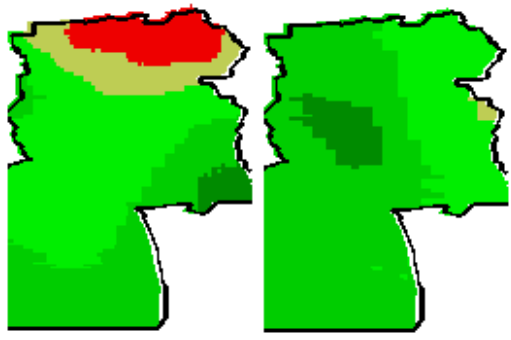

1986

1987

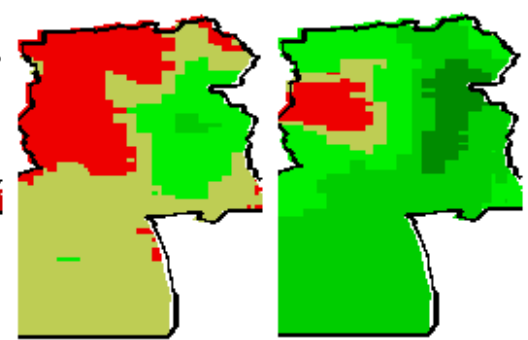

1992

1993

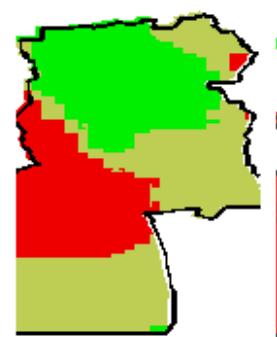

1998

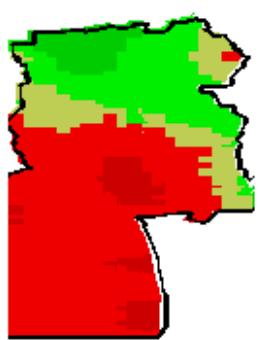

1999

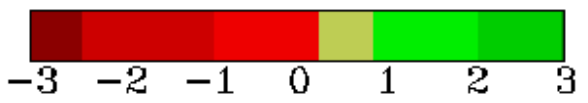

Standardised anomalies

Figure 8.6. Standardised anomalies in precipitation amount for the Shetsky district during the period 1982-1999. By comparison of magnitudes and spatial patterns of the precipitation anomalies with NDVI anomalies shown in Figure 8.5 a clear correspondence between the two variables is evident.

\subsection{Within-season relations between NDVI and rainfall}

\subsubsection{Spatial patterns in intra-annual dynamic of NDVI and climate parameters}

Figure 8.7 and 8.8 describe the intra-annual patterns of monthly NDVI and rainfall. The green-up begins in April, when NDVI jumps from zero to greater than 0.08 in the southern region, and from zero to greater than 0.12-0.16 in the north. In May, the rapid growth of NDVI values continued across the entire region driven by a high precipitation amounts overall in the region. In the north, NDVI reaches values above 0.20 and rises further, while in the south, NDVI reaches its maximum peak values. In June, growing higher 
temperatures in combination with a precipitation decreased over the all part of the region strongly influence vegetation conditions, and cause drop of NDVI values in the south. Steppe vegetation in the north reaches its maximum NDVI values and peaks. July is characterized by higher precipitation amounts throughout the region. Even though precipitation amount is high, the vegetation conditions are growing poorer than in June because of maximum values of air temperature. NDVI values in the south drop to minimum and remain at this level during the rest period of the growing season. The NDVI values decrease also in the mid part of the region where semi-desert vegetation dominates. In the North, NDVI remains high values and drops significantly only in August. The rest of the growing season is characterized by permanent low NDVI values in the south and constant slow drop of NDVI values in the middle part and in the north of the region. September is characterized by dry conditions and low NDVI values across the region. On the contrary, in October, precipitation amount lightly increases in the northern part and is high in the desert zone in the south. These conditions lead to different vegetation development in these areas. In the north, NDVI were continuing to drop because of a rapid decrease in air temperature. But in the northern part of the desert zone, where temperature was yet sufficiently high, NDVI values were lightly increasing.

The analysis of patterns in NDVI and precipitation in the study region proved a strong dependence of vegetation intra-annual cycle on climatic factors. Both precipitation and temperature seem to correlate strongly with NDVI dynamic. On the one hand, the temperature is the most important predicting factor at the beginning and the end of the growing season because plants can grow only under definite temperature conditions, namely, when temperature rises over zero. On the other hand, when the temperature continues to grow and reaches its maximum values in June-July, it stresses the vegetation and restrains the plant growth. Probably, during these months, precipitation begins to play the main role in determining vegetation development. At the end of the growing season the temperature rapidly drops across the entire region. In the areas where it does not drop below the $5^{\circ} \mathrm{C}$ limit the vegetation can rehabilitate for a short time again. This was observed in the desert zone. 

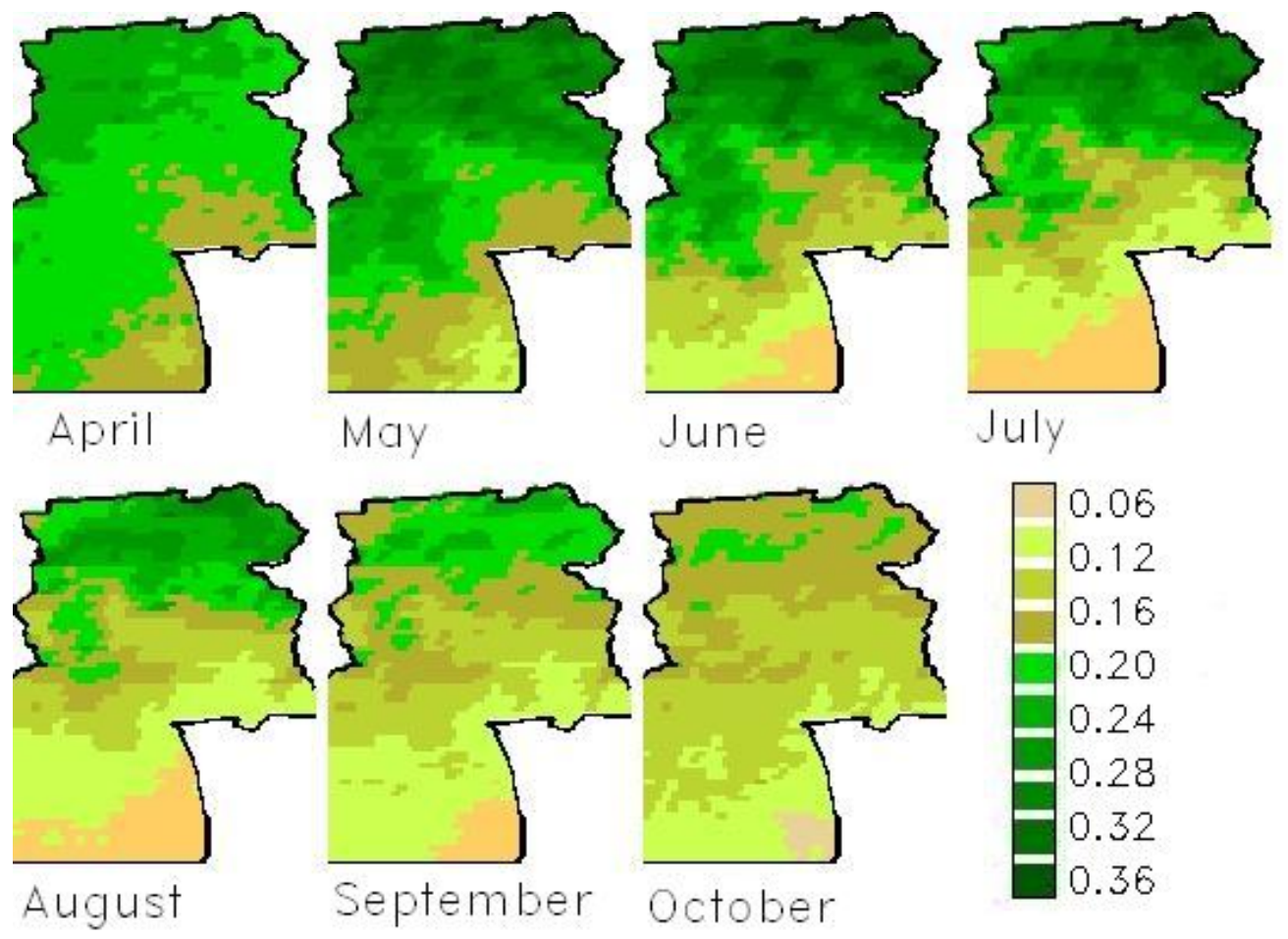

Figure 8.7. Maps of mean monthly composite NDVI for the territory of the Shetsky district.
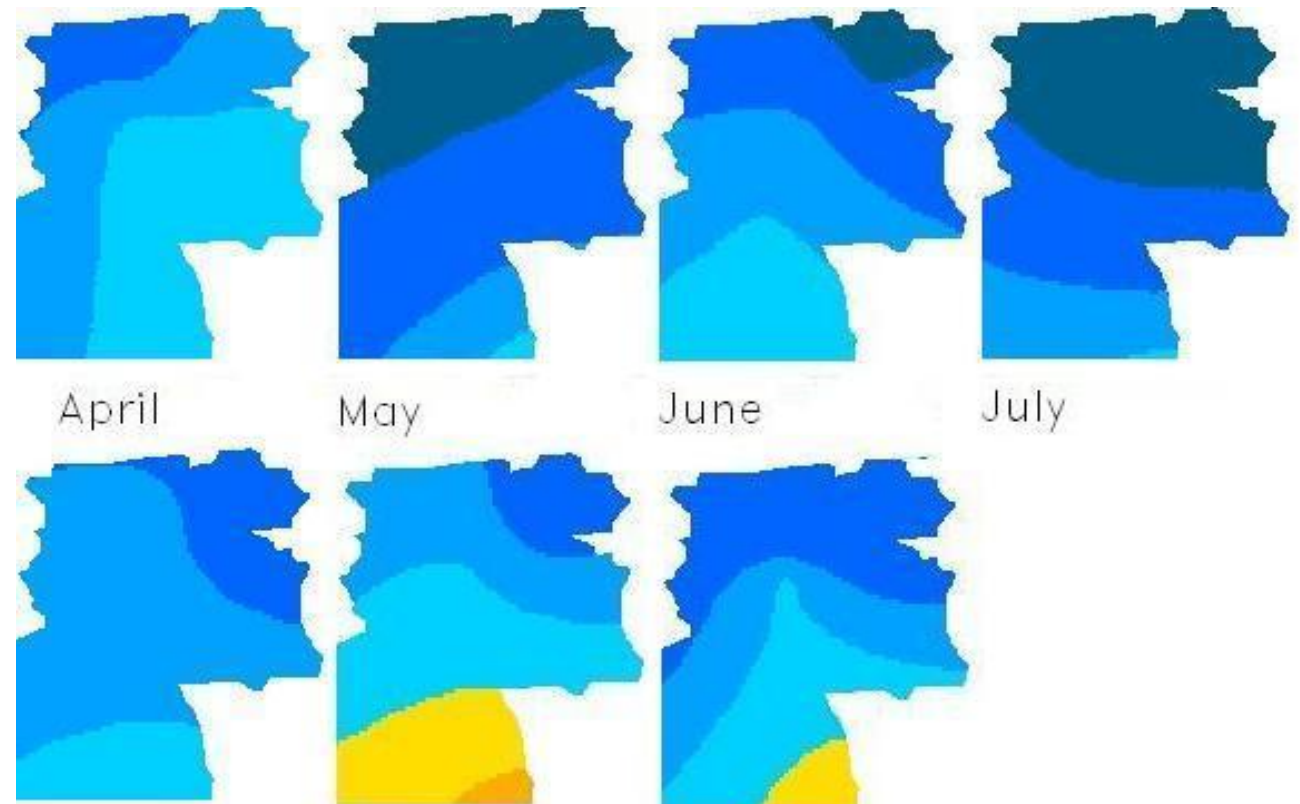

May

June

July
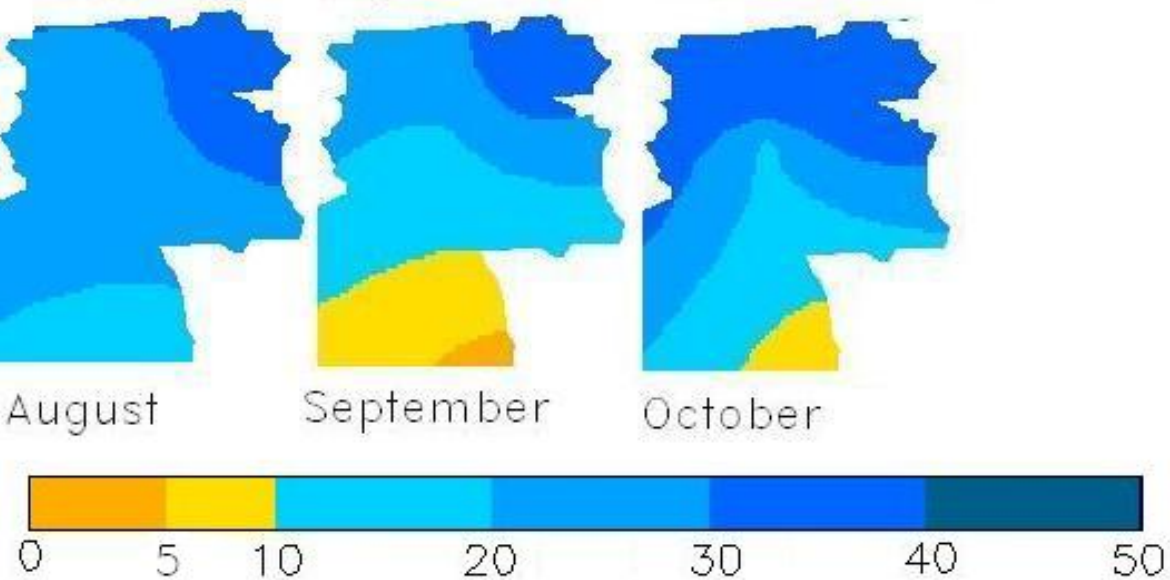

Figure 8.8. Maps of averaged monthly precipitation amount $(\mathrm{mm})$ for the territory of the Shetsky district. 


\subsubsection{Within-season NDVI-rainfall correlation coefficients}

Based on analyses of correlation coefficients values, we found that spatial relations between NDVI and precipitation were different at every decade of the growing season (Figures 8.9 and 8.10). Correlation coefficients were generally small in April, increased rapidly in May when the NDVI increased, and achieved in the third decade their maximum. Generally, correlation coefficients slowly decreased during June and after that increased in July, fluctuating only slightly and then decreased in August and September. In the first and second decades of October correlation coefficients again reached their maximum values followed by an abrupt decrease in the third decade.

In a wet year 1988, correlation coefficients permanently increased from April to first decade of September and then dropped off during last five decades of growing season. On the contrary, in 1995, a dry year, correlation coefficients reached the maximum values in first and second decades of June and then decreased (with high oscillations) until October. Either in a wet year or in dry year correlation coefficients rashly dropped off in last decade of growing season and had at this time the autumn minimum values.

Time lags (one, two, three, four or five decade period lags) between rainfall and NDVI values had only a weak influence on decadal correlation coefficients in years with dry and normal rainfall values and a higher influence in wet years (data not shown). Generally, correlation coefficients were worse with time lags of two or three decades in May, September and October, while they improved in June, July and August.

Remarkable is the dropping of values of correlation coefficient during the summer months. This may be interpreted through a phase of dormancy or semi-dormancy for vegetation. During the summer months, a water deficit reached its peak in mid to late summer when temperature shows the highest values and precipitation is low or missing. The potential evapo-transpiration is very high and the perennial vegetation makes all possible to reduce the transpiration rates. The ephemeral vegetation abundant in semi-desert and desert had been finishing its life cycle is not present in the vegetation cover at this time. Due to absent of ephemeral species and dormancy of perennial species, the vegetation fraction of land cover significantly decreases in summer months. The decrease of vegetation density is particularly notable in desert and semi-desert areas. The vegetation cover with lower density exhibits a weaker correlation with rainfall patterns. 

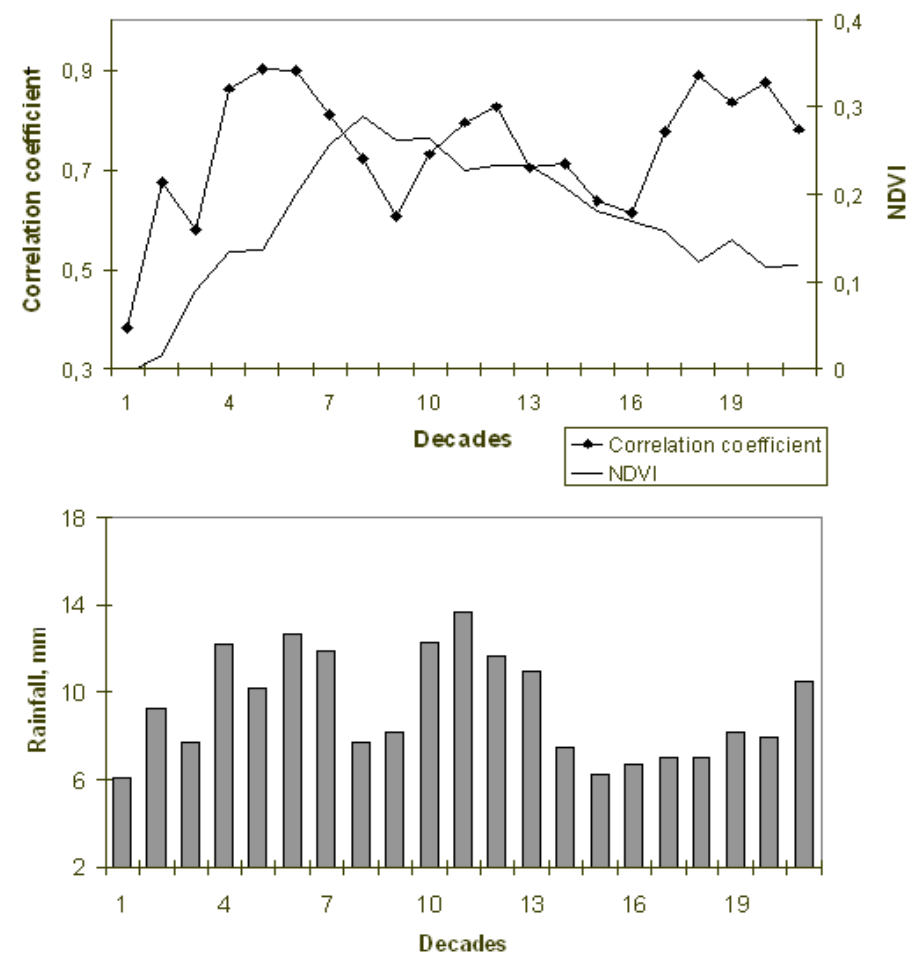

Figure 8.9. NDVI values, correlation coefficients between spatial distribution of 10-day NDVI and precipitation (upper diagram) and 10-day rainfall (lower diagram). The data are averaged over the whole study period.
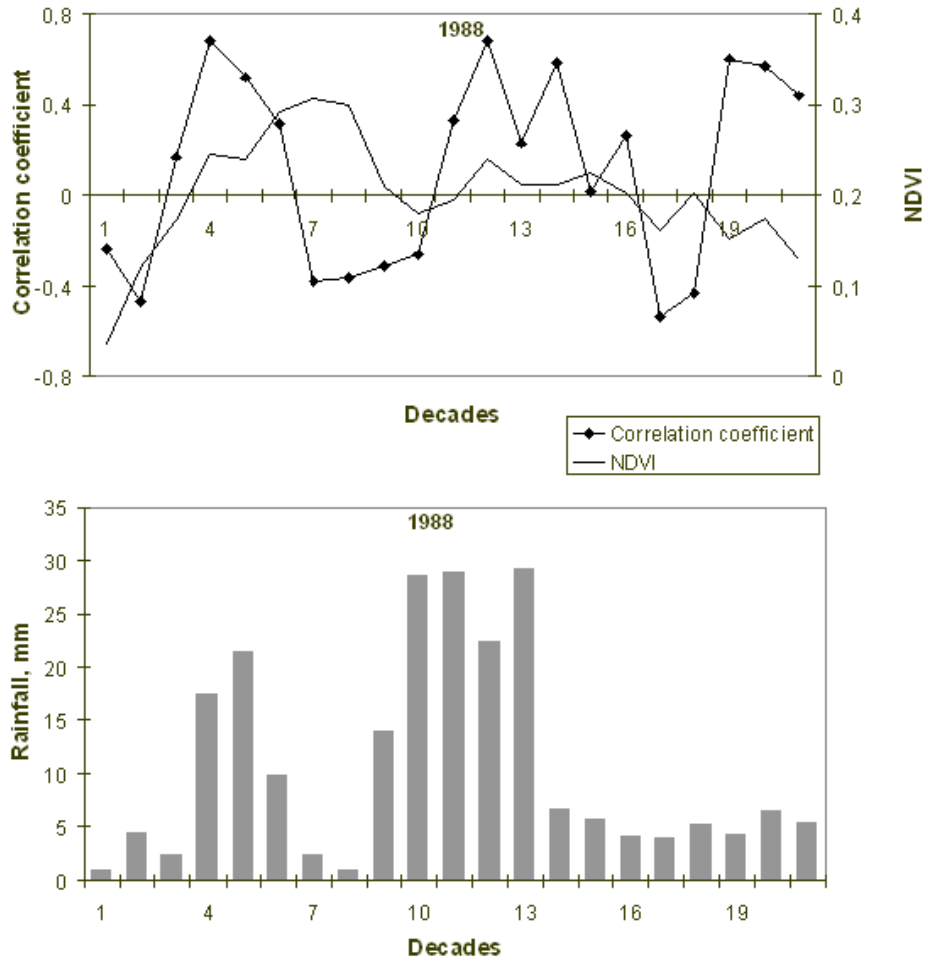

Figure 8.10. The same as in Figure 8.7 but for a wet year 1988 . 


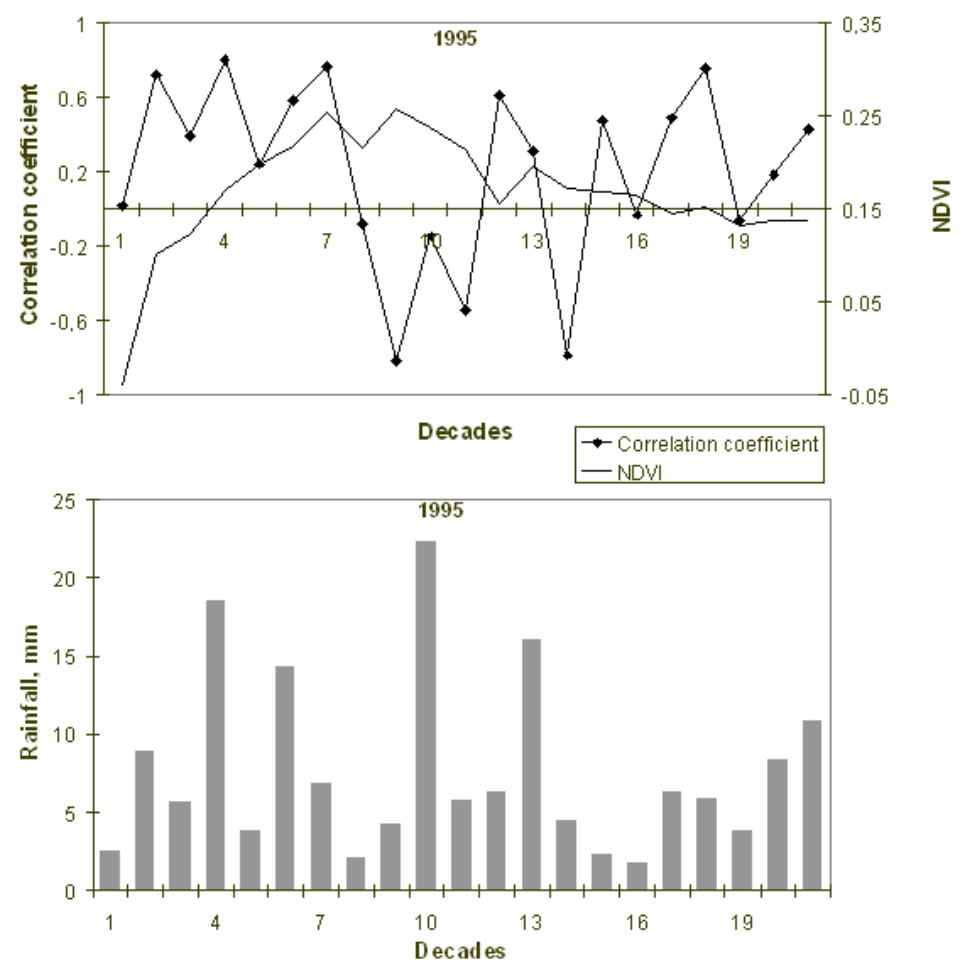

Figure 8.11. The same as in Figure 8.7 but for a dry year 1995 . rainfall

8.2.3. Influence of vegetation type on within-season relations between NDVI and

The within-season relationship between NDVI and rainfall were quite different for various vegetation types. Both correlation coefficient value and its time-profile had individual characteristics for each of the vegetation types in the study area (Figures $8.12-8.14$ ). Only the semi-desert vegetation has shown a time-profile of correlation coefficients some like that calculated for the whole region.

There is significant difference between values of the correlation coefficient and its time-profile in dry and wet years. We found that the strength of correlation between spatial pattern of the semi-desert vegetation and rainfall is always higher in wet years, 1987, 1988, 1990, 1993 and 1998 during the entire growing season. The results derived for desert vegetation and steppe vegetation are more complicated.

In wet years, desert vegetation shown higher values of correlation coefficient $(r=0.6$ 0.8) exceptionally in April, May and June. During the other months coefficients remained low, fluctuating only slightly. The higher values of the correlation coefficient at the beginning of the growing season may be caused by the snowmelt in March and April, and high rainfall amounts in May. During these two months desert vegetation had the highest values of NDVI. 
Vegetation reaches the maximum of cover density. As the consequence, flash precipitation and overland runoff are relative low. The greatest part of precipitation is utilized at the locality of the rainfall. This results in higher NDVI-rainfall correlation coefficients. Then the photosynthetic activity of vegetation decreases. As the vegetation cover decreases, plant growth and over ground biomass begins to depend less on rainfall pattern. In dry years, 1986, 1995 and 1997, there was no peak of rainfall amount in the spring months. The photosynthetic activity of vegetation and its dependence on rainfall pattern remained low during the entire growing season.

Correlation coefficient values for steppe grassland range from 0.42 to 0.81 during growing season in wet years. The values were very high at the beginning of the growing season, and then they decreased gradually until June and culminated in the growing season minimum at 2 or 3 June decades. After that, the correlation coefficients increased into 2-3 July decades and remained high $(r=0.65-0.75)$ during August, September and October. In dry years, the values of the correlation coefficient showed the same time-profiles as described, but had a lower range amplitude $(r=0.55-0.75)$. Comparing a growing season time-profile of correlation coefficient together with that of rainfall and NDVI, we found some notable characteristic properties for steppe grassland. At the beginning of growing season, as NDVI values and rainfall amounts were very low, correlation coefficients showed high values. They decreased during the three spring months, while the average NDVI value gradually increased. During May, June and first decade of July, the average NDVI displayed the highest values, while correlation coefficient showed the lowest values. Then, the correlation coefficients rapidly increased and remained at high level as NDVI values decreased over time. The increase of the correlation coefficients in July were caused by high rainfall amounts in this month. The highest value, $r=0.81$, is calculated for the July decade with the highest rainfall amount, $45.8 \mathrm{~mm}$. 

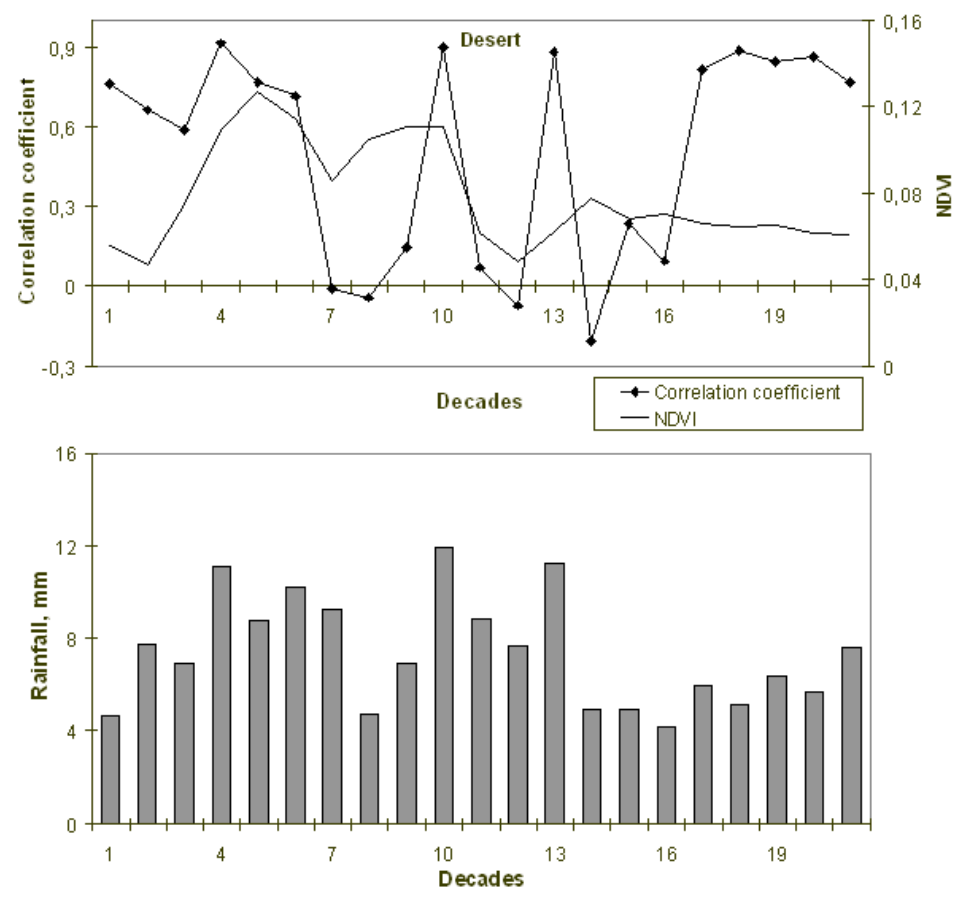

Figure 8.12. Correlation coefficient, 10-day NDVI values and 10-day rainfall for desert.
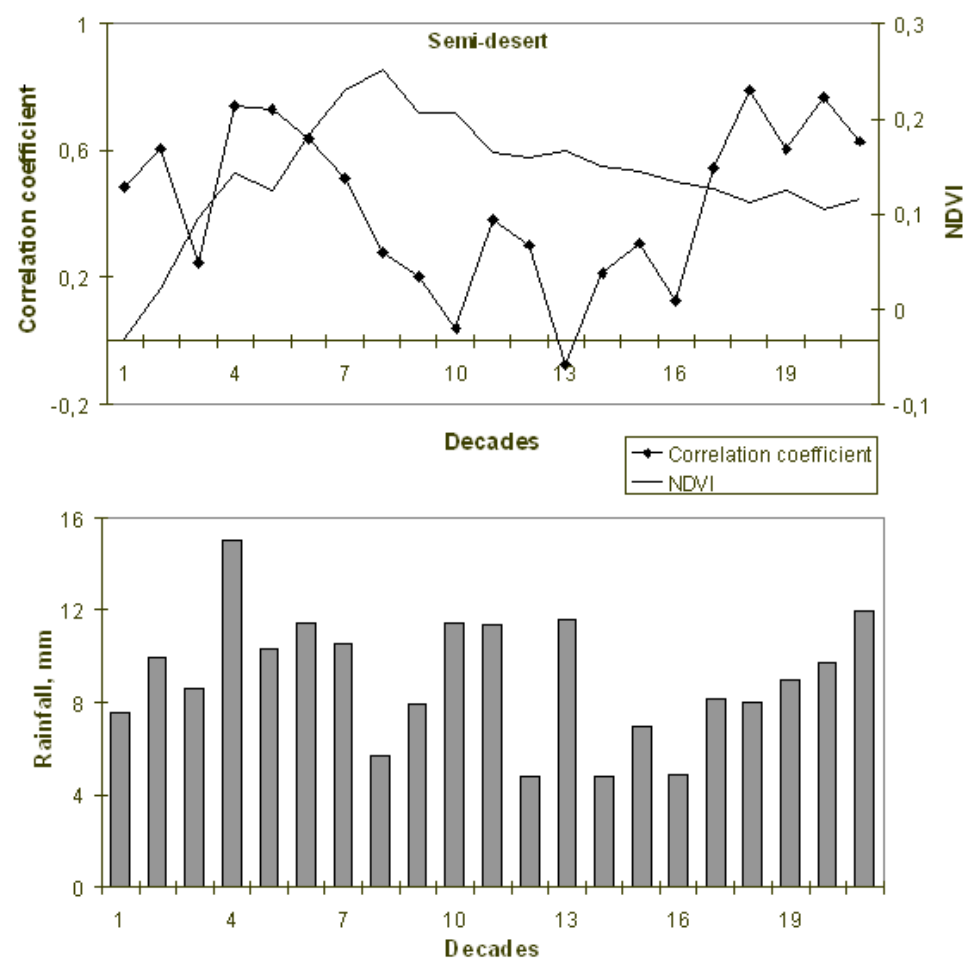

Figure 8.13. Correlation coefficient, 10-day NDVI values and 10-day rainfall for semi-desert. 

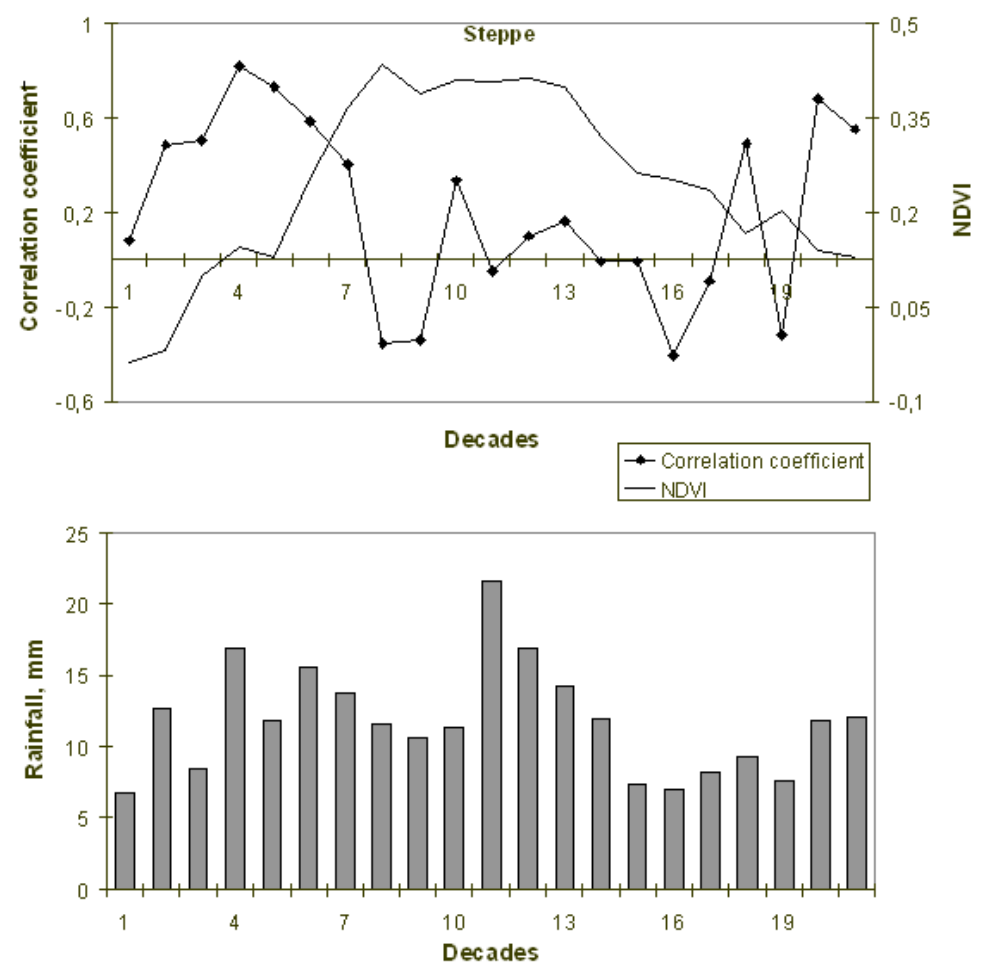

Figure 8.14. Correlation coefficients, 10-day NDVI values and 10-day rainfall for steppe grassland.

\subsubsection{Influence of precipitation amount on NDVI-rainfall relations}

Analysis of within-season time-series of 10-day NDVI, rainfall amounts and spatial correlation between these both variables showed that the within-season rainfall profile predicts the time profile of NDVI-rainfall correlation (Figures $8.12-8.14$ ). We found a strong association between the decades with high rainfall amounts and that with high NDVIrainfall correlation coefficients. High rainfall amounts in May, June and July, especially in the second decades of May and July, caused a significant increase of correlation coefficients in the corresponding decades. On the contrary, decades with low or no rainfall predicted lower positive or even negative correlation coefficients. In order to understand whether there are any statistically significant relations between these variables, the NDVI-rainfall correlation coefficients were plotted against rainfall amounts. The data presented in Figures $8.15-8.17$ supported our suggestion. The regression graphs in these figures present the long-time average, a wet year (1988) and a dry year (1995).

We found a non-linear relationship between 10-day NDVI-rainfall correlation coefficients and 10-day rainfall amounts in all years with exception of the years 1985, 1990, 1997. In particular, the correlation coefficients increased as long as the 10-day rainfall does not exceed a definite value. Above this limit, a "saturation" response occurs and the NDVI- 
rainfall correlation coefficients decrease. The limits, above which the NDVI-rainfall correlation coefficients begin to decrease, are different for dry and wet years. In dry years, the "saturation limit" amount to 12-14 mm of 10-day rainfall. In wet years, this limit is higher, approximately $28-32 \mathrm{~mm}$.

The "saturation limits" for land cover categories both for dry and wet years increase as one movies from desert, to semi-desert and to dry steppe (Table 8.1). The levels, beyond which the correlation coefficients between NDVI and rainfall decrease, are lower in dry years and associated with 10-12 mm, 12-14 $\mathrm{mm}$, and 25-27 $\mathrm{mm}$ for desert, semi-desert and dry steppe respectively. In wet years, these levels are about $70-100 \%$ higher. One may note that the influence of decade rainfall on the NDVI-rainfall correlation is higher in dry years. This result disagrees with the result derived for growing season relationships. An explanation will be given in the discussion section. Our study demonstrated the influence of rainfall on NDVIrainfall correlation for within-season relations and existence of a "saturation limit" in this influence.

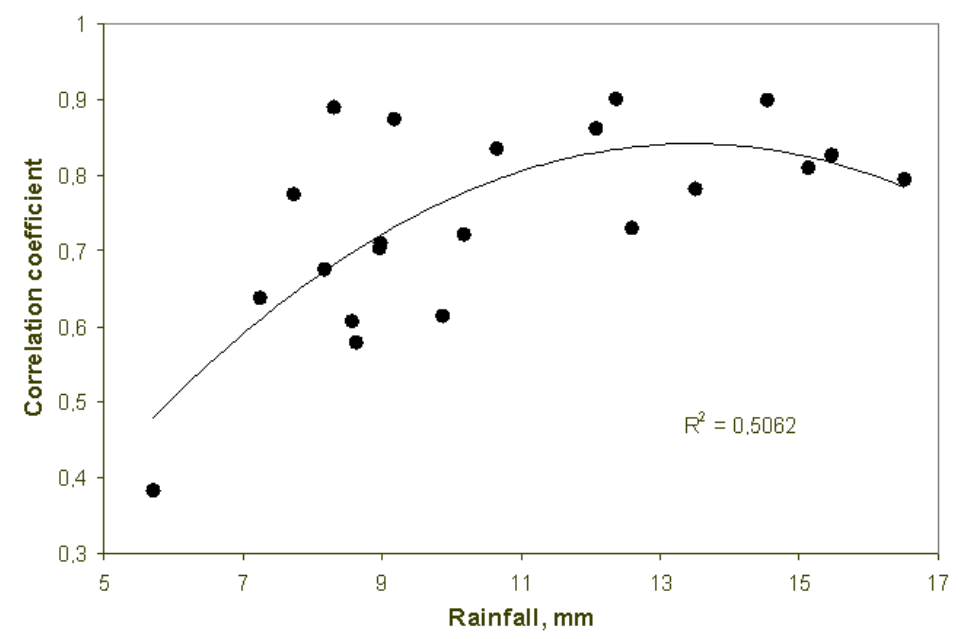

Figure 8.15. Regression graph between 10-day NDVI-rainfall correlation coefficients and 10-day precipitation averaged over the study period. 


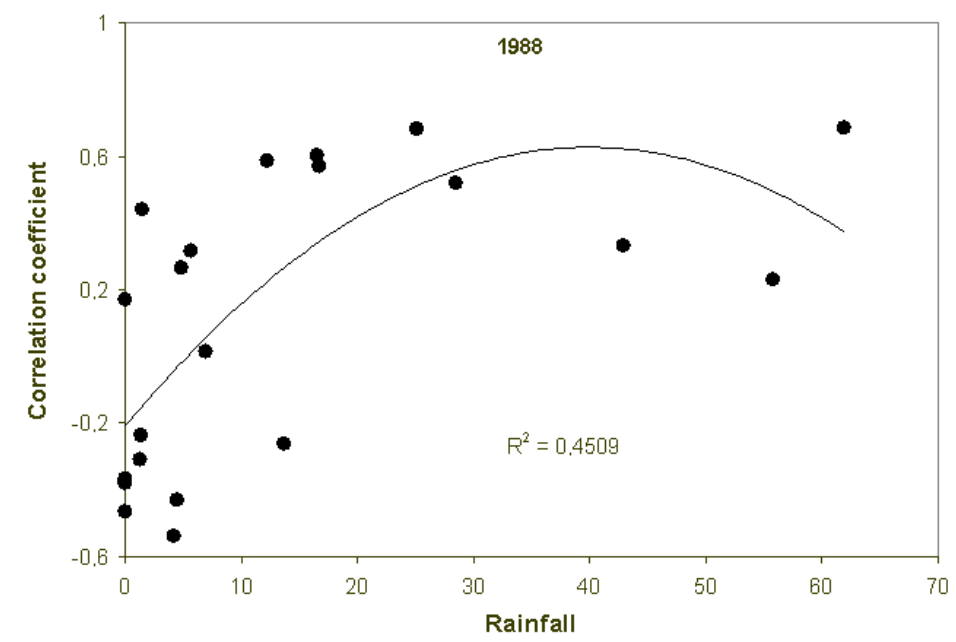

Figure 8.16. Regression graph between 10-day NDVI-rainfall correlation coefficients and 10-day precipitation for a wet year 1988 .

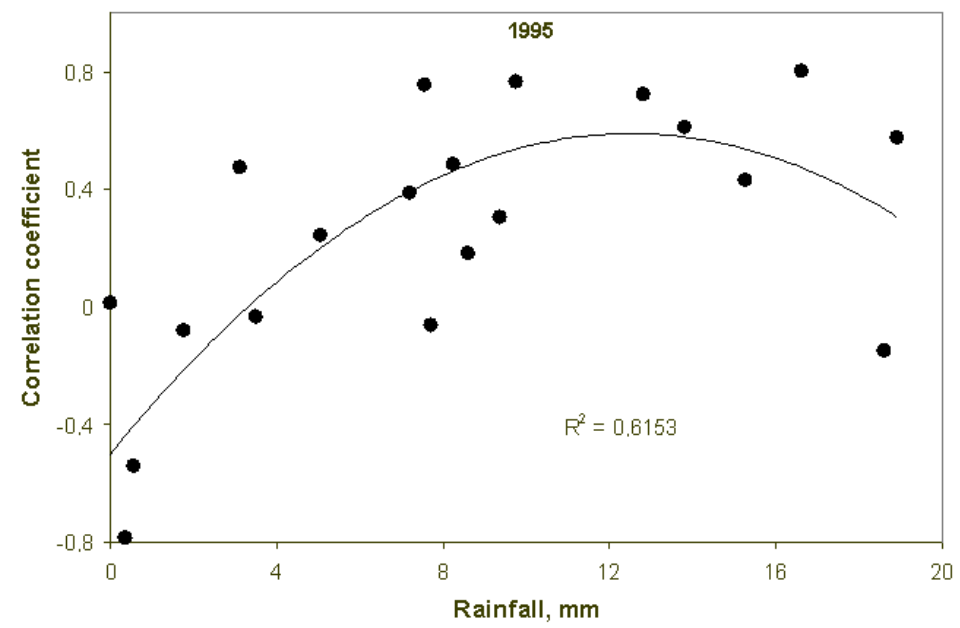

Figure 8.17. Regression graph between 10-day NDVI-rainfall correlation coefficients and 10-day precipitation for a dry year 1995.

Table 8.1. Strength of relationship between 10-day NDVI-rainfall correlation and 10-day rainfall amounts, and the "limit of saturation" (turning-point) for the three land cover categories.

\begin{tabular}{|l|l|l|l|l|}
\hline \multirow{2}{*}{ Land cover category } & \multicolumn{3}{|l|}{$\begin{array}{l}\mathrm{R}^{2} \text { between NDVI- } \\
\text { rainfall correlation } \\
\text { and rainfall amount }\end{array}$} & $\begin{array}{l}\text { Turning-point, } \\
\text { mm rainfall }\end{array}$ \\
\cline { 2 - 5 } & Wet year & Dry year & Wet year & Dry year \\
\hline Desert & 0.29 & 0.40 & $20-22$ & $10-12$ \\
\hline Semi-desert & 0.28 & 0.35 & $28-30$ & $12-14$ \\
\hline Dry steppe & 0.42 & 0.42 & $35-38$ & $25-27$ \\
\hline
\end{tabular}




\subsection{Growing season relationship between temperature and NDVI}

\subsubsection{NDVI-temperature correlation coefficients}

The calculated global correlations between NDVI and temperature pattern for every year of the study period indicate a strong spatial association between these variables. Growing season average NDVI showed high negative correlations with average temperature and temperature sum, weaker correlation with minimum and maximum growing season temperature. Correlation coefficient values among average NDVI and average temperature range between -0.78 and -0.86 with the mean value of -0.82 . The values are higher than that calculated for NDVI-rainfall relationship and this indicates a stronger dependence of NDVI on spatial pattern of temperature. Compared with temperature patterns, precipitation patterns play a minor role in explaining the pattern of vegetation. This result contradicts the research result obtained by Wang et al (2001) for central Grate Plains, but is in agreement with those obtained from China by Xiao \& Moody (2004) and Li et al. (2002).

The correlation coefficients between annual deviations of NDVI and annual deviations of temperature from the mean of the study period showed no significant values that could be interpreted. Only in 1985 and 1988 the correlation was significant $(r=0.41$ and $r=0.38$ ), but in other years it was very weakly negative or positive.

\subsubsection{NDVI-temperature correlation coefficients by vegetation type}

Correlation coefficients calculated for individual vegetation types are quite different from those obtained for global correlation. Thus, two vegetation types, desert and semi-desert, demonstrate a negative correlation between spatial patterns of temperature and that of the mean growing season NDVI. On the contrary, the spatial NDVI distribution in the steppe grassland correlate strongly positive with temperature (Figure 8.18), the coefficient of correlation is over 0.74 . The correlation coefficient calculated for desert vegetation is more lower, only -0.64 . The correlation for semi-desert is also significant (with a significance level 0.05 ) but it is lower than -0.50 . The semi-desert vegetation cover having been a transition zone between steppe and desert demonstrates the combine characteristics of NDVItemperature relationships observed by the both mean zones. By analysing the regression graph for the semi-desert vegetation in Figure 8.16, one may noted that the left part of the point cluster shows the characteristics like the desert point cluster (correlation is negative), but the right part began to like more to the steppe point cluster (correlation is weak positive or 
zero). The vegetation cover of semi-desert consists of mix of vegetation species from desert and steppe. The described behaviour of its various relations to spatial patterns of temperature means that the part of semi-desert vegetation cover where steppe species dominate tends to react on temperature so as this steppe vegetation makes. On the contrary, the part of semidesert vegetation cover with dominance of desert species demonstrates the NDVI-temperature relationship like that of desert vegetation.

We compared the correlation coefficients calculated between NDVI and temperature with that calculated for NDVI and rainfall. The results are presented in Table 8.2. Thus, the spatial patterns of NDVI in the steppe grassland are more dependent on that of rainfall. On the contrary, desert vegetation displays a high correlation for NDVI-temperature and a weaker correlation for NDVI-rainfall. Because of the different reaction of semi-desert vegetation cover to temperature patterns, an interpretation of results for this vegetation type would have no meaning.

\subsubsection{Influence of annual rainfall on NDVI-temperature correlation}

The correlation coefficient between NDVI and temperature varied during the study period in a wide range. In order to understand whether there was any significant influence of annual rainfall to NDVI-temperature relationships, we compared time-series of averaged annual rainfall amounts and that of NDVI-temperature correlations. The data presented in Figure 5.3.20 indicate that the strength of NDVI-temperature correlation is higher in years with rainfall amounts over the mean value (1987, 1989, 1992, 1993, 1996 and 1998). In 1987 and 1996, the wettest years of the study period, the correlation coefficient displays the highest values. In dry years the relationship between NDVI and temperature is not as strong as in wet years. In 1986, 1994, 1995 and 1997, the correlation coefficient showed values lower than 0.80 .

Table 8.2. Correlation between spatial patterns of growing season NDVI, growing season rainfall and growing season temperature for different vegetation types (calculated as mean for the study period 1985-2003).

\begin{tabular}{|l|l|l|l|}
\hline & Desert & Semi-desert & Steppe \\
\hline $\begin{array}{l}\text { NDVI-rainfall } \\
\text { correlation }\left(R^{2}\right)\end{array}$ & 0.36 & 0.60 & 0.66 \\
\hline $\begin{array}{l}\text { NDVI-temperature } \\
\text { correlation }\left(R^{2}\right)\end{array}$ & 0.38 & 0.22 & 0.51 \\
\hline
\end{tabular}




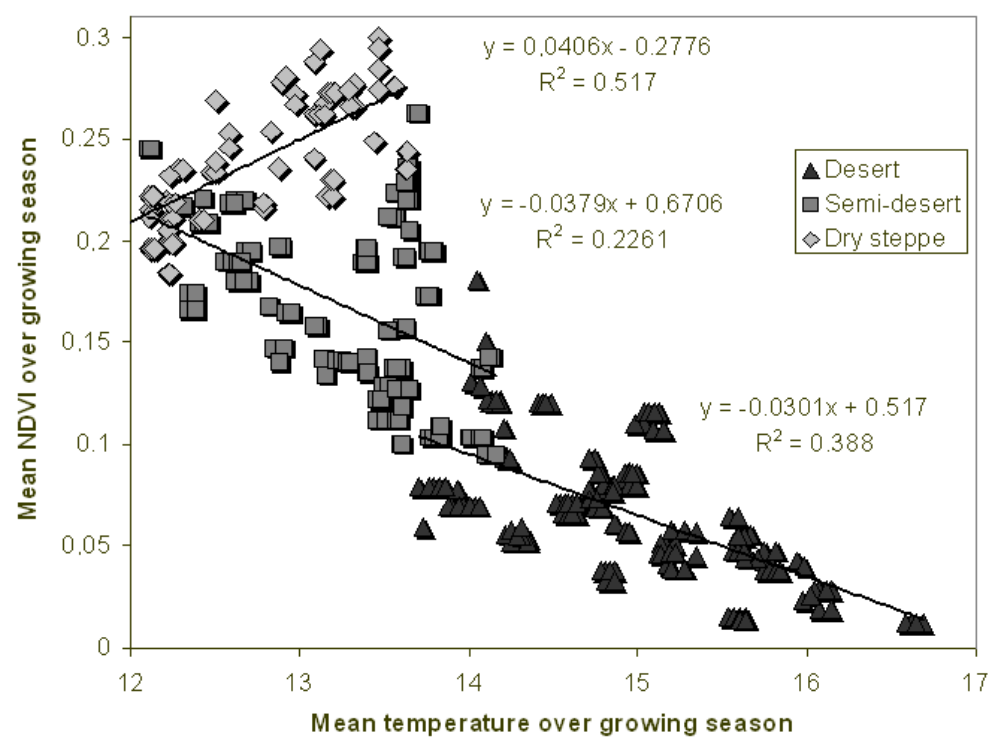

Figure 8.18. Correlation coefficients between spatial pattern of NDVI and temperature obtained for the data averaged over the period 1985-2001.

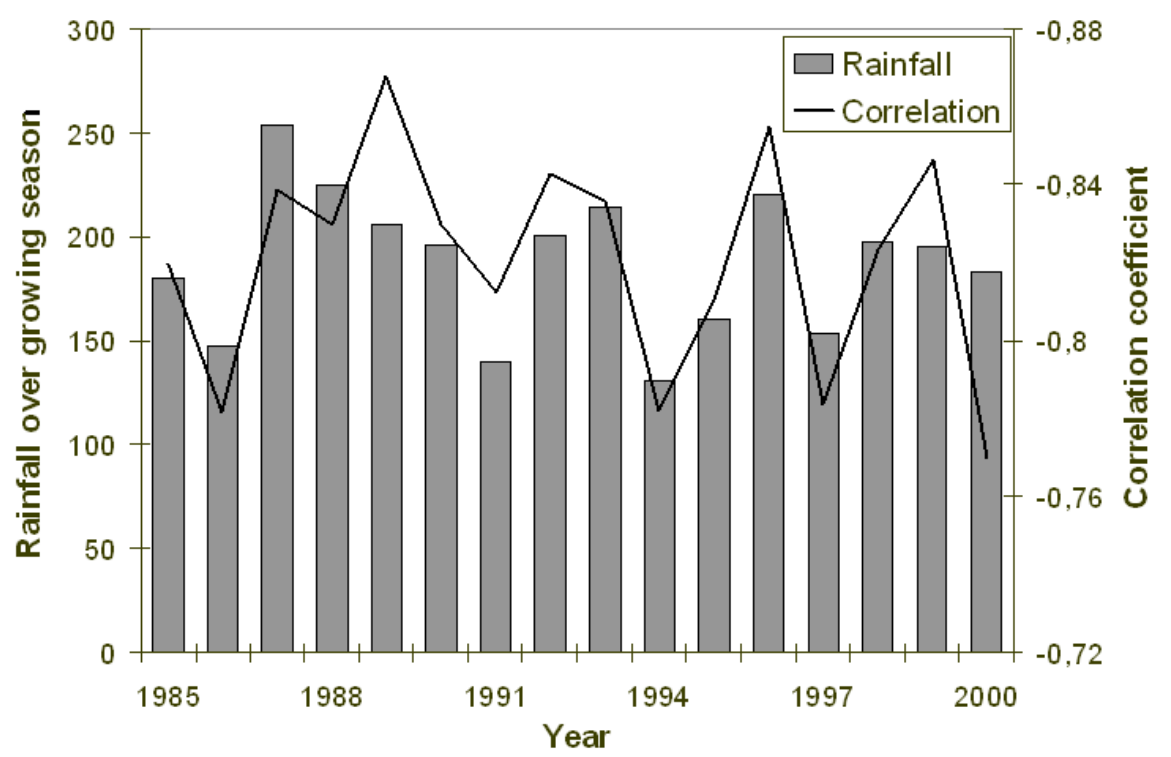

Figure 8.19. Total growing season rainfall versus NDVI-temperature correlation coefficient. 


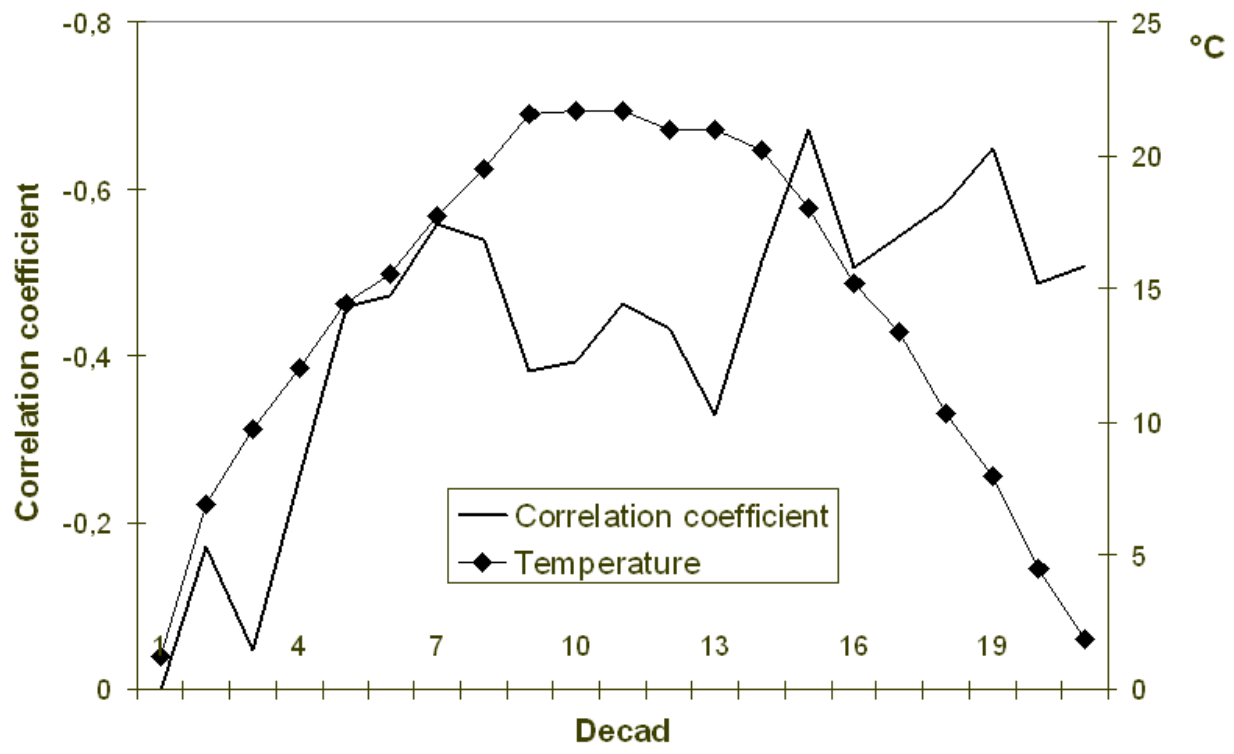

Figure 8.20. Time-profile of 10-day NDVI-temperature correlation coefficient and 10-day temperature averaged over the study period 1985-2000.

\subsection{Within-season relationship between NDVI and temperature}

\subsubsection{General patterns in the NDVI-temperature correlation}

Generally, the within-season time-profile of correlation coefficient between NDVI and temperature is similar to that of rainfall but it has the negative sign. Through the growing season, the correlation coefficients started with value about zero in April, slowly increasing from April to May as temperature increased and had their first peak with value of -0.58 at the beginning of June (Figure 8.20). After that, the value dropped to $-0.38-0.42$ and remained low during the three summer months, then increased to high values, $-0.50-0.55$, in September and October. Our results were quite similar by the use of different time lags.

Notable is the dropping of values of the correlation coefficient during the summer months. These months are characterized by the highest values of decade temperature, but the dependence of spatial patterns of NDVI on that of temperature severely decreased. 
8.4.2. Influence of cover types on within-season relationship between NDVI and temperature

In order to understand whether the within-season relation between NDVI and temperature varies between different cover types, we calculated correlation between these both variables for the three vegetation types, desert semi-desert and steppe, occurring in the study area. The vegetation types show quite different individual time-profiles of correlation coefficient (Figure 8.21).
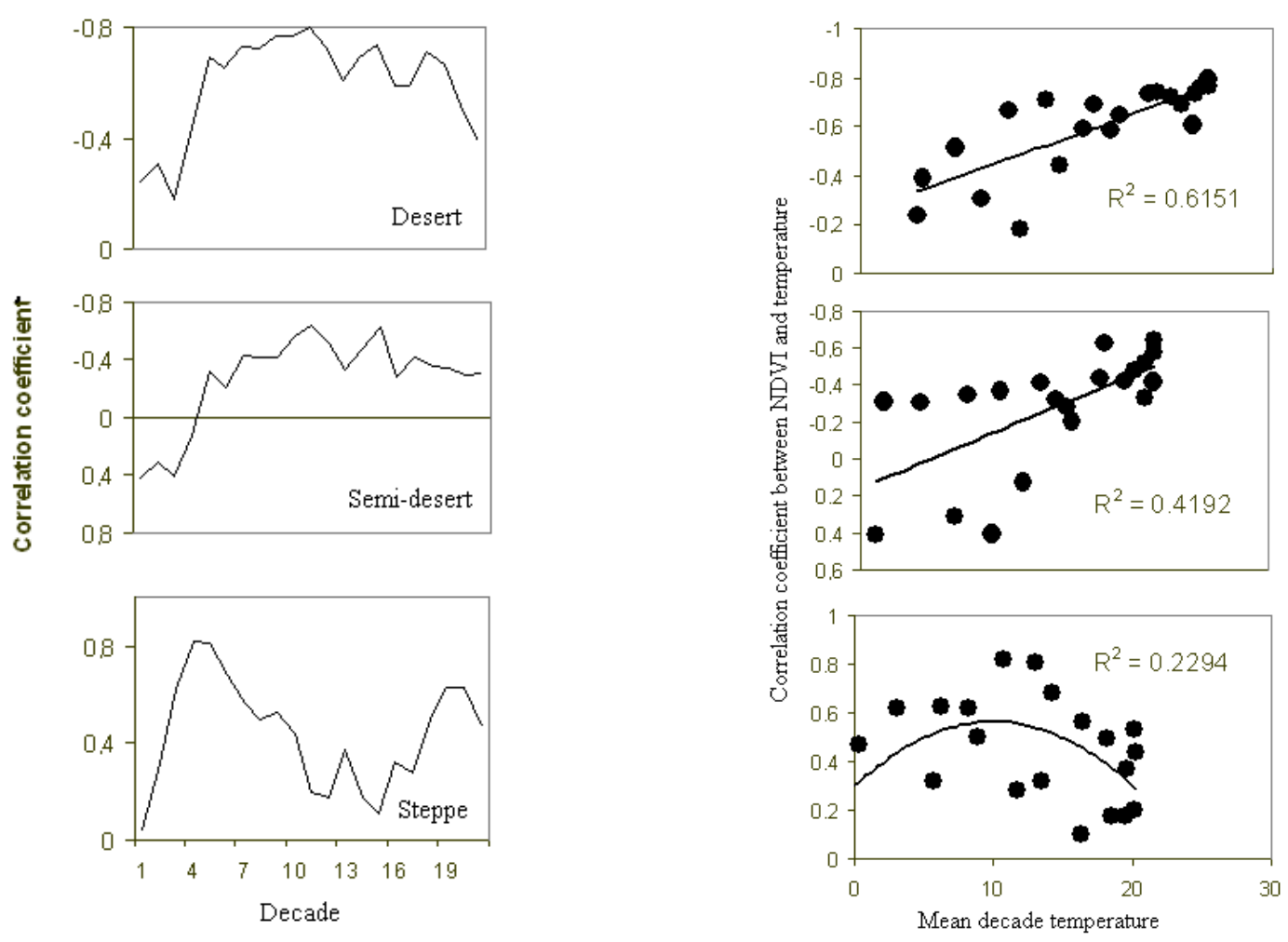

Figure 8.21. Left: Time-profiles of 10-day correlation coefficient between spatial patterns of NDVI and temperature for desert, semi-desert and steppe vegetation cover. Right: Relationship between 10day NDVI-temperature correlation and mean 10-day temperature for different vegetation types.

For desert, correlation coefficients are always negative during growing season. They started with value of -0.20 in April and increased rapidly until the beginning of May. After that, correlation coefficients continued to grow gradually but not so rapidly and achieved the maximum value, -0.80 , at 11 decade. Then coefficients remained high, fluctuating only slightly during the summer and September; and finally coefficients decreased during October. For steppe, on the contrary, the correlation coefficients are always positive. They started with a value of near zero and increased promptly to the highest values. In the mid and the end of May the values of the correlation coefficient were equal to $0.80-0.82$. After that, a graduate 
decrease of correlation coefficients was noticed until the end of July. An increase of values was observed once more in August and September. October was characterized by a rapid dropping of correlation coefficients to lower values.

The results derived for semi-desert vegetation are more complicated. The time-profile of correlation coefficients displays both positive and negative values. The correlation coefficient began in the growing season with a positive value, 0.40 , decreasing over time and at the middle of May turned over to negative values. Afterwards, the course of correlation coefficients is almost identical to that of desert vegetation.

\subsection{Discussion and conclusion}

In this chapter, spatial distribution of vegetation associated with geographical environment has been studied using correlation analysis at inter-annual and within-season time-scales. Sensitivity of vegetation cover to inter-annual changes of climatic conditions has also been investigated.

Generally, vegetation response to the climate parameters, rainfall and temperature proved to be strong and statistically significant both at inter-annual and within-season scales. The relationship between vegetation and temperature at growing season scale is negative while between NDVI-precipitation it is positive. Temperature played a leading role in vegetation patterns in the study region during the period 1985-2001. The correlation coefficient between NDVI and temperature exhibited a mean value of -0.83 , whereas that for NDVI-precipitation exhibited a mean value for all years of 0.77 . The results demonstrated a drift in correlation coefficients between different vegetation types. Both NDVI-temperature and NDVI-precipitation relationship was the strongest in steppe grassland and the weakest in desert shrubland.

There was a high inter-annual variability in the correlation coefficient both for NDVItemperature and NDVI-precipitation relationship. We found influence of year rainfall on the NDVI-precipitation and NDVI-temperature relationship. Generally, NDVI-precipitation correlation increased with the rise of rainfall amount until it had achieved the "saturation" limit. This limit is localized at $240-250 \mathrm{~mm}$ growing season precipitation. Wet years with very high rainfall amount, 1987 and 1988, are associated with a decreasing correlation coefficient. The influence of temperature also depended on total rainfall per year and was stronger during wet years and weaker during dry years. Standardized anomalies of NDVI and 
precipitation were computed and mapped. There was strong spatial association between interannual anomalies of NDVI and rainfall at the scale of the Shetsky district.

Within-season dynamic of NDVI-climate relationship exhibited high variability. The patterns in this dynamics are associated with patterns in rainfall throughout the growing season. In short grassland and steppe grassland, there was a lag time of 1-2 decade between rainfall events and increase of the correlation coefficient. Desert vegetation reacted to precipitation immediately. Values of the correlation coefficients for NDVI-precipitation were higher in decades with high rainfall amounts and low or negative in dry decades. Like the results for inter-annual dynamics, the within-season results also indicated the existence of a "saturation" limit for within-season NDVI-precipitation relationship. This limit was quantified separately for every vegetation type. 


\section{Chapter 9}

\section{Application of the geographically weighted regression to modelling}

relationship between vegetation patterns and climate factors

\subsection{Problem of non-stationarity in modelling spatial relationship and approaches to overcome it}

The mostly used method for investigation of the relationship between vegetation patterns and climate is conventional ordinary least squared (OLS) regression analysis. In our study, both simple and multiple OLS regressions have been applied for analysis in the previous chapters. However, these conventional statistical methods were criticized by some authors for their inadequate modelling results particularly at regional and global scales (Brundson et al., 2001; Fotheringham, 1999).

One should take into account that modelling the spatial NDVI-climate relationship one has to deal with a phenomenon of non-stationarity of this relationship in space. However, the global OLS method applied in the previous chapter for modelling is stationary in a spatial sense. Stationarity means that a single model is fitted to all data and is applied equally over the whole geographic space of interest. This regression model and its coefficients are constant across space assuming the relationship to be also spatially constant. That is usually not adequate for spatially differentiated data, especially by quantifying relationships at regional or global scales. The differences between regression models established at different locations can be large with both the magnitude and sign of the model parameters varying. In such circumstances, the parameters of the global regression model derived by applying conventional global regression may not represent local conditions within the study area. One may suppose that especially in the areas with high variance of relief conditions, vegetation and soil types the local model parameters should vary more significant.

The easiest method to improve the regression model and to reduce the differences at localities is the fitting of an individual OLS model for each land-cover or vegetation type. By this method, the variance in regression parameters between land-cover types can be highlighted and the prediction power of the regression model increases significantly (Wang et al., 2001; Li et al., 2002; Ji \& Peters, 2004). In chapter 5 and 6, we have already shown differences between the main vegetation types in their response to climate factors. But this 
method did not highlight the local non-stationarity in the relationship within the land-cover type.

An interesting and efficient alternative is to allow the parameters of the model to vary with space. Such non-stationary modelling has greater prediction precision because the model being fitted locally is more tuned to local circumstances. Local regression techniques, such as localized OLS (moving window regression) or geographically weighted regression (GWR) help to overcome the problem of non-stationarity and calculate the regression model parameters varying in space.

In this chapter, we analysed spatial relationship between NDVI and rainfall amounts using the geographically weighed regression technique as an alternative approach for data modelling. The aim was to derive a regression model focusing on the accuracy of model prediction at the local scale. The GWR model worked at the pixel scale and highlighted nonstationarity in the NDVI-rainfall relationship within each land-cover type. The differences between the results obtained by OLS with that obtained by GWR were demonstrated and quantified. The prediction power of these regression models, global and local was compared. It was also demonstrated that the prediction accuracy increases by taking into account local circumstances. The results produced a more accurate estimation of the NDVI-precipitation relationship than the conventional statistical methods used in the previous chapter.

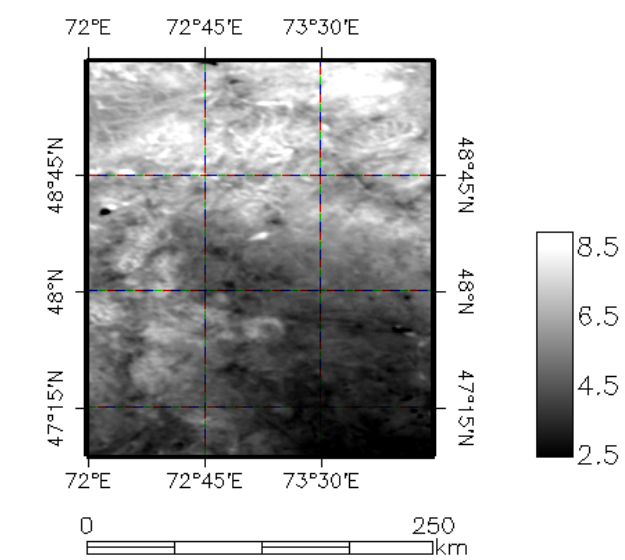

(a)

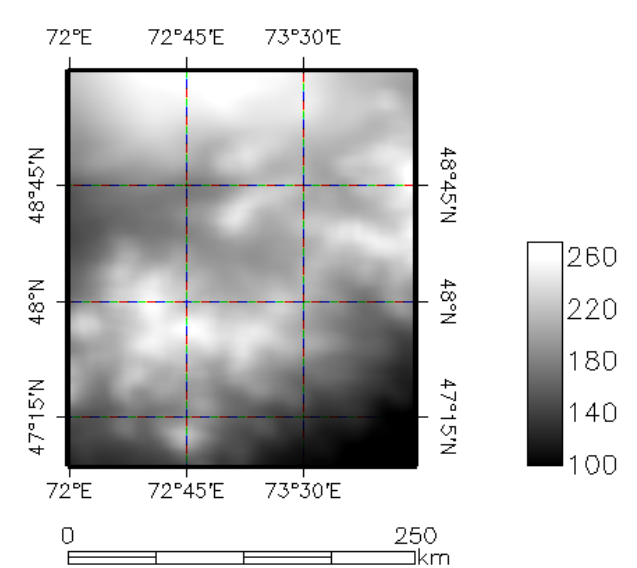

(b)

Figure 9.1. (a) Accumulated growing season NDVI calculated from a combination of 1-km NOAA AVHRR and SPOT-VEGETATION for the period 1992-95/1998-2004. (b) Regionalized total precipitation amount throughout the growing season. The graph presents an average over the period 1985-2004. 


\subsection{Reducing uncertainty in modelling NDVI-precipitation relationship: a comparison between OLS and GWR regression techniques}

\subsubsection{Global OLS regression model and its deficiencies}

Regression analysis based on the applying of conventional global OLS regression revealed that there is a strong relationship between the spatial distribution of the 8-km NDVI and precipitation (see Chapters 6 and 7). The estimated $\mathrm{R}^{2}$ of the regression equations ranges from 0.67 to 0.91 over the period 1985-2001 and shows a mean value for all years of 0.64. Figure 9.1 displays maps of the 1-km accumulated growing season NDVI, $N D V I_{\text {accum }}$, and the corresponding precipitation amount. There is a strong association between spatial patterns in both variables. Fitting regression with 1-km NDVI data, we did not expect any great change in the goodness-of-fit in comparison to $8-\mathrm{km}$ data. The further analysis supported this assumption.

Figure 9.2 shows the scatter plot between measured $N D V I_{\text {accum }}$ and predicted $N D V I_{\text {accum }}$ based on the global OLS regression. This regression model explains about $63 \%$ of spatial variance in $N D V I_{a c c u m}$ and was expressed as:

$$
N D V I_{\text {accum }}=0.0854+0.0258 * P \quad\left(\mathrm{R}^{2}=0.63\right)
$$

where $P$ is precipitation.

The standard error used as a measure for prediction accuracy was 0.21 or about $5 \%$ from the mean $N D V I_{\text {accum }}$ value. The relatively low value of the standard error might backup the assumption that the derived regression model provides an accurate description of the relationship between variables. However, the result of the OLS analysis indicates that much of the variance remains unexplained, and this may drive further work that aims to increase the understanding of the variables responsible for this variance. One possible way how to reduce the amount of the unexplained variance is to introduce other variables into the model specification. Another way may be an improving regression model by disaggregating (stratification) the global regression model into a separate model for each of the main land cover types.

The two regression variables, both $N D V I_{\text {accum }}$ and precipitation data contain positive autocorrelation (Figure 9.3). The graph shows a high positive autocorrelation over short 
distances and a low one at large distances. These autocorrelograms indicate that both $N D V I_{\text {accum }}$ and precipitation are positively autocorrelated up to ca. $90 \mathrm{~km}$. Their Moran's $I$ values are significantly larger than the values expected under the null hypothesis of no positive autocorrelation. This spatial autocorrelation can be interpreted in terms of trend or linear gradient across the study area (Griffith, 2003). Most ecological and climatic variables tend to represent a positive spatial autocorrelation because of the natural phenomena are geographically organized.

But spatial autocorrelation is problematic for statistical analysis like OLS regression. When conventional OLS regression is applied to the analysis of data containing positive autocorrelation, there are two problems: (1) the standard error of the regression coefficient is underestimated, and tests of hypothesis on this coefficient may show that the indicator variable is significant when it really not, (2) the residual mean square may seriously underestimate the variance of the error term, hence the coefficient of determination $\left(\mathrm{R}^{2}\right)$ is overestimated (Clifford et al., 1989). Recent studies tried to overcome these problems by applying spatial regression technique that can adjust for spatial autocorrelation inherent in the regression model on the basis of a variogram function (Tiefelsdorf, 2000; Ji \& Peters, 2004).

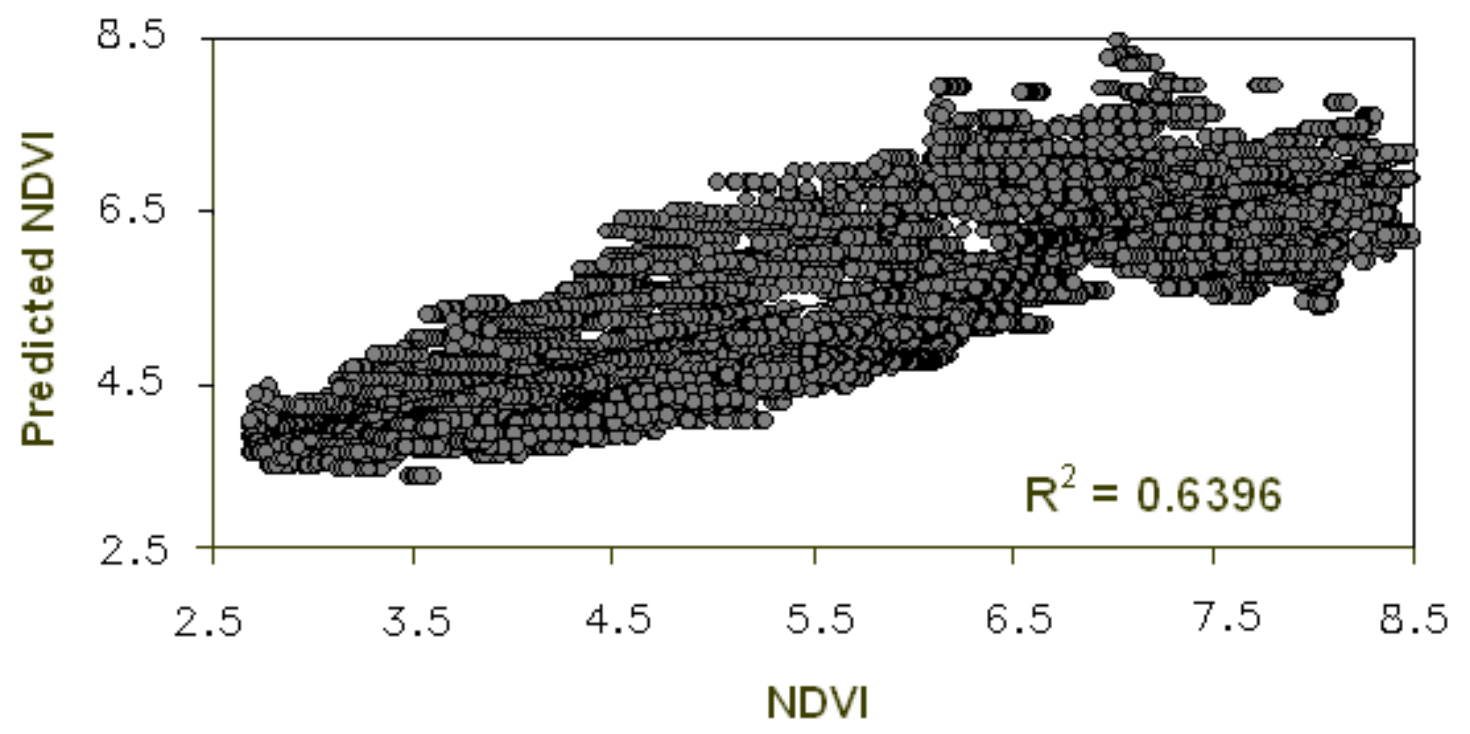

Figure 9.2. Scatter diagram between measured and predicted. $N D V I_{\text {accum }}$ 


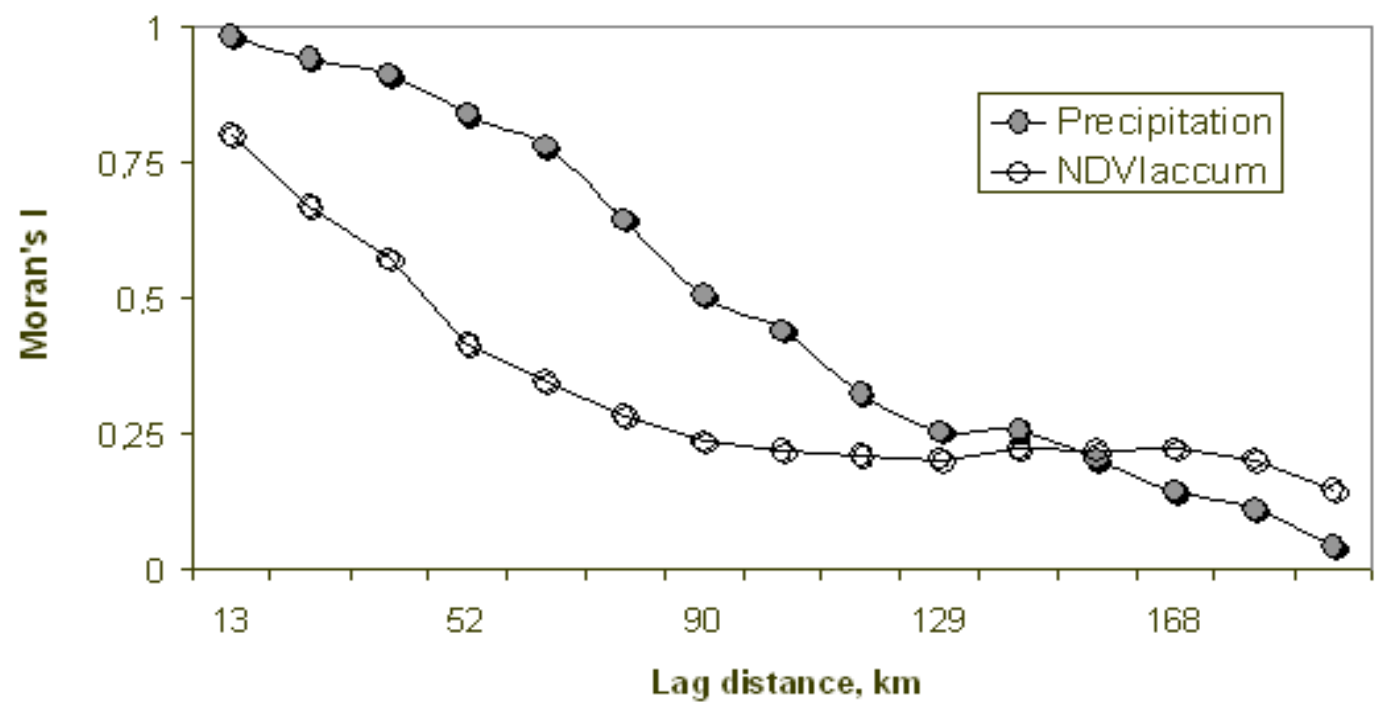

Figure 9.3. Spatial autocorrelogramms for $N D V I_{\text {accum }}$ and precipitation.

\subsubsection{Stratification of NDVI-precipitation relationship by land cover type}

In order to reduce the amount of $N D V I_{\text {accum }}$ unexplained and the negative influence of spatial autocorrelation, the OLS regression analysis has been performed separately to the four main vegetation types presented in the study region. Figure 9.3 shows the results of the stratified OLS regression between rainfall and $N D V I_{\text {accum }}$ fitted to the land cover classes. With regard to vegetation type, the results indicate that the coefficient of determination, $\mathrm{R}^{2}$, increases from desert to semi-desert, to short grassland, and to steppe, with value of 0.36 , $0.44,0.52$, and 0.67 respectively. The components of the regression equation vary in a wide range: there are notable differences in regression slope and intercept between the vegetation types. The stratification of the OLS model by land-cover types clearly illustrates the presence of non-stationarity in the general relationship between $N D V I_{\text {accum }}$ and precipitation which may now be written as:

$$
N D V I_{\text {accum }}=(0.6668-6.3178)+(0.0017-0.0205) * P \quad\left(\mathrm{R}^{2}=0.75\right)
$$

Values for the range in both intercept and slope parameters are given in brackets. Analysing this fact leads to the conclusion that the global OLS regression can not possibly be considered stationary. There is spatial variation in intercept and slope parameters as well as in 
the coefficient of determination, $\mathrm{R}^{2}$, between the land-cover types. These results assume a different response of vegetation to precipitation by various land cover categories. That agrees with the results of other research works from dry regions which reported about influence of NDVI-rainfall relationships by land cover type (Yang et al., 1997; Li et al., 2002; Wang et al., 2001).

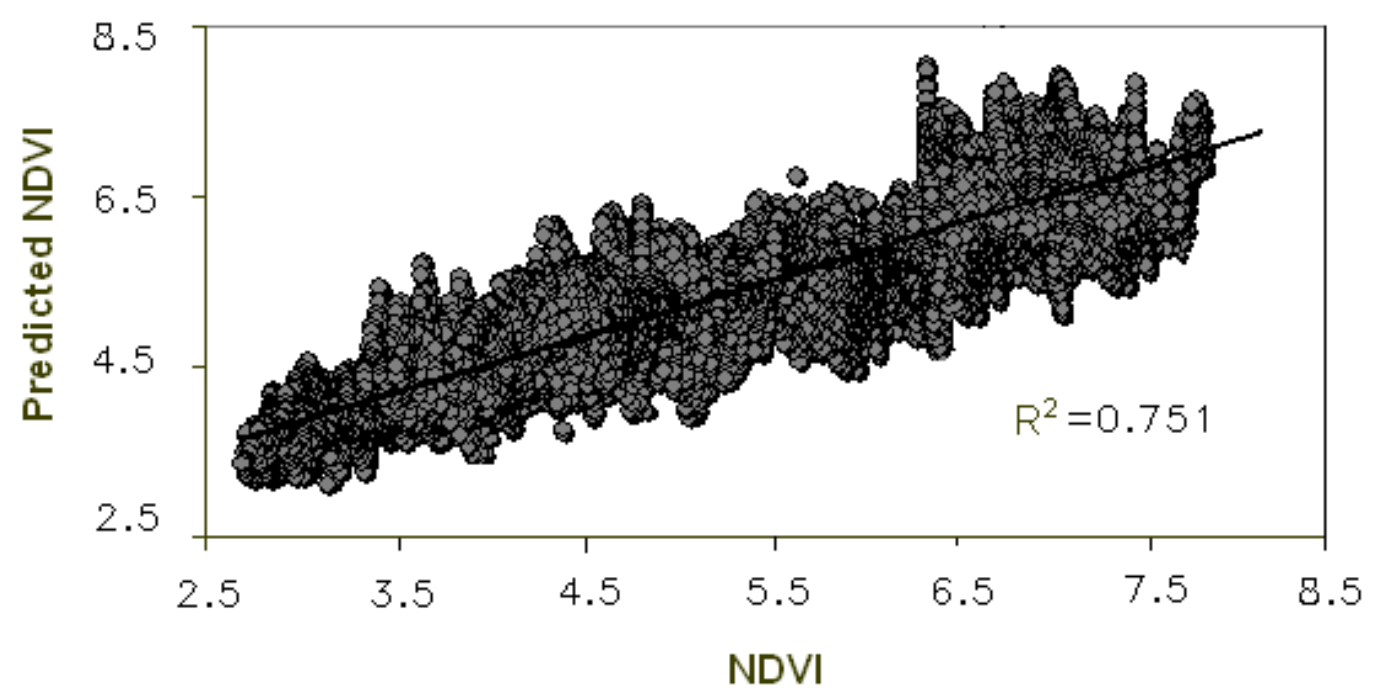

Figure 9.4. Scatter diagram between measured $N D V I_{\text {accum }}$ and $N D V I_{\text {accum }}$ predicted by the stratified OLS regression model.

All natural geographical phenomena tend to display in space rather systematic continual change than rapid interruptions, especially at regional scale (Griffith, 2003). Thus, the spatial patterns of the regression variables both $N D V I_{\text {accum }}$ and precipitation amount exhibit smoothed change in the space without any contradicted jumps in their values. One of the best evidences for that is high positive spatial autocorrelation of the regression variables over short distances. Therefore, one may assume that the relationship between $N D V I_{\text {accum }}$ and precipitation could systematically change from one sub-region to others. But the relationship may change also within each sub-region because of its non-homogeneity by scaling down from the sub-region scale to the pixel scale. Thus, we may expect non-stationarity in the relationship also within each sub-region (land-cover type). As a result of these hypothesis, we expect that the estimated intercept parameter will decrease systematically from the north and north-west to the south across the study area, while the estimated slope parameter will increase in the same direction. 
The applying of the regression models derived for the individual land cover types enlarged the prediction power of the global OLS significantly, although the strength of the relationship between $N D V I_{\text {accum }}$ and rainfall calculated separately for the desert, the semidesert and short grassland was not as high as that derived for the global OLS. A large amount of variance in $N D V I_{\text {accum }}$ remains unexplained for each land cover type. But there is a significant decrease of standard error in comparison with the global OLS model. The smallest $\mathrm{SE}$ was 0.10 for steppe grassland, while the largest SE of prediction is equal to 0.17 and was calculated for short grassland.

Disaggregating of global OLS regression model into four stratified OLS models has improved the modelling certainty and quality. Although, the unexplained amount of variance in $N D V I_{\text {accum }}$ remains relatively high, but the accuracy of the prediction is significantly increased. Some patterns of residual distribution disappeared and become more smoothed.

\subsubsection{Local variability in relationship between vegetation and precipitation}

The GWR method has also been applied for modelling relationship between $N D V I_{\text {accum }}$ and precipitation. To obtain localized results, a 9 by 9 pixels window was placed over each pixel which provides 81 data points for the model calibration at each pixel location. This was the window size which was determined by minimisation of the cross validation square sum, CVSS (Fotheringham et al., 2002). The GWR model allows the regression parameters to vary in space and establishes considerably stronger relationship between the two variables. The general regression equation may be given as:

$$
N D V I_{\text {accum }}=(-4.98-5.03)+(-2.36-1.97) * P \quad\left(\mathrm{R}^{2}=0.97\right)
$$

In the brackets range values for regression intercept and slope parameters are written.

Figure 9.5 summarizes the results derived from the geographically weighted regression analysis between $N D V I_{a c c u m}$ and rainfall. Panel a shows spatial distribution of the intercept which had a mean of -0.32 and a range of -4.98 to 5.03. Large positive values are distributed mainly in the north of the region where short grassland and steppe grassland 
dominate while low values are mainly in the mid and in the south. Here semi-desert and desert vegetation dominate.
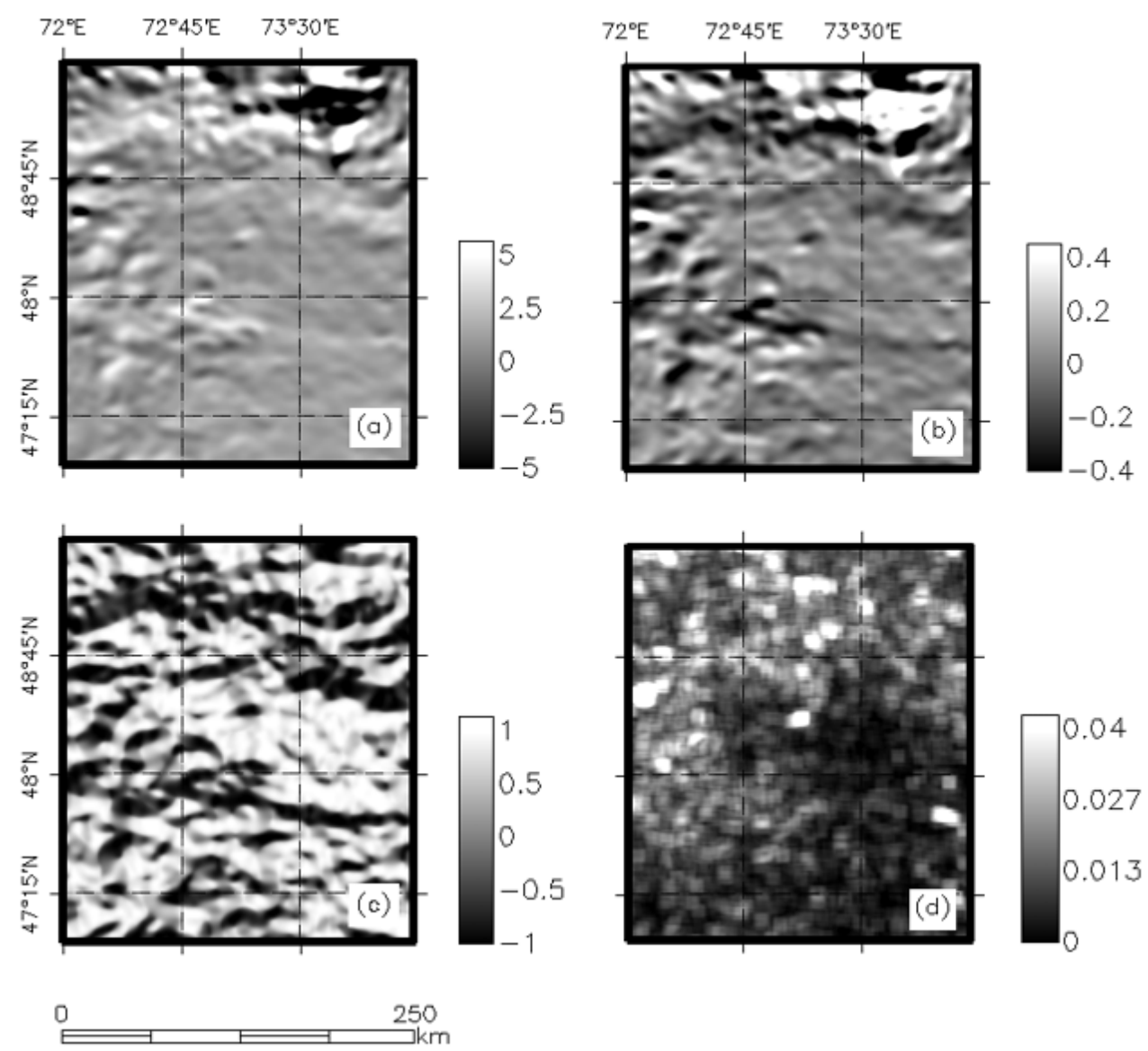

Figure 9.5. Spatial variations in regression outputs from the GWR analysis of growing season accumulated NDVI against precipitation: (a) model intercept, (b) model slope parameter, (c) local coefficient of determination, $\mathrm{R}^{2}$, (d) standard error of the model prediction.

Panel $b$ shows spatial variation in the slope parameter. This parameter had a mean of 0.0418 with a range of -2.36 to 1.97 and a standard deviation of 0.22 . Negative values of the slope parameter indicate that in some locations $N D V I_{\text {accum }}$ decreases when precipitation increases. Negative values are to be found mainly in the northern and western parts of the study region where crop fields/grassland mosaics dominate. The valley bottoms in the northeast also exhibit negative values of the slope parameter. Panel c displays the spatial variation in the strength of the relationship. The goodness-of-fit, measured by the coefficient of determination, $\mathrm{R}^{2}$, varied in the space and ranged from 0.016 to 0.99 , with $\mathrm{R}^{2}>0.75$ for twothirds of the study region. Low values of $\mathrm{R}^{2}$ are mainly distributed in the west and over a swath of land from the east to the north-west in upper part of the map. The entire model performance was significantly improved both for standard error of prediction accuracy and for 
the prediction power. Figure 9.6 shows the scatter plot between measured $N D V I_{\text {accum }}$ and predicted $N D V I_{\text {accum }}$ using the GWR model.

Panel d presents the standard error term which has been used as a guide to prediction accuracy. Standard error estimated for the GWR ranged from -0.0012 to 0.04 . Values of standard error are several times smaller than that estimated for the global OLS (SE $=0.21$ ) and stratified OLS models ( $\mathrm{SE}=0.10-0.17$ ). The GWR model enables to estimate and map the standard error for every pixel. The spatial patterns in the standard error reveal the danger of using the single estimate for SE derived from a global OLS locally, they vary in magnitude from pixel to pixel. The spatial patterns of SE clearly correspond to that of land-cover categories. This suggests that the GWR model significantly improved prediction of $N D V I_{\text {accum }}$ by rainfall over the OLS model.

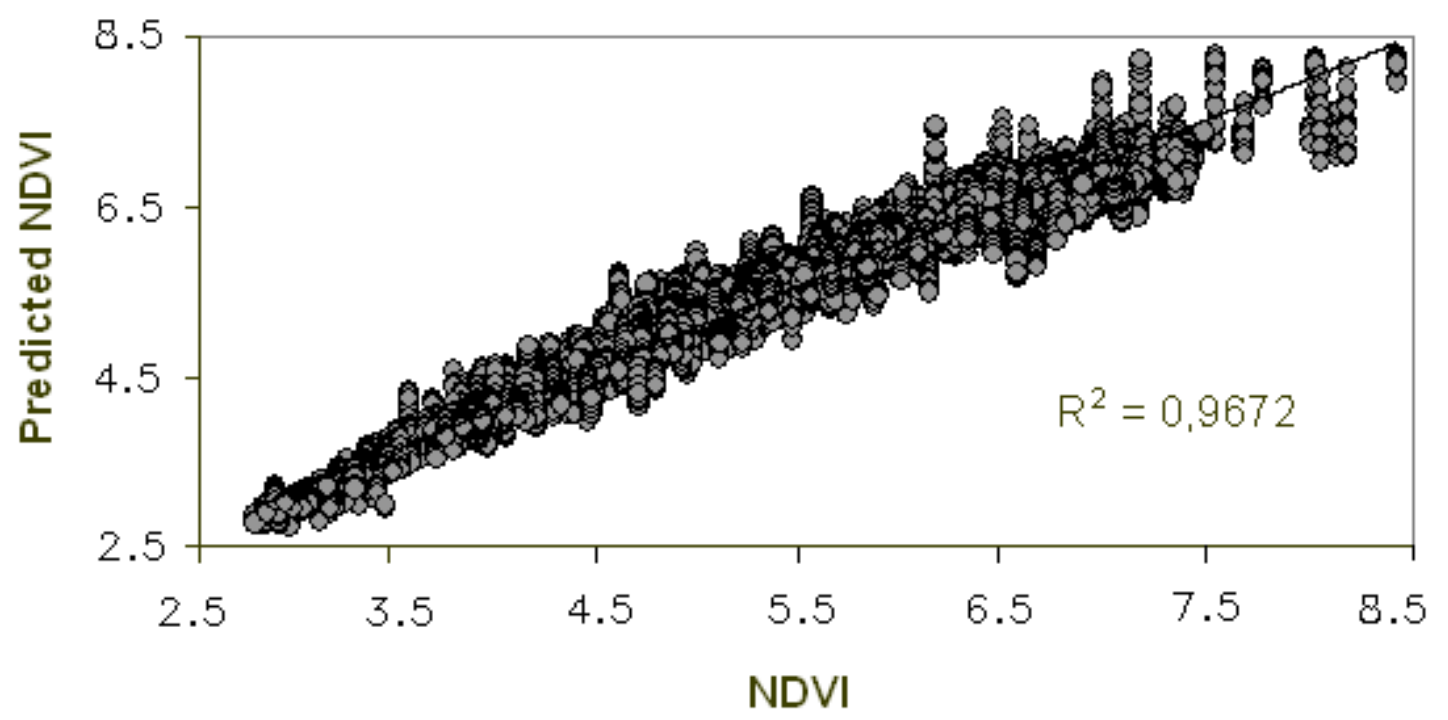

Figure 9.6. Scatter plot between measured $N D V I_{\text {accum }}$ and computed from the GWR model.

The spatial patterns in the parameter estimated from the GWR analysis illustrate the geography of the relationship. Generally, the spatial patterns in the intercept and slope parameter appear to correspond with some patterns in land cover distribution. The intercept parameter increases in order from desert, to semi-desert, to short grassland and to steppe, while the slope parameter decreases in the same direction. The large spatial variation in the regression parameters suggests that spatial non-stationarity exists and that there are different responses of vegetation to precipitation not only between the land-cover types but also within every land-cover type. 
In order to answer the question "Why does the $N D V I_{\text {accum }}$-precipitation relationship vary from location to location within a land-cover type?", one need detailed local knowledge from subsequent fieldwork and from fine resolution satellite data. According to our analysis, the main reasons for variation in the $N D V I_{\text {accum }}$-precipitation relationship within the landcover categories are the following: (1) relief; a vegetation located on hill slope exhibits a lower response to precipitation than a vegetation located on plain, (2) shift in vegetation species building the plant community due to change in land-use aspect or it's intensity, (3) shift in vegetation species due to natural factors such as geological underground, soil type, groundwater table, etc., (4) land degradation of locations.

\subsubsection{Analysis of regression residuals}

Both residuals values and spatial pattern of residuals are important indices to examine how accurate the regression model reveals the real relationship. The validity of the regression statistics depends on the distribution of the residuals. There are three conditions which have to be fulfilled by the residuals: (a) the residuals must be normally distributed; (b) the residuals must be homoscedastic; (c) the residuals must not be autocorrelated (Wackernagel, 1998). The residuals value also serves as a measure of accuracy of the regression model estimation. Generally, the less is the distance between every regression point and the regression line the higher is the accuracy of the regression model. The residuals of a linear regression model are also required to be independently distributed over space with a mean of zero and constant variance. If the residuals exhibit some non-random patterns the model created is problematic. A diagnostic statistics indicating problems in regression modelling is the degree of spatial autocorrelation exhibited by the residuals from the model. The standard errors are usually underestimated when positive autocorrelation is present.

We analysed both the values and the spatial distribution of the residuals for each of the three regression models created. All three models showed a normal distribution of their residuals with a mean of zero (Figure 9.7), but the range of the residuals value varies from one model to another. The residuals histograms shown on Figure 9.7 contain important information about the residuals value and the residuals variation. Thus, the peakedness (kurtosis) of the residual histograms increases in order from of the OLS model, to OLS 2 model, and to GWR model. The residuals from the GWR show the most peaked histogram. That means the best concentration of the residuals about zero. The absolute values of the residuals from the two OLS models range between $-1.2-1.2$ and $-1.0-1.0$ respectively, 
while that of the GWR residuals between -0.5 and 0.5 . There was a significant decrease of standard deviation of regression residuals if one moves from the global OLS model, to the OLS stratified by land-cover type, and to the GWR model. For the global OLS model, the standard deviation of residuals was 0.48 or $9.17 \%$ of mean $N D V I_{\text {accum }}$ value, for the OLS stratified by land-cover type, the standard deviation of residuals was a few less, 0.39 or 7.11 $\%$ of mean $N D V I_{\text {accum }}$. The standard deviation of the GWR residuals was only 0.24 or $3.26 \%$ of mean $N D V I_{\text {accum }}$.

A visual interpretation of the residual maps shown in Figure 9.7 gives us a good impression that there is a clear separation of the residuals from the global OLS in the space. In the northern part of the study area, the residuals tend to exhibit positive values, while in the southern part, the residuals values are mainly negative. The global OLS model underestimates when $N D V I_{\text {accum }}$ is high and overestimates when NDVI is low. Patterns in the mapped residual values appear to correspond clearly with patterns in land-cover. The positive deviations are associated with the dry steppe vegetation cover, while the negative deviations are mainly observed in the desert zone. The spatial patterns of the residuals from the OLS stratified by land-cover type are not as clear as those for the global OLS model, but the separation in the space also remains. Only the GWR model allowed destructing the spatial dependence of the regression residuals (Figure 9.7, c). The GWR residuals display no clear spatial patterns and their distribution over the study area seems to be close to random.

Spatial autocorrelation measures the similarity between samples for a given variable as a function of spatial distance. For the global OLS model and the GWR model, we calculated the Moran's $I$ of the residuals to examine the effect of calibration of the models locally by GWR rather than globally. It is proved that the local calibration removes much of the problems of spatially autocorrelated error terms included in the traditional global OLS model (Wang et al., 2005; Fotheringham et al., 2003, pp. 112-117). We were interested in the comparison of the results from the global and local models.

Figure 9.8 shows the spatial correlograms for the global OLS model residuals and the residuals from the GWR model. As expected, the error terms are most strongly autocorrelated for the global OLS model. The OLS model residuals had significant spatial autocorrelation up to circa $50 \mathrm{~km}$. In comparison, no significant positive spatial autocorrelation was found for the GWR model residuals. It suggests that the calibration of a local model reduces the problem of spatially autocorrelated error terms. The GWR model demonstrates the ability to deal with spatial non-stationary problems. 

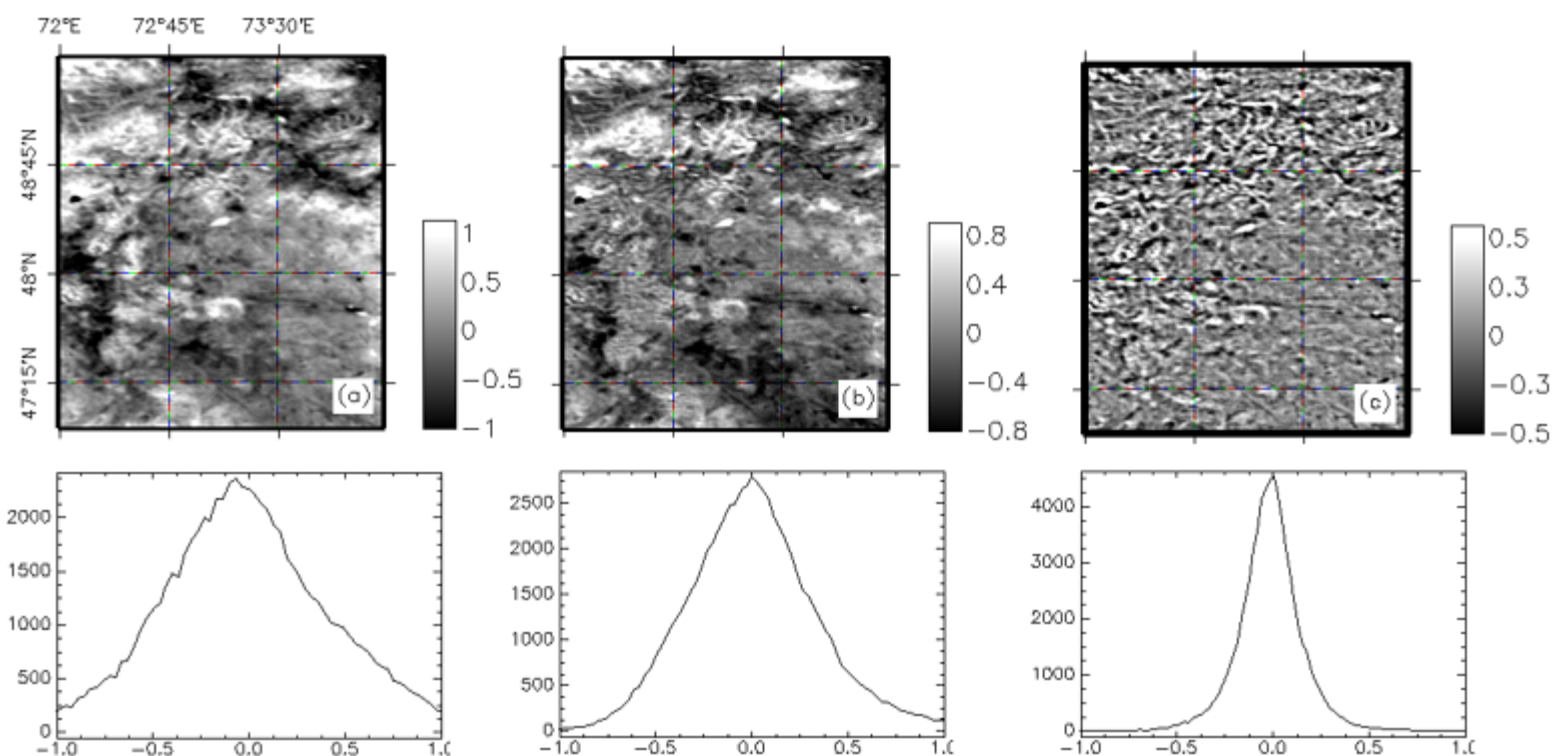

Figure 9.7. Spatial patterns of regression residuals (upper panels) and corresponding residuals histograms (lower panels) for the global OLS model (a), the OLS model based on stratification by land-cover types (b), the GWR model (c).

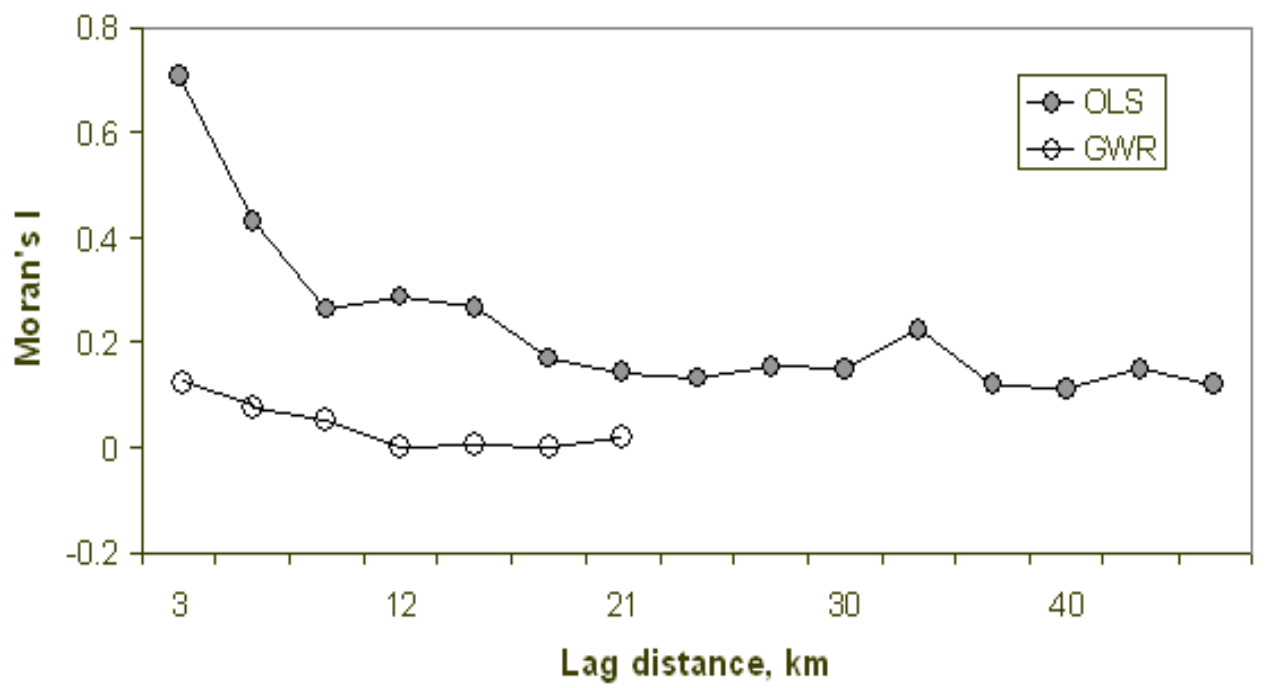

Figure 9.8. Spatial autocorrelograms for OLS residuals and residuals from the GWR model. The autocorrelogram of the OLS residuals indicates that Moran's I values up to a lag distance of more than $40 \mathrm{~km}$ are significantly larger than the value expected under the null hypothesis of no positive autocorrelation. The autocorrelogram of the GWR residuals displays no significant positive autocorrelation. 


\subsection{Analysis of temporal variations in NDVI-precipitation relationship using GWR}

Variability in the relationship between vegetation distribution and patterns in climate predictors has already been shown in chapter 6 and 7 by analysing data with a spatial resolution of $8 \mathrm{~km}$. The correlation coefficient for growing season NDVI-precipitation varied from 0.67 to 0.91 during the period 1985-2001. The correlation coefficient for NDVItemperature showed variability; although the magnitude was lower (data not shown). In chapter 6 and 7, the scale of the analysis has been either the entire study region or a separate vegetation type. The OLS regression model has no possibility to model relationship at the local level or at the scale of a pixel. On the contrary, GWR approach enables us to analyse the relationship between NDVI and climatic factors at the per-pixel basis. Thus, one can use timeseries of the NDVI-climate models to analyse variability of vegetation response to external factors. However, the 1-km dataset cover only a period 1998-2004. Certainly, the relationship varies also during this relatively short period. But for this work, it was more interesting to monitor variance in the relationship during a longer period which would comprise the years before and after the constitutional change in Kazakhstan. Therefore, GWR modelling has been applied for every year from the 8-km dataset covering the period of 1985-2001.

\subsubsection{Variations in the relationship strength}

The results demonstrated high variability both in the strength of relationship and the regression parameters over the period at the scale of vegetation type and at the pixel scale. Figure 9.9 displays some results. Spatial patterns of the coefficient of variations of $\mathrm{R}^{2}$ appear to correspond exactly with patterns of vegetation cover: variability of $\mathrm{R}^{2}$ decreases from shrubs and desert vegetation in the south of the study area, to semi-desert, to steppe vegetation in the north. These results indicate a major degree of temporal variation in the relationship between NDVI and rainfall in the study area. There may be many reasons for this fact. One of the reasons may be different resilience strength of vegetation types to interannual climate variability. Definite vegetation communities may react to rainfall inter-annual variations more sensitive than others. Intra-annual spatial distribution of rainfall over the study area can vary significantly and may distribute to variation in the relationship of NDVIrainfall. 

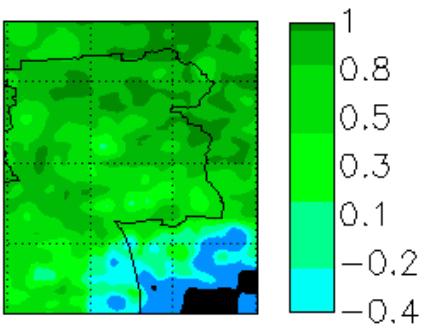

b
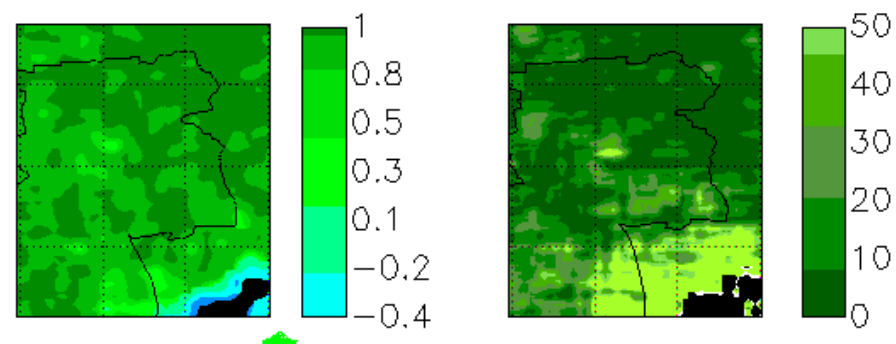

c

Figure 9.9. Maps demonstrating variability in NDVI-precipitation relationship during 1985-2001. (a) Minimum value of the determination coefficient, $\mathrm{R}^{2}$, (b) its maximum value and (c) coefficient of variation.

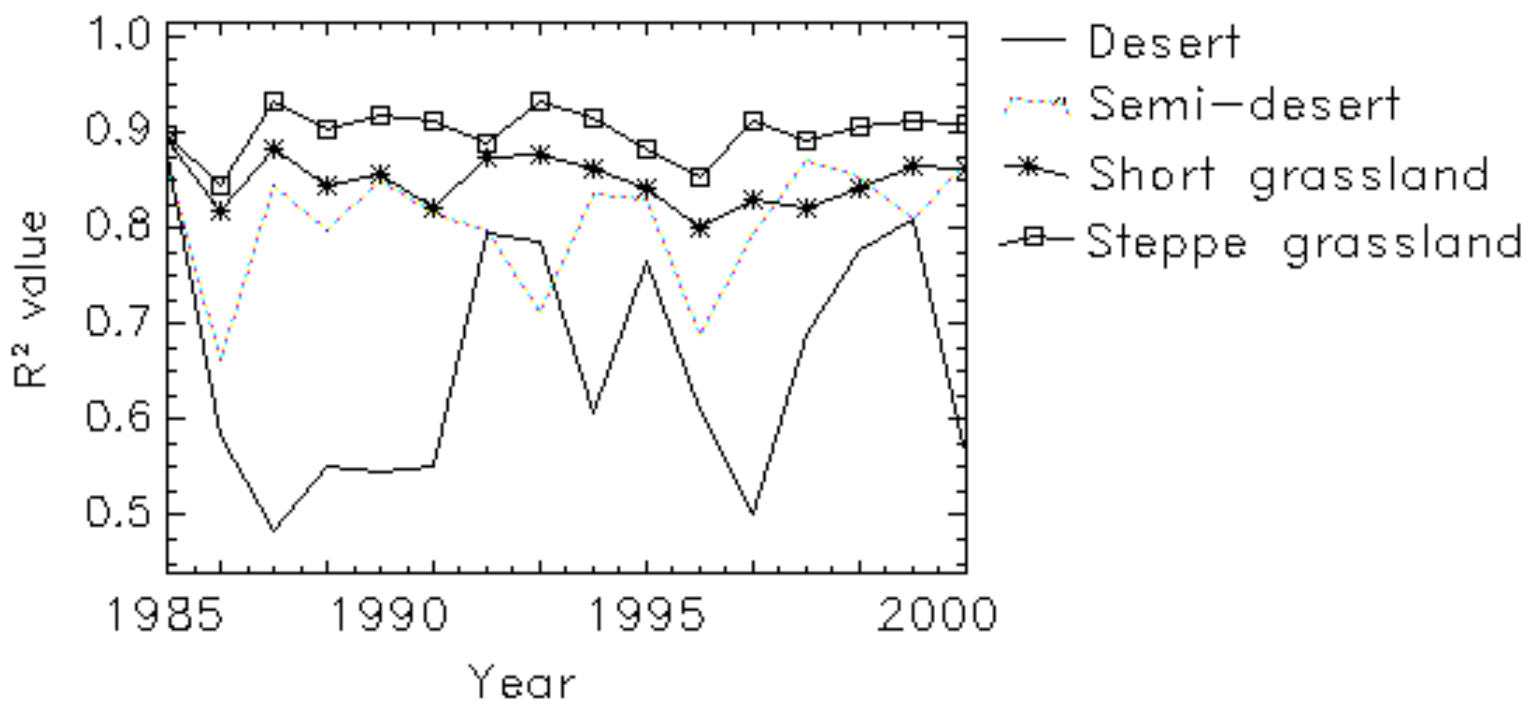

Figure 9.10. Inter-annual variations in $\mathrm{R}^{2}$ averaged for vegetation types.

\subsubsection{Trends in NDVI-rainfall relationship and their linkages to land use/land cover} change

The strength of relationship between NDVI and rainfall, along with the use of regression statistics, provides useful information for assessment of land cover performance. In the dry regions, areas with exceptionally low NDVI-rainfall correlation identify sites where vegetation cover is damaged and land degradation is going on (Li et al., 2004). Looking into time-series of regression statistics, especially such of $\mathrm{R}^{2}$, the ability of the land surface to respond to rainfall over the time period can be implied. Thus, a decrease of $\mathrm{R}^{2}$ over the study period would indicate a decreasing dependence of the vegetation cover on rainfall patterns 
and an increasing dependence on others factors such as temperature patterns or human influence. This negative trend would indicate an area with vegetation cover being damaged. On the contrary, an increase of $\mathrm{R}^{2}$ over time may indicate a surface with an increasingly better response of the vegetation cover to rainfall and a decreasing role of other predictive factors. There is no doubt, that any change in land cover or in land use would be reflected in a change of $\mathrm{R}^{2}$ value. So, abandonment or expansion of cultivated areas as well as taking virgin land into agricultural use should be noticeable in the time-series of $\mathrm{R}^{2}$.

In order to prove this hypothesis, we selected some representative sites with noticeable LULC change and processed time-series of $\mathrm{R}^{2}$ for these areas. Squares with a size $3 * 3$ pixels were extracted for each of the test sites from the developed time-series of $\mathrm{R}^{2}$. For evidence about changes of surface features we looked at multi-temporal Landsat images and used available historic reports. During field surveys in 2004 and 2005 surveys of indicators for land degradation have been verified in areas which had been considered degrading on the Landsat images.

Basically, four trend types (fifth type is insignificant trend!) can be found in the NDVI-rainfall relationship in the study region. Figure 9.11 displays typical patterns of $\mathrm{R}^{2}$ time-series for the characteristic sites:

1. Panel (a) shows a site in which agricultural use was evident during the entire study period. Generally, for this site, the strength of the NDVI-rainfall relationship decreased from 1985 to 2000, implying a decreased ability of the land surface to respond to rainfall over this period. Clear sings of increasing land degradation were identified on the Landsat images and during the field trips.

2. Panel (b) shows a site located in the steppe section and which was used as pasture land. Clear positive trend in $\mathrm{R}^{2}$ after 1990 is associated with a rapid reduce of animals pressure on the pasture land because of a dramatic decrease of livestock caused by the collapse of the socialistic economic system.

3. The clearest trends are related either to the abandonment of cultivated areas or to newly established cultivated areas. Panel (c) represents a site which had 
been cultivated intensively until 1992 and then has been abandoned. The cultivation of the site led to land degradation and a permanent decrease of vegetation response to rainfall during 1985-1992. The abandonment of the cultivated field enhanced a rapid recovery of the vegetation cover and the positive trend in $\mathrm{R}^{2}$, although there were two years with exceptionally low $\mathrm{R}^{2}$ values.

4. Panel (d) shows a process which is reverse to that described for Panel (c). The site of this panel had experienced no or very slight human influence in form of grazing during 1985-1992 and was taken into intensive agricultural use after 1992. The ploughing up of the virgin land of this site enhanced degradation of the upper soil layer caused by wind erosion and was expressed in a decrease of $\mathrm{R}^{2}$ values over the period 1992-2000.
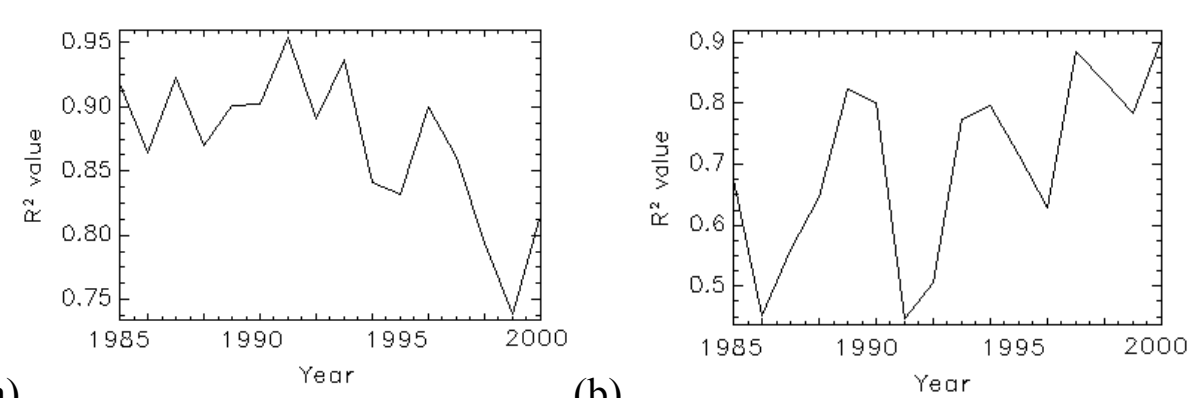

(a)

(b)
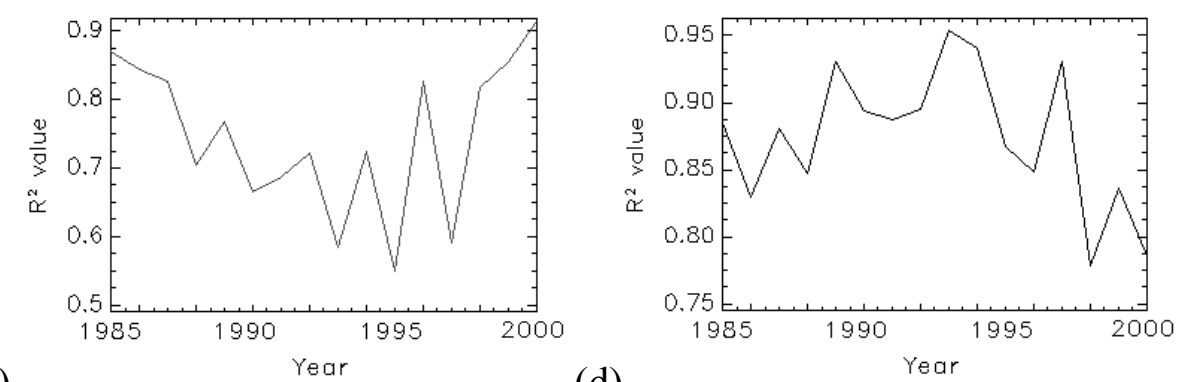

(c)

(d)

Figure 9.11. Time-series of $\mathrm{R}^{2}$ for four individual sites demonstrating typical linkages between the NDVI-rainfall relationship and LULC change (see supplementary description in the text). 


\subsection{Discussion and conclusion}

In this chapter spatial relationship between NDVI and precipitation have been analysed using a local regression technique known as geographically weighted regression. In order to demonstrate differences in the modelling procedures and the end results, GWR modelling was carried out parallel to OLS modelling. The GWR method allows the regression parameters and the strength of the relationship to vary over the space. The results of the GWR suggest that it provides more accurate predictions than the OLS regression model.

The study found a high spatial non-stationarity in the strength of relationship and regression parameters both between the land-cover types and within each land-cover type. The ordinary least squares regression model which had been applied to the whole study area was superficially strong $\left(\mathrm{R}^{2}=0.63\right)$, however it gave no local description of the relationship. Applying the OLS at the scale of the separate land cover classes revealed a different response of various vegetation types to rainfall within the study area. The strength of the relationship between NDVI and rainfall increased in order from desert $\left(\mathrm{R}^{2}=0.36\right)$, to semi-desert $\left(\mathrm{R}^{2}=\right.$ $0.44)$, to short grassland $\left(\mathrm{R}^{2}=0.52\right)$, and to steppe grassland $\left(\mathrm{R}^{2}=0.67\right)$. The coefficient of determination, $\mathrm{R}^{2}$, was higher for the GWR model. The approach of geographically weighted regression provided considerably stronger relationships from the same data sets $\left(\mathrm{R}^{2}\right.$ value for the general regression $=0.97$ ), as well as highlighted local variations within the land cover classes. The amount of variance in NDVI remaining unexplained was not as large as was expected from the OLS analysis. The standard error (SE) was used as a guide to accuracy of the predictions. For the global OLS modeling, SE was 0.21. The SE calculated through the stratified OLS model for the land-cover types were a few smaller than for the whole region. Fitting the regression model at pixel scale what was achieved through application of the GWR significantly reduces error terms. As expected, the errors terms shown by the results of the GWR are several times low ranging from 0.0012 to 0.04 .

Applying the GWR method for dealing with spatial relationship significantly reduces both the degree of autocorrelation and absolute values of the regression residuals. The residuals from the global OLS model clearly exhibited positive spatial autocorrelation with an area of positive residuals grouped together (in the north) and also an area of negative residuals grouped together (in the south). The spatial autocorrelation in the residuals from the equivalent GWR model was no evident. There were no obvious patterns to the residuals which appear randomly over the region. The results suggest that GWR provides a better 
solution to the problem of spatially autocorrelated error terms in spatial modelling compared with the global regression modelling.

Application of the GWR model on time-series of 8-km AVHRR NDVI enabled to analyse inter-annual variability in NDVI-precipitation relationship at per-pixel scale. This analysis highlighted presence of temporal variations in both regression model parameters and coefficients of determination $\mathrm{R}^{2}$ over the period 1985-2000. Patterns in the temporal variation in the slope and in the intercept parameter as well as in the $\mathrm{R}^{2}$ appeared to correspond with patterns in vegetation cover. The variation was generally large in the areas covered by desert vegetation and low in the areas covered by steppe vegetation. Generally, changes in NDVIrainfall relationship proved to be dependent on changes in land use and land cover. This hypothesis has been proved in the study region on examples from a number of typical test sites. The results indicated strong relationship between land cover change and NDVI-rainfall correlation coefficient. 


\section{Chapter 10}

\section{Detection of climate-induced and human-induced vegetation}

\section{change}

Vegetation cover is one of the major components of an ecosystem that is very sensitive to external effects. The main external effects are climate and human impact which are not constant in time. Due to remote sensing techniques it is possible to monitor conditions of vegetation cover during relatively long time periods and to compare these with climatic variability and variability in human influence. Theoretically, modelling vegetation dynamic with dynamics of climate and human influence may help to understand the combined role and the individual roles of these both external factors in vegetation long-time change (Richard \& Poccard, 1998; Wang et al., 2003; Li et al., 2002). Studies by Tateishi \& Ebata (2001) and Xiao \& Moody (2004) found evidences that in many cases, climate change was a driving force for trends in vegetation activity.

But the discrimination between climate-induced and human-induced vegetation changes remains difficult and uncertain. There are a number of modern studies that tried to discriminate between these two factors and described methods to solve this problem (for example, Li et al., 2004; Evans \& Geerken, 2004). All these studies have offered a problem solution through identification of climate signal in time-series of NDVI and removing it. After the climate signal had been removed, changes remaining in NDVI time series may be associated with anthropogenic factor. If these changes are positive, one may speak about improvement of vegetation cover due to changes in land use and agricultural practices. In case of these changes being negative, in that case vegetation cover is degrading due to human influence.

In the main, discrimination between climate-induced and human-induced changes in vegetation cover should start on with identification of climate signal in the changes of vegetation activity. After this signal is identified, we may attribute defined vegetation changes to climate change. If this attribution is not possible, the changes may be associated with human or other external influence. The preceding chapters investigated the inter-relationship between vegetation cover and climatic effect at both within-season and inter-annual timescales. The results of those chapters proved a presence of a strong climatic signal in the interannual dynamic of vegetation cover in the study region. But the inter-annual dynamic is not always equal to inter-annual change. Under the term dynamic we have to understand interannual oscillations of vegetation cover near the long-time value. The term "inter-annual 
change" refers to a shift of this long-time mean value over a defined time. Mathematically this is expressed through time trend. Generally, the results of the previous chapters showed that we have a great chance to detect the climatic signal in changes of vegetation cover if they occurred during the study period. The action we have to undertake is to detect trends in NDVI and compare them with trends in climate factors. The only condition which is to fulfil by the areas to be examined is a presence of statistically significant relationship between inter-annual dynamic of NDVI and a corresponding climate factor. The methodology of analysis and the decision framework as well as a technique for analysis of areas without any trends in NDVI has been described in Chapter 4.

This chapter examines trends in vegetation cover over 1982-2003 and their explanation by the trends in climate factors. Areas with NDVI trends explained by trends in precipitation and temperature were determined and measured. Areas with insignificant NDVI trends which seamed to be stable during the study period but in fact undergone improvement or degradation of vegetation cover were also identified. The identification of these areas was based on analysis of changes in response of vegetation cover to climate factors. Increasing response is associated with improving vegetation cover. In opposition to that, decreasing response considered to indicate degradation of vegetation cover. The results were validated on test sites using field survey records and analysis of Landsat imagery.

\subsection{Trends in spatially averaged NDVI}

\subsubsection{Trends in growing season NDVI}

The spatially averaged time-series of growing season NDVI exhibited a statistically significant upward trend with an increase of $6.46 \%$ for all vegetated pixels over the period 1982-2003 (Table 10.1). The determination coefficient of the trend is high enough, $\mathrm{R}^{2}=0.19$. The growing season NDVIs also exhibited significant upward trends for each land-cover type with an exception of semi-desert. For semi-desert, the trend was found to be insignificant even though it had shown an increase magnitude of $5.05 \%$. The magnitude of NDVI trend varied by land-cover type, the highest total increase with a value of $6.92 \%$ was observed in steppe grassland. For short grassland and desert shrubland, the total increase of NDVI during 22 years was $6.12 \%$ and $5.53 \%$, correspondingly. The determination coefficient of the trend lines, $\mathrm{R}^{2}$, ranged from 0.14 to 0.26 . 


\subsubsection{Trends in seasonal NDVI}

The spatially averaged time-series of seasonal NDVIs showed significant upward trends in spring for all land-cover types and in summer for short grassland and steppe grassland. The total increase averaged for all vegetated pixels was $8.10 \%$ for spring, and only $3.16 \%$ for summer, with $\mathrm{R}^{2}=0.47$ and 0.18 , respectively. The magnitude of the spring trend varied by vegetation type, with the highest values of $13.78 \%$ and $10.91 \%$ registered in steppe and short grassland. These two vegetation types also showed the greatest $\mathrm{R}^{2}$ of all trends.

There were no significant trends in summer NDVI for desert and semi-desert vegetation types. Summer NDVI of steppe grassland increased to $6.88 \%$ during 1982-2003. The increase in summer NDVI for short grassland was lower, $4.54 \%$, but also statistically significant. On the whole, summer NDVI showed only weak ascend over the period of 19822003. For the entire area, the increase was $3.16 \%$. Autumn NDVI did not exhibited any significant trends in seasonal or growing season NDVI during 1982-2003.

The results of trends in seasonal NDVI suggested that the trends in vegetation activity for each vegetation type and the entire area are primary attributed to spring rather than the whole growing season. In cases of steppe and short grassland, summer also plays a role but less important than spring. This is consistent with results from previous studies undertaken in similar latitudes at global and regional scales. The reason for the higher change rates of grassland vegetation activity in spring corresponds to general upward trends in winter and spring temperatures (Kuwabata et al., 2001; Tucker et al., 2001; Xiao \& Moody, 2004). This increase in winter and spring temperatures enables an earlier start of greening phase and a more rapid climb of NDVI values in spring.

Table 10.1. Trends of spatially averaged time-series of growing season, spring, summer and autumn NDVI over 1982-2003

\begin{tabular}{|l|r|c|r|r|r|r|}
\hline Vegetation type & \multicolumn{2}{|c|}{$\begin{array}{c}\text { Growing } \\
\text { season NDVI }\end{array}$} & \multicolumn{2}{l|}{ Spring NDVI } & \multicolumn{2}{|c|}{$\begin{array}{c}\text { Summer } \\
\text { NDVI }\end{array}$} \\
\cline { 2 - 7 } & $\begin{array}{c}\text { Change, } \\
\%\end{array}$ & $\mathrm{R}^{2}$ & $\begin{array}{c}\text { Change, } \\
\%\end{array}$ & $\mathrm{R}^{2}$ & $\begin{array}{c}\text { Change, } \\
\%\end{array}$ & $\mathrm{R}^{2}$ \\
\hline Desert & 5.53 & 0.26 & 3.95 & 0.17 & Insignificant \\
\hline Semi-desert & \multicolumn{2}{|c|}{ Insignificant } & 4.02 & 0.13 & Insignificant \\
\hline Short grassland & 6.12 & 0.14 & 10.91 & 0.52 & 4.54 & 0.13 \\
\hline Steppe grassland & 6.92 & 0.19 & 13.78 & 0.64 & 6.88 & 0.27 \\
\hline & & & & & & \\
\hline Area average & 6.46 & 0.19 & 8.10 & 0.47 & 3.16 & 0.18 \\
\hline
\end{tabular}




\subsection{Spatial patterns of NDVI trends}

Since spatial averaging hides the geographical variability of NDVI, it is to expect that the NDVI trends will exhibit some spatial patterns within every land-cover type. These spatial patterns may be highlighted by calculation of trends on a pixel-by-pixel basis. We identified all vegetated pixels with linear trends in NDVI that were statistically significant. This analysis was repeated for each season. It was also to expect that not all pixels should show upward trends in NDVI, some pixels may exhibit downward trends. That was supported by the statistical analysis.

Over the entire study region, the results of our calculations show that $28.11 \%$ of all vegetated pixels exhibited a significant upward trend for the growing season over the study period, and $4.36 \%$ of all pixels exhibited a significant downward trend (Table 10.2 and 10.3). Greening patterns are mostly observed in the northern and southern portions of the region (Figure 10.1, a). Downward trends in growing season NDVI were mainly concentrated in the middle part. The percentage of pixels with upward NDVI trend varied substantially by landcover type ranging from $11.85 \%$ to $40.62 \%$. These extreme values are associated with desert shrubland and short grassland, respectively. For steppe grassland, $37.81 \%$ of all pixels exhibited positive trend and $19.20 \%$ for semi-desert.

The percentage of pixels with significant trends also varied from season to season. The highest percentage of pixels with an upward trend is observed for spring NDVI, $39.04 \%$. The greening pattern in spring is more immense than in any other season (Figure 10.1, b). Especially high percentage showed short grassland and steppe grassland with a value of $57.31 \%$ and $74.65 \%$, respectively. Pixels with positive trends in spring NDVI are densely distributed across the whole study region, except in its middle part. Altogether, $4 \%$ of all vegetated pixels had the negative trend in spring NDVI.

In summer, $20.61 \%$ of all vegetated pixels showed positive trends in NDVI over 1982-2003. These areas are mainly distributed in the northern part of the study region, and sparsely in the southern and middle parts (Figure 10.1, c). The summer season revealed the highest percentage of pixels with downward trend, $8.33 \%$ of total pixel amount. These pixels occupied large areas in the central and the east-central section. Small areas of negative trends are distributed in the north and in the south of the study region. Most parts of them are located in desert and semi-desert zones. These vegetation types exhibited high percentage of pixels with a downward trends in summer NDVI, $10.01 \%$ and $9.81 \%$, respectively. The pixels with downward trend in summer NDVI may represent severe degraded areas which are associated with a vegetation cover decreasing over the period 1982-2003. 
In autumn, positive NDVI trends were observed only for a little part of the total pixel number, $2.93 \%$. Relatively high percentage of pixels with increasing autumn NDVI was observed in steppe grassland, $6.55 \%$. For other land-cover types, the percentage of pixels with a positive trend is very low. NDVI increasing trends were mostly found in the southern stripe of the region, and only densely in the north (data not shown). There were not any significant downward trends in autumn NDVI.

Table 10.2. Number of pixels with significant upward trends in growing season, spring, summer, and autumn NDVI for individual vegetation types and for the area average.

\begin{tabular}{|c|c|c|c|c|c|c|c|c|c|}
\hline \multirow[t]{2}{*}{ Vegetation type } & \multirow[t]{2}{*}{$\begin{array}{r}\text { Total } \\
\text { pixels }\end{array}$} & \multicolumn{2}{|c|}{$\begin{array}{c}\text { Growing } \\
\text { season NDVI }\end{array}$} & \multicolumn{2}{|c|}{$\begin{array}{l}\text { Spring } \\
\text { NDVI }\end{array}$} & \multicolumn{2}{|c|}{$\begin{array}{l}\text { Summer } \\
\text { NDVI }\end{array}$} & \multicolumn{2}{|c|}{$\begin{array}{l}\text { Autumn } \\
\text { NDVI }\end{array}$} \\
\hline & & Pixels & $\%$ & Pixels & $\%$ & Pixels & $\%$ & Pixels & $\%$ \\
\hline Desert & 3967 & 470 & 11.85 & 1036 & 26.12 & 195 & 4.92 & 43 & 1.08 \\
\hline Semi-desert & 9458 & 1816 & 19.20 & 1266 & 13.39 & 558 & 5.90 & 162 & 1.71 \\
\hline Short grassland & 9101 & 3697 & 40.62 & 5216 & 57.31 & 3043 & 33.44 & 324 & 3.56 \\
\hline Steppe grassland & 3586 & 1356 & 37.81 & 2677 & 74.65 & 1585 & 44.20 & 235 & 6.55 \\
\hline Area average & 26112 & 7339 & 28.11 & 10195 & 39.04 & 5381 & 20.61 & 764 & 2.93 \\
\hline
\end{tabular}

Table 10.3. Number of pixels with significant downward trends in growing season, spring, and summer NDVI for individual vegetation types and for the area average.

\begin{tabular}{|l|r|r|c|r|r|r|r|}
\hline Vegetation type & $\begin{array}{c}\text { Total } \\
\text { pixels }\end{array}$ & \multicolumn{2}{|c|}{$\begin{array}{c}\text { Growing } \\
\text { season NDVI }\end{array}$} & \multicolumn{2}{l|}{ Spring NDVI } & \multicolumn{2}{c|}{$\begin{array}{c}\text { Summer } \\
\text { NDVI }\end{array}$} \\
\cline { 3 - 8 } & & Pixels & \multicolumn{1}{c}{$\%$} & Pixels & \multicolumn{1}{c|}{$\%$} & Pixels & \multicolumn{1}{c|}{$\%$} \\
\hline Desert & 3967 & 190 & 4.79 & 294 & 7.41 & 397 & 10.01 \\
\hline Semi-desert & 9458 & 445 & 3.65 & 670 & 7.08 & 928 & 9.81 \\
\hline Short grassland & 9101 & 284 & 3.12 & 76 & 0.84 & 621 & 6.82 \\
\hline Steppe grassland & 3586 & 220 & 3.35 & 2 & 0.06 & 230 & 6.41 \\
\hline & & & & & & & \\
\hline Area average & 26112 & 1139 & 4.36 & 1042 & 3.99 & 2176 & 8.33 \\
\hline
\end{tabular}



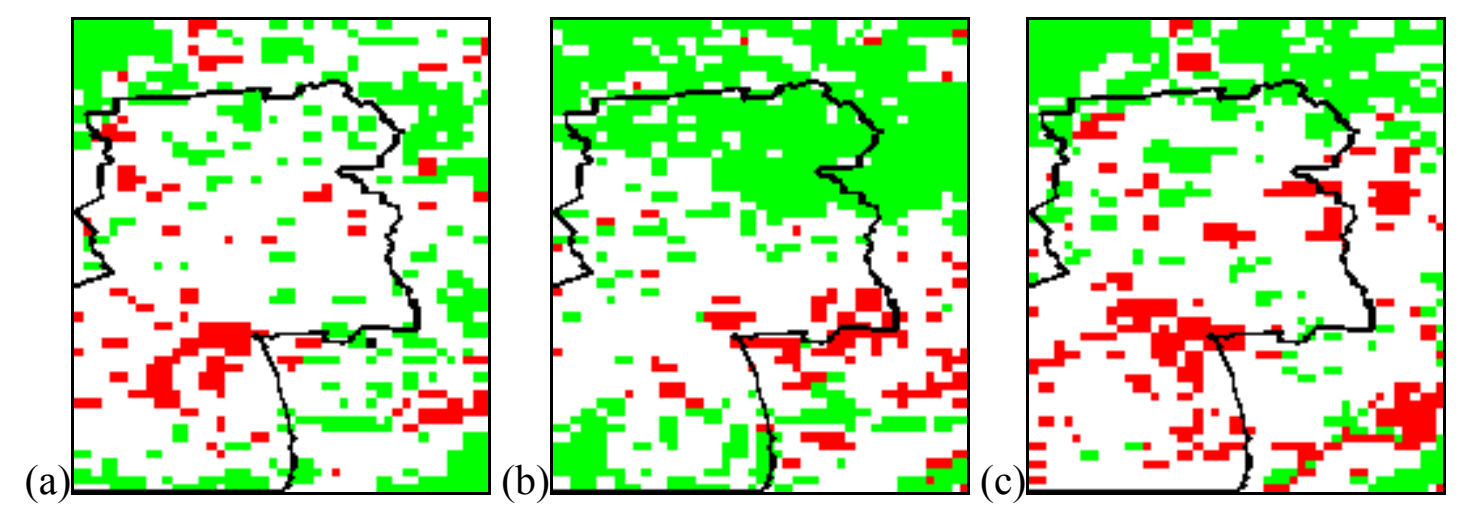

Figure 10.1. Areas of statistically significant linear trends of NDVI in the study region from 1982 to 2003. Areas with upward trends are coloured green. Red indicates areas with downward trends: (a) Growing season, (b) spring, (c) summer.

\subsection{Effects of precipitation and temperature on NDVI trends}

\subsubsection{Effects of climate on changes in spatially averaged NDVI}

Inter-annual relationships between spatially averaged NDVI and climate parameters have been described in sections 7.2.1 and 7.2.2. At this place, we give only a brief concretisation concerning the significant trends. All analysed correlations at the scale of individual vegetation types exhibited a positive value which means a general improvement of vegetation cover in the study region driven by the climate change. This agree with the results of section 5.3.2 which has investigated trends in precipitation and temperature. Even though the most trends in climatic factors were relatively weak and statistically insignificant, their direction corresponds to trends in NDVI and they may be considered to be the major driving force in the long-time change in vegetation cover. The correlation analysis between interannual NDVI and the corresponding precipitation and temperature data brought evidences for this appraisal.

Taking into account that not all vegetation types exhibited significant trends in NDVI, the results clearly indicate strong explanation of significant vegetation changes by climate effect at the scale of spatially averaged data. Both precipitation and temperature are considered to be driving forces for trends in NDVI of individual vegetation types but the response of vegetation cover to temperature was stronger than that to temperature. For the study area average, the correlation coefficient between spring NDVI-temperature amounted to 0.84 , whereas between growing season NDVI-precipitation $r=0.65$. There were significant correlations also between trends in summer NDVI and summer precipitation for the entire 
area and for two vegetation types, short grassland and steppe, with value of correlation coefficient $0.58,0.56$ and 0.68 , respectively.

\subsubsection{Spatial patterns in climate effects on NDVI trends}

The correlation analysis was repeated for every pixel with significant trends in NDVI over the study period. Then, the percentage of pixels with significant trend that can be attributed to the climatic explanatory factors, precipitation and temperature was measured within every vegetation type. The results clearly indicate that not all trends in growing season or seasonal NDVI can be associated with trends in climatic factors.

Generally, trends in NDVI are significantly correlated with trends in climate parameters. Over the entire region, about $48 \%$ of the vegetated pixels with significant upward trends in growing season NDVI exhibited positive correlations with growing season precipitation (Table 10.4). These pixels are mainly distributed in the northernmost portion of the region (Figure 10.2, a). The percentage of those pixels with upward growing season NDVI trends which may be attributed to the inter-annual change in precipitation was $60.91 \%$. More than a half of the downward trends remained explained by rainfall.

The observed trends in summer NDVI depended stronger on trends of the precipitation amount. Taken together, $58.17 \%$ of all pixels with a significant trends in summer NDVI demonstrated positive correlation with summer precipitation. These pixels are mainly distributed over a swath of land from north-west to south including small areas in the middle part of the study region (Figure 10.2, b). Compared with growing season rainfall, summer rainfall plays major role in explaining the greening pattern through 1985-2003. On the contrary, for the pixels with significant downward trends, summer rainfall makes a smaller contribution to decrease of NDVI than growing season rainfall does. It contributed to $39 \%$ of all decreasing NDVIs.

For all vegetated pixels with a significant upward trend in NDVI, 78.14 \% exhibited positive NDVI-temperature correlations for the spring season. These pixels are distributed throughout the study region but most of them occupy the northernmost and southern portion (Figure 10.2, c). Over the entire study area, 1042 pixels exhibited significant downward trends in spring NDVI. About $90 \%$ of these pixels demonstrated correlation with spring temperature. These pixels are only situated in the surroundings of the meteorological station Aktogay where a decrease of spring temperature was observed (see section 5.3.2). 
Taking into account the relatively low percentage of upward pixels correlating with precipitation, $47.88 \%$ and $58.17 \%$ for growing season and summer, respectively, the growing season trend in NDVI in the study region may be entirely attributed to other factors such as the increase in spring temperature or anthropogenic impact. A general decrease of human influence in the study region may be a driving force for rehabilitation of ecosystems and, correspondingly, for the observed upward trends in NDVI. The negative trends demonstrated relatively good explanation by precipitation of growing season and low by that of summer, with pixel percentage of $60.91 \%$ and $38.97 \%$, respectively. That is because of the mostly anthropogenic origin of these vegetation decreases. Most of the areas of negative trends in growing season and summer NDVI are located closely to settlements where after the year 1991 they were intensively used for pasture or crop production and show at Landsat images clear sings of overgrazing or soil degradation.

Table 10.4. Total number of pixels with significant upward or downward trend and number of pixels which trends are explained by climate change for growing season, spring and summer.

\begin{tabular}{|l|c|c|c|c|c|c|c|c|c|}
\hline \multirow{2}{*}{$\begin{array}{c}\text { NDVI } \\
\text { trends }\end{array}$} & \multicolumn{3}{|c|}{ Growing season NDVI } & \multicolumn{3}{|c|}{ Spring NDVI } & \multicolumn{3}{c|}{ Summer NDVI } \\
\cline { 2 - 10 } & Pixels & $\begin{array}{l}\text { explained by } \\
\text { precipitation }\end{array}$ & $\%$ & Pixels & $\begin{array}{l}\text { explained by } \\
\text { temperature }\end{array}$ & $\%$ & Pixels & $\begin{array}{l}\text { explained by } \\
\text { precipitation }\end{array}$ & $\%$ \\
\hline Upward & 7339 & 3514 & 47.87 & 10195 & 7165 & 78.14 & 5972 & 3474 & 58.18 \\
\hline Downward & 939 & 572 & 60.91 & 1042 & 937 & 89.96 & 3507 & 1367 & 38.95 \\
\hline
\end{tabular}

(a)
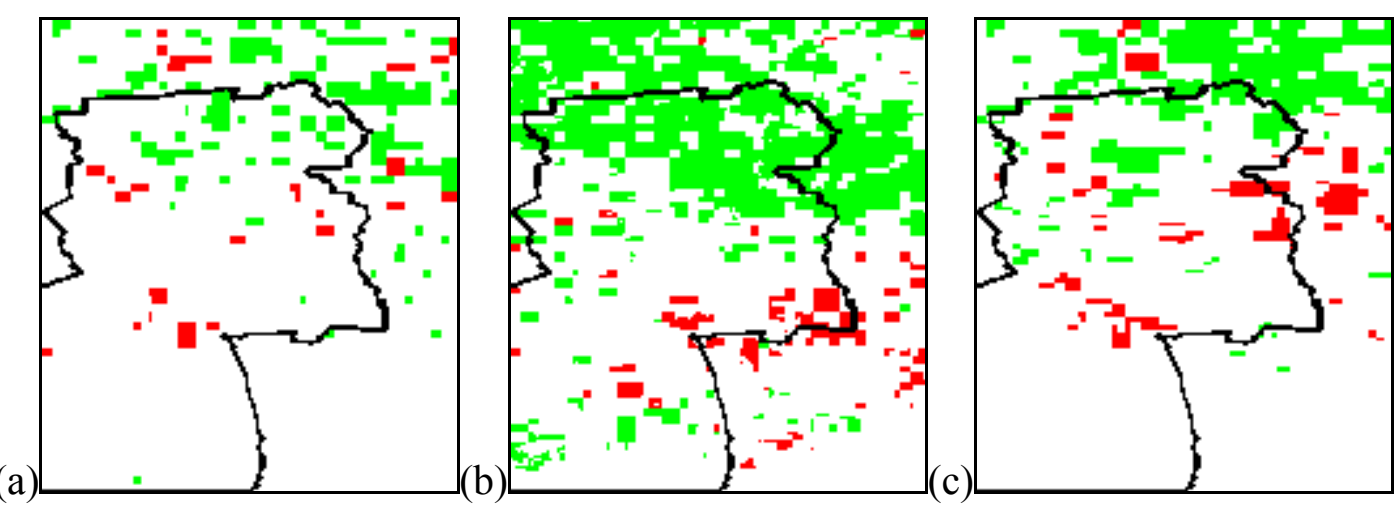

Figure 10.2. Distribution of trends in NDVI that are driven by trends in climate parameters. Coloured areas represent those pixels with both statistically significant $(p<0.05)$ trends in NDVI and statistically significant $(\mathrm{p}<0.05)$ correlation between NDVI and precipitation or temperature. Green areas indicate upward trends and red areas indicate downward trends. (a) Growing season, (b) spring, (c) summer. 


\subsection{Vegetation changes which are not explained by climate}

\subsubsection{Spatial patterns in NDVI trends not explained by rainfall and temperature}

The results of the preceding section showed that there are large areas for which significant increases in NDVI were not explained by temperature or, particularly, precipitation. For example, the upward trends in growing season NDVI were explained only to about $48 \%$ by precipitation, the upward trends in summer NDVI to $58 \%$. The explanation degree of downward trends was higher for the growing season NDVI and lower for the summer NDVI. Undoubtedly, the unexplained trends were driven by other forces which are not associated with climate change in the study region.

Spatial patterns of the unexplained trends are presented in Figure 10.3. These geographical areas that exhibit both strong trends in NDVI and insignificant correlation with precipitation or temperature required closer examination. Four test sites which showed negative trends both in growing season and summer NDVI were selected for a closer analysis and examination of possible causes of their vegetation change which follow in the next section.

\section{(a)}
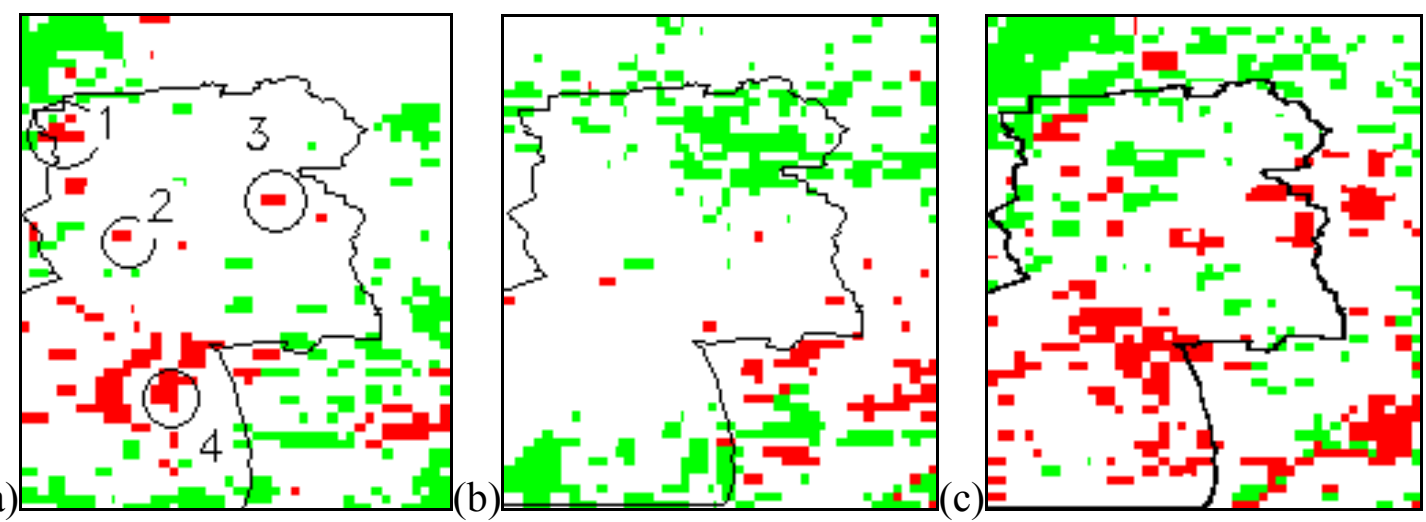

Figure 10.3. Distribution of trends in NDVI which are not explained by climate factors. Coloured areas represent those pixels with statistically significant $(p<0.05)$ trends in NDVI and insignificant correlation between NDVI and climatic parameters. Green areas indicate upward trends and red areas indicate downward trends. (a) Growing season, (b) spring, (c) summer. Panel (a) also displays location of the four test sites.

\subsubsection{Verification of results and explanation of trends induced by non-climatic} factors

The most efforts for finding explanations for non-climatic NDVI trends were focused on sites with significant negative trends. Essentially, four characteristic explanations of these 
trends which are not coupled on climatic factors could be found. A number of test sites were examined and four sites were selected for discussion and presentation of these explanations. A description of the sites shown in Figure 10.3 (a), including general results for each site will be given below:

1. The first site reveals wide areas of degraded soil due to long-time use for crop production. The ground surface of this site is characterized by a high reflectance in the visible bands of Landsat TM and Landsat ETM (Figure 10.4). A field survey in 2004 brought evidences for process of land degradation there. Analysis of a Landsat MSS image from 1975 proved a great expansion of the area used for crop production between 1975 and 1992. The constitutional change in 1991 did not shown any influence on the land use there, the crop fields remained in extensive use. The process of soil degradation which has begun in the time between 1975 and 1992 continued currently. This process combined with decreasing vegetation cover resulted in negative trends in NDVI over the period 1982-2003.

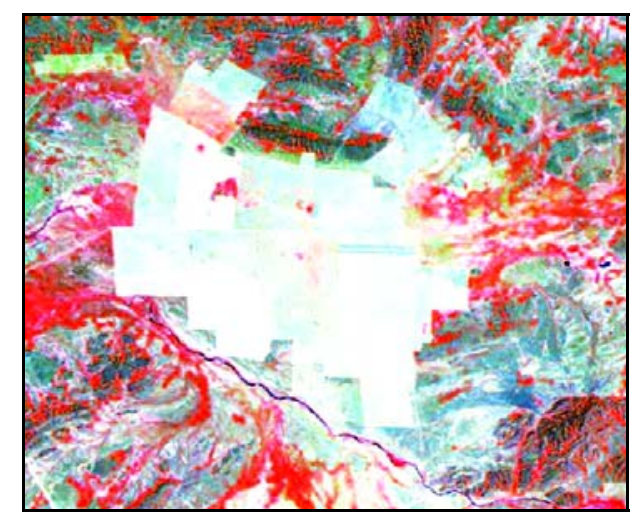

Figure 10.4. Landsat TM image of the first test site. Time of acquisition is July, 1992. RGB = Band $4,1,2$.

2. The second test site is located in the mid part of the study region in an area with a well developed drainage network and reveals clear signs of soil degradation due to water erosion. A comparison of Landsat MSS and Landsat TM images confirmed a great increase of degraded areas between the years of image acquisitions. This area was used as pasture since about 1950; therefore, one may assume livestock concentration as a cause for degradation of vegetation cover and soil erosion. But most of the degradation is associated with the area around a settlement in the south-eastern part of the Landsat image (Figure 10.5). Probably, the degradation degree around the settlement increased after the constitutional change, because of abolishment of the pasture system which had functioned during the Soviet Era. Since 1991, 
the shepherds do not undertake long outstrips with their herds and let the livestock graze the territory close to settlements. This leads to rapid exhaustion of pastures and starts on process of degradation.

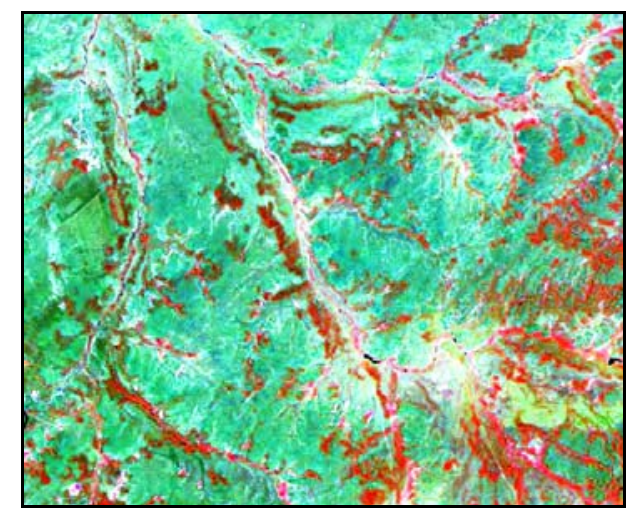

Figure 10.5. Test site 2 on the Landsat TM image. RGB $=$ Band 4,1,2.

3. Generally, the trends associated with the introduction or abandonment of agriculture are much larger and clearer than those associated with degradation of rangeland or cropland (Evans \& Geerken, 2004). Test site 3 support this assumption. Using multi-temporal Landsat data, abandonment of fields can easy be monitored from the pattern of field structures and their disappearance. Figure 10.6 displays three Landsat images of this site. Crop fields are clearly to be seen on the first two images. There are undoubted sings of expansion of existing crop fields and establishment of new cultivated areas between 1975 and 1992. In the image from 2001 sings of cultivation disappeared entirely at many places and smoothed at all others. This site was checked out in 2005 . Several abandoned crop plots were observed in the field. An interview with local authorities revealed a gradual abandonment of these fields since 1994-1995. Accordingly to Evans \& Geerken (2004), former cultivated areas typically display exceptionally low NDVI values in the years following their abandonment. Destruction of seed banks and the uprooting of the natural shrub and grass cover through ploughing cause a negative NDVI trend. 

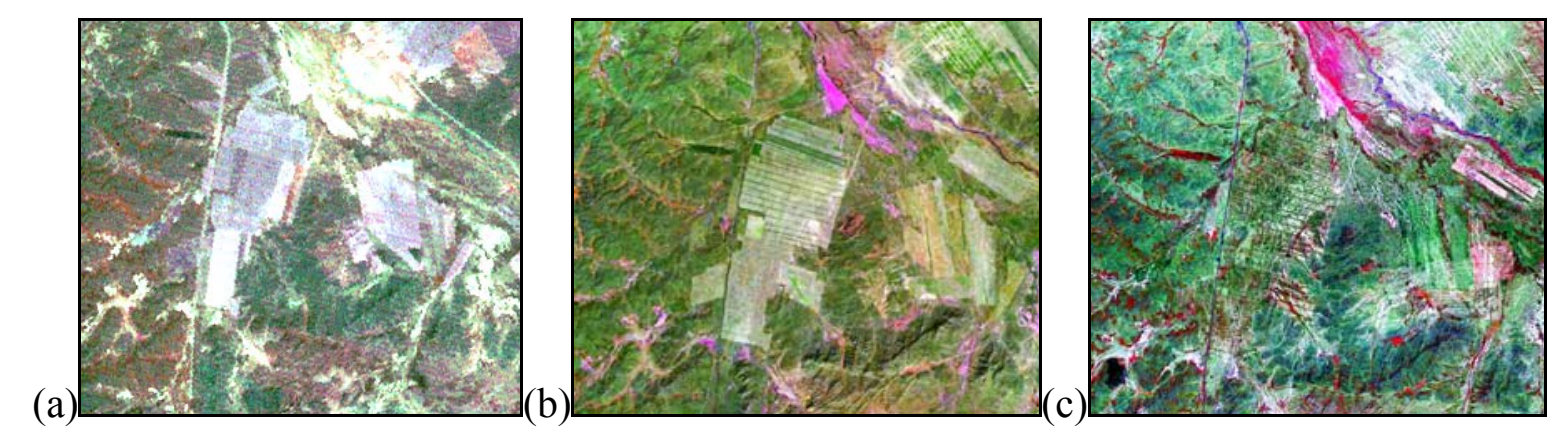

Figure 10.6. Test site 3. (a) Landsat MSS image from 1975, RGB = Band 4,1,2. (b) Landsat TM image from 1992, $\mathrm{RGB}=$ Band 4,7,2. (c) Landsat ETM+ image from 2001, RGB = Band 4,7,2. The corresponding NDVI series are displayed in Figure 10.7.

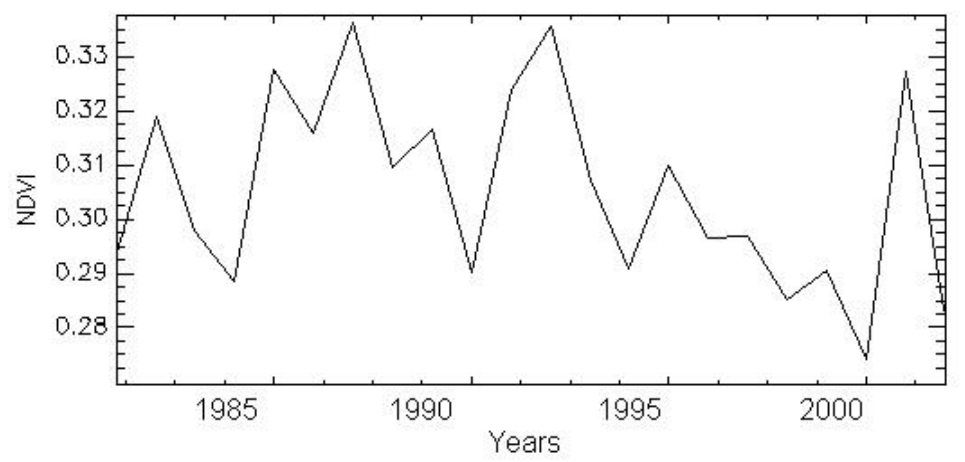

Figure 10.7. Time-series of growing season NDVI during 1982-2003 averaged over the third test site.

We can look at NDVI time-profile of this site, in order to understand changes occurring with the vegetation cover (Figure 10.7). During the years 1982-1993, NDVI of site 3 showed values above 0.30 , even though exhibited high inter-annual variability. There was a weak increase in NDVI over this period. The NDVI abruptly dropped after 1993 and was decreasing during the next 6 years. Then, in 2002 there was a high jump of NDVI values followed by a drop in 2003. By analysis of Landsat images coupled with ground site observation and interview with local authorities, the history of vegetation cover could be restored and the negative trends in NDVI could be explained. The site had been extensively used for wheat-grass production throughout 1982-1993. During this time, significant extensions of crop fields were made at the expense of the surrounding areas. There were no sings of land degradation or desertification on the Landsat MSS and TM images. The wheat yield had strongly correlated with annual precipitation amount. This can be assumed from comparison of the NDVI profile in Figure 10.7 with precipitation data. The dry years 1985 , 1991, 1995 are associated with low values of NDVI. In 1994, the abandonment of the fields 
went on. But not all fields were abandoned simultaneously. Some fields were ploughed and sowed until 2001. This abandonment progressed from year to year; it means that more and more fields grew fallow land. In 2002, the greatest part of the fellow land was ploughed and sowed again. A strong enhance of NDVI is associated with this year.

For this site, the analysis results revealed a general decrease in vegetation activity by giving up the cultivated land. This is not in agreement with the results from Chapter 8 which postulated an increase in vegetation response to precipitation in an abandoned cultivated area, but agrees with the results reported by Evans \& Geerken (2004) for Jordanian dryland. There is a large distinction between the plot reported in Chapter 8 and this test site. The first was degraded because of agricultural use and the second was not. This distinction may be a reason of different behaviour of vegetation cover after land use change. After the abandonment, the vegetation cover of the degraded plot was rapidly conquered by hardly grass and shrub species with domination of Artemisia and Agropyron, because of a general bad adaptation of cultural plants to the conditions of degraded land. The invader species can develop a higher over-ground biomass under the same conditions. Due to that, we observed increasing response of vegetation to precipitation. On the contrary, abandonment of the non-degraded cultural land manifested itself in low NDVI values as it was explained above.
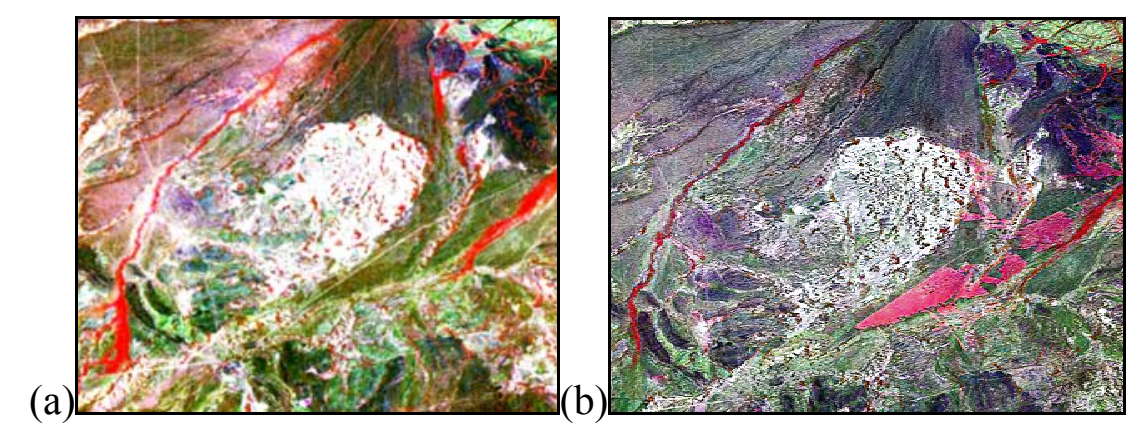

Figure 10.8. (a) Landsat TM image of test site 4. (b) Landsat ETM+ image. RGB = Band 4,7,2.

4. This site reveals areas of sparse vegetated surface on a foothill in the southern part of the study region. These almost bare surfaces occupy most part of the alluvial fan of a small river streaming from the north-east to the south-west. Figure 10.8 displays satellite images of this site from 1992 and 2001. The area is characterized by very high reflection in visual bands of Landsat satellite. On the Figure 10.8, the sparse vegetated areas display very high brightness values.

Depositions on the alluvial fan are steadily renewed and this prevents development of a dense vegetation cover. The density of the vegetation cover depends on the amount of 
alluvial material which is transported by the river into the fan. The larger this amount is the scarcer is the vegetation cover. The amount of alluvial material depends on runoff of the river. One can propose that the runoff slightly increased during the period 1982-2003 because of a positive trend in precipitation amount in the study region (see Chapter 5). This means an increase of material transport. This resulted in a decrease of vegetation cover in the alluvial fan area.

In the case of test site 4 , we notice with an indirect effect of climate on vegetation cover. The precipitation increased at another place far from this site but the effect of its increase has been yielded here. The place of the precipitation increase is teleconnected with the site 4 through the river system.

\subsection{Human-induced change in vegetation cover in areas without significant NDVI trends}

\subsubsection{General approach}

In areas where there were no statistically significant trends in NDVI over the study period, the changes in vegetation cover were determined with the approach described in section 4.6.3. This approach based on removing of the climatic signal from the NDVI time series and estimating changes in the remained noise. The remained noise is considered to present anthropogenic impact on the long-time NDVI trends.

The quintessence of this approach considers a change in response of vegetation cover to climatic factors by change in degree of anthropogenic impact. This phenomenon has been investigated in section 8.3.2 where the long-time trends in NDVI-precipitation relationship and their linkages to land use/land cover were examined. Strong associations between the correlation coefficient and the human impact on the vegetation cover were found.

An investigation of the long-time response of vegetation to climatic factors can help to detect pixels undergoing change in vegetation cover. This investigation was made through observation of the deviations from the regression between NDVI and one or two climatic factors calculated for every years from the study period. The regression line was understood as the climatic signal. Deviations of the observed NDVI values from the values of NDVI predicted by the regression was understood as indicators of the vegetation response to climate. Thus, positive any deviation indicates better response while any negative deviation indicates worse response. If there is a trend in the deviations over the time, then a change in the 
response of vegetation to the given climatic factor is present. This means that a change in vegetation cover caused by anthropogenic influence is evident.

An examples for one linear regression between NDVI and precipitation is shown in Figure 10.9, with the linear regression describing the expected $N D V I_{\text {pred }}$ for any particular rainfall amount. Figure 10.9 (a) shows a strong relationship between NDVI and precipitation, above $61 \%$ of all variations in NDVI are explained by precipitation. But the observed NDVI values show distinct deviations from the linear regression, suggesting that at times they respond better or worse to the precipitated rainfall amounts. After arranging the residuals in their temporal order (Figure 10.9, b) there is a clear negative trend indicating an increasingly worse response of NDVI to rainfall. If this trend is statistically significant, it would indicate an area experiencing human-induced degradation.

(a)

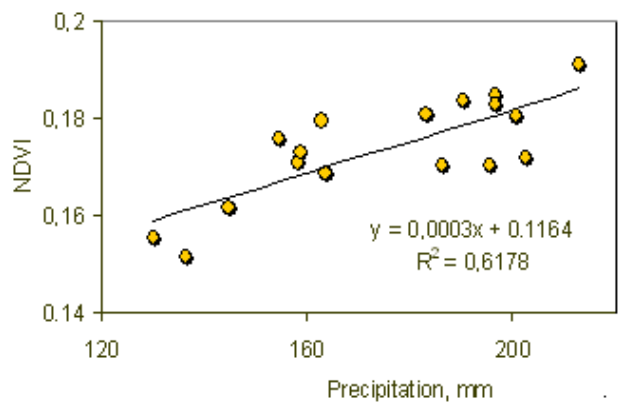

(b)

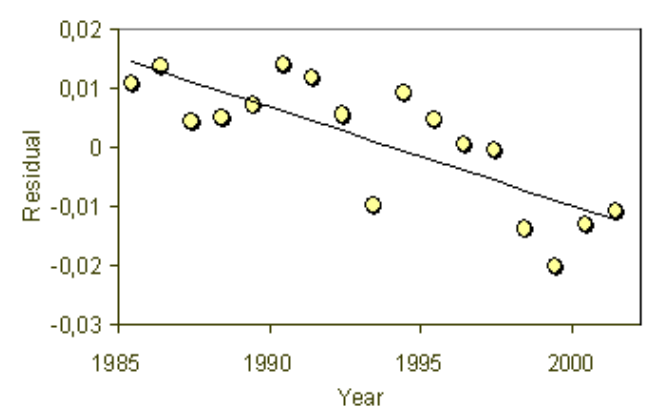

Figure 10.9. Linear regression between growing season precipitation and NDVI (a), and the temporal trend of associated residuals (b).

\subsubsection{Implementation of the suitable regression models for identification of the} climatic signal

Chapter 6-9 demonstrated a distinct relationship between NDVI and the climatic parameters at all possible temporal and spatial scales. This relationship was modelled using spatial and temporal models. The spatial modelling was carried out at all scales from the regional to the local using different techniques, the ordinary least squares regression and the geographically weighted regression. The results of these chapters exhibited that the interannual climatic signal in the NDVI time series is strong and statistically significant for defined combinations of NDVI and climate data.

Different regression models were tested for discrimination between human- and climate-induced changes in vegetation cover in the areas where no significant trends in NDVI 
were found. The results of these regression models were compared and evaluated in order to find the most suitable for this task. The criteria for model evaluation were the following:

o Goodness-of-fit statistic expressed in the correlation coefficient, $r$, or determination coefficient, $\mathrm{R}^{2}$,

o The accuracy of the prediction expressed in standard error of estimation, SE,

o Spatial distribution of the model residuals. The measure for patterns/randomness of this distribution was the Moran's $I$ autocorrelation.

Further, the tested models will be presented and briefly discussed.

\section{(a) Spatial models based on the global ordinary least squares (OLS) regression}

The results of calculations for every year from 1985-2001 are shown in Table 10.5. The correlations coefficients vary from year to year, but the general nature of the relationships appeared relatively stable. A multiple regression equation for each year was calculated to joint the explanatory variables for estimation of NDVI distribution throughout the study region. The mean coefficient of multiple correlation is $R=0.83$. The contribution of rainfall to the multiple correlation coefficient $\left(r_{a b . c}=0.43\right)$ is less than that of temperature $\left(r_{a c . b}=-0.51\right)$. The presence of multicollinearity produced serious problems for statistical analysis and prediction based on regression models. It results in extremely unstable regression parameters and makes the prediction very uncertain. Because the stepwise selection is not applicable to the model with multicollinearity, the ridge standardized regression procedure was used to eliminate multicollinearity and select useful predictors from the full model.

Ridge standardized regression estimators were obtained by introducing a non-negative constant into the least square normal equation (Hoerl \& Kennard, 1970). This makes the predictors nearly orthogonal and the coefficients less variable. At the end effect, this eliminates multicollinearity. 
Table 10.5. Simple, partial and multiple correlation coefficients between NDVI and explanatory variables for period 1985-2001.

\begin{tabular}{|c|c|c|c|c|c|c|c|c|c|c|c|c|}
\hline Year & $r_{a b} *$ & $r_{a c}$ & $r_{b c}$ & $r_{a d}$ & $r_{a b . c}$ & $r_{a c . b}$ & $r_{a b . d}$ & $r_{a c . d}$ & $R_{a b c}$ & $R_{a b d}$ & $R_{a c d}$ & $\begin{array}{l}\text { Multiple regression } \\
\text { equation** }\end{array}$ \\
\hline 1985 & 0.76 & -0.82 & -0.79 & 0.53 & 0.41 & -0.41 & 0.35 & -0.11 & 0.81 & 0.77 & 0.79 & $\mathrm{NDVI}=0.00125^{*} \mathrm{P}-0.0283^{*} \mathrm{~T}+0.31$ \\
\hline 1986 & 0.81 & -0.79 & -0.69 & 0.60 & 0.54 & -0.59 & 0.41 & -0.15 & 0.87 & 0.83 & 0.79 & $\mathrm{NDVI}=0.00164 * \mathrm{P}-0.0301 * \mathrm{~T}+0.43$ \\
\hline 1987 & 0.76 & -0.83 & -0.84 & 0.51 & 0.48 & -0.25 & 0.43 & -0.29 & 0.82 & 0.77 & 0.81 & $\mathrm{NDVI}=0.00101 * \mathrm{P}-0.0302 * \mathrm{~T}+0.40$ \\
\hline 1988 & 0.65 & -0.81 & -0.57 & 0.58 & 0.54 & -0.42 & 0.45 & -0.08 & 0.77 & 0.74 & 0.71 & $\mathrm{NDVI}=0.00102 * \mathrm{P}-0.0353^{*} \mathrm{~T}+0.44$ \\
\hline 1989 & 0.81 & -0.85 & -0.79 & 0.55 & 0.41 & -0.49 & 0.48 & -0.19 & 0.85 & 0.82 & 0.79 & $\mathrm{NDVI}=0.0011 * \mathrm{P}-0.0249 * \mathrm{~T}+0.441$ \\
\hline 1990 & 0.84 & 0.82 & -0.9 & 0.53 & 0.18 & -0.45 & 0.43 & -0.23 & 0.84 & 0.82 & 0.80 & $\mathrm{NDVI}=0.00127 * \mathrm{P}-0.0368 * \mathrm{~T}+0.45$ \\
\hline 1991 & 0.75 & -0.81 & -0.82 & 0.48 & 0.25 & -0.41 & 0.27 & -0.2 & 0.76 & 0.75 & 0.71 & $\mathrm{NDVI}=0.00114 * \mathrm{P}-0.0257 * \mathrm{~T}+0.40$ \\
\hline 1992 & 0.71 & -0.83 & -0.86 & 0.47 & 0.33 & -0.23 & 0.37 & -0.16 & 0.74 & 0.71 & 0.74 & $\mathrm{NDVI}=0.0010 * \mathrm{P}-0.0187 * \mathrm{~T}+0.261$ \\
\hline 1993 & 0.7 & -0.82 & -0.75 & 0.62 & 0.56 & -0.26 & 0.4 & -0.15 & 0.81 & 0.77 & 0.79 & $\mathrm{NDVI}=0.0011 * \mathrm{P}-0.0184 * \mathrm{~T}+0.285$ \\
\hline 1994 & 0.67 & -0.80 & -0.72 & 0.55 & 0.52 & -0.28 & 0.38 & -0.15 & 0.77 & 0.72 & 0.75 & NDVI $=0.0012 * \mathrm{P}-0.027 * \mathrm{~T}+0.364$ \\
\hline 1995 & 0.72 & -0.76 & -0.7 & 0.38 & 0.39 & -0.45 & 0.42 & -0.17 & 0.77 & 0.72 & 0.74 & $\mathrm{NDVI}=0.0016 * \mathrm{P}-0.0295^{*} \mathrm{~T}+0.378$ \\
\hline 1996 & 0.83 & -0.80 & -0.7 & 0.48 & 0.42 & -0.64 & 0.49 & -0.1 & 0.86 & 0.83 & 0.81 & $\mathrm{NDVI}=0.0009 * \mathrm{P}-0.0354 * \mathrm{~T}+0.51$ \\
\hline 1997 & 0.67 & -0.84 & -0.71 & 0.29 & 0.18 & -0.34 & 0.31 & -0.13 & 0.68 & 0.57 & 0.52 & $\mathrm{NDVI}=0.001 * \mathrm{P}-0.0253 * \mathrm{~T}+0.36$ \\
\hline 1998 & 0.78 & -0.77 & -0.64 & 0.52 & 0.54 & -0.58 & 0.63 & -0.16 & 0.85 & 0.82 & 0.76 & NDVI $=0.0014 * \mathrm{P}-0.0349 * \mathrm{~T}+0.45$ \\
\hline 1999 & 0.67 & -0.82 & -0.74 & 0.5 & 0.51 & -0.25 & 0.28 & -0.16 & 0.76 & 0.68 & 0.72 & $\mathrm{NDVI}=0.001 * \mathrm{P}-0.0351 * \mathrm{~T}+0.53$ \\
\hline 2000 & 0.91 & -0.84 & -0.61 & 0.48 & 0.62 & -0.86 & 0.82 & -0.14 & 0.94 & 0.93 & 0.81 & $\mathrm{NDVI}=0.0011 * \mathrm{P}-0.0358 * \mathrm{~T}+0.5$ \\
\hline 2001 & 0.83 & -0.77 & -0.7 & 0.46 & 0.42 & -0.64 & 0.49 & -0.1 & 0.86 & 0.83 & 0.81 & NDVI $=0.00114 * \mathrm{P}-0.031 * \mathrm{~T}+0.43$ \\
\hline Mean & 0.80 & -0.82 & -0.81 & 0.51 & 0.43 & -0.51 & 0.45 & -0.11 & 0.83 & 0.78 & 0.76 & NDVI $=0.00125 * \mathrm{P}-0.0282 * \mathrm{~T}+0.31$ \\
\hline
\end{tabular}

Comments:

$* r$ is the simple or the partial correlation coefficient, $R$ is multiple correlation coefficient, the small letters $a, b, c$ represent NDVI, rainfall, temperature and altitude; the point between two letters in partial coefficients signs that the variable standing after the point is excepted,

** in the equations of multiple regression letters $\mathbf{P}$ and $\mathbf{T}$ represent total precipitation and mean air temperature of growing season (April-October). 


\section{(b) Spatial models based on the geographically weighted regression (GWR)}

The superiority of the GWR over the conventional spatial regression model is proved and discussed in Chapter 9. The advantage of the GWR is its local approach to analysing relationship between spatial variables. This enables to use the non-stationarity in the relationship for better prediction. The results of the GWR from the 1-km data modelling showed a large improvement of the model accuracy in comparison to the OLS modelling. This improvement was expressed in a significant decrease of the SE and elimination of the patterns in the regression residuals.

(a)

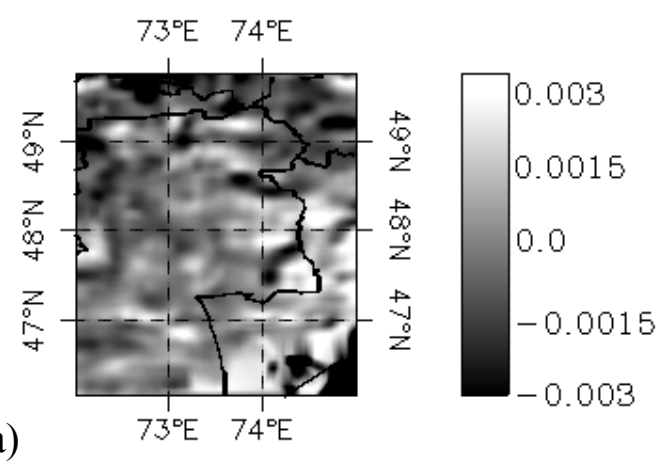

(b)

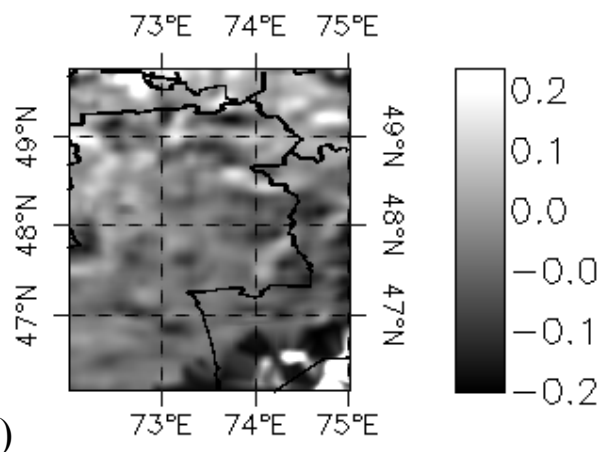

(d)

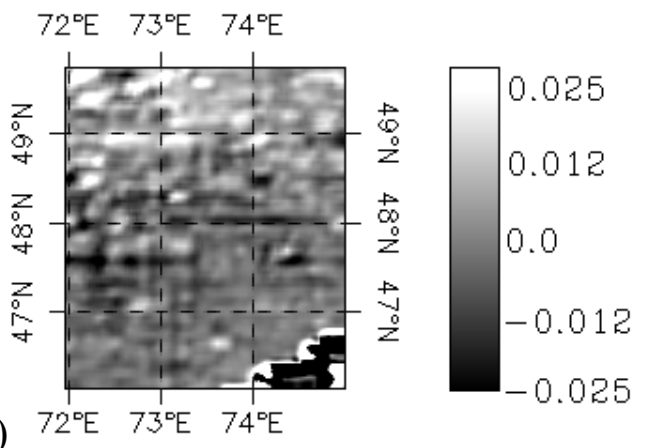

Figure 10.10. Parameters of the GWR between NDVI and precipitation related to year 1988. (a) shows the slope, (b) the intercept, (c) the determination coefficient, $\mathrm{R}^{2}$, and (d) the spatial distribution of the residuals of the regression.

The GWR models were also computed using the 8-km data for every year from the study period. An example of the GWR parameters is presented in Figure 10.10. Note the values of the goodness-of-fit statistic shown in Figure 10.10 (c). In comparison to the results of the OLS model (Table 10.5), the values of the $\mathrm{R}^{2}$ obtained for the GWR are significantly larger. The using standard error of estimation, SE, as a guide to accuracy of the prediction also revealed advantage of the GWR. For the OLS modelling SE averaged throughout the 18year period showed a value of 0.018 , while for the GWR only 0.008 . 


\section{(c) Temporal models}

The inter-annual and inter-seasonal relationship between time series of NDVI and the corresponding time series of the climatic parameters was not as strong as the spatial relationship (compare Chapter 7 and 8). At the per-pixel scale, the results of modelling indicate that not all pixels exhibit significant relationship between NDVI and the climatic factors. Figure 10.11 displays the results of the temporal regression model between growing season NDVI and growing season precipitation on concurrent basis. About $42 \%$ of all pixels demonstrated significant correlation coefficient with growing season rainfall, the percentage of pixels with significant correlation between summer NDVI and summer precipitation is else less, only $15 \%$ (Section 7.2.3, Table 7.2). The percentage of pixels with significant correlation was higher for the relationship between spring NDVI and spring temperature, 75 $\%$ of all vegetated pixels. The most areas of desert and a large part of semi-desert showed no significant correlation with any of the climatic predictors. This means that the use of temporal models with only one explanatory variable for identification of the climatic signal is problematic.

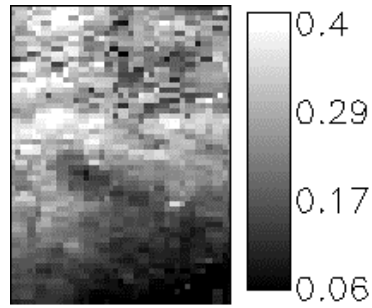

Intercept

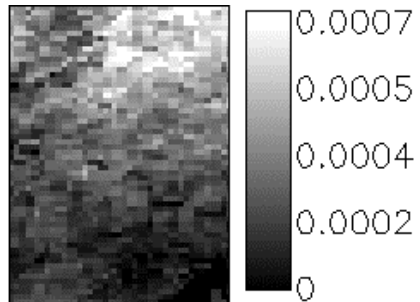

Slope

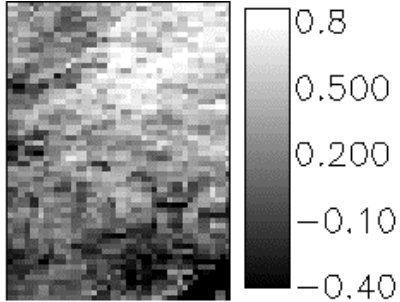

$\mathrm{R}^{2}$

Figure 10.11. Results of the temporal regression between growing season NDVI and precipitation for the period 1985-2003. The images show the spatial variation in (a) the intercept, (b) the slope parameter, and (c) the local estimate of the coefficient of determination $\left(\mathrm{R}^{2}\right)$.

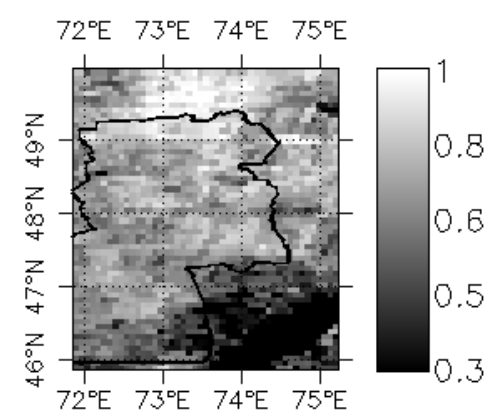

Figure 10.12. Goodness-of-fit statistic, $\mathrm{R}^{2}$, for the multiple regression incorporating NDVI and the both climatic parameters, precipitation and temperature. 
The deficiencies of the temporal model could be diminished or fully overcome through a combination of the both climatic parameters in a multiple regression equations. Application of the multiple temporal regression increased the prediction power of the model and significantly enlarged the areas with significant relationship. After applying the multiple model, about $92 \%$ of all vegetated pixels showed values of the $\mathrm{R}^{2}$ above 0.30 (Figure 10.12).

\subsubsection{Modelling the climatic signal in the inter-annual NDVI time series}

In the preceding section, three model types were described regarding their suitability for identification of the climatic signal in the inter-annual NDVI time series. In spite of differences in the goodness-of-fit statistic and prediction accuracy between the models, all models were found to be suitable for fulfilling this task. Using these regression models, predicted NDVI values were computed for every pixel and every year. To give an example, Figure 10.13 shows maps of the $N D V I_{\text {pred }}$ for every year from 1985-2000 computed by the multiple temporal regression model. Similar maps were obtained after application of the spatial OLS model and the GWR model. The $N D V I_{\text {pred }}$ represent the regression line, e. g. the climatic signal for every defined year. The real values of NDVI can deviate more or less from this regression line. The magnitude of this deviation observed in each defined year depends on the response of the vegetation cover to the climatic predictors. The differences in spatial patterns of observed and predicted NDVI values are expressed in residuals images. The residuals images were obtained for every model and for every year.
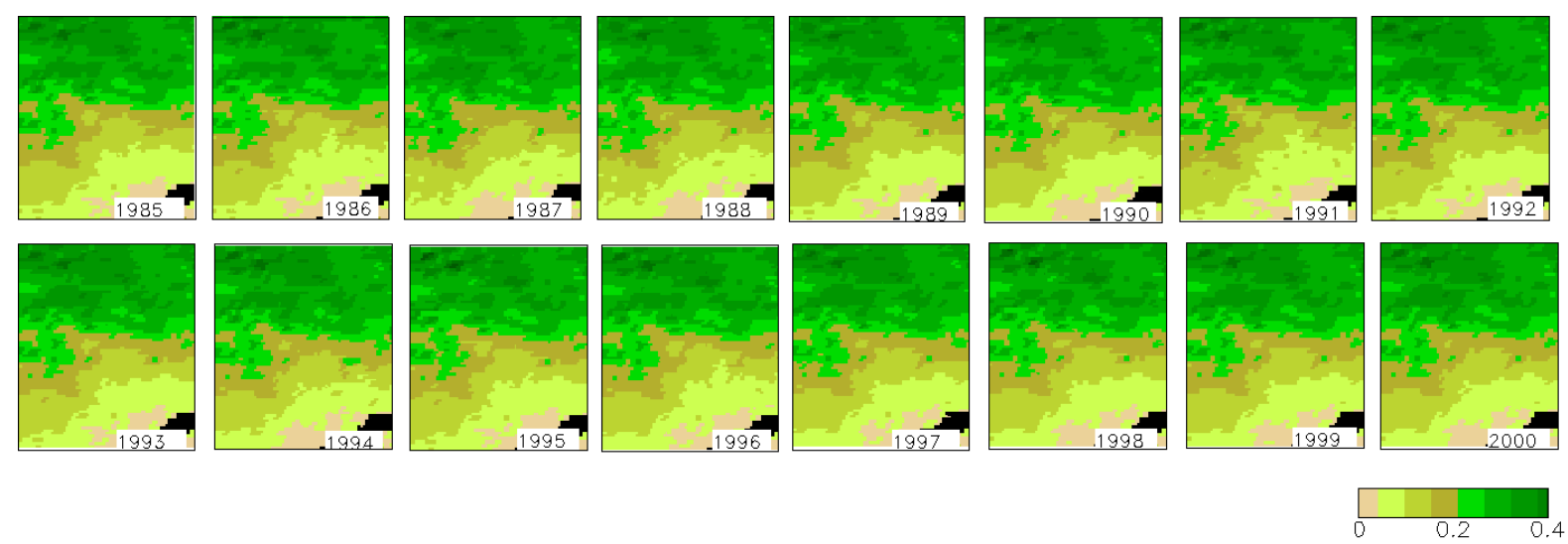

Figure 10.13. Maps of growing season NDVI predicted by the temporal multiple regression modelling. 
As it was shown in section 9.2.4, spatial distribution of the model residuals contains information about the accuracy of the model prediction. If the residuals exhibit any clear spatial patterns, then the accuracy of the model is low and the standard error is underestimated. The best model should show a random distribution of the residuals over the space. The Moran's I has been commonly used as a guide to estimation of the residuals autocorrelation. Section 9.2.4 also demonstrated that the calibration of the local model based on the GWR approach disaggregates spatial patterns in the model residuals and reduces the spatial autocorrelation of the residuals.

In order to select the most appropriated model for detection of the climatic signal, the maps of the residuals from the three model types were examined for spatial autocorrelation. The temporal regression model represents a kind of a local regression model too. This model is fitted at each pixel individually. Theoretically, the temporal model should exhibit a near random distribution of the residuals. Figure 10.14 displays autocorrelograms of the residuals from the three models related to 1985. As expected, the error terms are most strongly autocorrelated for the global OLS model. The OLS model residuals had significant spatial autocorrelation up to over 25 pixels. In comparison, for the GWR model residuals, distance lag of significant positive spatial autocorrelation was found to be 10 pixels. Similar results are shown by the multiple temporal regression model. It suggests that the calibration of local model reduces the problem of spatially autocorrelated error terms. Both the GWR and the multiple temporal model demonstrate the good ability to deal with spatial non-stationary problems. If only the global OLS model fitted at the regional scale represents the relationship between NDVI and climatic factors relatively good, but the use of it is undesirable in the case of modelling the inter-annual climatic signal at the local scale.

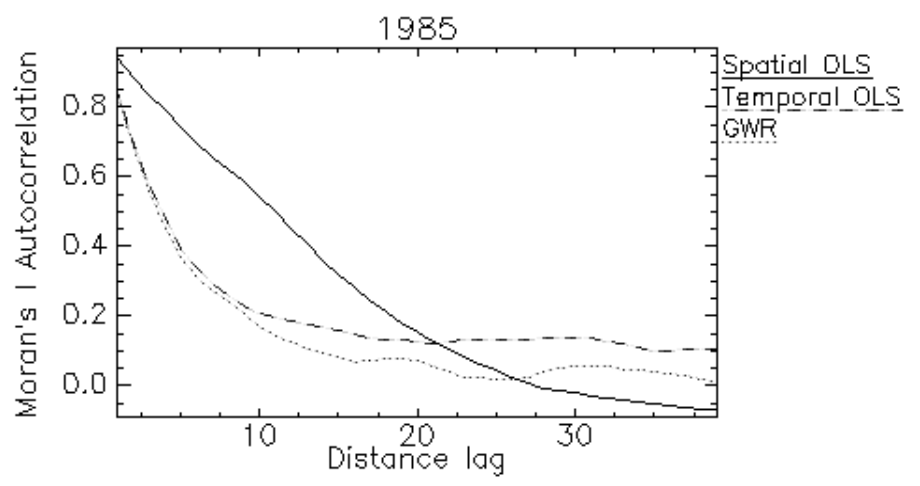

Figure 10.14. Spatial autocorrelograms for residuals from the spatial OLS model, the multiple temporal model and the GWR model. Distance lag is measured in pixel. 


\subsubsection{Identification of areas experiencing human-induced vegetation change}

In this study, the GWR was used for modelling the climatic signal in the inter-annual time series of NDVI. The residuals from the annual GWR models represents the remained anthropogenic noise in the NDVI time series after removing the climatic signal. In order to detect areas experiencing human-induced change in vegetation cover, the time-trend of the residuals was computed for every pixel. Figure 10.15 shows where statistically significant trends in regression residuals are taking place. The residuals with positive trend are widely distributed in the northern part of the study region within areas of steppe grassland. There are only three small spots with negative trend in residuals. The most residual trends are observed in areas without any significant trend in NDVI over the study period. This may have two explanations:

0 these areas experienced improvement of vegetation cover in spite of absence of any significant NDVI trends,

o these areas exhibited no trends in vegetation cover in spite of decreasing precipitation amount over the study period. Hypothetically, this case would also indicate an improvement of vegetation cover (see Section 4.6.3 and Figure 4.3).

The both explanations consider human impact on the vegetation cover as the reason for improvement of vegetation which can not be driven by the climate.
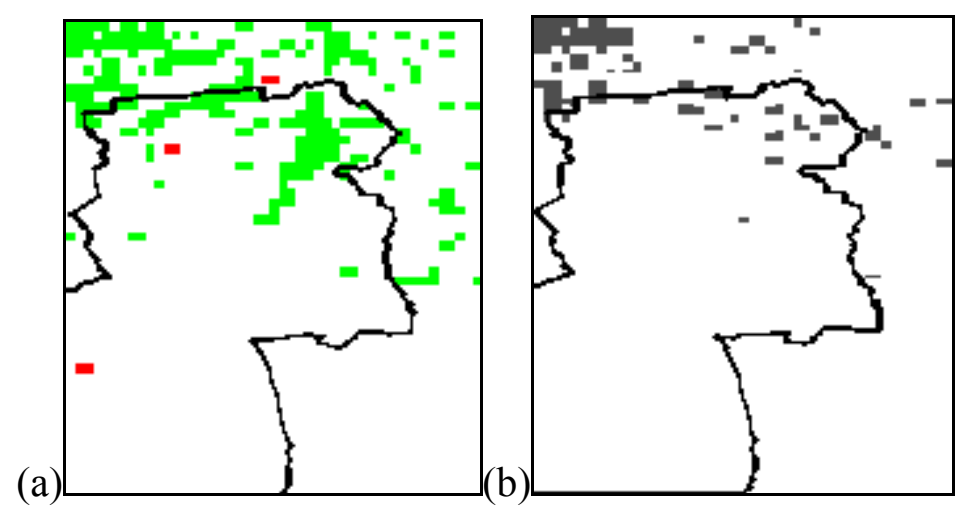

Figure 10.15. (a) Significant trend in residuals from the GWR model 1985-2003. Green indicates areas with upward trends, red indicates areas with downward trends. (b) Intersect of the (a) with the trends in growing season NDVI. The map displays areas with both significant trend in GWR residuals and significant trends in growing season NDVI over 1982-2003. 
But many pixels with trend in residuals are located within the sectors which exhibit trends in growing season and spring NDVI (Figure 10.15, b). These pixels represent areas where magnitudes of trends in NDVI and precipitation show high discrepancy. This case is described in Section 4.6.3. The magnitude of the NDVI increase is much higher than that of the precipitation increase. This case may indicate an improvement of vegetation cover due to a rapid reduce of the human impact. It is known that such a reduce of the anthropogenic influence was taking place in the study region after the constitutional change in 1991 (see Section 2.5 and 2.6). This supported the hypothesis about an anthropogenic reason for the trend in regression residuals derived from the GWR modelling.
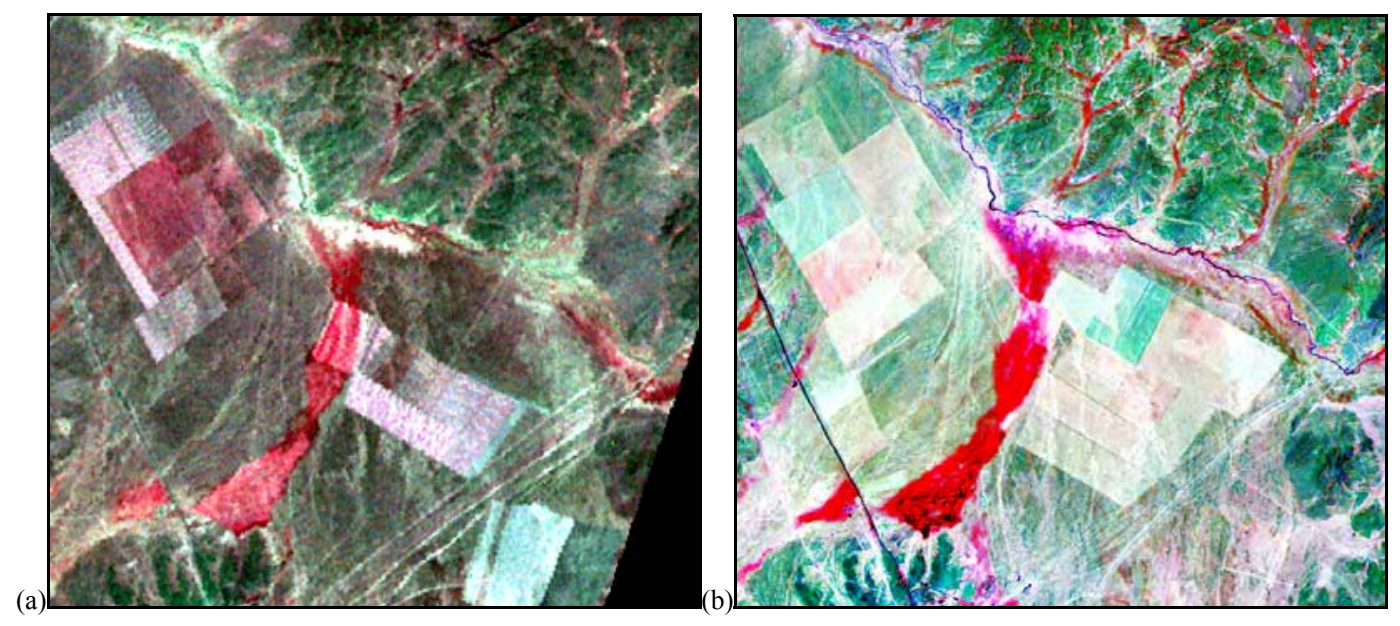

Figure 10.16. Comparison of two subsets from Landsat TM $(\mathrm{RGB}=$ Band 4,1,2) and Landsat ETM+ $(\mathrm{RGB}=$ Band 4,1,2) showing the expansion of wheat cultivation into the steppe grassland between years (a) 1992 and (b) 2001. Clear signs of land degradation are to see in image (b).

A few number of places has not experienced any reduce of the anthropogenic influence during the last decade of $20^{\text {th }}$ century. On the contrary, the expansion of cultivated field was observed for some sites during this time. One of such sites is shown in Figure 10.16. This site represents the northernmost spot with downward trend in regression residuals shown in Figure 10.15 (a). Expansion of agriculture and followed land degradation is responsible for negative trend in regression residuals.

\subsection{Discussion and conclusion}

Sections 10.2 and 10.3 investigated trends in vegetation activity over the period of 1982-2003. The results of these investigations are in agreement with other published reports on trends in vegetation activity over the last two decades undertaken at the global and regional 
scales (Muneni et al, 1997; Tucker et al, 2001; Zhou et al, 2001; McCloy et al, 2005). The results indicate a $6.46 \%$ increase in growing season NDVI in the study region between 1982 and 2003. The magnitude of the greening trend in the study region is consistent with trends reported for the northern high latitudes in Eurasia and North America by Tucker et al. (2001) and by Zhou et al. (2001), as well as for China by Xiao \& Moody (2004).

About $28 \%$ of all vegetated pixels exhibited statistically significant positive trends in growing season NDVI. Areas with negative trends in growing season NDVI were also calculated and measured. The percentage of these areas is $4.36 \%$. The percentage of area with trends in growing season NDVI varied significantly according to land-cover type. It is particularly high for short grassland and steppe grassland. Above $48 \%$ of all pixels with the positive trend in growing season NDVI exhibited strong correlation with precipitation. The analysis of the relationship between NDVI and climatic factors for the pixels with negative trends showed higher determination of that by precipitation, more than $60 \%$ of all pixels with downward trend exhibited significant correlation with precipitation.

All vegetation types demonstrated significant upward trends in spring NDVI between 1982 and 2003. The general magnitude of this trend was higher than that for the growing season or for summer. The significant upward trend in spring NDVI occurred in $39 \%$ of the total vegetated area but the percentage varied by land-cover type. The highest percentages were observed in short grassland and steppe with values of $57 \%$ and $74 \%$, respectively. For $78 \%$ of this area, positive trends were correlated with spring temperatures. The results from spring support the suggestion about a high increase in early-season vegetation activity and its strong prediction by temperature established in the recent literature (Tucker et al, 2001; Zhou et al, 2001; Xiao \& Moody, 2004).

Totalled over the entire area, about $20 \%$ of all vegetated pixels experienced significant upward trend in summer NDVI whereas $8 \%$ of all pixels exhibited downward trend. Most of the areas with these trends were explained by climate change, over $58 \%$ of pixels with positive trend demonstrated strong correlation with precipitation. The negative trends in summer NDVI were explained in $38 \%$ of all cases.

There were large areas for which increases or decreases in vegetation activity could not be explained by climatic factors, especially concerning trends in growing season and summer NDVI. It is clear that spring NDVI is the main contributor to the general greening trend in the study region and the driving factor for this trend is the spring temperature. But the other large contributor to the growing season trends, summer NDVI, does not seem to be clearly explained by climate. Particularly, this concerns the negative trends in summer NDVI. 
Most areas with these unexplained trends are located in semi-desert and steppe zone of the study region. It may be suggested that the trends in NDVI in these land-cover types were mainly driven by land use change between 1982 and 2003. After the collapse of the socialistic economical system in 1991, numerous crop fields were abandoned, the number of cattle and sheep declined by about $60 \%$. The rapid diminishing of human impact made possible an improving of vegetation cover throughout the pasture and crop lands possible lead to the massive increase in NDVI.

In section 10.4, the technique allowing the monitoring trends in vegetation cover triggered by human-impact was presented and discussed. This technique used the calculations of trends from the preceding sections. Trends which demonstrated no correlation with climatic factors were considered to present non-climatic (human-induced) change in vegetation cover. The areas of these trends were measured and mapped. Areas with degrading trends were checked carefully to prove their anthropogenic cause. Four defined areas where change in vegetation cover has been verified by independent methods (Landsat image interpretation, ground site observation) were presented and described. For three of these test sites, human impact was proved to be a driving force for change in vegetation cover during the study period. As shown, negative trends can be linked to degrading or abandoned cultivated land as well as to soil erosion due to overgrazing around settlements. For the fourth site, an indirect climate influence was revealed. The climate change affected the vegetation cover of the fourth site through teleconnection with the alluvial fan of a river system. In three of four cases, the verification of the results proved the hypotheses about human impact as the driving force for change in vegetation activity.

Section 10.5 illustrated the application of the GWR technique to assessment of humaninduced changes in vegetation cover in the areas: 1. where trends in NDVI were insignificant or default, 2. where trends in NDVI and the climatic parameter showed a high discrepancy in magnitude. This technique based on modelling the climate signal in the inter-annual NDVI time series. Three different models between NDVI and climatic factors were compared and evaluated concerning the identification of the climatic signal. It is proved that the local calibration removes much of the problems of spatially autocorrelated error terms and significantly improves the prediction accuracy. These results agree with the results reported by Wang et al. (2005) and Fotheringham et al. (2002). After the modelling, the climate signal was removed from the NDVI time series. The remained noise in the inter-annual NDVI time series considered to represent human signal. This signal increasing throughout the study period may indicate degrading vegetation cover. On the contrary, a decreasing human signal 
believed to indicate improving vegetation cover. The resulting maps coupled with highresolution Landsat imagery and field-level knowledge of the region provided a good framework for scrupulous analysis of causes of the vegetation change at the local scale. These local analyses supported the postulation about anthropogenic source of the vegetation change. The system of discrimination between climate- and human-induced changes in vegetation cover developed in this study improves significantly the models described by Evans \& Geerken (2004) and Li et al. (2004). 


\section{Chapter 11}

\section{Summary}

The present work is the first study on the dynamics of drylands in Kazakhstan which investigated the problem from different views and combined analyses at multiple time- and spatial scales. The study examined and modelled inter-relationship between vegetation cover and climate in the region of Northern Balkhash in the Middle Kazakhstan using the Normalized Difference Vegetation Index (NDVI) obtained from Advanced Very High Resolution Radiometer (AVHRR) as the proxy for vegetation activity and the climate records obtained from 9 weather stations. The entire spectrum of this inter-relationship, - spatial and temporal, at regional, sub-regional and local scale, inter-annual and within the growing season, - has been analysed, described and discussed. A monitoring system was developed and applied for the discrimination between driving forces of changes in vegetation cover. In this system, the noise in inter-annual time series of NDVI remained after removing the climatic signal was understood as anthropogenic signal in long-time change in vegetation cover.

The study illustrated that satellite based vegetation reflectance data can serve as a good proxy for studying variability of dryland ecosystems. The use of this dataset enabled the extraction of temporal signals of ecosystem variations and the mapping of their spatial patterns. The NDVI data revealed substantial sensitivity to the climatic signal both in time and space and allowed the investigation of the influence of climate and human activity on the ecosystem.

The study showed high temporal variability of the vegetation cover and the climatic parameters in the desert, semi-desert and steppe zones. The magnitude of the changeability increases in order from North to South when moving from steppe to semi-desert and to desert. The study found a strong determination of the vegetation dynamics by the climatic factors precipitation and temperature, both at inter-annual time-scale and within the growing season. Inter-annual dynamics of the vegetation cover proved to be coupled more on variability in the total precipitation. Within the growing season, in comparison to precipitation, the correlation between NDVI and temperature was higher for all vegetation types. The influence of temperature on the vegetation growth was huge during the early and late growing season, while during the mid of growing season, temperature showed no correlation with NDVI. In grasslands, precipitation influences strongly the plant growth during the period spring- 
summer, while in shrublands, the constantly strong influence of precipitation is only during the spring months.

The study demonstrated the presence of non-stationarity in the relationship between NDVI and the climate. The strength of the relationship varied among vegetation types and geographical location. The response of the vegetation cover to precipitation and temperature increases when moving from desert to semi-desert and to steppe grassland. In the same direction the reaction time and the duration of the climate effect to the vegetation cover increases. Time lags associated with NDVI's response to precipitation also increase in order from desert, to semi-desert and to steppe. Taking into account the non-stationarity, enhanced model of relationship between NDVI and precipitation was established and used for identification of the climatic signal in the inter-annual change in vegetation cover.

The results exhibit significant changes in vegetation cover over the period 1982-2003 in large areas throughout the study region. Particularly high magnitudes of changes are associated with spring NDVI values. The climate is an important driving force for long-time trends in vegetation cover in all vegetation types. The research established spring temperature to be the major explanatory factor for upward trends in spring NDVI throughout the last two decades, while the trends in growing season NDVI were mostly explained by the human impact and changes in precipitation amount. According to the research results, about $35 \%$ of all growing season trends in NDVI are explained by climate and about $43 \%$ by human impact. The rest remains unexplained.

The maps of climate- and human-induced changes coupled with high resolution Landsat imagery and field knowledge of the region provided a good framework for analysis of the changes and the understanding their causes at the local scale. This analysis revealed the role of land use change in trends of vegetation cover. The cause of the significant land use change is considered to be the constitutional change in 1991 when the Republic of Kazakhstan became independent. The economical crisis that followed the independence reduced significantly the human impact in the most areas of the study region. This led to a rapid rehabilitation of the vegetation cover and upward trends in NDVI. Human-induced downward trends in NDVI are associated with areas of degraded lands which are used for crop cultivation or grazing.

The study results improve the understanding of the nature and mechanisms of the ecosystem dynamics in the inner Eurasia and provide the basis for predicting changes in productivity that accompany changes in climate and human activity. 


\section{References}

Anyamba A., Tucker C. J. \& Eastman J. R. 2001. NDVI anomaly patterns over Africa during the 1997/98 ENSO warm event. Int. J. Remote Sensing, 22: 1847-1859.

Babaev A. G. \& Kharin N. G.. 1999. The Monitoring and Forecast of Desertification Processes. In: Desert Problems and Desertification in Central Asia. Edited by A. G. Babaev. SpringerVerlag, Berlin: 59-76.

Binns T. 1990. Is Desertification a Muth? Geography, 75: 106-113.

Brunsdon, C. F., Fotheringham, A. S. \& Charlton, M. E. 1996. Geographically weighted regression: a method for exploring spatial non-stationarity. Geographical Analysis, 28: 281-298.

Brunsdon, C., McClatchey, J. \& Unwin, D. J. 2001. Spatial variations in the average rainfall-altitude relationship in Great Britain: An approach using geographically weighted regression. Int. Journal of Climatology, 21: 455-466.

Budde, M. E., Tappan, G., Rowland, J. Lewis, J. \& Tieszen, L. L. 2004. Assessing land cover performance in Senegal, West Africa using 1-km integrated NDVI and local variance analysis. J. of Arid Environments, 59: 481-498.

Chen Z. M., Babiker I. S., Chen Z. X., Komaki K., Mohamed M. A. A. \& Kato K. 2004. Estimation of Interannual Variation in Productivity of Global Vegetation Using NDVI Data. Int. J. Remote Sensing, 25: 3139-3159.

Clifford, P., Richardson, S. \& Hemon, D. 1989. Assessing the significance of the correlation between two spatial processes. Biometrics, 45: 123-134.

Darkoh, M. B. K. 1998. The nature, causes and consequences of desertification in the drylands of Africa. Land Degrad. Develop., 9: 1-20.

DeBeurs K. M. \& J. Henebry. 2004. Land Surface Phenology, Climatic Variations, and Institutional Change: Analysing Agricultural Land Cover Change in Kazakhstan. Remote Sens. Environment, 89: 497-509.

Evans J. \& R. Geerken. 2005. Discrimination Between Climate and Humane-Induced Dryland Degradation. J. of Arid Environments, 57: 535-554.

Foody G. M. 2003. Geographical weighting as a further refinement to regression modelling: an example focused on the NDVI-rainfall relationship. Remote Sens. Environment, 88: 283-293.

Foody, G. M. 2005. Spatial nonstationary and scale-dependancy in the relationship between species richness and environmental determinants for the sub-Saharan endemic avifauna. Global Ecol. Biogeogr., 13: 315-320.

Fotheringham, A. S., Brunsdon, C. \& Charlton, M. 2002. Geographically weighted regression: the analysis of spatially varying relationships. Chichester, Willey.

Fotheringham, A. S., Charlton, M. E. \& Brundson, C. 1996. The geography of parameter space: and investigation into spatial non-stationarity. International Journal of GIS, 10: 605-627. 
Gisladottir, G. \& Stocking, M. 2005. Land degradation control and its global environmental benefits. Land Degrad. Develop., 16: 99-112.

Gomez-Hernandez, J., Cassiraga, E., Guardiola-Albert, C. \& Alvarez R. J. 2001. Incorporating information from a digital elevation model for improving the areal estimation of rainfall. In: GeoENV III: Geostatistics for Environmental Applications. Edited by P. Monestiez, D. Allard \& R. Froidevaux. Dordrecht, Kluwer Academic: 67-78.

Griffith, D. A. 2003. Spatial autocorrelation and Spatial Filtering. Berlin, Springer-Verlag.

Gurgel, H. C. \& Ferreira, N. J. 2003. Annual and inter-annual variability of NDVI in Brazil and its connection with climate. Int. J. Remote Sensing, 24: 3595-3609.

Gutman G., Csiszar I. \& Romanov P. 2000. Using NOAA/AVHRR products to monitor El Nino impacts: focus on Indonesia in 1997-98. Bulletin of the American Meteorological Society, 81: 1188-1205.

Hellden, U. 1991. Desertification - Time for An Assessment? Ambio, Vol.20, N.8: 372-383.

Herrman, S. M. \& Huttchinson, C. F. 2005. The changing content of the desertification debate. J. of Arid Environments, 63: 538-555.

Hevesi, J. A., Istok, J. D. \& Flint, A. L. 1992a. Precipitation estimation in mountainous terrain using multivariative geostatistics. Part I: structural analysis. J. of Applied Meteorology, 31: 661-676.

Holben, B. N. 1986. Characteristics of maximum-value composite images from temporal AVHRR data. Int. J. Remote Sensing, 7:1417-1434.

Illius, A. W. \& Conor, T. G. 1999. On the relevance of non-equilibrium concepts to arid and semi-arid grazing systems. Ecological Applications, 9: 798-813.

IPCC, 2001. Third assessment report of the Intergovernmental Panel on Climate Change. Cambrige: Cambrige University Press.

Ji, L. \& A. J. Peters. 2004. A Spatial Regression Procedure for Evaluating the Relationship between AVHRR-NDVI and Climate in the Nothern Great Plains. Int. J. Remote Sensing, 25: 297-311.

Justice, C. O., Townshend ,J. R. G., Holben, B. N., Tucker, C.J.,1985. Analysis of the phenology of global vegetation using meteorological satellite data. Int. J. of Remote Sensing, 6: 1271-1318.

Kharin, N. 2002. Vegetation degradation in Central Asia under the impact of human activities. Dordrecht, Kluwer Academic Publishers.

Kogan, F. N. 1997. Global drought watch from space. Bulletin of the American Meteorological Society, 78: 621-636.

Kowabata A., Ichi K. \& Yamaguchi Y. 2001. Global Monitoring of Inter-annual Changes in Vegetation Activities Using NDVI and its Relationship to Temperature and Precipitation. Int. J. Remote Sensing, 22: 1377-1382.

Lambin E. F. \& D. Ehrlich. 1996. The Surface Temperature-Vegetation Index Space for Land Cover and Land-Cover Change Analysis. Int. J. Remote Sensing, 17: 465-487. 
Li, B., Tao, S. \& Dawson, R. W. 2002. Relation between AVHRR NDVI and ecoclimatic parameters in China. Int. J. Remote Sensing, 23: 989-999.

Li, J., Lewis, J., Rowland, J., Tappan, G., Tieszen, L. 2004. Evaluation of land performance in Senegal using multi-temporal NDVI and rainfall series. J. of Arid Environments, 59: 463-480.

Lloyd, C. D. 2002. Increasing accuracy of prediction of monthly precipitation in Great Britain using kriging with an external drift. In: Uncertainty in remote sensing and GIS. Edited by G. M. Foody \& P. M. Atkinson. Chichester, John Willey \& Sons Ltd: 243-269.

Los S. O. 1993. Calibration Adjustment of the NOAA AVHRR Normalized Difference Vegetational Index Without Resource to Component Channel 1 and 2 Data. Int. J. Remote Sensing, 14: 1907-1917.

Lubimtseva, E., Cole, R. Adams, J. M. \& Kapustin, G. 2005. Impacts of climate and land-cover changes in arid lands of Central Asia. J. of Arid Environments, 62: 285-308.

Mainguet, M. \& Da Silva, G. G. 1998. Desertification and drylands development:what can be done? Land Degrad. Develop., 9: 375-382.

Mainguet, M. 1999. Aridity: drought and human development. Berlin, Springer-Verlag.

McCloy K. R., Los S., Lucht W. \& Hojsgaard S. 2005. A comparative analysis of three long-term datasets derived from AVHRR satellite data. EARSeL eProceedings, 4: 52-70.

McMillen, D. P. 1996. One hundred fifty years of land values in Chicago: a non-parametric approach. J. of Urban Economics, 40: 100-124.

Murray, M. R. \& Baker, D. E. 1991. MWINDOW: an interactive FORTRAN-77 program for calculating moving-window statistics. Computers \& Geoscience, 17: 423-430.

Myneni R. B., Keeling C. D., Tucker C. J., Asrar G. \& Nemani R. R. 1997. increased plant growth in the northern high latitudes from 1981 to 1991. Nature, 386: 698-702.

Myneni R. B., Tucker C. J., Asrar G. \& Keeling C. D. 1998. Inter-annual variations in satellite-sensed vegetation index data from 1981 to 1991. J. of Geophysical Research, 103: 6145-6160.

Nelzin, N. P., Kostianoy, A. G. \& Li, B. L. 2005. Inter-annual variability and interaction of remotesensed vegetation index and atmospheric precipitation in the Aral Sea region. J. of Arid Environments, 62: 677-700.

Nicholson, S. E. \& Farrar, T. J. 1994. The influence of soil type on the relationships between NDVI, rainfall and soil moisture in Semiarid Botswana. I. NDVI response to rainfall. Remote Sens. of Environment, 50: 107-120.

Nicholson, S. E. \& Farrar, T. J. 1994. The influence of soil type on the relationships between NDVI, rainfall and soil moisture in Semiarid Botswana. Remote Sens. of Environment, 50: 107-120.

Olsson, L., Eklundh, L. \& Ardo, J. 2006. A recent greening of the Sahel - trends, patterns and potential causes. J. of Arid Environment, 63: 556-566. 
Paez, A., Uchida, T. \& Miyanmoto, K. 2002a. A general framework for estimation and inference of geographically weighted regression models: 1. Local-specific kernel bandwidths and a test for local heterogeneity. Environment and Planning A, 34: 733-754.

Paez, A., Uchida, T. \& Miyanmoto, K. 2002b. A general framework for estimation and inference of geographically weighted regression models: 2. Spatial association and model specification tests. Environment and Planning A, 34: 883-904.

Pavlov, A. D. 2000. Space-varying regression coefficients: a semi-parametric approach applied to real estate markets. Real Estate Economics, 28: 249-283.

Potter C. S. \& Broocks V. 1998. Global analysis of empirical relations between annual climate and seasonality of NDVI. Int. J. Remote Sensing, 19: 2921-2948.

Potter, C. S. \& Brooks, V. 1998. Global analysis of empirical relations between annual climate change and seasonality of NDVI. Int. J. Remote Sensing, 19: 2921-2948.

Reed, B. C., Brown, J. F., Vanderzee, D., Loveland, T. R., Merchant, J. W., Ohlen, D. 1994. Measuring phonological variability from satellite imagery. J. of Vegetation Science, 5: $703-$ 714.

Richard Y. \& Poccard I. 1998. A statistical study of NDVI sensitivity to seasonal and inter-annual rainfall variations in southern Africa. Int. J. Remote Sensing, 19: 2907-2920.

Robinson, S., Milner-Gulland, E. L. \& Alimaev, I. 2002. Rangeland degradation in Kazakhstan during the Soviet-era: re-examining the evidence. J. of Arid Environments, 53: 419-439.

Schultz P. A. \& Halpert M. S. 1995. Global analysis of the relationships among a vegetation index, precipitation and land surface temperature. Int. J. Remote Sensing, 16: 2755-2776.

Shepherd, N. \& Caughley, G. 1987. Options for management of Kangaroos. In: Kangaroos: their ecology and management in the sheep rangelands of Australia: 188-219. Edited by Caughley, G., Shepherd, N. \& Short, J. Cambrige: Cambrige University Press.

Sillivan S. \& Rode, R. 2002. On non-equilibrium in arid and semi-arid grazing systems. J. of Biogeography, 29: 1595-1618.

Song X., Saito G., Kodama M. \& H. Sawada. 2004. Early Detection System of Drought in East Asia Using NDVI from NOAA/AVHRR Data. Int. J. Remote Sensing, 25: 3105-3111.

Song, X., Saito, G., Kodama, M. \& Sawada, H. 2004. Early detection system of drought in East Asia using NDVI from NOAA/AVHRR data. Int. J. Remote Sensing, 20: 3105-3111.

Steven, M. D., Malthus, T. J., Baret, F., Xu, H. \& Chopping, M. J. 2003. Intercalibration of vegetation indices from different sensor systems. Remote Sens. of Environment, 88: 412-422.

Symeonakis E. \& Drake N. 2004. Monitoring Desertification and Land Degradation Over SubSaharan Africa. Int. J. Remote Sensing, 25: 573-592.

Tadesse, T., Brown, J. F. \& Hayes, M. J. 2005. A new approach for predicting drought-related vegetation stress: integrating satellite, climate, and biophysical data over the U.S. central plains. ISPRS Journal for Photogrammetry \& Remote Sensing, 59: 244- 253. 
Tateishi, R. \& Ebata, M. 2004. Analisis of phonological change patterns using 1982-2000 Advanced Very High Resolution Radiometer (AVHRR) data. Int. J. Remote Sensing, 25: 2287-2300.

Thomas D. S. G. 1997. Science and the Desertification Debate. J. of Arid Environments, 37: 599-608.

Tiefelsdorf, M. 2000. Modelling spatial processes: the identification and analysis of spatial relationships in regression residuals by means of Moran's I. Berlin, Springer-Verlag.

Tucker C. J. \& Nicholson S. E. 1999. Variations in the size of the Sahara Desert from 1980-1997. Ambio, 28: 587-591.

Tucker C. J. \& P. J. Sellers. 1986. Satellite remote sensing of primary vegetation. Int. J. Remote Sensing, 7: 1395-1416.

Tucker C. J. \& P. J. Sellers. 1986. Satellite remote sensing of primary vegetation. Int. J. Remote Sensing, 7: 1395-1416.

Tucker C. J., Slayback D. A., Pinzon J. E., Los S. O., Muneni R. B. \& Tailor M. G. 2001. Higher Nothern Latitude Normalized Difference Vegetation Index and Growing Season Trends from 1982 to 1999. Int. J. Biometeorol., 45: 184-190.

Tucker C. J., Slayback D. A., Pinzon J. E., Los S. O., Muneni R. B. \& Taylor M. G. 2001. Higher northern latitude Normalized Difference Vegettion Index and growing season trends from 1982 to 1999. Int. J. Biometeorol., 45: 184-190.

Tucker, C. J., Pinzon, J. E., Brown, M. E., Slayback, D. A., Pak, E. W., Mahoney, R., Vermote, E. F. \& El Saleous, N. 2005. An extended AVHRR 8-km NDVI dataset compatible with MODIS and SPOT vegetation NDVI data. Int. J. Remote Sensing, 26: 4485-4498.

Tucker, C. J., Vanpra, C. L., Sharman, M. J.,Van Ittersum, G. 1985. Satellite remote sensing of total herbaceous biomass production in the Senegalese Sahel: 1980-1984. Remote Sensing of Environment, 17: 233-249.

UNEP Geo Data Portal. http://geodata.grid.unep.ch/

Verdin, J., Funk, C., Klaver, R. \& Robert, D. 1999. Exploring the correlation between Southern Africa NDVI and Pacific sea surface temperatures: results for the 1998 maize growing season. Int. $J$. Remote Sensing, 20: 2117-2124.

Veron, S. R., Paruelo, J. M. \& Oesterheld, M. 2006. Assessing desertification. J. of Arid Environments, 66: 751-763.

Vetter, S. 2005. Rangelands at equilibrium and non-equilibrium: recent developments in the debate. $J$. of Arid Environments, 62: 321-341.

Wackernagel, H. 1998. Multivariative Geostatistics. Berlin, Sprinter-Verlag.

Wang J., Rich P. M. \& Price K. P. 2003. Temporal responses of NDVI to precipitation and temperature in the central Great Plains, USA. Int. J. of Remote Sensing, 24: 2345-2364.

Wang, J., Price, K. P. \& P. M. Rich. 2001. Spatial patterns of NDVI in response to precipitation and temperature in the central Great Plains. Int. J. Remote Sensing, 22: 3827-3844. 
Wang, Q., Ni, J. \& J. Tenhunen. 2005. Application of a geographically weighted regression analysis to estimate net primary production of Chinese forest ecosystem. Global Ecol. Biogeogr., 14: 379393.

Weiss J. L., Gutzler, D. S., Coonrod, J. E. A., C. N. Dahm. 2004. Long-Term Monitoring With NDVI in a Diverse Semi-Arid Setting Central New Mexico, USA. J. of Arid Environment, 58: 248274.

Weiss, E., Marsch, S. E. \& Pfirman, E. S. 2001. Application of NOAA-AVHRR NDVI time-series data to assess changes in Saudi-Arabia's rangelands. Int. J. Remote Sensing, 22: 1005-1027.

Wessels K. J., Prince S. D., Frost P. E. \& d. van Zyl. 2004. Assessing the Efects of Human-Induced Land Degradation in the former Homeland of Nothern South Africa with a $1 \mathrm{~km}$ AVHRR NDVI Time-Series. Remote Sens. Environments, 91: 47-67.

Xiao J. \& Moody A. 2004. Trends in vegetation activity and their climatic correlates: chin 1982 to 1998. Int. J. Remote Sensing, 20: 5669-5689.

Yang, L., Wylie, B., Tieszen, L. L., Reed, B. C., 1998. An analysis of relationships among climate forcing and time-integrated NDVI of grasslands over the U.S. Northern and Central Great Plains. Remote Sensing of the Environment, 65: 25-37.

Young S. S. \& Harris R. 2005. Changing patterns of global-scale vegetation photosynthesis, 19821999. Int. J. Remote Sensing, 26: 4537-4563.

Zhou L., Tucker C. J., Kaufmann R., Slayback D., Shabanov N. \& Myneni R. B. 2001. Variations in northern vegetation activity inferred from satellite data of vegetation index during 1981 to 1999. J. of Geophysical Research, 106: 20069-20083. 